\title{
Identificação e visualização de dependências em sistemas de software orientados a objetos
}

\author{
Gustavo Ansaldi Oliva
}

DisSERTAÇÃo APRESENTADA

$\mathrm{AO}$

Instituto DE MATEMÁticA E ESTATÍSTICA

DA

UNIVERSIDADE DE SÃo PAULO

PARA

OBTENÇÃo Do TÍtulo

$\mathrm{DE}$

Mestre EM CIÊNCIAS

Programa: Ciência da Computação
Orientador: Prof. Dr. Marco Aurélio Gerosa

Durante o desenvolvimento deste trabalho o autor recebeu auxílio financeiro da HP (projeto Baile) e da European Comission (projeto FP7 CHOReOS) 


\section{Identificação e visualização de dependências em sistemas de software orientados a objetos}

Esta dissertação contém as correções e alterações sugeridas pela Comissão Julgadora durante a defesa realizada por Gustavo Ansaldi Oliva em 22/09/2011.

$\mathrm{O}$ original encontra-se disponível no Instituto de Matemática e Estatística da Universidade de São Paulo.

Comissão Julgadora:

- Prof. Dr. Marco Aurélio Gerosa (orientador) - IME-USP

- Prof. Dr. Cleidson R. B. de Souza - IBM Research

- Prof. Dr. Ítalo Santiago Vega - PUC-SP 


\section{Agradecimentos}

Ao Prof. Dr. Fabio Kon, pelas valiosas observações por ocasião de sua participação como membro da banca de qualificação.

Ao Prof. Dr. Ítalo Santiago Vega, não só pela indiscutível dedicação com que avaliou meu trabalho, mas principalmente pela inspiração que me instilou durante o tempo em que convivemos na PUC-SP.

Ao Prof. Dr. Cleidson R. B. de Souza, pela disponibilização da ferramenta XFlow, sem a qual este trabalho se inviabilizaria. Agradeço-o, ainda, pela sensível contribuição no desenho do estudo de caso e por muitas outras cuja menção compreenderia um compêndio.

Ao Prof. Dr. Arnaldo Mandel, meu primeiro orientador no IME-USP e que me ajudou a dar sequência na vida acadêmica.

Ao Prof. Dr. Marco Aurélio Gerosa, pela absoluta seriedade e competência com que me orientou ao longo do mestrado. Agradeço-o, sobretudo, pela sincera amizade.

Ao Prof. Dr. Alfredo Goldman, por partilhar seus conhecimentos, pela sua simpatia e constante bom humor.

Aos meus ex-professores da PUC-SP, pela parte que lhes coube em minha formação acadêmica.

Aos meus colegas do grupo de arquitetura do IME-USP, em especial Mauricio Aniche e Mauricio De Diana, que me ajudaram no projeto dos estudos empíricos conduzidos nessa pesquisa.

Ao Francisco Werther Santana, pela troca de experiências e espírito de parceria durante as incontáveis horas em que trabalhamos juntos.

Aos meus colegas da IBM, pelo aprimoramento da minha formação em Engenharia Software e pelos momentos divertidos que passamos. Agradecimentos especiais para Bruno Maioli, Marcela, Victor Izawa, Maruen, Gustavo Castellano, Rafael Pierote, John Mancini, Franciane, Viviane e Luciana.

Aos amigos de infância Caio, Rafael, Leonardo, Douglas, Felipe Figueiredo, Felipe Breda e José Augusto pelo conforto de ter com quem compartilhar minhas alegrias e tristezas. 
Ao Desembargador Olavo Zampol pelo grande incentivo e inestimável auxílio material.

Aos meus tios Paulo, Adriana, Fernando e Deise, por alegrarem minha vida e me fazerem uma pessoa melhor.

Aos meus avós, Luiz, Zulmira (in memorian), Laercio e Cida, pelos mimos e imensa ternura com que me tratam.

As minhas primas Camila, Carolina e Bruna, pelos inúmeros momentos de felicidade que trouxeram à minha vida.

Ao meu irmão Rafael, por sua lealdade e por sempre estar ao meu lado.

À Eloisa, minha amada e futura noiva, pelo apoio e paciência que teve comigo durante os momentos em que não pude dar-lhe a devida atenção.

Por fim, aos meus queridos pais Luiz e Denise. Simplesmente não tenho palavras para expressar o quanto os amo. 


\section{Resumo}

Degradação do design é um problema central investigado na área de Evolução de Software. A densa rede de interdependências que emerge entre classes e módulos ao longo do tempo resulta em código difícil de mudar, não reutilizável e que não comunica por si só sua intenção. Dentre outros motivos, designs degradam porque requisitos mudam de maneiras não antecipadas pelo design inicial, ou seja, as modificações no código introduzem dependências novas e não planejadas entre classes e módulos do sistema. A gerência de dependências visa reduzir a degradação do design por meio de uma série de mecanismos que auxiliam na administração da complexidade estrutural inerente de sistemas orientados a objetos. Neste trabalho, investigamos as técnicas de identificação de dependências estruturais e lógicas. Em particular, por meio de um estudo de larga escala, comparamos os conjuntos desses dois tipos de dependências. Em seguida, conduzimos um estudo de caso a fim de identificar as origens de dependências lógicas. Por fim, fazemos um levantamento das técnicas de visualização de dependências e mostramos a ferramenta XFlow.

Palavras-chave: evolução de software, manutenção de software, gerência de dependências, dependências estruturais, dependências lógicas, mineração de repositórios de software, visualização de software, arquitetura de software, design orientado a objetos. 


\section{Abstract}

Design degradation is a central problem investigated in the area of Software Evolution. The dense web of interdependencies that emerges among classes and modules over time results in code that is hard to change, not reusable and that does not communicate its intention. Among other reasons, designs degrade because requirements changes in ways that were not anticipated by the initial design, i.e. the changes in code introduce new and unplanned dependencies among classes and modules of the system. Dependency management aims to reduce design degradation by means of a series of mechanisms that helps in the management of the inherent structural complexity of object oriented systems. In this work, we investigate structural and logical dependencies identification techniques. In particular, by means of a large scale study, we compare the sets of these two kinds of dependencies. Afterwards, we conduct a case study in order to uncover the origins of logical dependencies. Finally, we survey dependency visualization techniques and present the XFlow tool.

Keywords: software evolution, software maintenance, dependency management, structural dependencies, logical dependencies, mining software repositories, software visualization, software architecture, object oriented design. 


\section{Sumário}

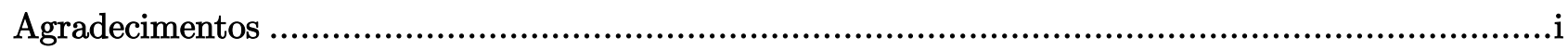

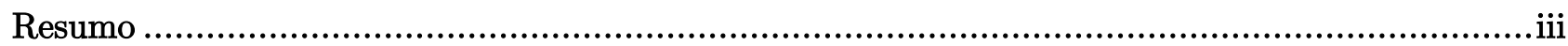

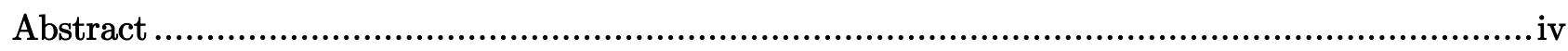

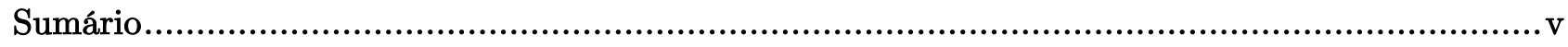

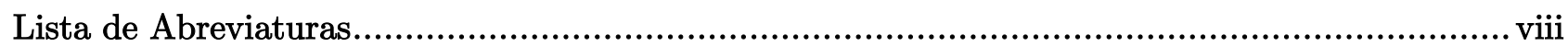

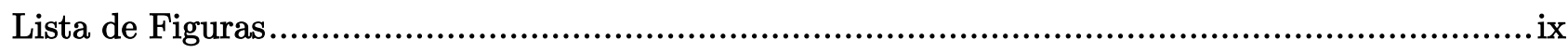

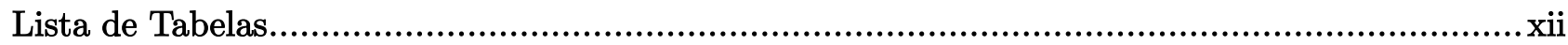

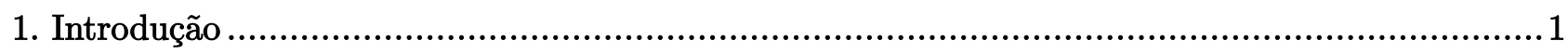

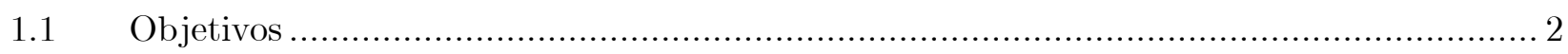

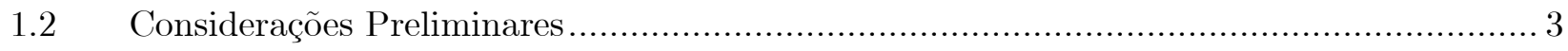

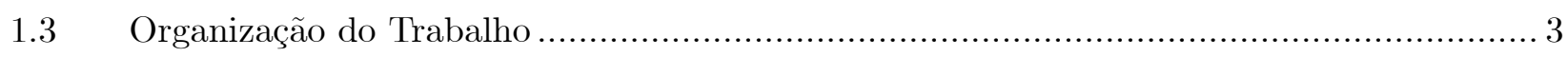

2. Evolução de Software e Gerência de Dependências.............................................................. 4

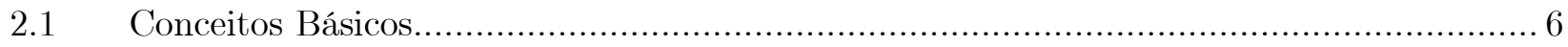

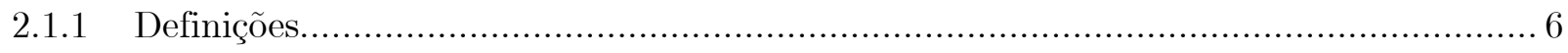

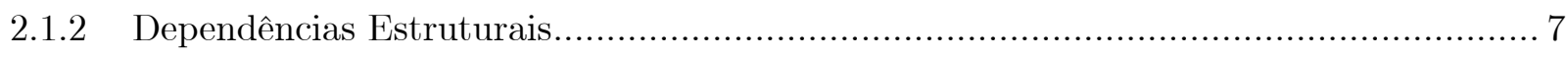

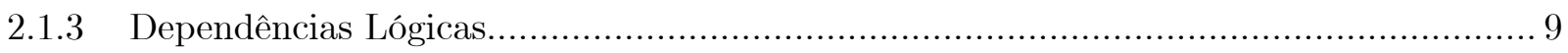

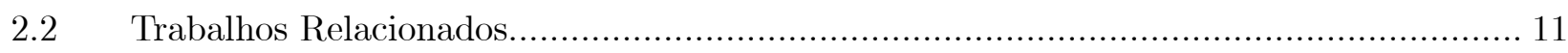

2.3 O Ciclo da Gerência de Dependências............................................................................ 12

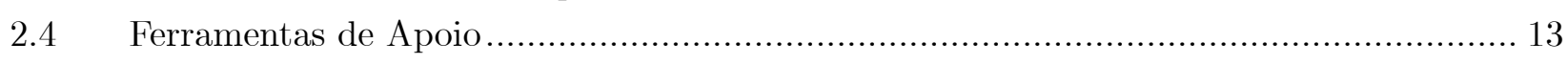

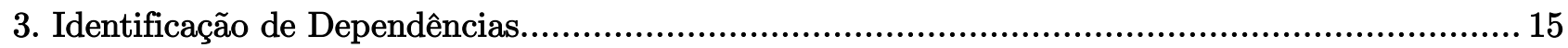

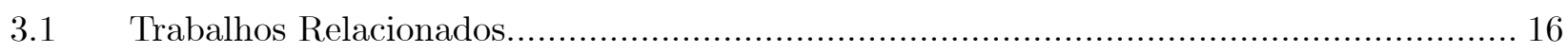

Identificação de Dependências Estruturais ................................................................ 16

3.3 Identificação de Dependências Lógicas .................................................................... 17

4. Dependências Estruturais vs. Lógicas..................................................................... 19

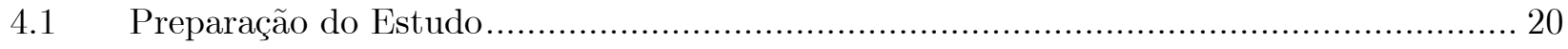

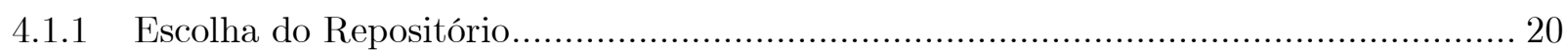

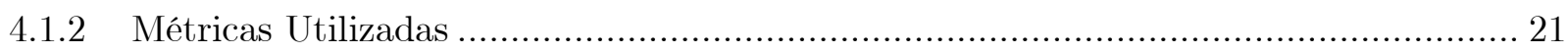

4.1.3 Suporte Ferramental .................................................................................... 21

4.2 Instrumentos e Métodos para Coleta de Dados ....................................................... 23

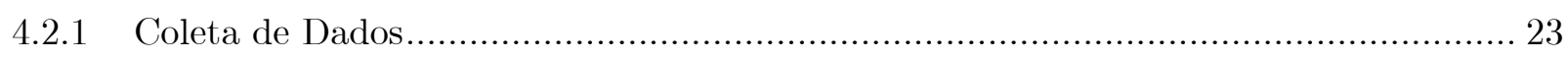

4.2.2 Identificando dependências e calculando acoplamento ....................................... 25 


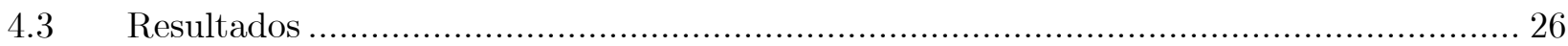

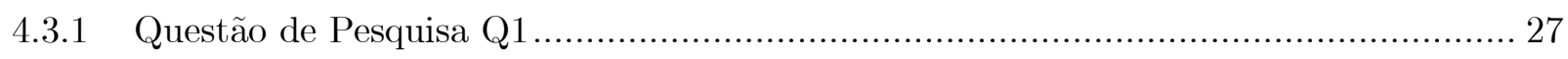

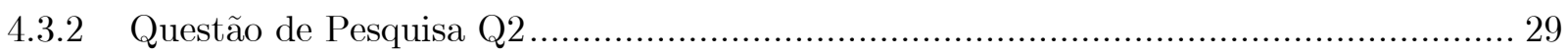

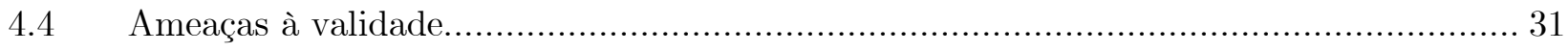

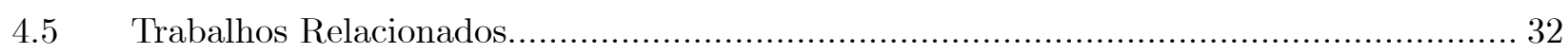

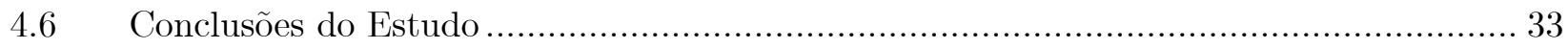

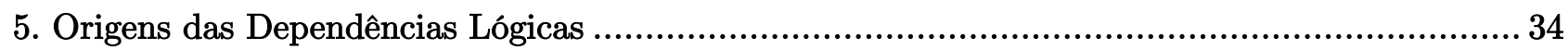

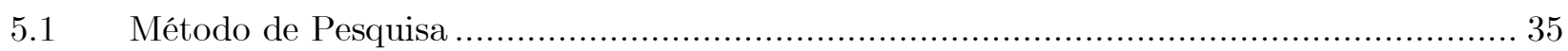

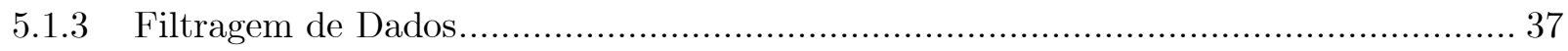

5.1.4 Instrumentos e Métodos para Análise de Dados .................................................... 37

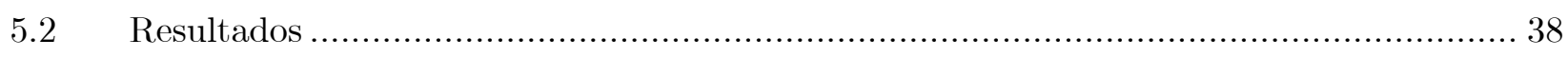

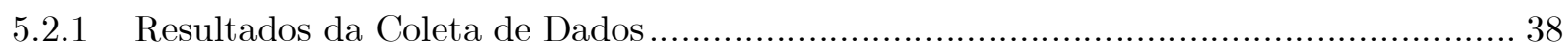

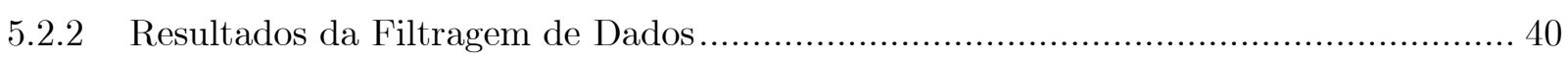

5.2.3 Origens das Dependências Lógicas ................................................................. 42

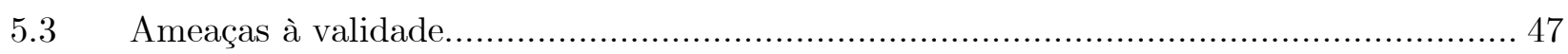

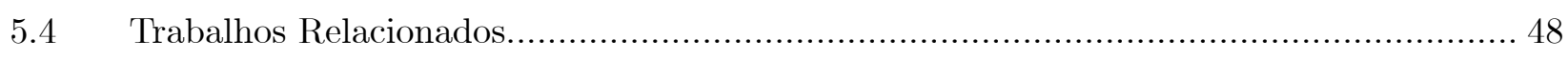

5.5 Conclusão e Trabalhos Futuros ........................................................................... 49

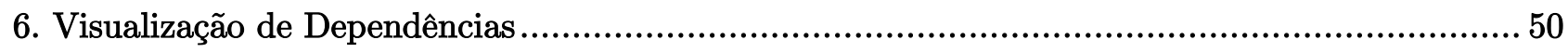

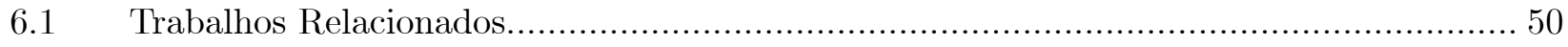

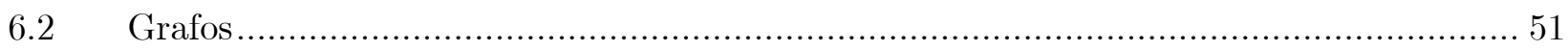

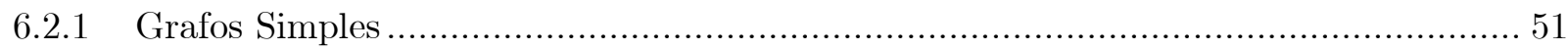

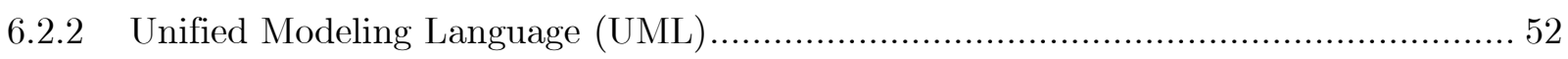

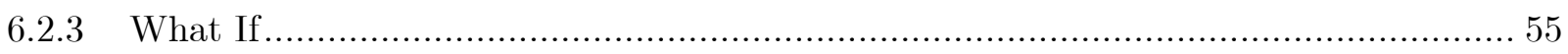

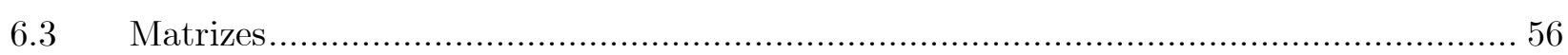

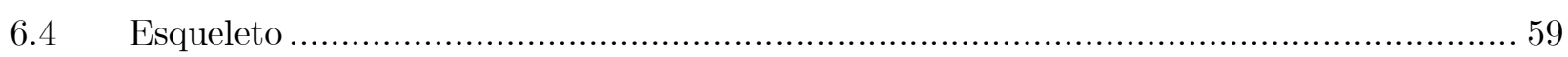

7. XFlow - Uma Ferramenta para Visualização de Dependências............................................ 60

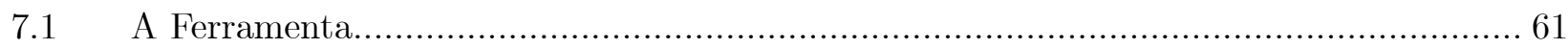

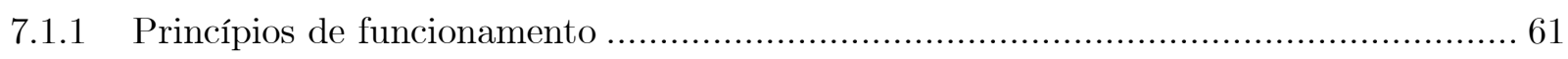

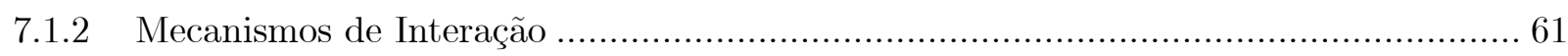

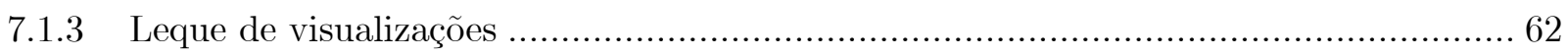

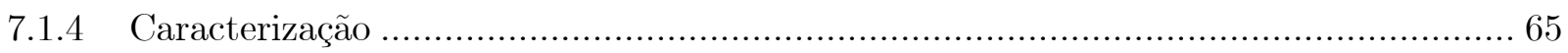

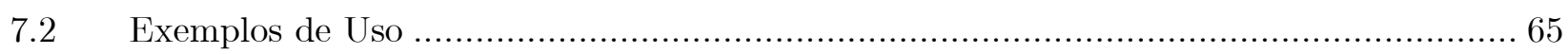

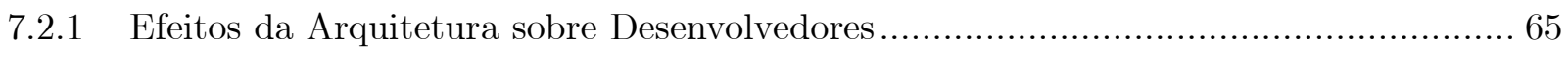

7.2.2 Compreendendo o Papel de Desenvolvedores....................................................... 66

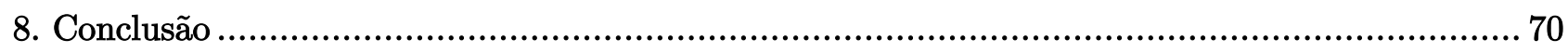

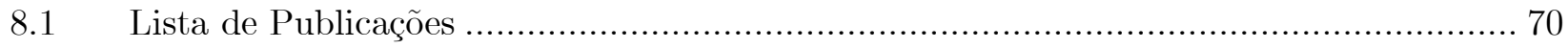

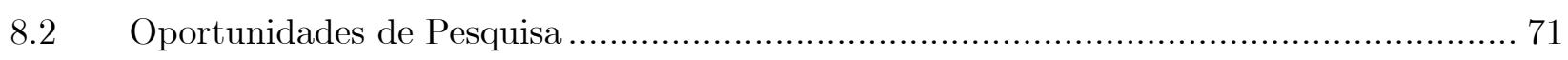

A. Design, Arquitetura e Implementação................................................................ 72

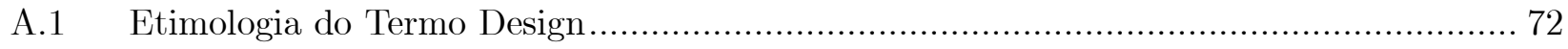

A.2 Distinção entre Arquitetura, Design e Implementação …........................................ 72

B. Identificação de Dependências Estruturais em Código Java Compilado ..................................76 


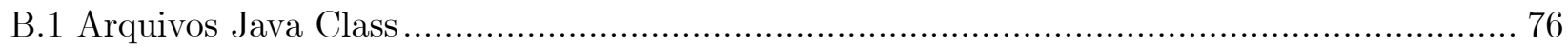

B.2 Identificando Dados Brutos sobre Dependências ....................................................... 77

B.3 Implementação com Dependency Finder …...................................................... 78

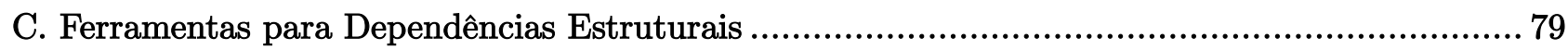

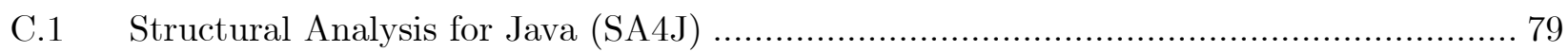

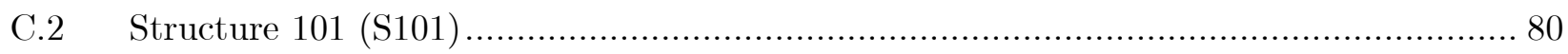

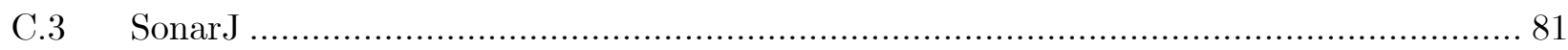

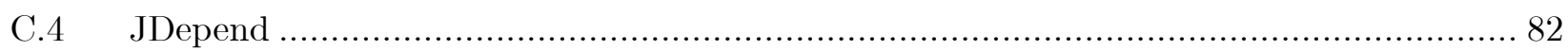

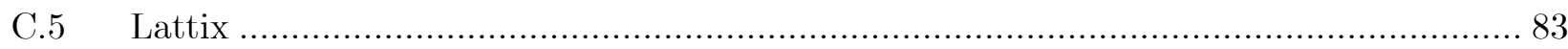

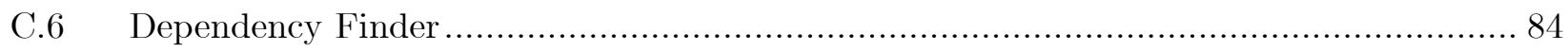

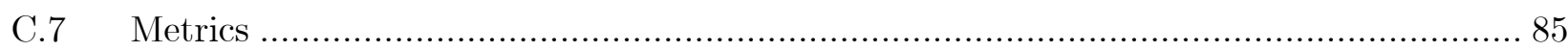

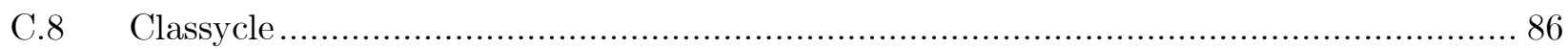

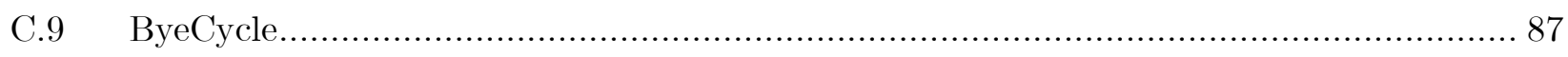

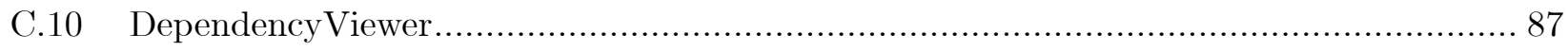

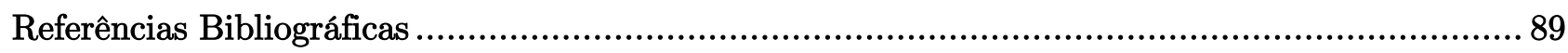




\title{
Lista de Abreviaturas
}

\author{
ADP Princípio das Dependências Acíclicas (Acyclic Dependencies Principle) \\ CASE Engenharia de Software Apoiada por Computador (Computer-Aided Software \\ Engineering) \\ CBO Acoplamento entre Objetos (Coupling Between Objects) \\ CBSE Engenharia de Software Baseada em Componentes (Component-Based Software \\ Engineering) \\ CCP Princípio do Fechamento Comum (Common Closure Principle) \\ CRP Princípio do Reúso Comum (Common Reuse Principle) \\ CVS Concurrent Version System \\ DIP Princípio da Inversão de Dependências (Dependency Inversion Principle) \\ DSM Matriz de Estrutura de Dependências (Dependency Structure Matrix) \\ FLOSS Software Livre (Free/Libre/Open-Source Software) \\ GQM Objetivo-Questão-Métrica (Goal-Question-Metric) \\ GSD Desenvolvimento de Software em Escala Global (Global Software Development) \\ GW Groupware Workbench \\ ISP Princípio da Segregação de Interfaces (Interface Segregation Principle) \\ LSP Princípio da Substituição de Liskov (Liskov Substition Principle) \\ OCP Princípio do Aberto/Fechado (Open/Closed Principle) \\ QA Garantia de Qualidade (Quality Assurance) \\ REP Princípio da Equivalência de Lançamento e Reúso (Reuse/Release Equivalence \\ Principle) \\ RHDB Banco de Dados de Histórico de Lançamento (Release History Database) \\ S101 Structure 101 for Java \\ SA4J Structural Analysis for Java \\ SAP Princípio das Abstrações Estáveis (Stable-Abstractions Principle) \\ SDP Princípio das Dependências Estáveis (Stable-Dependencies Principle) \\ SEI Software Engineering Institute \\ SLOC Linhas de Código-fonte (Source Lines of Code) \\ SRP Princípio da Responsabilidade Única (Single Responsibility Principle) \\ SVN Subversion \\ UML Linguagem de Modelagem Unificada (Unified Modeling Language) \\ VCS Sistema de Controle de Versão (Version Control System)
}




\section{Lista de Figuras}

Figura 1: Mini-ciclo de mudança (traduzido de [MD08b]) ........................................... 4

Figura 2: Modelo de ciclo de vida em estágios [MD08b] ............................................... 4

Figura 3: Modelo conceitual UML para dependências estruturais em sistemas orientados a

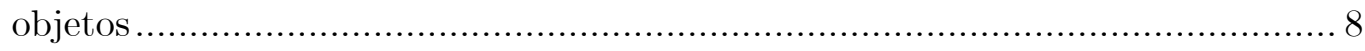

Figura 4: Modelo de identificação de dependências no Dependency Finder ........................ 9

Figura 5: Exemplo de regra de associação .......................................................... 10

Figura 6: Modelo conceitual UML para dependências estruturais em sistemas orientados a

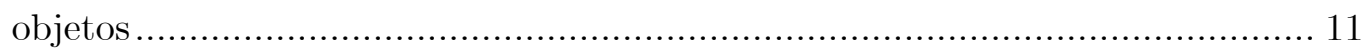

Figura 7: Arcabouço para gerência de dependências proposto por Pirklbauer et al. [PFK10]

Figura 8: Ciclo da gerência de dependências ........................................................... 13

Figura 9: Ênfase na atividade "Identificar dependências" do ciclo de gerência de

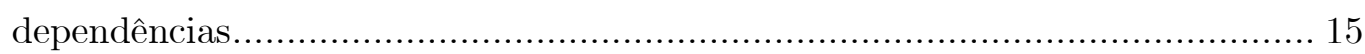

Figura 10: Taxonomia para identificação de dependências ............................................... 15

Figura 11: Janela fixa de tempo (fixed time window) [DLL09] ..................................... 17

Figura 12: Janela móvel de tempo (sliding time window) [DLL09] .............................. 17

Figura 13: Modelo parcial e traduzido do RHDB [DGLP08] ....................................... 18

Figura 14: Diagrama de Venn ilustrando as questões de pesquisa .................................. 20

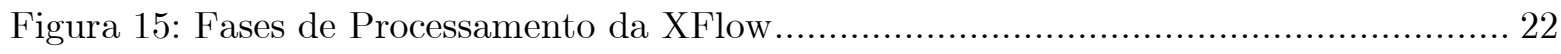

Figura 16: Resumo gráfico da distribuição da variável "número de arquivos por revisão"... 24

Figura 17: Diagrama de Venn ilustrando a questão de pesquisa Q1 ............................. 27

Figura 18: Dependências lógicas envolvendo unidades de compilação não estruturalmente

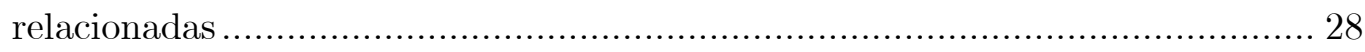

Figura 19: Porcentagem cumulativa para a medida de suporte …................................ 28

Figura 20: Distribuição de suporte para arquivos (A) pouco, (B) mediamente e (C) altamente acoplados logicamente ...................................................... 29

Figura 21: Diagrama de Venn ilustrando a estratégia empregada para responder a questão

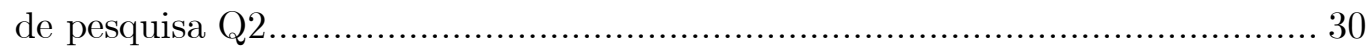

Figura 22: Valores de referência para a métrica CBO (mínimo, máximo, média, mediana, moda) [BLL09] …….................................................................. 30

Figura 23: Relação entre interseç̧ão de M e L e complexidade [Han07] ........................... 32

Figura 24: Resumo gráfico da distribuição da variável "número de arquivos por revisão"... 39

Figura 25: Número de arquivos modificados por desenvolvedor................................... 39

Figura 26: Número de commits (agrupados) por desenvolvedor ................................... 39

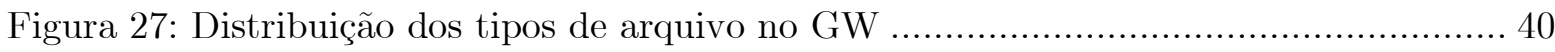




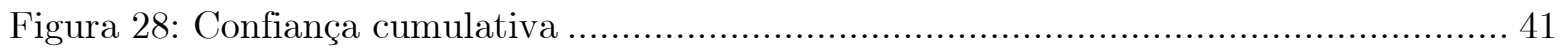

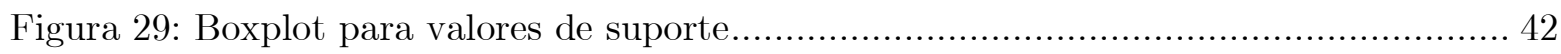

Figura 30: Exemplo de dependência estrutural cujo fornecedor pertence a uma classe semântica (entidade) que sofreu alteração (mudança do tipo de um atributo) . 44

Figura 31: Interesses transversais em um sistema de software ..................................... 45

Figura 32: Revisão multi-ação............................................................................. 46

Figura 33: Ênfase na atividade "Visualizar dependências" do ciclo de gerência de

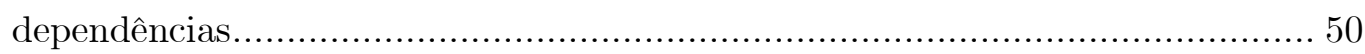

Figura 34: Taxonomia para visualização de dependências .............................................. 50

Figura 35: Visualização na forma de grafos através da ferramenta ByeCycle ..................... 52

Figura 36: Visualização na forma de grafos através da ferramenta Metrics ....................... 52

Figura 37: Notação UML para Dependência .............................................................. 53

Figura 38: Exemplo de dependência com estereótipo.................................................... 53

Figura 39: Meta-modelo UML destacando semântica do termo "dependência" segundo

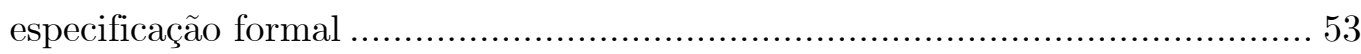

Figura 40: Um mesmo diagrama de classes gerado por ferramenta CASE da indústria (esquerda) e ferramenta GoVisual (direita) [Die10] ....................................... 54

Figura 41: Visualização na forma de grafos através da ferramenta SA4J ......................... 55

Figura 42: Visualização na forma de grafos através da ferramenta S101 ......................... 55

Figura 43: Visualização de dependências na forma What If na ferramenta SA4J .............. 56

Figura 44: Uma DSM simples (traduzida de [SJSJ05]) ............................................. 57

Figura 45: DSM bloco-triangular após particionamento (traduzida de [SJSJ05]) ................ 57

Figura 46: DSM triangular-inferior (traduzida de [SJSJ05]) ......................................... 57

Figura 47: DSM hierárquica (traduzida de [SJSJ05]) .................................................. 57

Figura 48: Sistema com arquitetura em camadas (esquerda) e sistema com arquitetura em camadas estritas (direita) [SJSJ05] .................................................. 58

Figura 49: DSM para Ant v1.4.1 com o auxílio da ferramenta Lattix [SJSJ05] ................. 58

Figura 50: Visualização de dependências na forma de esqueleto na ferramenta SA4J........ 59

Figura 51: Visualização do impacto de mudanças através de um esqueleto na ferramenta

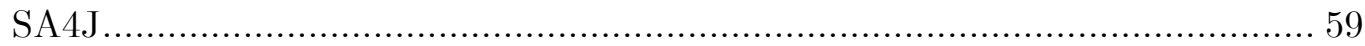

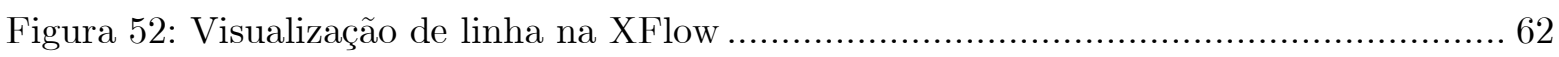

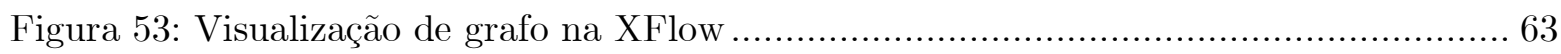

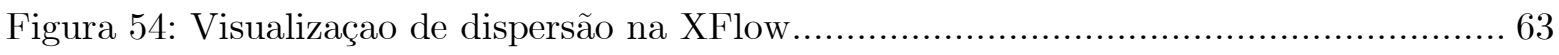

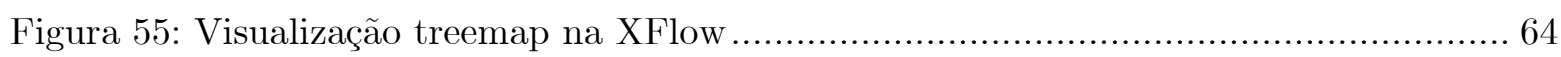

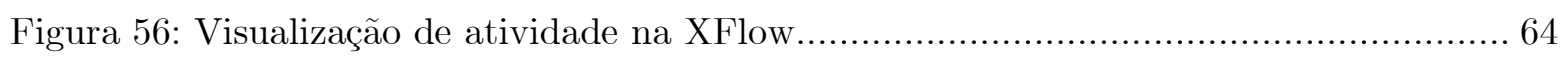

Figura 57: Taxonomia para abordagens de MSR (adaptada de [KCM07]) ....................... 65

Figura 58: Grafo de dependências (A) e requisitos de coordenação (B) do Apache Lucene. 66

Figura 59: Grafo de dependências (A) e requisitos de coordenação (B) do jEdit ................ 66

Figura 60: Requisitos de coordenação entre desenvolvedores (destaque no núcleo da rede) 67

Figura 61: Foco nos desenvolvedores analisados.................................................. 67

Figura 62: Visualização de dispersão (máxima centralidade na revisão) ........................... 68

Figura 63: Visualização de dispersão (máxima centralidade "até então") ........................... 68

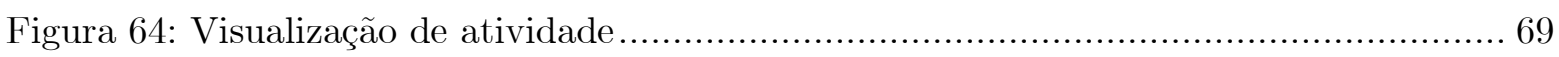

Figura 65: Noção informal dos termos 'arquitetura', 'design' e 'implementação' [EHK06] .. 73

Figura 66: Implicações da Hipótese da Intenção/Localidade [EHK06] ............................. 74 
Figura 67: Grafo de dependências do Dependency Finder ........................................ 78

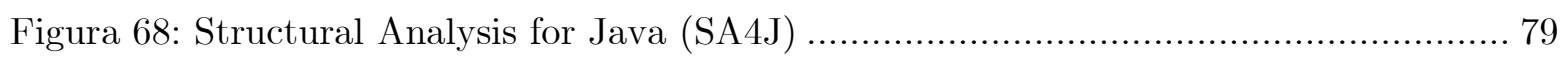

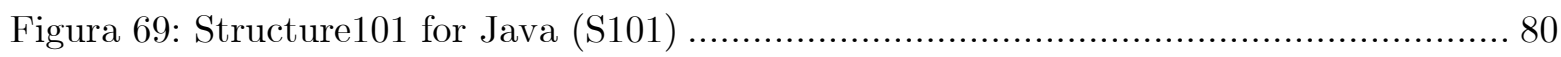

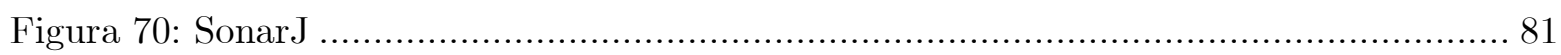

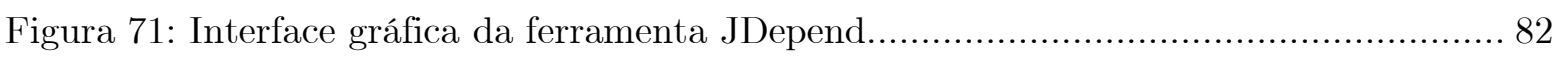

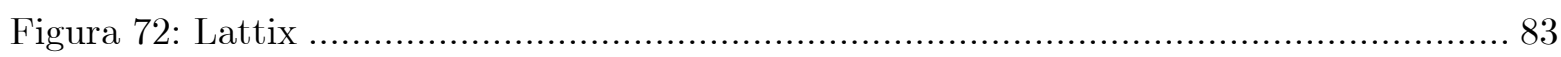

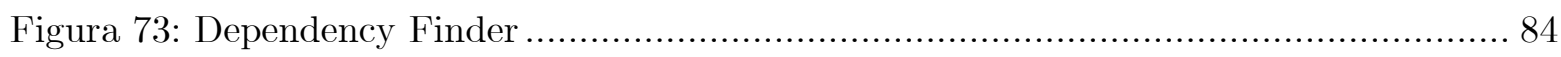

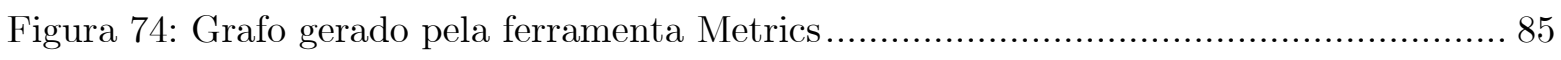

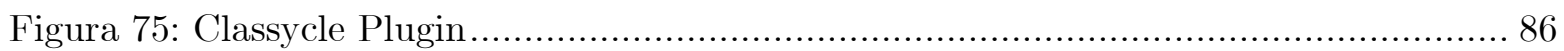

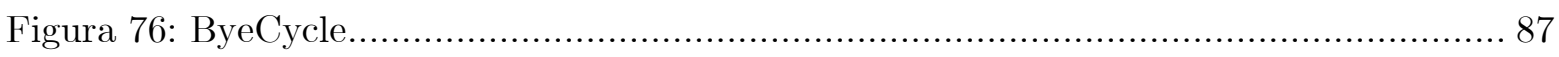

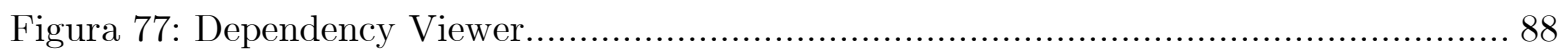




\section{Lista de Tabelas}

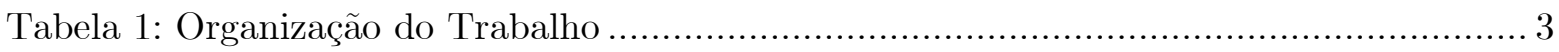

Tabela 2: Ferramentas para gerência de dependências ................................................... 14

Tabela 3: Número de Arquivos por Revisão no SVN da ASF - Estatísticas descritivas...... 23

Tabela 4: Número de Arquivos por Revisão no SVN da ASF - Análise de Quartis............ 24

Tabela 5: Dependências lógicas envolvendo unidades de compilação não estruturalmente

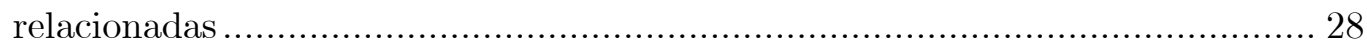

Tabela 6: Número de Arquivos por Revisão no Projeto GW - Estatísticas descritivas....... 38

Tabela 7: Número de Arquivos por Revisão no Projeto GW - Análise de Quartis ............. 38

Tabela 8: Número de dependências lógicas por valor de suporte .................................. 41

Tabela 9: Suporte das dependências lógicas - Análise de Quartis .................................. 41

Tabela 10: Dependências lógicas por tipo de arquivo .............................................. 42

Tabela 11: Exemplo real de dependência lógica no GW retratando diferentes razões para

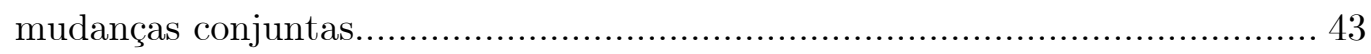

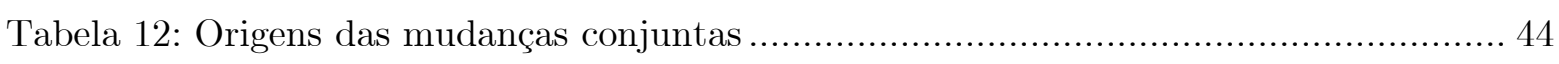

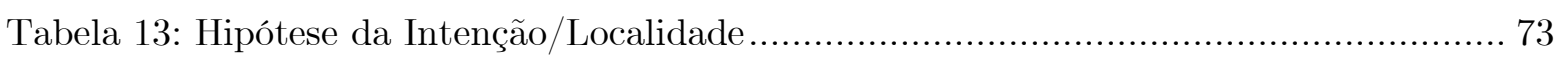

Tabela 14: Evidências corroborando a Hipótese da Intenção/Localidade [EHK06] ............. 75 


\section{Capítulo 1 Introdução}

O dinamismo da sociedade atual demanda mudanças frequentes nos sistemas que dão suporte às suas atividades. O grande investimento de capital e o tempo necessário para que essas mudanças sejam feitas, não dão espaço para que o software seja amplamente retrabalhado toda vez que um requisito muda. Assim, software não tolerante a modificações está fadado ao abandono ou substituição [BME+07], [MD08a].

A área de Evolução de Software investiga, dentre outros tópicos, a degradação da arquitetura e do design ao longo do tempo [MM06], [DDN09]. Uma das razões por detrás da degradação se refere ao fenômeno de entropia de software. Segundo Jacobson [Jac92], entropia se refere à tendência do software de se tornar difícil e custoso de manter ao longo do tempo, já que frequentemente se torna mais complexo e desorganizado à medida que cresce. Esse mesmo fenômeno é retratado pelas leis de evolução de software propostas por Lehman e Belady ao longo de 22 anos [LPR+97]. Em suma, as leis dizem que todo software em utilização será modificado (mudança contínua) e que, quando um software é modificado, sua complexidade aumenta (complexidade crescente), a menos que se trabalhe ativamente contra isso. Todo software útil é inerentemente complexo [BME +07$]$.

A degradação do software ocorre à medida que a elegância dos diversos módulos se perde na forma de remendos estruturais e violações de regras arquiteturais previamente estabelecidas [MM06]. Nesse cenário, uma densa rede de interdependências entre os módulos comumente emerge, resultando em código difícil de mudar, não reutilizável e que não comunica por si só sua intenção [FY99]. O grande esforço requerido para simples mudanças e a crescente carga de problemas do design se tornam tão onerosos que, não raro, os desenvolvedores e envolvidos no projeto (stakeholders) decidem realizar um amplo redesign ou até mesmo reescrever totalmente determinados módulos [Jac92], [MM06]. Como resultado, o software passa a evoluir de forma cada vez mais lenta e o custo de manutenção chega a atingir $90 \%$ do custo total de desenvolvimento [Bro95], [Pre09]. Assim, em vez de refatorar continuamente os módulos, acumula-se uma grande dívida de projeto que raramente é paga [Ker04].

Outra razão para a degradação reside numa ênfase desmedida na qualidade do design inicial em detrimento de um cuidado contínuo. Durante muito tempo imaginou-se que um bom design inicial iria evitar, ou ao menos mitigar, o processo de degradação. Porém, observou-se que o design de um sistema sofre constante evolução e que, para mantê-lo apropriado com relação às necessidades de negócio, é imperativo que seja continuamente cuidado ao longo de todo o ciclo de vida do projeto. Segundo Martin [MM06], tal cuidado é mais importante do que o próprio design inicial, já que um conceito inicial pobre pode ser corrigido por meio de cuidado contínuo, enquanto que sem cuidado contínuo, um bom design inicial fatalmente irá se degradar. 
Segundo Fowler [Fow03], à medida que os sistemas crescem, é necessário atentar cada vez mais para as dependências entre módulos, caso contrário alterações simples podem ter amplo efeito de propagação, prejudicando a evolução do software. Assim, a gerência de dependências apresentase como uma proposta para auxiliar no controle da complexidade estrutural inerente de sistemas de software.

Neste trabalho, investigamos técnicas de identificação de dependências estruturais e lógicas (esses conceitos são apresentados no início do próximo capítulo). Em particular, por meio de um estudo de larga-escala, comparamos os conjuntos de dependências estruturais e lógicas. Em seguida, conduzimos um estudo de caso a fim de revelar as origens de dependências lógicas. Após isso, investigamos as técnicas de visualização de dependências por meio de um levantamento da área. Por fim, como aplicação do estudo de visualização, utilizamos a ferramenta XFlow e investigamos alguns fenômenos sociotécnicos do desenvolvimento de software.

\subsection{Objetivos}

O objetivo geral desse trabalho é investigar as técnicas de identificação e visualização de dependências, bem como suas implicações, no contexto de sistemas de software orientados a objetos. Os objetivos específicos, por sua vez, são:

(i) Comparar os conjuntos de dependências estruturais e lógicas;

(ii) Descobrir algumas das reais origens das dependências lógicas;

(iii) Realizar um levantamento da área de visualização de dependências.

As principais contribuições deste trabalho são:

(i) Um estudo de larga-escala que viabilizou a comparação entre conjuntos de dependências estruturais e lógicas (Capítulo 4) [OG11];

(ii) Um estudo de caso que possibilitou compreender algumas das reais origens das dependências lógicas (Capítulo 5) [OSGdS11];

(iii) Uma taxonomia para técnicas de visualização de dependências (Capítulo 6);

(iv) Investigação de fenômenos sociotécnicos por meio da ferramenta XFlow (Capítulo 7) [SOdSG11].

Contribuições adicionais desse trabalho incluem:

(i) Um modelo conceitual para dependências estruturais (Capítulo 2 - Seção 2.1.2);

(ii) Um modelo conceitual para dependências lógicas (Capítulo 2 - Seção 2.1.3);

(iii) Um discussão etimológica envolvendo os termos design, arquitetura e implementação (Apêndice A);

(iv) Um levantamento de ferramentas de apoio para gerência de dependências estruturais (Apêndice C). 


\subsection{Considerações Preliminares}

O escopo do trabalho não inclui análise de dependências estruturais em sistemas escritos com linguagens de programação dinâmicas ou que dão suporte a tipagem dinâmica. Além disso, ao mencionarmos o termo "dependência estrutural", estamos tratando também de associações, agregações, composições, generalizações e realizações. Essa consideração é usual e aparece em referências clássicas de análise e design orientados a objetos como [Lar04]. Quando tivermos a intenção de falar sobre o relacionamento específico "dependência estrutural" segundo a UML, nós o faremos explicitamente. Por fim, não trataremos de dependências estruturais entre componentes distribuídos e nas implicações de se plugar ou desplugar tais componentes em tempo de execução.

\subsection{Organização do Trabalho}

Este trabalho está organizado como segue:

\begin{tabular}{|c|c|}
\hline & $\begin{array}{l}\text { Discorremos sobre evolução de software e gerência de dependências (contextualização } \\
\text { da pesquisa), apresentando os conceitos básicos, trabalhos relacionados, o ciclo da } \\
\text { gerência de dependências e ferramentas de apoio. }\end{array}$ \\
\hline Capítulo 3 & $\begin{array}{l}\text { Tratamos sobre a atividade de identificação de dependências estruturais e lógicas, } \\
\text { apresentando trabalhos relacionados. }\end{array}$ \\
\hline Capítulo 4 & $\begin{array}{l}\text { Relatamos o estudo empírico de larga-escala para comparar os conjuntos de } \\
\text { dependências estruturais e lógicas, discutindo o método, as ameaças à validade e os } \\
\text { trabalhos relacionados. }\end{array}$ \\
\hline Capítulo 5 & $\begin{array}{l}\text { Conduzimos o estudo de caso a fim de compreender as origens de dependências } \\
\text { lógicas, discutindo o método, as ameaças à validade e os trabalhos relacionados. }\end{array}$ \\
\hline Capítulo 6 & $\begin{array}{l}\text { Apresentamos um levantamento das técnicas existentes para visualização de } \\
\text { dependências. }\end{array}$ \\
\hline Capítulo 7 & $\begin{array}{l}\text { Apresentamos a ferramenta XFlow e relatamos as análises de cunho sociotécnico } \\
\text { conduzidas, evidenciando a relação entre dependências e fatores sociais do } \\
\text { desenvolvimento. }\end{array}$ \\
\hline Capít & Apresentamos nossas considerações finais e sugestões para trabalhos futuros. \\
\hline
\end{tabular}

Tabela 1: Organização do Trabalho 


\section{Capítulo 2}

\section{Evolução de Software e Gerência de Dependências}

Durante a década de 70, percebeu-se que a atividade de manutenção deveria acontecer ao longo do desenvolvimento das várias versões de um sistema, e não apenas após sua entrega. Naquela década, preocupados com o impacto de mudanças no software, Lehman et al. [LPR +97 ] deram início à formulação das leis de evolução de software. As leis dizem, dentre outras coisas, que todo software útil muda continuamente e tende a sofrer aumento de complexidade. No fim dos anos 70, Yau et al. [YCM78] propuseram o primeiro modelo para o processo de mudanças em artefatos de código. Esse modelo foi chamado de mini-ciclo de mudança (change mini-cycle) e se preocupava explicitamente com a questão da evolução e o impacto de mudanças (Figura 1).

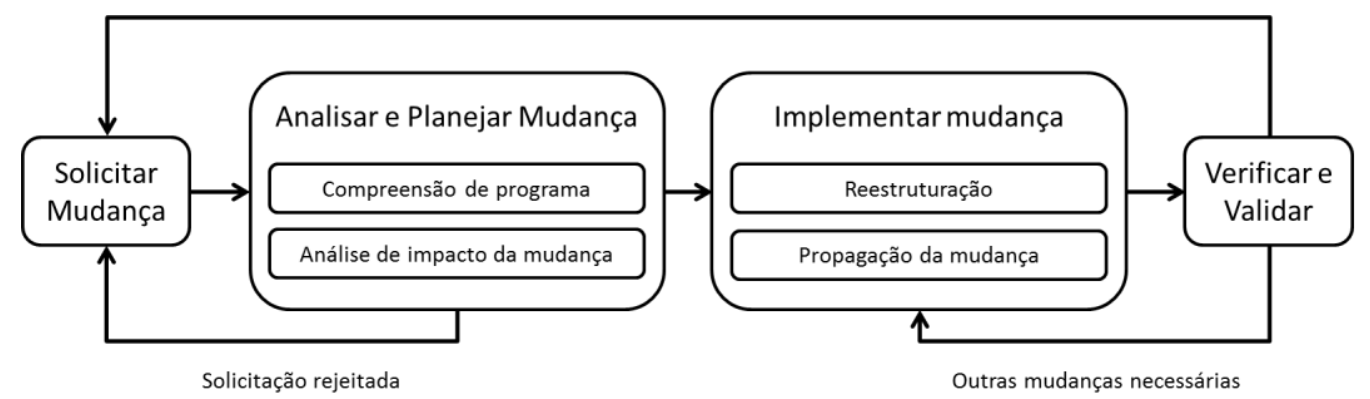

Figura 1: Mini-ciclo de mudança (traduzido de [MD08b])

Contudo, demorou até a década de 90 para que o termo "evolução de software" ganhasse ampla aceitação e se consolidasse como área de pesquisa [MD08b]. No fim da década 90, Bennet e Rajlich propuseram um modelo de ciclo de vida de software chamado staged model [BR00]. Esse modelo representa o ciclo de vida como uma sequência de fases (estágios), que começa com o "desenvolvimento inicial". A principal contribuição do modelo está na separação da manutenção em dois blocos: (i) o estágio de "evolução" (evolution) e (ii) os estágios de "em serviço" (servicing), "em término" (phase out) e "fechamento" (close down). A Figura 2 exibe esse modelo de ciclo de vida.

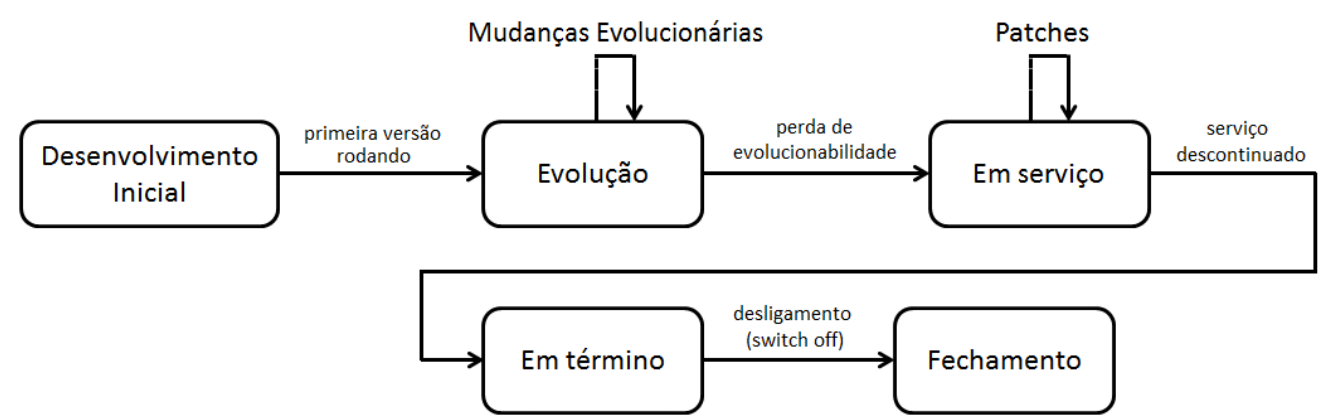

Figura 2: Modelo de ciclo de vida em estágios [MD08b] 
Atualmente, a área de Evolução de Software é classificada como um subdomínio da Engenharia de Software que investiga meios para adaptar aplicações aos instáveis requisitos e ambiente operacional. A área também estuda o processo de mudança em si, analisando artefatos de software sob o aspecto temporal para extrair tendências, fazer predições ou compreender a natureza da evolução [MD08a]. Segundo Chapin [CHK+01], evolução de software é "a aplicação de atividades e processos de manutenção de software que geram uma nova versão de software operacional com uma funcionalidade (ou propriedade) modificada e experimentada pelo cliente (...) junto com atividades e processos de QA e com a gerência das atividades e processos". Além dessa, outras definições podem ser encontradas em [TRDL07].

A área de Evolução de Software tem sido foco de maior atenção desde a década passada. Tal é a importância do tema que, em 2004, o ACM/IEEE Software Engineering Curriculum Guidelines $^{1}$ apontou "Evolução de Software" como uma das 10 áreas chave de conhecimento para a educação em Engenharia de Software. Evolução de software é também um ingrediente crucial de métodos ágeis de desenvolvimento, como Programação Extrema [BA04] e Scrum [Coh09]. A Evolução de Software é analisada com base em dados que abrangem o histórico de lançamento (release history), código-fonte, informações sobre mudanças, dados de relatórios de erros e dados que podem ser extraídos do sistema em execução. Enquanto a recuperação de dados residindo em sistemas de controle de versão como CVS, Subversion e Git tornou-se um tópico bem explorado, o desafio principal ainda consiste na interpretação dos dados recuperados [DGLP08], isto é, na extração de informação útil.

A habilidade de evoluir o software em face às constantes mudanças nos requisitos é um grande desafio para a Engenharia de Software. Em particular, aplicar uma sequência de mudanças sem provocar acentuada degradação na arquitetura e no design é ainda um problema em aberto. Uma série de alternativas complementares têm sido propostas para tratar esse problema, tais como: processos de desenvolvimento de software (mais notoriamente, a família de métodos ágeis de desenvolvimento [Coc02], [DDM10]), paradigmas de construção de software (por exemplo, programação orientada a aspectos [KH01] e design dirigido por domínio [Eva03]), técnicas de visualização (por exemplo, visualização de software como cidades [LM06]) e abordagens para gerência de dependências entre classes e módulos [SJSJ05, MM06, PFK10]. O foco desse trabalho está concentrado na última alternativa.

A gerência de dependências, além de primariamente auxiliar na avaliação do grau de acoplamento entre os elementos do software, exibe uma série de outros benefícios que apoiam a evolução de software. Por meio dela, pode-se determinar o impacto de mudanças realizadas num elemento específico, revelando o grau de encapsulamento dos módulos e viabilizando a realização de manutenção planejada. Pode-se também detectar antipadrões estruturais, entender a evolução da arquitetura e avaliar se o design implícito (isto é, o código) obedece às restrições arquiteturais previamente estabelecidas. Para linguagens como $\mathrm{C}++$, a gerência de dependências auxilia na redução do tempo de compilação do código [Lak96]. Segundo Tessier, gerenciar dependências significa garantir o encapsulamento e assegurar que o código segue a arquitetura, além de ser essencial para a modularização e favorecer o reúso ${ }^{2}$.

\footnotetext{
${ }^{1}$ http://sites.computer.org/ccse/SE2004Volume.pdf

${ }^{2}$ http://depfind.sourceforge.net/Manual.html
} 
O objetivo deste capítulo é situar o leitor quanto ao contexto desta pesquisa. Assim, começamos o capítulo apresentando os conceitos básicos relacionados à gerência de dependências. Em seguida, discutimos trabalhos relacionados e apresentamos o ciclo da gerência de dependências. Por fim, encerramos o capítulo apresentando um comparativo das ferramentas existentes de apoio à gerência de dependências (estruturais).

\subsection{Conceitos Básicos}

Apresentamos, a seguir, os conceitos básicos para gerência de dependências em sistemas orientados a objetos.

\subsubsection{Definições}

A fim de reduzir ambiguidades, listamos a seguir as definições adotadas para alguns conceitos utilizados ao longo deste trabalho.

- Abstração. O ato de concentrar as qualidades essenciais ou gerais de conceitos semelhantes [Lar04]. A arte de amplificar "o que interessa" e esconder os detalhes.

- Arquitetura de software. A arquitetura de um programa é a estrutura composta de elementos de software, as propriedades externamente visíveis desses elementos, e os relacionamentos entre eles [BCK03]. Assim, a arquitetura guia o design do software. Informalmente, a arquitetura pode ser vista como uma descrição da organização, motivação e estrutura de um sistema [Lar04].

- Bug. Uma falha em um programa que faz com o que tal programa se comporte de modo não desejado ou inesperado [MK07].

- Design ${ }^{3}$. Um processo que usa os produtos da análise a fim de produzir uma especificação para implementação um sistema. Uma descrição lógica de como um sistema irá funcionar [Lar04].

- Artefato de software. Termo genérico para denotar qualquer produto de uma atividade no desenvolvimento de um software: código, esquema do banco de dados, documentação, diagramas, modelos, etc. [Lar04]. Ainda, todo artefato deve ser acompanhado ao longo do tempo.

- Unidade de Compilação (Compilation Unit). Termo utilizado para indistintamente denotar classes abstratas, classes concretas e interfaces.

- Pacote. Elemento de organização utilizado para organizar e agrupar constructos definidos na UML [Fow03]. Pacotes são tipicamente usados para organizar e agrupar unidades de compilação. Em sistemas orientados a objetos, um módulo é usualmente representado por

\footnotetext{
${ }^{3}$ Ao longo deste trabalho, utilizaremos o termo não traduzido "design". As razões para tal estão descritas no Apêndice A.1.
} 
um pacote ou grupo de pacotes. Assim, no contexto dessa dissertação, um módulo não deve ser entendido como uma unidade de compilação.

- Dependência. Segundo o dicionário Aurélio, uma dependência é uma "sujeição" [dHF10]. De fato, no contexto de sistemas de software, um relacionamento de dependência indica que um elemento cliente (de qualquer espécie, inclusive classes, pacotes, casos de uso, etc.) tem conhecimento de outro elemento fornecedor e que uma modificação no fornecedor pode afetar o cliente [Lar04]. Também, uma dependência implica que a semântica do cliente não é completa sem o fornecedor ${ }^{4}$. Essa definição contempla o termo "dependência" em seu sentido mais amplo. Dependências estruturais e dependências lógicas são definidas nas duas próximas subseções respectivamente.

\subsubsection{Dependências Estruturais}

Dependências estruturais (também conhecidas como dependências sintáticas, físicas e de programa) ocorrem sempre que uma unidade de compilação depende de outra em tempo de compilação ou de ligação. Todos os relacionamentos da UML, incluindo generalização, associação e realização, são conceitualmente tipos de dependências estruturais [Fow03]. Logo, tipos comuns de dependências estruturais incluem: ter um atributo do tipo do fornecedor (associação), receber um parâmetro do tipo do fornecedor, herdar de uma superclasse (generalização), realizar uma interface (realização) e enviar uma mensagem para um fornecedor. Nesse último caso, o fornecedor pode se apresentar na forma de um atributo, uma variável de parâmetro, uma variável local ou uma variável global. Ressaltamos, por fim, que a presença de relacionamentos de dependência em um diagrama de classes UML não tem qualquer implicação em semânticas específicas referentes a tempo de execução, pois esse tipo de relacionamento ocorre somente no contexto de uma visão estática e, portanto, não se aplica para instâncias (objetos). A UML é tratada com mais detalhes no Capítulo 6.

A fim de apoiar a identificação e compreensão das entidades que julgamos significativas no domínio de dependências estruturais, propomos o modelo conceitual ilustrado na Figura 3.

\footnotetext{
${ }^{4}$ Definição extraída de http://www.omg.org/technology/documents/formal/uml.htm
} 


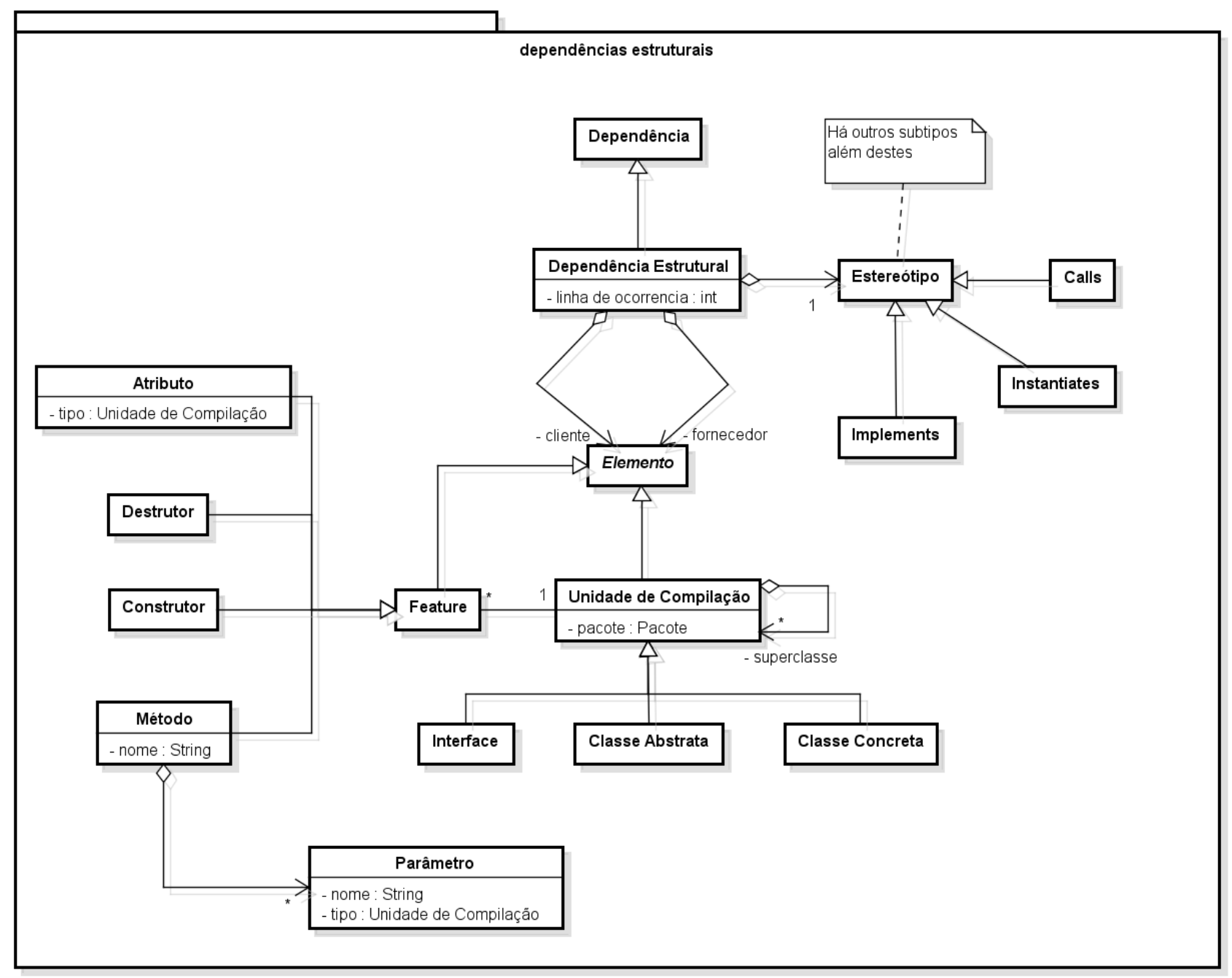

Figura 3: Modelo conceitual UML para dependências estruturais em sistemas orientados a objetos

O conceito de Feature foi inspirado na ferramenta Dependency Finder (Apêndice B) e representa os Construtores, Destrutores, Atributos e Métodos de cada unidade de compilação. A presença do conceito de Feature no diagrama possibilita mapear a origem da dependência estrutural (por exemplo, um método de uma classe chamando outro método de outra classe). Unidade de compilação representa tanto classes como interfaces, sendo que o autorelacionamento é justificado pela eventual presença de herança. Dependência Estrutural representa os relacionamentos estruturais entre dois Elementos (classes, interfaces e features). Em particular, conforme descrito em detalhes no Apêndice B, para a linguagem Java, basta descobrir as dependências entre (i) feature e feature, (ii) feature e classe e (iii) classe e classe para que se obtenha todas as outras dependências estruturais no sistema (Figura 4). 


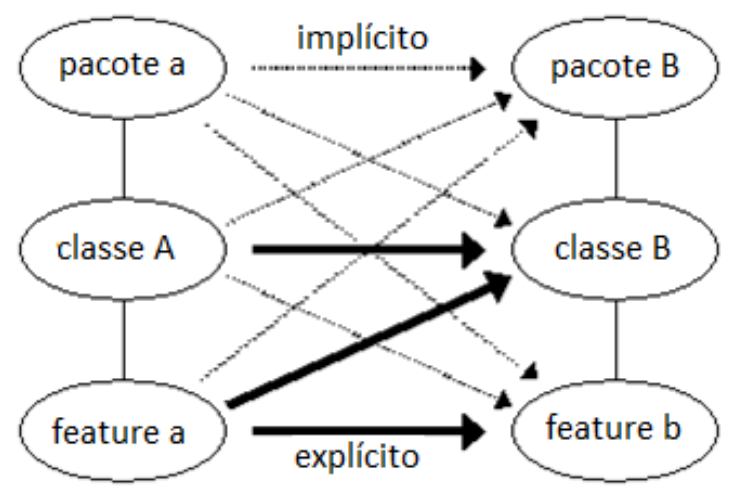

Figura 4: Modelo de identificação de dependências no Dependency Finder

Por fim, Estereótipo é um supertipo que abstrai os estereótipos existentes para dependências e relacionamentos, tais como calls, instantiates e implements.

\subsubsection{Dependências Lógicas}

Dependências lógicas (também conhecidas como dependências de mudança [DGLP08], dependências evolucionárias [BDW05] e co-changes [BN05]) são dependências implícitas que ocorrem entre artefatos de software que evoluem juntos [BAHS97], [GHJ98]. Esses artefatos não são necessariamente estruturalmente relacionados, já que estão conectados a partir de um ponto de vista evolucionário, ou seja, esses artefatos mudaram juntos com frequência no passado e, portanto, estão inclinados a mudarem juntos no futuro. Desse modo, enquanto dependências estruturais são definidas para um instante de tempo específico, dependências lógicas são definidas com base em um intervalo de tempo.

Dependências lógicas são comumente tratadas como regras de associação, que é um conceito oriundo da área de mineração de dados (data mining). Formalmente, uma regra de associação é uma implicação da forma $\mathrm{X}_{1} \Rightarrow \mathrm{X}_{2}$, que diz que quando $\mathrm{X}_{1}$ ocorre, $\mathrm{X}_{2}$ também ocorre. $\mathrm{X}_{1}$ e $\mathrm{X}_{2}$ são dois conjuntos disjuntos de itens. $\mathrm{X}_{1}$ é chamado de antecedente (também conhecido como left-handside e LHS) e $\mathrm{X}_{2}$ é chamado de consequente (também conhecido como right-hand-side e RHS). Por exemplo, a regra $\{\mathrm{A}, \mathrm{B}\} \Rightarrow\{\mathrm{C}\}$ encontrada nos dados das vendas de um supermercado indicaria que se um cliente compra A e B juntos, esse mesmo cliente é propenso a também comprar C. No contexto desse estudo, uma dependência lógica de um artefato $\mathrm{f}_{2}$ (cliente) para outro artefato $\mathrm{f}_{1}$ (fornecedor) é denotada pela regra $\mathrm{F}_{1} \Rightarrow \mathrm{F}_{2}$, na qual o antecedente e o consequente são conjuntos unitários que contém $\mathrm{f}_{1}$ e $\mathrm{f}_{2}$ respectivamente.

Medidas de interesse e significância para regras de associação são usualmente dadas por limiares (thresholds) de suporte (support) e confiança (confidence). Em nosso estudo, a medida de suporte denota o número de vezes que dois artefatos foram mudados juntos. A medida de confiança define o grau em que artefatos estão logicamente conectados, caracterizando assim a força da relação. Zimmerman et al. [ZWDZ05] formalizaram esses conceitos para o sistema de controle de versão CVS, isto é, um sistema sem suporte à commit atômico. Nós adaptamos tal formalização de modo que se tornasse apropriada para sistemas de controle de versão com suporte à commit atômico. Descrevemos, a seguir, a formalização adaptada:

- Frequência de um conjunto de arquivos $\mathrm{F}$ em um conjunto de commits $\mathrm{C}$ :

frq $(C, F)=\mid\{C \mid C \in C$ e inclui todos os arquivos em $F\} \mid=P(F)$ 
- Suporte de uma dependência lógica $F_{1} \Rightarrow F_{2}$ :

$\operatorname{supp}\left(C, F_{1} \Rightarrow F_{2}\right)=\operatorname{frq}\left(C, F_{1} \cup F_{2}\right)=$ número de commits que contém ambos $f_{1} e f_{2}$

- Confiança de uma dependência lógica $\mathrm{F}_{1} \Rightarrow \mathrm{F}_{2}$ :

$\operatorname{conf}\left(C, F_{1} \Rightarrow F_{2}\right)=\operatorname{supp}\left(C, F_{1} \Rightarrow F_{2}\right) / \operatorname{frq}\left(C, F_{1}\right)$ = valor de suporte dividido pelo número de commits que contém $f_{1}$

Deve-se notar que os valores de confiança para $F_{1} \Rightarrow F_{2}$ e $F_{2} \Rightarrow F_{1}$ são diferentes. No primeiro caso, o valor de confiança determina, por definição, o grau em que o artefato $\mathrm{f}_{2}$ é cliente de outro artefato $\mathrm{f}_{1}$. Analogamente, no segundo caso, a confiança determina o grau em que o artefato $\mathrm{f}_{1}$ é cliente de $\mathrm{f}_{2}$. Para ilustrar essa sutil diferença, considere o exemplo mostrado na Figura 5.

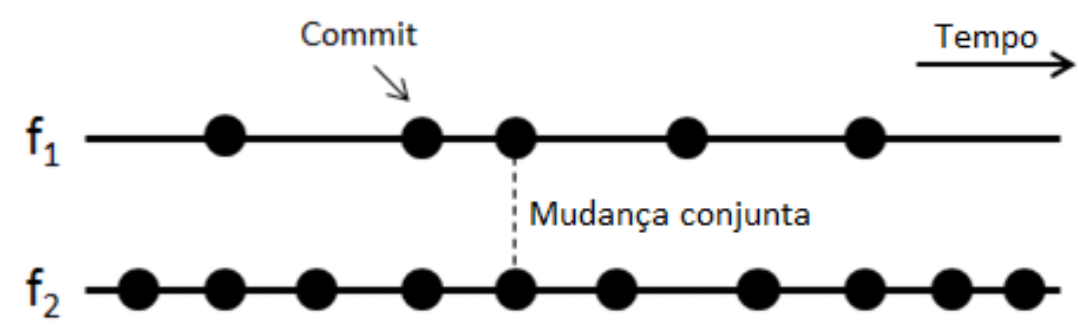

Figura 5: Exemplo de regra de associação

$\mathrm{Na}$ maior parte das vezes, quando $\mathrm{f}_{1}$ é incluído em um commit, $\mathrm{f}_{2}$ também é. Portanto, a regra $F_{1} \Rightarrow F_{2}$ (que diz que $f_{2}$ depende de $\left.f_{1}\right)$ tem uma alta confiança: $\operatorname{conf}\left(C, F_{1} \Rightarrow F_{2}\right)$ = número de commits que contem ambos $f_{1}$ e $f_{2} /$ número de commits que contém $f_{1}=4 / 5=80 \%$. Por outro lado, a regra $F_{2} \Rightarrow F_{1}$ (que diz que $f_{1}$ depende de $f_{2}$ ) tem metade da confiança da regra anterior: $\operatorname{conf}\left(C, F_{2} \Rightarrow F_{1}\right)$ = número de commits que contem ambos $f_{1}$ e $f_{2} /$ número de commits que contém $f_{2}=4 / 10=40 \%$.

A fim de apoiar a identificação e compreensão das entidades que julgamos significativas no domínio de dependências lógicas, propomos o modelo conceitual ilustrado na Figura 6. 


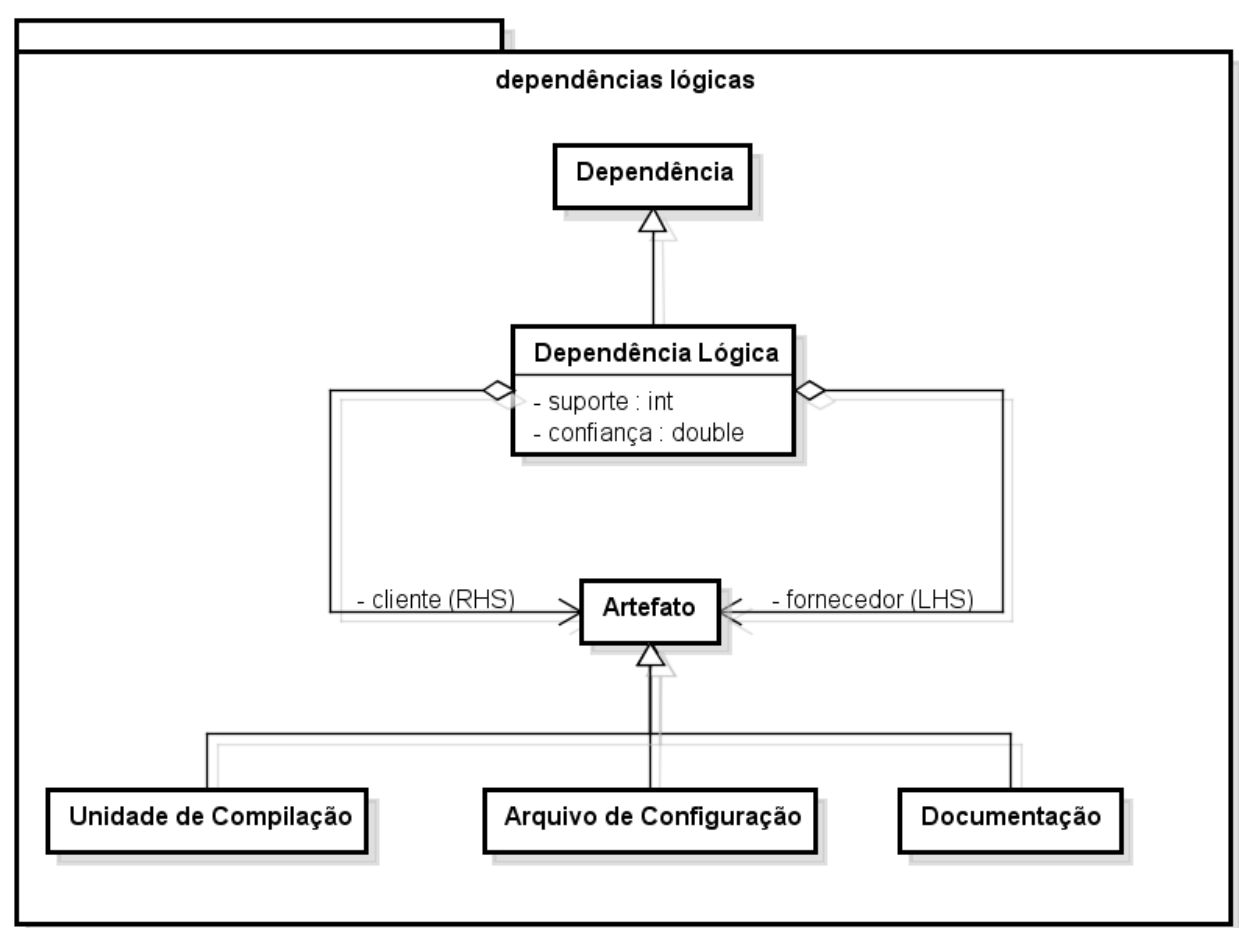

Figura 6: Modelo conceitual UML para dependências estruturais em sistemas orientados a objetos

O modelo conceitual revela que, diferentemente de dependências estruturais, as dependências lógicas podem ser estabelecidas entre quaisquer artefatos armazenados no sistema de controle de versão, tais como unidades de compilação (classes, interfaces), arquivos de configuração e documentação. Ainda, vale ressaltar que o cliente da dependência é o consequente da regra (RHS) e o fornecedor é o antecedente da regra (LHS) de associação. Por fim, os valores para suporte e confiança mudam de acordo com o conjunto de commits considerado durante o processo de identificação de dependências lógicas.

\subsection{Trabalhos Relacionados}

Abordagens, métodos ou processos para gerência de dependências. Há poucos estudos na literatura que propõem uma estratégia ou abordagem para gerência de dependências. Sangal et al. propõem uma abordagem para gerência da arquitetura de sistemas complexos usando matrizes de dependências [SJSJ05]. Essas matrizes são conhecidas pela sigla DSM e serão apresentadas com mais detalhes na Seção 6.3. A abordagem é baseada na experiência dos autores como consultores e é apoiada por uma ferramenta chamada Lattix (Seção C.5 do Apêndice C). Os autores realizam um estudo de caso e mostram que a abordagem auxilia na visualização da arquitetura, identificação de problemas estruturais e checagem de resultados de refatorações. Pirklbauer et al. propõem um processo e ferramenta para gerência de dependências, dando foco para o aspecto de análise de impacto de mudanças [PFK10]. Um destaque da ferramenta proposta consiste no agrupamento de dependências estruturais e lógicas em uma única base de dados, que depois serve de entrada para mecanismos de visualizações desenvolvidos pelos autores (Figura 7). 


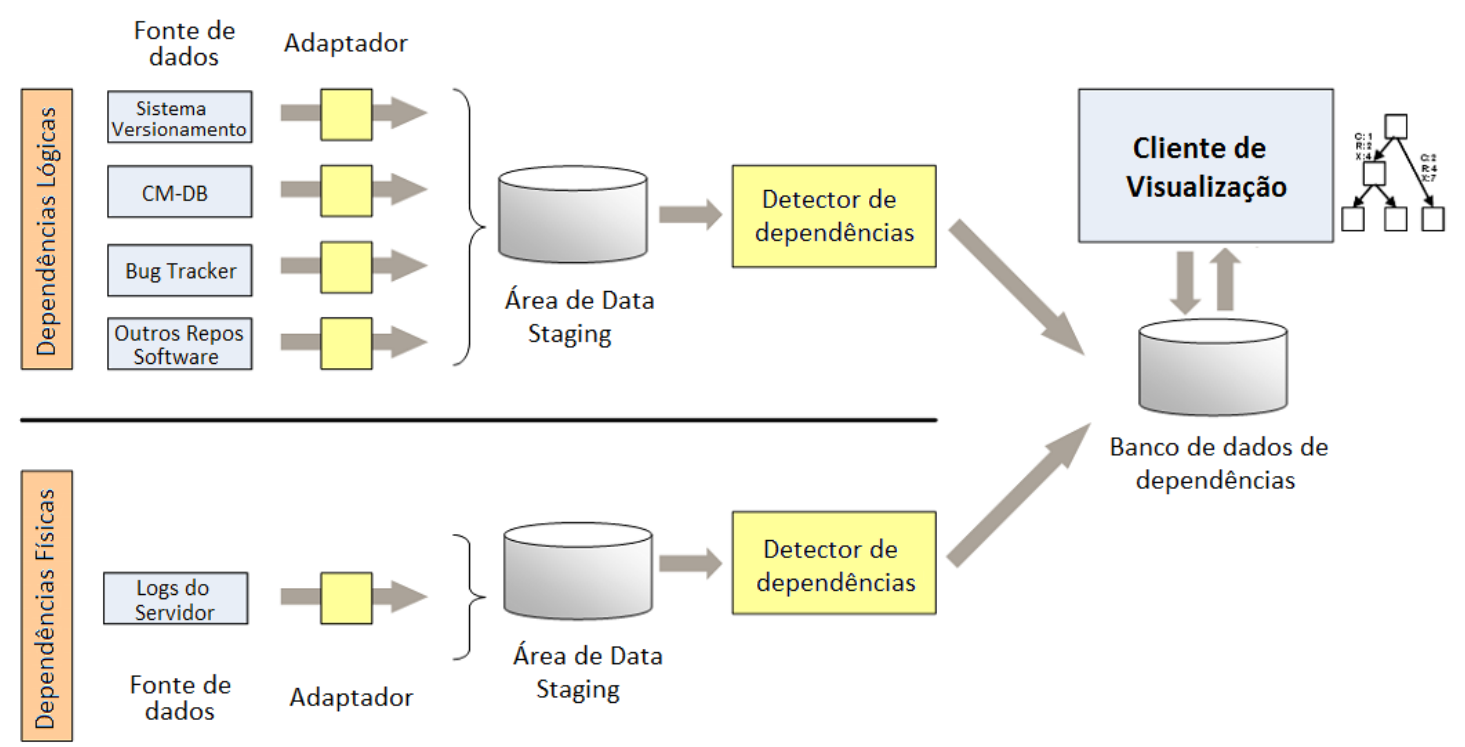

Figura 7: Arcabouço para gerência de dependências proposto por Pirklbauer et al. [PFK10]

Uso de dependências estruturais para atividades de gerência de dependências. A literatura em Engenharia de Software há tempos reconheceu a importância de dependências estruturais para pesquisa em qualidade de software [Bin07]. Em particular, esse tipo de dependência tem sido investigado nos contextos de análise de impacto (de mudanças) [BDW99], propensão a falhas [SB91], propagação de mudança [YCM78], [Raj97], [Raj00], conformação arquitetural [SJSJ05], testes de regressão [WJRR08] e outros.

Uso de dependências lógicas para atividades de gerência de dependências. O relacionamento entre dependências lógicas e qualidade de software também tem sido amplamente investigado. Destacamos a alguns resultados recentes. Graves et al. [GKMS00] mostraram que mudanças passadas são bons preditores de falhas futuras. Mockus e Weiss [MW00] verificaram que, em um grande sistema de software, a propagação de uma mudança ao longo de vários subsistemas era um forte indicador de que a mudança conteria um defeito. Cataldo et al. [CMRH09] mostraram por meio de um detalhado estudo empírico que o efeito de dependências lógicas em propensão a falhas era complementar e significativamente mais relevante que o impacto de dependências estruturais para dois projetos de corporações diferentes. Dependências lógicas também têm sido empregadas para detectar problemas de design [DLL09], inferir decadência do código (code decay) [EGK +02$]$, predizer falhas em artefatos de software [ZWDZ05] e descobrir requisitos de coordenação [CWHC06].

\subsection{O Ciclo da Gerência de Dependências}

A gerência de dependências pode ser entendida como um ciclo perpétuo que visa minimizar a degradação do design de sistemas de software ao longo do tempo. Na Figura 8 ilustramos esse ciclo, destacando as principais atividades envolvidas. 


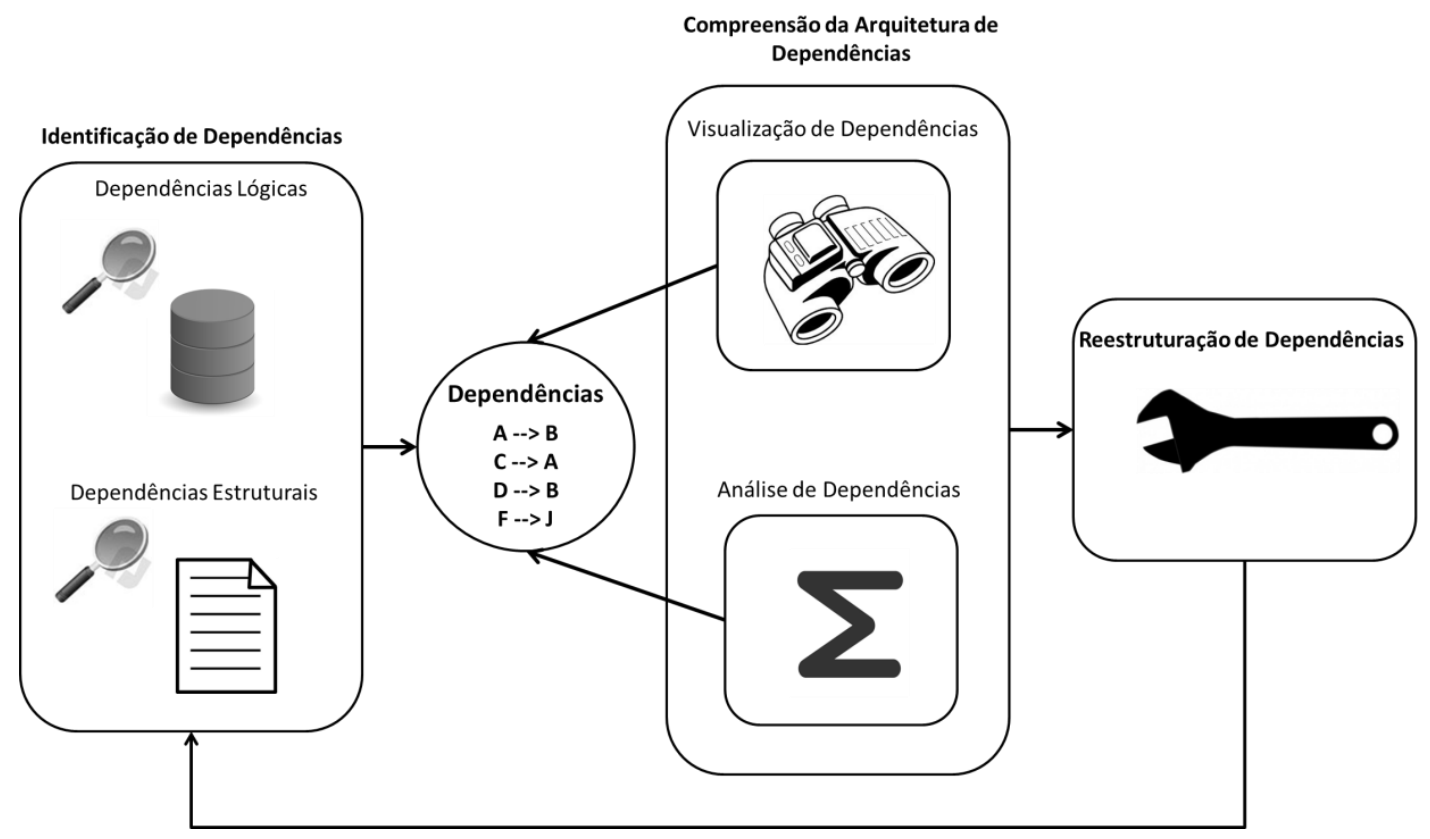

Figura 8: Ciclo da gerência de dependências

A primeira atividade compreende a identificação de dependências, que podem ser de variados tipos. No contexto dessa pesquisa, considerados dependências estruturais e lógicas. O passo seguinte envolve a compreensão humana das dependências outrora identificadas. Essa compreensão ocorre por meio do uso de técnicas e ferramentas de visualização e análise de dependências. Para uma ampla revisão sobre as técnicas de análise de dependências, sugerimos a revisão sistemática de Trosky et al. [CASA11]. Por fim, uma vez que a arquitetura das dependências é conhecida e os problemas são identificados, realiza-se a atividade de reestruturação de dependências, na qual técnicas de reestruturação e reengenharia são aplicadas.

Neste trabalho, investigamos a atividade de identificação de dependências estruturais e lógicas. Ademais, exploramos os mecanismos existentes que apoiam na visualização dessas dependências. As atividades de análise de dependências (métricas, verificação de anti-padrões estruturais, conformação arquitetural) e de reestruturação de dependências estão fora do escopo dessa pesquisa.

\subsection{Ferramentas de Apoio}

Há várias ferramentas que apoiam a gerência de dependências, oferecendo recursos para identificação, visualização, análise e reestruturação de dependências. As ferramentas variam bastante com relação ao número de recursos oferecidos, licença e outros aspectos. Dada essa diversidade, apresentamos nessa seção um sumário comparativo (Tabela 2) de diversas ferramentas para gerência de dependência estruturais encontradas na literatura e nos mecanismo de busca da Web. Caso o leitor deseje mais informações sobre ferramentas, o Apêndice $\mathrm{C}$ do trabalho oferece uma apresentação mais detalhada sobre cada uma delas. Todos os sítios de referência das ferramentas foram consultados pela última vez em 01 de junho de 2010. 
Ferramenta Licença Linguagens Plataforma de Execução Sítio de Referência

\begin{tabular}{ccccc}
\hline $\begin{array}{c}\text { Structural Analysis } \\
\text { for Java (SA4J) }\end{array}$ & $\begin{array}{c}\text { IBM } \\
\text { AlphaWorks } \\
\text { License }^{5}\end{array}$ & Java & Standalone & www.alphaworks.ibm.com/te \\
ch/sa4j
\end{tabular}

Tabela 2: Ferramentas para gerência de dependências

${ }^{5}$ http://www14.software.ibm.com/cgi-bin/weblap/lap.pl?la_formnum=\&li_formnum=L-JLCO-

6 HQ6QK\&title $=$ Structural + Analysis + for + Java\&l $=$ pt 


\section{Capítulo 3}

\section{Identificação de Dependências}

As dependências são classificadas em estruturais e lógicas. A identificação de dependências estruturais ocorre por meio de processamento do código-fonte ou do código compilado, enquanto que a identificação de dependências lógicas é usualmente dada pela investigação do sistema de controle de versão (Figura 10). Neste trabalho, a atividade de identificação de dependências gera os dados para as visualizações e para a análise (Figura 9).

O capítulo está estruturado como segue. Primeiro, apresentamos os trabalhos relacionados com a atividade de identificação de dependências. Em seguida, abordamos como dependências estruturais são identificadas e quais as dificuldades desse processo (um exemplo de implementação com a ferramenta Dependency Finder [BI02] pode ser visto no Apêndice B). Após isto, mostramos como dependências lógicas são identificadas por meio da análise do sistema de controle de versão segundo a abordagem proposta por D'Ambros et al. [DGLP08]. Por fim, introduzimos os estudos empíricos que conduzimos (e que são detalhados nos capítulos seguintes).

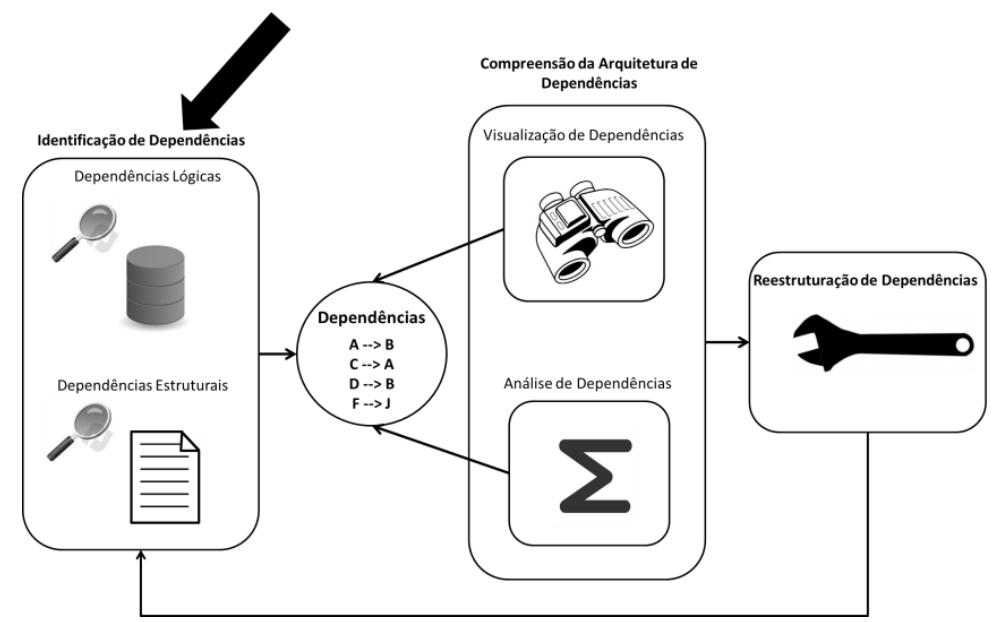

Figura 9: Ênfase na atividade "Identificar dependências" do ciclo de gerência de dependências

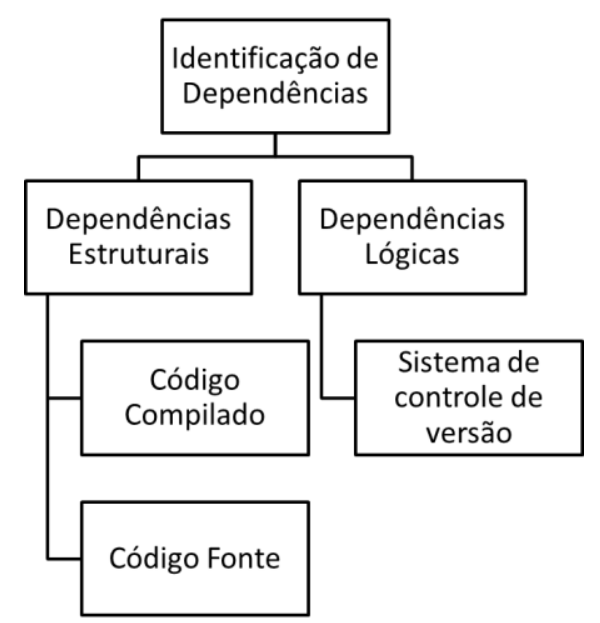

Figura 10: Taxonomia para identificação de dependências 


\subsection{Trabalhos Relacionados}

Barowski e Cross [BI02] discutem uma técnica para identificação de dependências estruturais em código Java compilado. Jean Tessier implementa uma ferramenta chamada Dependency Finder para esse fim. Melton e Tempero [MT06] propõem um algoritmo para identificação de dependências estruturais em código-fonte Java e discutem os benefícios de se analisar código-fonte em vez de código compilado. Sutton e Maletic [SM07] propõem uma abordagem de engenharia reversa para recuperar diagramas de classe UML a partir de código-fonte escrito em $\mathrm{C}++$. Terceiro et al. desenvolveram um sistema chamado DoxyParse, que é construído em cima do DoxyGen, e que dá suporte para a identificação de dependências estruturais em códigofonte escrito em diversas linguagens, dentre elas $\mathrm{C}, \mathrm{C}++, \mathrm{C} \#$, Java, Python, Fortran e PHP $[\mathrm{TCM}+10]$.

Cataldo et al. [CWHC06] propõem uma abordagem para identificação de dependências lógicas que se baseia em uma análise sintática (parsing) de commits e na construção de uma matriz quadrada simétrica e esparsa que armazena o número de vezes que um artefato mudou juntamente com outro ao longo do tempo. D'Ambros et al. [DLL09] propõem uma ferramenta chamada Evolution Radar para identificação de dependências lógicas no CVS que utiliza a técnica da janela móvel de tempo (sliding time window). Essa técnica é descrita com mais detalhes na Seção 3.3.

\subsection{Identificação de Dependências Estruturais}

A identificação de dependências estruturais envolve primariamente identificar dependências e seus respectivos cliente e fornecedor. Adicionalmente queremos identificar o tipo de relacionamento, já que cada tipo revela um grau de acoplamento próprio e também enriquece os modelos de visualização. Por exemplo, uma classe A pode ter uma associação com uma classe B (por possuir um atributo do tipo de B) e também ter uma dependência (de acordo com a nomenclatura da UML) com B (ao instanciar um objeto do tipo de B).

Informações sobre dependências estruturais são obtidas por meio do processamento do código-fonte ou do código compilado. A maior parte das ferramentas de análise de dependências apresentadas no Apêndice A utiliza o código compilado como entrada. No caso particular da linguagem Java, há três vantagens importantes ao utilizar arquivos class (código objeto). Primeiro, o compilador já fez o trabalho complexo de analisar sintaticamente o código-fonte (code parse) e construiu a tabela de símbolos. Segundo, as dependências no código-fonte não estão sempre claras. Dependências não óbvias podem existir e dependências aparentes podem não ser reais. Os compiladores se encarregam de identificar essas dependências corretamente. Por fim, pode ser que o código-fonte não esteja disponível.

A principal desvantagem de se utilizar arquivos class para colher informações sobre dependências é que o compilador Java em alguns casos altera dependências criando métodos sintéticos. Outra desvantagem é que a localização das dependências no código-fonte é dada apenas pelo número da linha (o compilador não guarda o número da coluna). Esses dois problemas são discutidos em detalhes em [BI02]. Finalmente, investigar arquivos class requer que o código-fonte seja primeiramente compilado, o que pode dificultar o processamento de aplicações que necessitam bibliotecas externas ou modificações no script de construção (build) para o ambiente local. 


\subsection{Identificação de Dependências Lógicas}

Mineração de repositórios de software (MSR) consiste em aplicar técnicas de mineração de dados (data mining) em dados históricos do projeto de software. A mineração de repositórios é comumente utilizada para apoiar na compreensão acerca do processo evolutivo de sistemas de software. Além disso, também é frequentemente utilizada como base para fazer predições sobre o software em si e o contexto no qual ele está imerso. Por exemplo, MSR pode ajudar na melhoria do processo de desenvolvimento de software, indicando uma proficiência particular de um desenvolvedor e localizar padrões de mudança em artefatos de códigos [OIAGAG05], [Koc07]. Repositórios de software incluem: sistemas de controle de versão (por exemplo, SVN, Git), sistemas de rastreamento de bugs (por exemplo, Bugzilla) e arquivos de comunicação (por exemplo, fóruns de discussão e e-mails) [KCM07]. De acordo com Koch, a abordagem MSR tem bom custobenefício, não perturba o processo de desenvolvimento e possibilita a execução de análises que consideram todo o histórico do projeto [Koc07].

A identificação de dependências lógicas faz uso de técnicas de MSR e revela acoplamentos "ocultos" entre quaisquer artefatos de código que estejam sob um sistema de controle de versão. A informação sobre as mudanças conjuntas está presente no sistema de controle de versão ou é inferida analiticamente. Por exemplo, o SVN marca arquivos mudados juntos em tempo de commit como pertencendo ao mesmo conjunto de mudança (change set), o que é possível graças à implementação de commit como operação atômica. Por outro lado, no CVS os arquivos que são logicamente dependentes devem ser inferidos a partir do horário de modificação de cada arquivo individual [DGLP08]. Há basicamente duas abordagens para a realização dessa inferência: a janela fixa de tempo (fixed time window) e a janela móvel de tempo (sliding time window), sendo a segunda um aperfeiçoamento da primeira [ZW04]. A Figura 11 e a Figura 12 mostram um exemplo de cada abordagem.

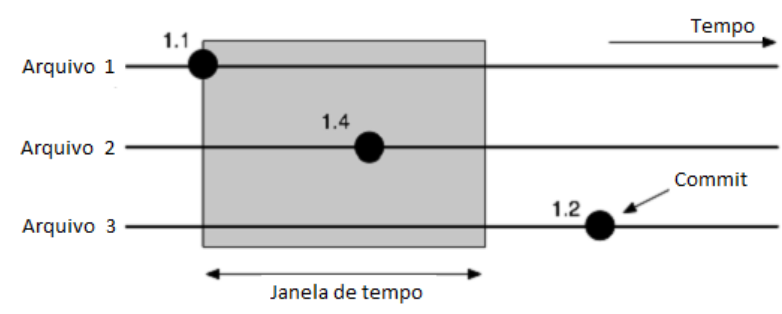

Figura 11: Janela fixa de tempo (fixed time window) [DLL09]

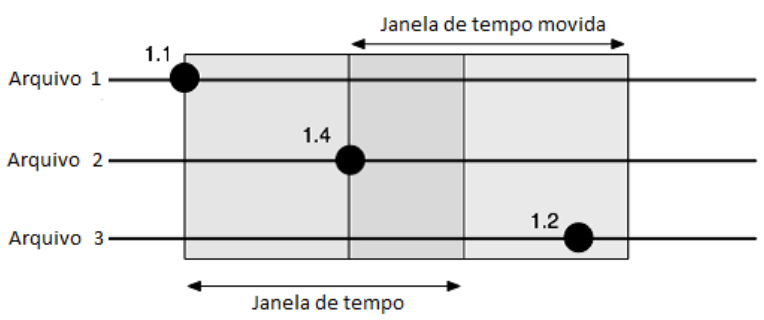

Figura 12: Janela móvel de tempo (sliding time window) [DLL09]

$\mathrm{Na}$ janela fixa de tempo, o início da janela é fixado no primeiro commit (Arquivo 1, versão 1.1). Assim, todos os outros commit com estampa de tempo (timestamp) dentro da janela são considerados como pertencentes à mesma transação (apenas Arquivo 2, versão 1.4). Com a janela móvel, o início da janela é movido para o commit mais recente reconhecido como pertencente à transação (com isso, o Arquivo 3 também é incluído na transação). Note que as transações reconstruídas utilizando a janela móvel de tempo incluem commits que demoram mais do que o tamanho da janela de tempo.

Para exemplificar o processo de identificação dessas dependências, apresentamos a abordagem proposta por D'Ambros et al. [DGLP08]. Nessa abordagem, dado um sistema para análise, a recuperação dos dados é realizada por meio do processamento dos logs do sistema de 
controle de versão. Em seguida ocorre a etapa de modelagem, em que os dados relevantes são estruturados na forma de um modelo previamente concebido. Essa abordagem propõe o armazenamento desses dados em um Banco de Dados de Histórico de Lançamento (Release History Database - RHDB), cujo esquema representa o modelo (Figura 13). Tal banco de dados é utilizado por diversas ferramentas, sendo uma delas o Evolution Radar [DLL09], [DL10].

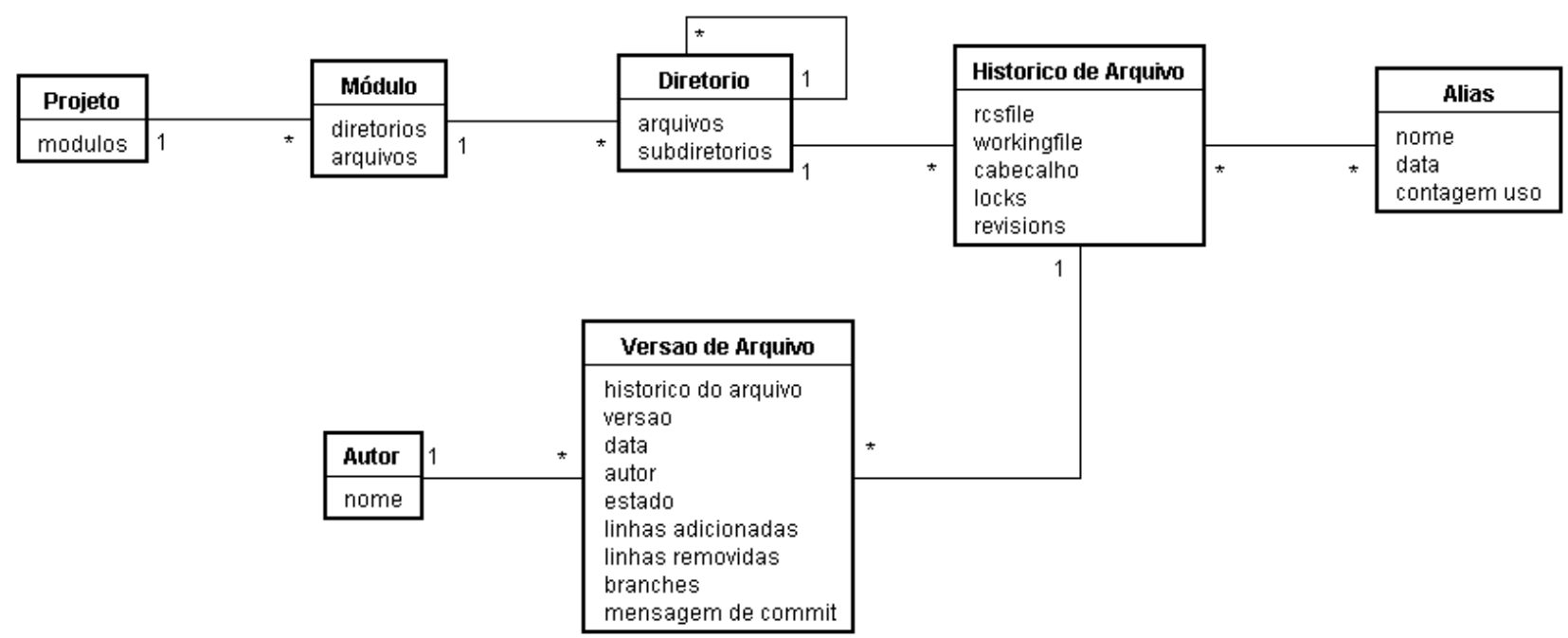

Figura 13: Modelo parcial e traduzido do RHDB [DGLP08]

A tabela Versão de Arquivo contém informações relativas ao commit: versão associada ao commit, data, autor, estado (exp, dead), linhas adicionadas, quantidade de linhas adicionadas e removidas com relação ao commit anterior, branches associados com a versão e o comentário escrito pelo autor. Um Histórico de Arquivo corresponde a um arquivo real do sistema de arquivos e é composto por uma sequência de versões, um por commit. Os campos rcsfile e working file correspondem ao nome do arquivo com e sem o caminho completo respectivamente. Um histórico pode estar associado com vários Alias, utilizados para marcar lançamentos do sistema. Por fim, um Projeto é composto de Módulos que contêm Diretórios e Históricos de Arquivo.

Nos próximos dois capítulos, apresentaremos dois estudos empíricos que conduzimos e que estão diretamente relacionados à atividade de identificação de dependências. 


\section{Capítulo 4}

\section{Dependências Estruturais vs. Lógicas}

Enquanto parece claro que ambos os tipos de dependências desempenham um papel importante durante a evolução do software, nenhum estudo de larga-escala foi conduzido para investigar a relação entre tais tipos. Em particular, a proporção de dependências lógicas que envolvem elementos estruturalmente relacionados ainda é obscura. Além disso, a literatura clássica de Engenharia de Software há tempos difunde que acoplamento estrutural deve ser minimizado, porque quando uma classe fornecedora muda, seus clientes ficam propensos a mudar [Par72] [Lar04], [BME+07]. Contudo, pouco se sabe sobre a verdadeira proporção de dependências estruturais que efetivamente levam a dependências lógicas.

Ambas as abordagens para detecção de dependências apresentam limitações. No caso de dependências estruturais, por definição, há uma dependência entre duas classes apenas se existir um relacionamento estrutural explícito entre elas. Assim, se duas classes não dependentes estruturalmente apresentarem trechos de código idênticos (ou muito semelhantes), não será identificada uma dependência entre elas. No caso de dependências lógicas, também por definição, apenas os artefatos mudados juntos são considerados dependentes. Portanto, se uma classe A depender estruturalmente de uma classe B e o desenvolvedor não realizar o commit de A junto com B, não será identificada uma dependência lógica entre as classes.

Assim, um conhecimento mais profundo acerca da sobreposição envolvendo esses dois tipos de dependências é fundamental para pesquisa em Evolução de Software. Por exemplo, se tal sobreposição for grande, então dependências estruturais e lógicas podem ser usadas indistintamente como entrada para métodos e ferramentas de gerência de dependências e análises sociotécnicas. Por outro lado, se a sobreposição for pequena, torna-se então necessário conceber e desenvolver novos métodos e ferramentas que incorporam ambos os tipos de dependências. Essa última situação hipotética implica que dependências estruturais e lógicas representam diferentes dimensões da evolução do software.

Assim, no contexto desta dissertação, investigaremos duas questões de pesquisa (Figura 14).

Q1) Qual a proporção de dependências lógicas estabelecidas que envolvem elementos nãoestruturalmente relacionados?

Q2) Qual a proporção de dependências estruturais formadas que envolvem elementos nãologicamente relacionados? 


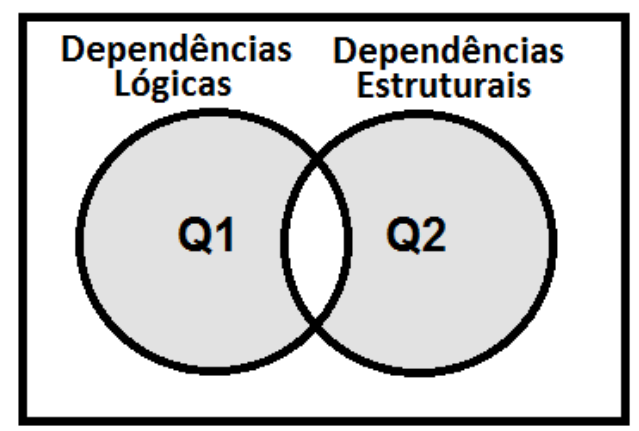

Figura 14: Diagrama de Venn ilustrando as questões de pesquisa

Identificamos dependências estruturais e lógicas a partir de um conjunto inicial de 150 mil revisões do repositório Subversion (SVN) da Apache Software Foundation (ASF). Utilizamos o par de ferramentas Doxygen/Doxyparse [TCM+10] para calcular dependências estruturais a partir de arquivos de código-fonte Java. Em contrapartida, utilizamos a ferramenta XFlow para o cálculo de dependências lógicas. Uma vez que as dependências foram capturadas, nós conduzimos uma série de análises estatísticas para responder as questões de pesquisa.

As principais contribuições deste estudo incluem (i) desenvolver uma abordagem algorítmica para calcular e comparar os graus de acoplamento estrutural e lógico; (ii) realizar uma análise segmentada de acordo com diferentes valores de suporte e confiança para responder Q1; (iii) utilizar valores de referência de métricas orientadas a objetos para responder Q2. Outras contribuições incluem prover uma análise quantitativa do número de arquivos por revisão no repositório da ASF, melhorias no cálculo de métricas pelo Doxyparse e melhorias no desempenho de coleta de dados da XFlow.

O restante desse capítulo é organizado da seguinte maneira. Na Seção 4.1, nós apresentaremos a preparação do estudo, evidenciando as razões relacionadas à escolha do repositório de software a ser analisado e do suporte ferramental. Na Seção 4.2, descreveremos o método de pesquisa e os algoritmos de identificação de dependências empregados neste estudo. Na Seção 4.3, nós discutiremos os resultados e na Seção 4.4 discutiremos as ameaças à validade. Na Seção 4.5, nós apresentaremos os trabalhos relacionados e, na Seção 4.6, colocaremos nossas conclusões finais e ideias para trabalhos futuros.

\subsection{Preparação do Estudo}

Antes de conduzir o estudo em si, precisamos tratar questões relativas à escolha do repositório de software e a seleção de ferramentas para identificação de dependências. Nas próximas subseções, mostraremos os critérios por detrás das escolhas efetuadas.

\subsubsection{Escolha do Repositório}

A Apache Software Foundation (ASF) é uma corporação sem fins lucrativos que já desenvolveu quase uma centena de projetos de software relevantes. Exemplos de projetos incluem Apache HTTP Server, Apache Geronimo, Cassandra, Lucene, Maven, Ant e Struts. A ASF possui atualmente um único repositório SVN (com aproximadamente 1.1 milhão de revisões) que hospeda todos os projetos e subprojetos da Apache. Escolhemos minerar esse repositório porque (i) ele 
hospeda um grande número de projetos FLOSS relevantes; (ii) embora os projetos sejam semiautônomos, eles seguem um modus operandi relativamente bem definido com relação a políticas de commit $^{6}$; (iii) informações sobre características do repositório e instruções gerais de uso são providas $^{7}$.

\subsubsection{Métricas Utilizadas}

Este estudo envolve o uso de duas métricas orientadas a objetos. A primeira é Coupling Between Objects (CBO), que mede o número de classes as quais uma determinada classe está acoplada. A definição de CBO original de Chidamber and Kemerer [CK94] considera o número de classes que uma classe A referencia (também conhecido como Fan-Out) mais o número de classes que referenciam A (também conhecido como Fan-In). Se uma classe aparece em ambos os conjuntos, ela é contada apenas uma vez. Outra métrica utilizada nesse estudo se chama Message Passing Coupling (MPC) [LH93], que mede o número de chamadas a operações externas, isto é, o número de chamadas a partir de métodos de uma classe para operações de outras classes. No contexto desse estudo, denotamos por $\mathrm{MPC}^{*}$ a aplicação da métrica MPC para um único cliente e um único fornecedor, ou seja, $\mathrm{MPC}^{*}$ mede o número de chamadas que uma classe específica $\mathrm{A}$ faz para outra classe específica B.

\subsubsection{Suporte Ferramental}

Estudos envolvendo mineração de repositório dependem de ferramental apropriado para a extração e análise dos dados. Descreveremos, a seguir, as ferramentas que dão suporte para a condução do estudo em questão.

XFlow. Estudos de mineração de repositórios usualmente requerem extensivo suporte ferramental por conta da quantidade de dados complexos que precisam ser coletados, processados e analizados [BWKG05]. XFlow é uma ferramenta interativa, de arquitetura flexível e de código aberto e que foi projetada para prover uma análise abrangente do processo de evolução de projetos de software, levando em consideração tanto os aspectos técnicos quanto os aspectos sociais desses projetos. A XFlow coleta dados de sistemas de controle de versão, identifica dependências lógicas, calcula métricas a respeito dos dados coletados e, finalmente, apresenta ricas visualizações interativas (Figura 15). A ferramenta XFlow é descrita em detalhes no Capítulo 7.

\footnotetext{
${ }^{6}$ http://www.apache.org/dev/new-committers-guide.html

${ }^{7}$ http://www.apache.org/dev/version-control.html
} 


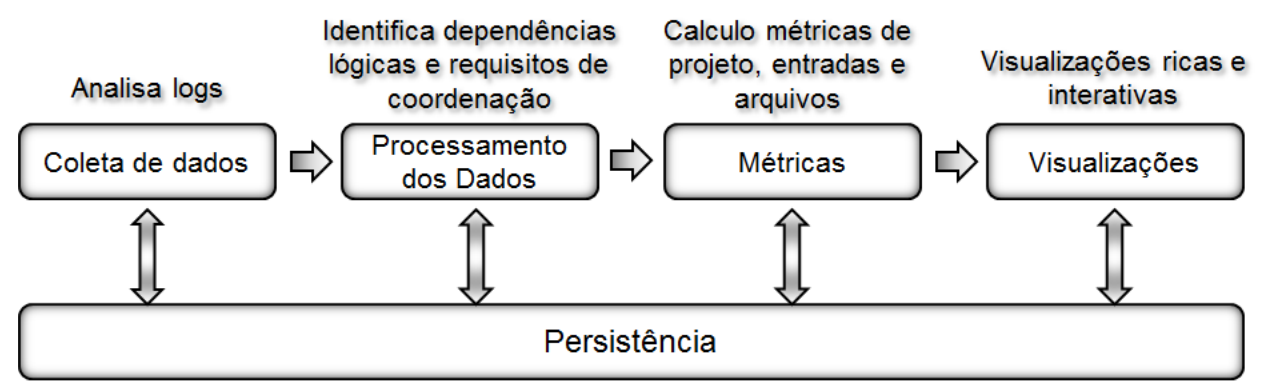

Figura 15: Fases de Processamento da XFlow

A fim de facilitar o agrupamento e análise dos resultados, decidimos conduzir todo o estudo usando uma única ferramenta de análise de dependências. Portanto, aproveitamos a arquitetura extensível da XFlow e construímos um módulo de identificação de dependências estruturais. Esse novo módulo desenvolvido utiliza o par de ferramentas Doxygen/Doxyparse.

Doxygen e Doxyparse. Durante o planejamento do estudo, definimos os seguintes requisitos para a ferramenta de identificação de dependências estruturais.

(i) Identificar dependências através de processamento de código-fonte Java: já que estamos lidando com um sistema de controle de versão, seria mais prático e direto se a identificação de dependências fosse feita diretamente sobre o código-fonte de unidades de compilação Java.

(ii) Calcular acoplamento estrutural contando o número de chamadas de operações de um cliente para um fornecedor, de modo a obtermos nossa métrica para acoplamento estrutural. Essa métrica pode ser vista como uma aplicação da métrica MPC para um único cliente e um único fornecedor. Doravante, nós a denotamos por MPC*.

Doxygen é um sistema de documentação para C, C++, Java, Objective-C, Python, IDL (versão Corba e Microsoft), Fortran, VHDL, PHP e C\#. Doxygen é distribuído sob a licença GPL e roda em uma variedade de sistemas operacionais. Doxyparse é um analisador (parser) multilinguagem de código-fonte que satisfaz nossos requisitos e que foi construído a partir do Doxygen. A ferramenta Doxyparse foi concebida no contexto do projeto Analizo [TCM+10], que é um toolkit para análise de código-fonte e que conta com a colaboração de pesquisadores do IMEUSP em seu desenvolvimento.

Melhorias no Doxygen/Doxyparse e na XFlow. Doxygen não era capaz de detectar chamadas repetidas para a mesma operação do fornecedor no caso em que tais chamadas eram feitas dentro do escopo de um mesmo método no cliente. Por exemplo, se o método a ( ) da classe A chamasse por três vezes uma operação b () de uma classe B, o Doxygen somente a contaria uma vez. Assim, nós modificamos o programa de modo que ele contasse todas as operações (três, no exemplo). Além disso, a fim de melhorar o desempenho do processo de identificação de dependências estruturais, modificamos o programa Doxyparse para remover informações de sua saída que eram desnecessárias no contexto deste estudo. Com relação à ferramenta XFlow, ela não estava inicialmente preparada para dar suporte a estudos de larga-escala (tal como este, que envolve 150 mil revisões). Portanto, durante a preparação do estudo, nós aperfeiçoamos o desempenho da coleta de dados na XFlow, utilizando novas estruturas de dados e otimizando trechos de código. 
Minitab. Todas as análises estatísticas dos dados foram feitas com o auxílio da ferramenta Minitab $^{8}$. Minitab é um pacote estatístico simples e poderoso bastante utilizado pela indústria e por diversas universidades ao redor do mundo. Escolhemos essa ferramenta principalmente por conta do grande conjunto de funcionalidades oferecido e da facilidade de uso.

\subsection{Instrumentos e Métodos para Coleta de Dados}

Uma vez que repositório foi escolhido e o suporte ferramental foi selecionado e devidamente adaptado, nós procedemos com o estudo. Nas próximas subseções, apresentamos que tipos de dados foram coletados do repositório, bem como os procedimentos executados. Depois disso, mostramos estatísticas descritivas básicas relacionadas ao número de arquivos por revisão. Por fim, nós discutimos como dependências lógicas e estruturais foram identificadas e como os valores de acoplamento foram calculados.

\subsubsection{Coleta de Dados}

Nós analisamos 150 mil revisões do repositório SVN da ASF, que engloba um período de atividade de aproximadamente 2 anos e 4 meses (outubro de 2002 até fevereiro de 2005). Escolhemos analisar revisões iniciais, de modo que as características de crescimento e evolução do projeto fossem preservadas para a análise de dependências lógicas. Selecionar um intervalo arbitrário resultaria em informações imprecisas sobre a evolução dos artefatos.

A fim de lidar com a instabilidade do repositório remoto, construímos um espelho (mirror) local desse repositório. Depois de concluirmos o espelhamento, executamos a etapa de coleta de dados na XFlow, que corresponde a recuperar e analisar sintaticamente as mensagens de $\log$ de todas as 150 mil revisões. Já que também precisamos identificar dependências estruturais, configuramos a XFlow para que ela fizesse o download do código-fonte de todos os arquivos versionados. Arquivos que não tinham a extensão java foram desconsiderados das revisões. Além disso, revisões sem arquivos Java foram desprezadas. Escolhemos analisar somente código-fonte Java porque as medidas de acoplamento estrutural variam de linguagem para linguagem.

Depois da coleta de dados, nós calculamos estatísticas descritivas básicas para melhor compreender as características da variável número de arquivos por revisão (Tabela 3 e Tabela 4). Um resumo gráfico é dado na Figura 16A.

\begin{tabular}{cccccc}
\hline $\mathbf{N}$ & Soma & Média & Desvio Padrão & Assimetria & Curtose \\
\hline 40.518 & 251.691 & 6,21 & 36,24 & 33,54 & $1.608,65$
\end{tabular}

Tabela 3: Número de Arquivos por Revisão no SVN da ASF-Estatísticas descritivas

${ }^{8}$ http://www.minitab.com/ 
Número de revisões e número de arquivos. A coleta de dados na XFlow resultou em 40.518 revisões contendo pelo menos um arquivo Java, o que corresponde a $27 \%$ da nossa amostra inicial. Essas revisões englobaram um montante de 251.691 arquivos.

Média e Desvio Padrão. O valor da média de arquivos por revisão é de aproximadamente 6 arquivos. Contudo, o valor do desvio padrão indica que a dispersão em torno da média é grande. As próximas medidas estatísticas foram empregadas para auxiliar numa melhor compreensão desse valor de dispersão.

Assimetria (Obliquidade). O valor positivo de assimetria apresentado na Tabela 3 indica que o conjunto de dados é assimétrico-positivo, isto é, a distribuição tem uma cauda direita. A assimetria positiva pode ser claramente notada na Figura 16A.

Curtose. O valor de curtose denota o "achatamento" de uma distribuição. Conjuntos de dados com alta curtose tendem a possuir um alto pico perto da média, declinar rapidamente e ter longas caudas. $\mathrm{O}$ alto valor de curtose apresentado na Tabela 3 pode ser claramente visualizado na Figura $16 \mathrm{~A}$.

Teste para normalidade. Uma análise de assimetria, curtose e do histograma de frequência mostrou que os dados não estão normalmente distribuídos. De fato, conduzimos o teste de Anderson-Darling para normalidade e obtivemos um $p$-value $<0,005$.

\begin{tabular}{cccccccc}
\hline Min & Q1 & Mediana & Q3 & Max & IQR & Whisker inferior & Whisker superior \\
\hline 1,0 & 1,0 & 1,0 & 4,0 & $2.450,0$ & 3,0 & 1,0 & 8,5 \\
\hline \multicolumn{7}{c}{ Tabela 4: Número de Arquivos por Revisão no $S V N$ da ASF - Análise de Quartis }
\end{tabular}

Análise de quartis. O boxplot fornece outra vista sobre a distribuição do conjunto de dados, mostrando sua forma, tendência central e variabilidade (Figura 16B). Whiskers inferior e superior revelam que as revisões usualmente englobam de 1 a 8 arquivos. A maior revisão incluiu 2.450 arquivos.

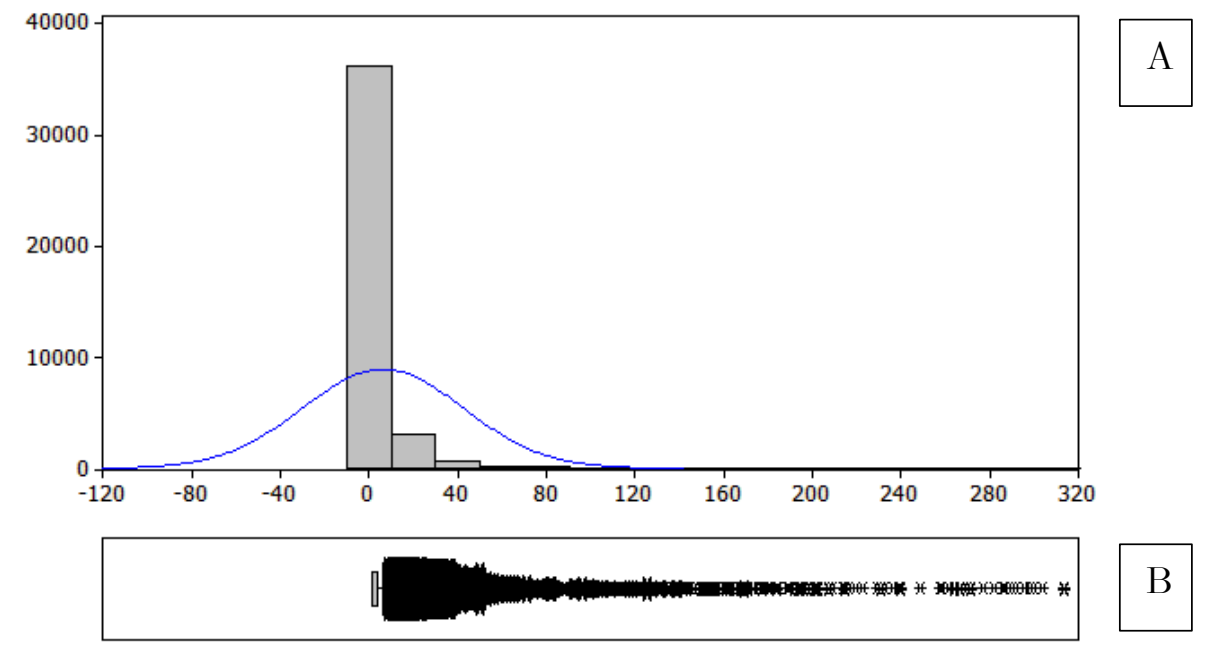

Figura 16: Resumo gráfico da distribuição da variável "número de arquivos por revisão"

Nas próximas subseções, descreveremos como as dependências foram identificadas. Ainda, apresentaremos as premissas e decisões tomadas durante essa tarefa. 


\subsubsection{Identificando dependências e calculando acoplamento}

Conforme indicado na Seção 4.1.3, empregamos a XFlow para detectar dependências estruturais e lógicas. Ainda, referimo-nos à análise de quartis para excluir revisões que continham um número extremo ${ }^{9}$ de arquivos, já que essas revisões são estatisticamente insignificantes e requereriam grandes recursos computacionais para serem processadas.

Dependências lógicas. A ferramenta XFlow aplica o método proposto por Cataldo para cálculo de dependências lógicas entre artefatos de software [CWHC06], que é mais simples do que aquela apresentada na Seção 3.3. A XFlow processa todas as revisões previamente analisadas sintaticamente e então constrói uma matriz quadrada esparsa e simétrica com as seguintes propriedades:

- $\operatorname{cell}(i, i)$ : número de vezes que um artefato i mudou (número de revisões que incluíram o arquivo $i)$.

- $\operatorname{cell}(i, j)$, para $i \neq j$ : número de vezes que o artefato $i$ e o artefato $j$ mudaram juntos (número de revisões que incluíram ambos os artefatos $i$ e $j$ ).

Duas dependências lógicas são estabelecidas para cada célula não vazia fora da diagonal da matriz: $i$ depende de $j$ e $j$ depende de $i$. O valor de tais células indica o suporte para ambas as dependências. A confiança para cada uma dessas dependências é calculada dividindo-se o suporte pelo valor em $(i, i)$ e em $(j, j)$ respectivamente.

Dependências estruturais. Enquanto dependências lógicas são definidas com base em um intervalo de tempo, dependências estruturais são definidas para um instante de tempo específico. Assim, a fim de responder a questão de pesquisa Q1, nós desenvolvemos uma abordagem algorítmica. A ideia básica é que, para cada dependência lógica criada ou modificada (em termos de suporte e confiança), nós verificamos a existência de uma dependência estrutural por meio do cálculo de MPC*. O seguinte pseudocódigo descreve o algoritmo (Listagem 1).

\footnotetext{
${ }^{9}$ Em uma análise de quartis, valores extremos são aqueles além de $Q 3+3.0$ * IQR
} 


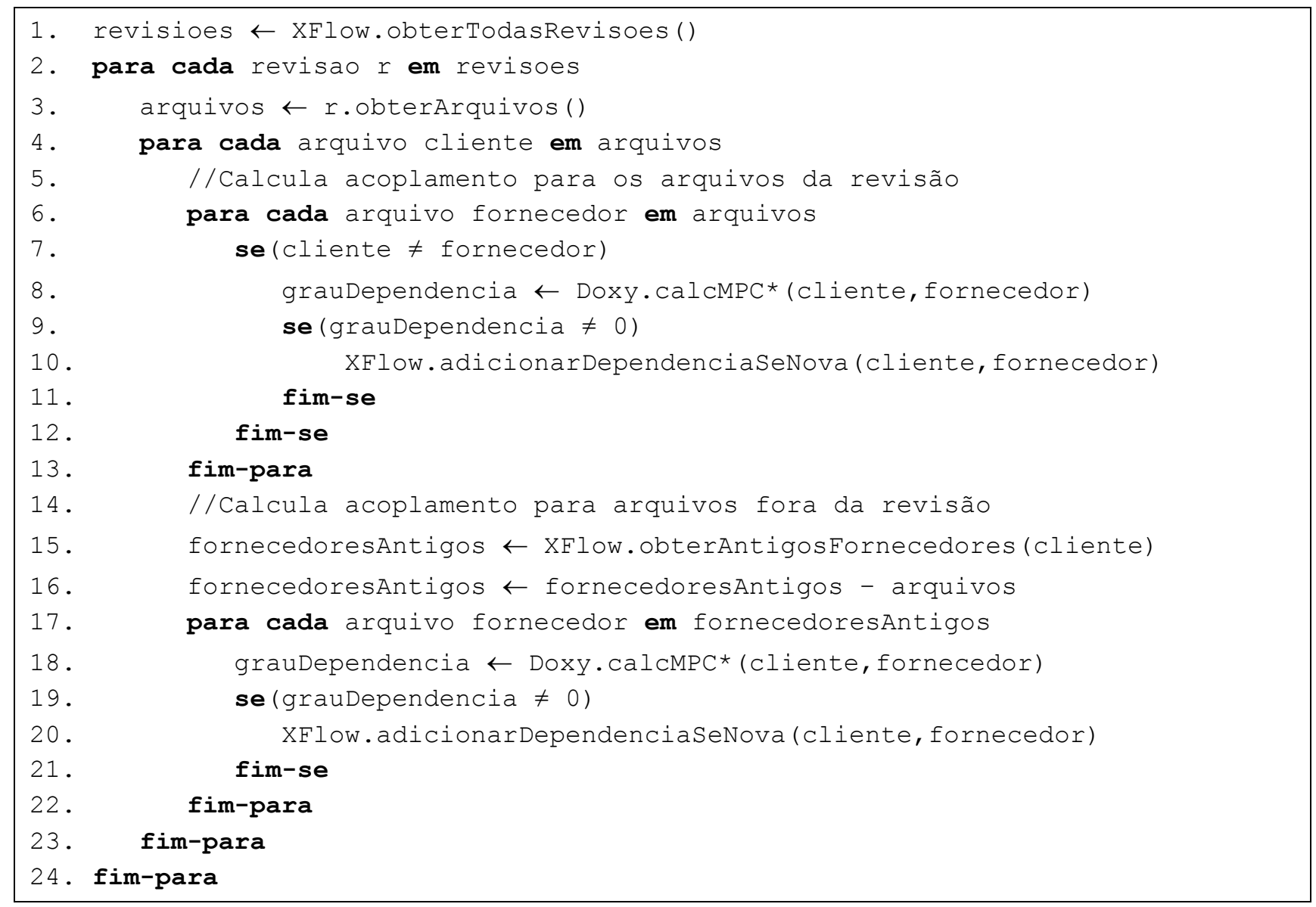

Listagem 1: Pseudocódigo descrevendo a estratégia empregada para cálculo do acoplamento estrutural

Nós primeiramente calculamos o $\mathrm{MPC}^{*}$ par a par considerando todos os arquivos de uma revisão (2-12). Caso exista pelo menos uma chamada de operação de cliente para fornecedor, então uma dependência estrutural é armazenada na XFlow. Dado que um arquivo de uma revisão específica pode já ter mudado junto com outros arquivos no passado, nós recalculamos o acoplamento estrutural entre esse arquivo e todos os seus antigos fornecedores lógicos (14-22). Analogamente, no caso de existir pelo menos uma chamada de operação de um cliente para um antigo fornecedor lógico, então uma dependência estrutural também é adicionada na XFlow (20).

\subsection{Resultados}

Nós primeiramente fizemos uma busca no banco de dados da XFlow e obtivemos um total de 270.010 dependências, juntamente com suas propriedades. Baseado em tais dados, nós construímos uma planilha com as seguintes colunas: antecedente (LHS), consequente (RHS), suporte, confiança e MPC*. Nós importamos a planilha no Minitab e começamos a investigar nossas questões de pesquisa.

Nas próximas subseções, analisamos e discutimos os resultados obtidos para cada uma das questões. 


\subsubsection{Questão de Pesquisa Q1}

Q1) Qual a proporção de dependências lógicas estabelecidas que envolvem elementos nãoestruturalmente relacionados?

Nós calculamos a proporção de dependências lógicas que envolveram elementos nãoestruturalmente relacionados (Figura 17) por meio da aplicação das abordagens descritas na Seção 4.2.2. Nós chamamos tal proporção de PAAL (proporção apenas-acoplamento-lógico).

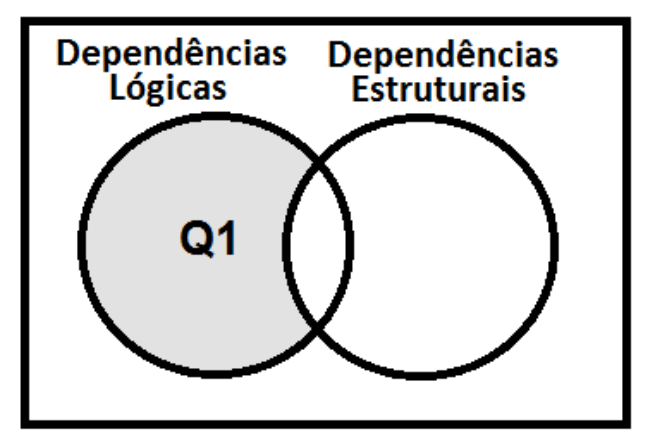

Figura 17: Diagrama de Venn ilustrando a questão de pesquisa $Q 1$

Conduzimos a análise calculando PAAL para três intervalos de confiança de mesmo tamanho:

- $\quad[0.00,0.33]:$ Acoplamento lógico baixo

- $\quad$ ]0.33, 0.66]: Acoplamento lógico médio

- ]0.66, 1.00]: Acoplamento lógico alto

A Tabela 5 mostra os resultados para todos os intervalos computados. Podemos ver que, conforme a confiança aumentou, o valor de PAAL também aumentou. Isso revela que os arquivos altamente logicamente acoplados foram aqueles que sofreram a menor influência do acoplamento estrutural (embora esses arquivos correspondam a apenas $0,1 \%$ do total de dependências lógicas). Além disso, a última linha da tabela, que engloba todas as dependências lógicas, também apresentou um alto valor para PAAL (91\%). Assim, já que valores para PAAL variaram de 91\% até aproximadamente 93\%, concluímos que dependências lógicas muito frequentemente envolvem elementos não-estruturalmente relacionados. Consequentemente, como correlação é necessária para causalidade linear, temos alguma evidência de que dependências lógicas não são causadas por dependências estruturais.

\begin{tabular}{cccc}
\hline Intervalo de Confiança & $\begin{array}{c}\text { Número de Dependências } \\
\text { Lógicas }\end{array}$ & $\begin{array}{c}\text { Dependências Lógicas } \\
\text { sem contrapartida estrutural }\end{array}$ & PAAL \\
{$[0,00,0,33]$} & $166.378(61,6 \%)$ & 151.397 & $91,0 \%$ \\
{$[0,33,0,66]$} & $103.265(38,2 \%)$ & 94.074 & $91,1 \%$ \\
{$[0,66,1,00]$} & $367(0,1 \%)$ & 341 & $92,9 \%$ \\
Total & $\mathbf{2 7 0 . 0 1 0 ( 1 0 0 \% )}$ & $\mathbf{2 4 5 . 8 1 2}$ & $\mathbf{9 1 , 0 \%}$ \\
\hline
\end{tabular}


Tabela 5: Dependências lógicas envolvendo unidades de compilação não estruturalmente relacionadas

A fim de investigar mais afundo essa questão de pesquisa, nós plotamos PAAL para os três intervalos de confiança (Figura 18). O eixo x se refere aos valores de suporte. Ademais, também computamos a porcentagem cumulativa para os valores de suporte (Figura 19), assim como a distribuição de frequência de suporte para arquivos fracamente, mediamente e altamente acoplados logicamente (Figura 20).

\section{PAAL}

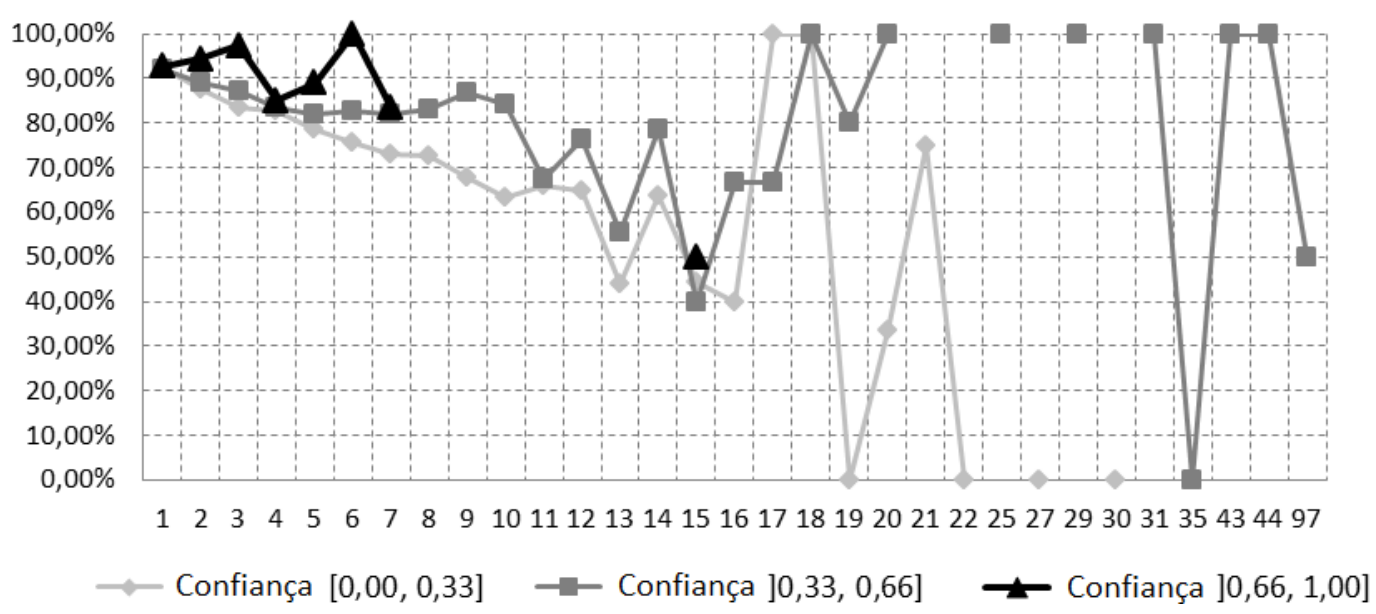

Figura 18: Dependências lógicas envolvendo unidades de compilação não estruturalmente relacionadas

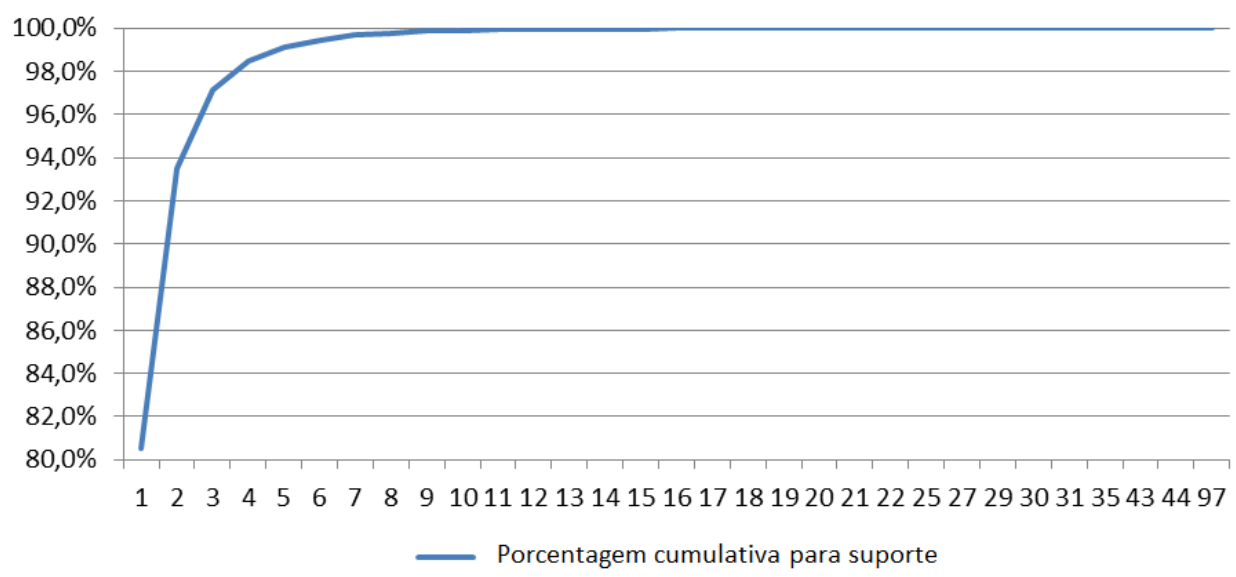

Figura 19: Porcentagem cumulativa para a medida de suporte

À luz desses resultados, verificamos que PAAL se comportou de maneira peculiar para alguns intervalos de suporte específicos:

- Intervalo de suporte [0, 10]: Esse intervalo de suporte compreende 99,9\% de todas as dependências lógicas identificadas (Figura 19). Arquivos pouco logicamente acoplados revelaram uma curva PAAL decrescente (Figura 18), isto é, há uma maior intersecção entre os dois tipos de dependência nesse caso. Unidades de compilação mediamente logicamente acopladas mostraram uma curva PAAL com poucas variações, ficando entre $90 \%$ e $80 \%$ para o intervalo 
de suporte considerado. Portanto, ao contrário do caso anterior, os valores de PAAL são altos para essa faixa de suporte.

- Intervalo de suporte $[11,31]$. Artefatos pouco, mediamente e altamente acoplados mostraram curvas com alta variação ao longo desse intervalo de suporte. Isso era de alguma forma esperado, já que tal intervalo compreende apenas $0.1 \%$ de todas as dependências lógicas (Figura 19).

- Intervalo de suporte [1, 7]: A curva para arquivos altamente logicamente acoplados ficou acima de $90 \%$ na maior parte do tempo, o que corrobora nossa descoberta anterior, isto é, o valor para PAAL é alto para artefatos fortemente logicamente acoplados. A Figura 20 também mostra que a distribuição de suporte para arquivos altamente acoplados logicamente (C) é mais suave que aquelas correspondentes a artefatos pouco (A) e mediamente (B) logicamente acoplados.
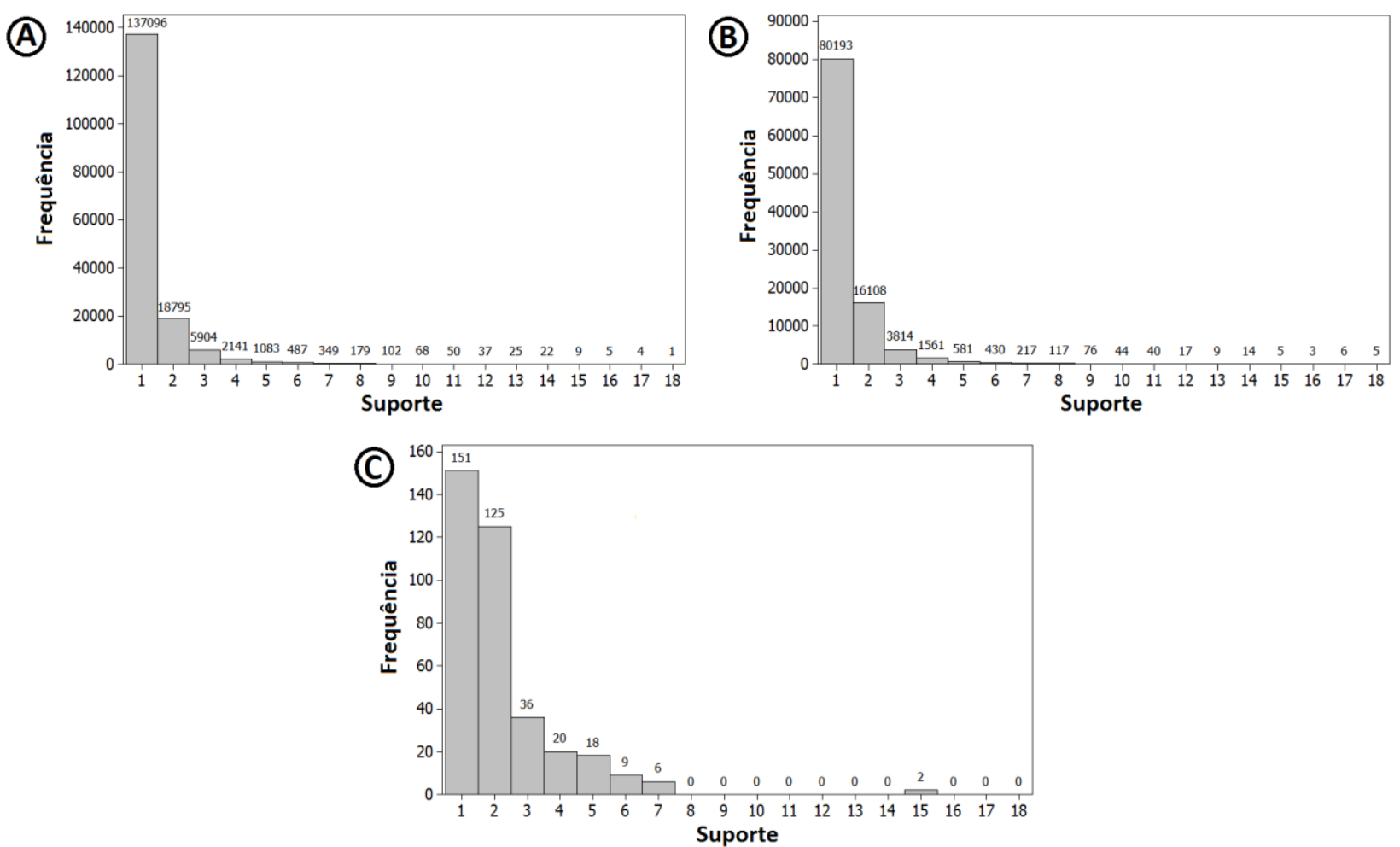

Figura 20: Distribuição de suporte para arquivos (A) pouco, (B) mediamente e (C) altamente acoplados logicamente

\subsubsection{Questão de Pesquisa Q2}

Q2) Qual a proporção de dependências estruturais formadas que envolvem elementos nãologicamente relacionados?

Nós empregamos uma estratégia de três passos para calcular a proporção de dependências estruturais que envolvem elementos não logicamente relacionados. Nós chamamos essa proporção de PAAE (proporção apenas-acoplamento-estrutural). Conforme ilustrado na Figura 21, nós (i) estimamos o tamanho do conjunto de dependências estruturais empregando valores de referência 
para a métrica CBO, (ii) calculamos o tamanho do conjunto de interseção e (iii) calculamos o tamanho do conjunto apenas-dependências-estruturais baseado nos resultados de (i) e (ii).

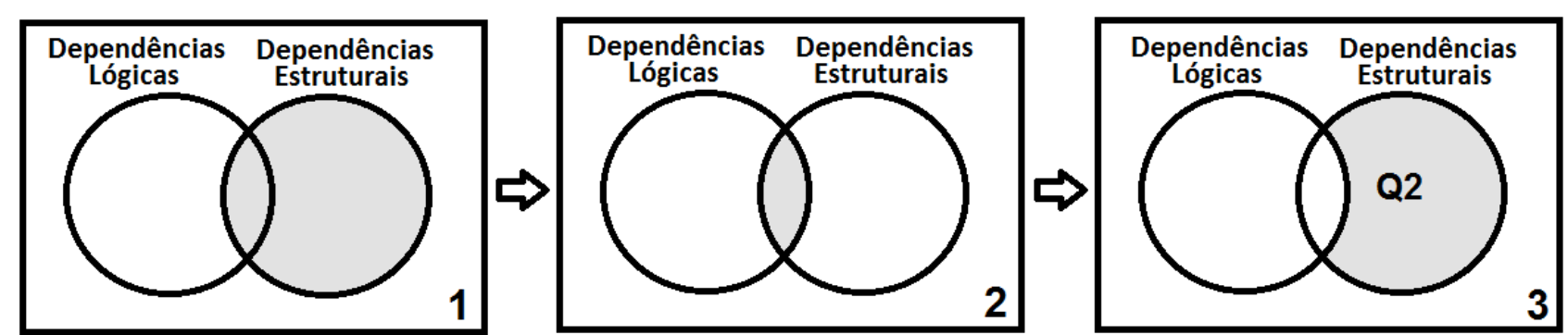

Figura 21: Diagrama de Venn ilustrando a estratégia empregada para responder a questão de pesquisa Q2

(i) Estimando o tamanho do conjunto de dependências estruturais. Barkmann et al. desenvolveram um conjunto de ferramentas para realizar uma análise de métricas em larga-escala envolveu 160 projetos FLOSS escritos em Java (70 mil unidades de compilação e 11 milhões de linhas de código) a fim de prover valores de referência e limiares (thresholds) [BLL09]. A Figura 22 mostra os valores de referência e um histograma para $\mathrm{CBO}$, no qual cada linha de grade corresponde a mil classes. Valores abaixo do histograma se referem a mínimo, máximo, média, mediana e moda respectivamente. Barkmann et al. computaram CBO considerando apenas o FanOut de uma unidade de compilação (API nativa foi descartada e construtores de classe não contaram como um método) [LLL08]. De fato, as métricas CBO e Fan-Out foram tratadas como sinônimos em uma série de estudos, por exemplo [KG02], [Cha03].

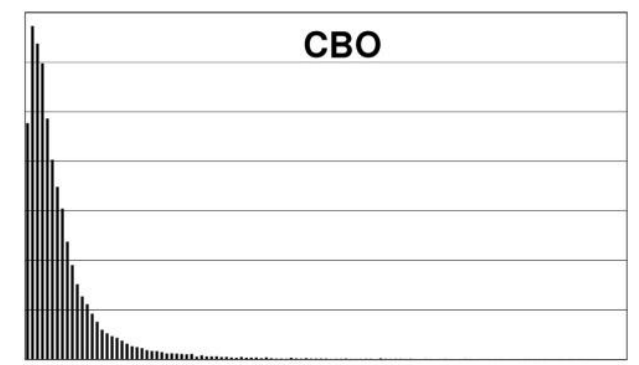

$$
0,184,6.71,4,1
$$

Figura 22: Valores de referência para a métrica CBO (mínimo, máximo, média, mediana, moda) [BLL09]

A fase de coleta de dados da XFlow identificou um total de 72.523 unidades de compilação distintas em meio as 150 mil revisões do repositório SVN da ASF. Dado que o valor de referência para a média de CBO é 6,71 (Figura 22), nós estimamos que o número total de dependências estruturais seja $72.523 * 6,71=486.630$.

(ii) Calculando o tamanho do conjunto de intersecção. A partir dos dados da última linha da Tabela 5, nós calculamos o tamanho do conjunto de interseç̧ão: $270.010-245.812=24.198$.

(iii) Calculando o tamanho do conjunto apenas-dependências-estruturais. Subtraindo (ii) de (i), calculamos o tamanho do conjunto apenas-dependências-estruturais: $486.630-24.198=$ 462.432. Como resultado, PAAE correspondeu a $95 \%$ do número estimado de dependências 
estruturais. Assim, concluímos que dependências estruturais muito frequentemente envolvem elementos não logicamente relacionados. Consequentemente, como correlação é necessária para causalidade linear, nós temos alguma evidência de que dependências estruturais não resultam em dependências lógicas.

\subsection{Ameaças à validade}

Há alguns fatores que podem ter influenciado a validade deste estudo. A seguir, discutiremos cada um deles.

Validade interna. Com relação à detecção de dependências lógicas em repositórios SVN, nós empregamos uma estratégia simples e recorrentemente utilizada. Embora Pirklbauer tenha recentemente feito um survey em que avaliou diferentes estratégias para detecção de dependências lógicas [Pir10], seus estudos apenas se aplicam para dois projetos de indústria e, portanto, não podem ser generalizados para nosso contexto. Algumas restrições na detecção de dependências lógicas foram impostas por decisões no projeto na XFlow. Uma decisão-chave é que arquivos substituídos foram considerados como arquivos adicionados. Isso pode quebrar a relação evolucionária entre pares de arquivos sob raras circunstâncias. Finalmente, embora tenhamos utilizado o repositório SVN da ASF para minimizar viés por conta de diferentes políticas de commit, projetos específicos podem não seguir tais políticas de forma estrita. Ademais, alguns projetos podem ter outras características particulares que eventualmente afetaram os resultados da estratégia empregada para detecção de dependências lógicas.

Para tratar a primeira questão de pesquisa, dividimos as dependências lógicas em três intervalos de confiança distintos e de mesmo tamanho. É possível que uma análise estatística mais profunda provasse que intervalos menores (ou até diferentes) serviriam como uma melhor entrada para a análise realizada. Também, reconhecemos que as medidas de suporte e confiança podem gerar resultados enganosos sob raras circunstâncias. Considere o exemplo no qual um arquivo $\mathrm{f}_{1}$ mudou juntamente com $\mathrm{f}_{2}$ por 5 vezes e que, depois disso, $\mathrm{f}_{1}$ mudou sozinho por outras 5 vezes e $\mathrm{f}_{2}$ não mudou mais. Assim, embora a confiança para a dependência lógica $F_{1} \Rightarrow F_{2}$ seja 0,5 , pode ser que, na realidade, $\mathrm{f}_{2}$ não dependa mais de $\mathrm{f}_{1}$ (por exemplo, uma refatoração ocorreu logo depois que $\mathrm{f}_{1}$ e $\mathrm{f}_{2}$ mudaram juntos pela última vez). Finalmente, embora o repositório investigado abrigue todos os projetos da ASF, nós encontramos uma quantidade insignificante de commits que englobaram arquivos de diferentes projetos. Além disso, revisões relacionadas a grande operações de repositório que envolveram muitos arquivos foram descartadas por conta da análise de quartis realizada. Portanto, os resultados apresentados na Tabela 5 não foram prejudicados pelo fato de termos analisado o SVN da ASF "como um todo".

Enquanto identificamos dependências estruturais somente contando o número de chamadas de operações externas (Listagem 1), os valores de referência para CBO usados para tratar a segunda questão de pesquisa adicionalmente apoiam-se em referências para instâncias externas. Contudo, referências a instâncias externas que não recebem chamadas de operações comumente representam situações de delegação. Logo, imaginamos que essas situações ocorram com pouca frequência, já que sistemas orientados a objetos são feitos de objetos que colaboram. De fato, mesmo que o tamanho do conjunto de interseção fosse duas vezes maior, o valor de PAAE ainda corresponderia a aproximadamente $90 \%$ do número total de dependências estruturais estimadas. Já 
que fizemos conclusões com base em valores de referência, nós reconhecemos que as evidencias para a segunda questão de pesquisa são menos confiáveis que aquelas obtidas na investigação da primeira.

Validade externa. Com relação à validade externa, nós podemos ter introduzido algum viés na generalização dos nossos resultados por termos analisado somente projetos da ASF. Embora essa decisão tenha nos ajudado em outras dimensões, uma análise mais ampla deveria considerar outros repositório de projetos FLOSS (como o SourceForge, por exemplo) e outras comunidades de desenvolvimento. Os resultados do nosso estudo são aplicáveis apenas para projetos de código aberto, já que projetos de software da indústria podem ter características distintas que não foram considerados nesta investigação empírica.

\subsection{Trabalhos Relacionados}

Embora dependências lógicas tenham sido extensivamente investigadas para diferentes propósitos (conforme discutido na Seção 2.2), poucos estudos exploraram a relação entre dependências estruturais e lógicas.

Hanakawa estudou a relação entre os conjuntos de elementos altamente acoplados estruturalmente (M) e de elementos altamente acoplados logicamente (L) [Han07]. A hipótese colocada pela autora é de que a média da interseção entre M e L tende a diminuir ao longo do tempo. Isso ocorre por conta de (i) um acréscimo de ações de "copiar e colar" código (resultando em acoplamento lógico apenas) e (ii) desenvolvedores esquecendo-se de fazer o commit de classes estruturalmente relacionadas de uma vez só (resultando em acoplamento estrutural apenas). Hanakawa propõe uma métrica de complexidade baseada no tamanho de tal interseção (Figura 23). Embora os resultados obtidos confirmem que a interseção entre M e L de fato diminui (isto é, a complexidade aumenta) na maior parte dos casos estudados, há pouca evidência de que tais resultados derivam das suposições da autora. Isso é particularmente evidente na análise de complexidade realizada envolvendo a ferramenta JUnit.

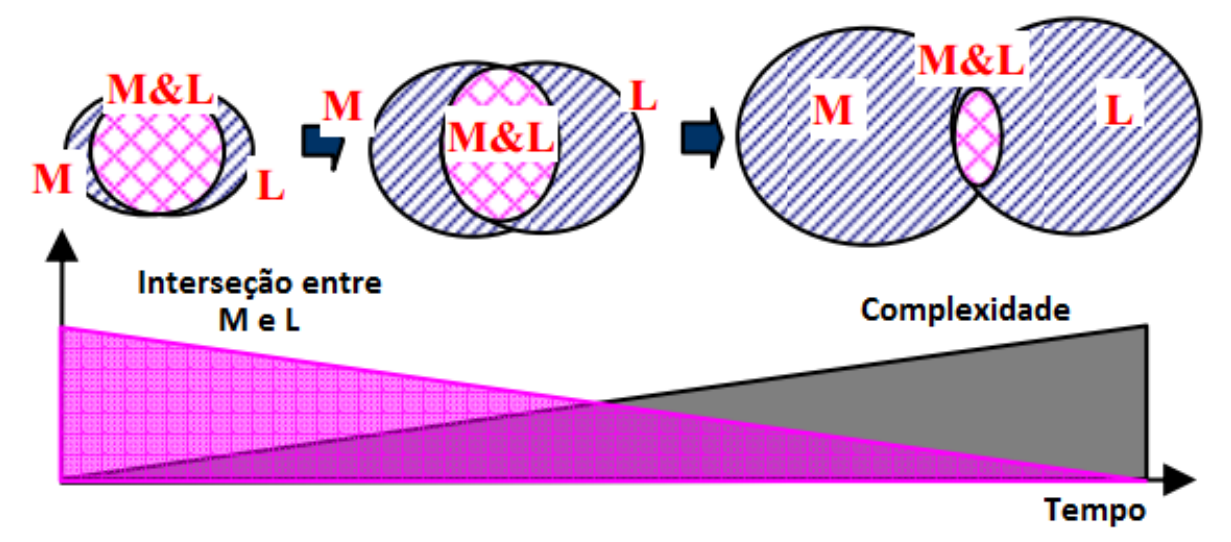

Figura 23: Relação entre intersecção de $M$ e L e complexidade [Han07]

Cataldo et al. [CMRH09] examinaram o impacto relativo que dependências estruturais e lógicas exercem na propensão a falhas em sistemas de software. Durante esse estudo, os autores analisaram dois projetos de diferentes empresas e verificaram que havia baixos níveis de correlação entre as medidas de dependências estruturais e lógicas na última versão de ambos os projetos. 
Embora detalhes de como as dependências foram capturadas não tenham sido fornecidos, o resultado deles é consistente com o nosso.

Cataldo e Nambiar [CN10] investigaram 189 projetos de desenvolvimento de software em escala global (GSD) e mostram que o acoplamento lógico era o fator mais significativo no impacto da qualidade de software dentre todos os fatores considerados, tais como acoplamento estrutural, maturidade de processo, experiência dos desenvolvedores, número de unidades regionais e dispersão de pessoal. Pirklbauer et al. [PFK10] desenvolveram um arcabouço para análise de impacto de mudanças que incorpora tanto dependências estruturais quanto lógicas (Seção 2.2).

\subsection{Conclusões do Estudo}

Conduzimos um estudo empírico de larga escala para investigar a relação entre dependências estruturais e lógicas em projetos FLOSS. Nós analisamos todos os arquivos Java das primeiras 150 mil revisões do repositório SVN da Apache Software Foundation a fim de quantificar (i) a proporção de dependências lógicas estabelecidas que envolvem elementos não-estruturalmente relacionados e (ii) a proporção de dependências estruturais formadas que envolvem elementos nãologicamente relacionados. Com relação a (i), nós concluímos que em pelo menos $91 \%$ dos casos, dependências lógicas envolvem arquivos que não são estruturalmente relacionados, isto é, temos alguma evidência de que dependências lógicas não são diretamente causadas por dependências estruturais. Com relação a (ii), concluímos que dependências estruturais muito frequentemente envolvem arquivos que não são logicamente relacionados, ou seja, temos alguma evidência de que dependências estruturais não levam a dependências lógicas. Portanto, concluímos que há uma interseção muito pequena entre os conjuntos de dependências estruturais e lógicas.

Embora mecanismos e arcabouços de análise sintática tenham provado seus valores para a manutenção e evolução de software ao longo dos anos [Bin07], nossas descobertas sustentam a ideia de que tal tipo de análise é ainda necessária, porém não suficiente. Como resultado, acreditamos que métodos e ferramentas para gerência de dependências devem se apoiar em ambos os tipos de dependências, já que eles representam diferentes dimensões da "evolucionabilidade" do software. Acreditamos que uma visão integrada desses dois tipos de dependências deve aperfeiçoar a efetividade das atividades de mudança e manutenção de software. Finalmente, também acreditamos que ferramentas de visualizações de software que incluam ambos os tipos de dependências devam constituir um campo fértil de pesquisa com fortes implicações em qualidade de software e áreas correlatas.

Como trabalho futuro, planejamos conduzir uma análise mais profunda acerca da relação entre dependências estruturais e lógicas. Em particular, vamos (i) considerar todo o repositório SVN da ASF (aproximadamente 1.1 milhão de revisões), (ii) empregar o algoritmo adaptado da janela móvel de tempo (sliding time window) para agrupar revisões relacionadas (a ser apresentado na Seção 5.1.2) e (iii) desenvolver um módulo mais eficiente de identificação de dependências estruturais, de modo que possamos responder a questão de pesquisa Q2 com base no conjunto de dados coletado (em vez de aplicar valores de referência para métricas). Como um ponto final, acreditamos que investigar a relação entre dependências estruturais e outros tipos de dependências, como por exemplo, ocultas (hidden/data flow) [VR10] e conceituais [PM06], [GSW05], [GDK+07], deva ser outro fértil tópico de pesquisa. 


\section{Capítulo 5 \\ Origens das Dependências Lógicas}

Conforme discutido anteriormente, dependências lógicas são relacionamentos implícitos estabelecidos entre artefatos de software que evoluem juntos. Apesar da reconhecida relação entre dependências lógicas e qualidade de software (Seção 2.2), a natureza desse tipo de dependência ainda é desconhecida na literatura. Diversos autores conjecturaram sobre suas origens, mas nenhum estudo empírico foi conduzido para investigar a real natureza dessas dependências. Algumas das conjecturas incluem: chamadas de função em cascata [CMRH09], dependências semânticas [CMRH09], evolução de plataforma [CMRH09], duplicação de código [Han07] e o uso das técnicas de injeção de dependência e reflexão (reflection) [dRCFdS08]. De acordo com Cataldo et al., um entendimento mais profundo e detalhado acerca das origens dessas dependências constitui uma importante direção de pesquisa com implicações em áreas como a de qualidade de software [CMRH09].

Neste estudo, nós investigamos as origens das dependências lógicas por meio de um estudo de caso [Rob02], [Yin03], [RH09] envolvendo um projeto FLOSS escrito em Java chamado Groupware Workbench $(\mathrm{GW})^{10}$, que oferece um toolkit baseado em componentes para o desenvolvimento de sistemas colaborativos Web 2.0. O GW tem recebido contribuição de doze desenvolvedores de diferentes instituições acadêmicas e está ativo desde 2008, sendo distribuído como software livre pelo Centro de Competência de Software Livre (CCSL) do IME-USP.

Nós mineramos o repositório de código do projeto com o apoio da XFlow, excluímos dados irrelevantes com base em análises estatísticas e realizamos uma inspeção manual das dependências lógicas para identificarmos suas origens utilizando informações dos comentários das revisões, diffs de código e entrevistas informais feitas com desenvolvedores do projeto. Resultados preliminares mostraram que dependências lógicas envolveram arquivos que mudaram juntos por uma série de razões diferentes, como mudanças em licença do software e refatoração de classes que pertenciam a uma mesma categoria semântica.

As principais contribuições da realização desse estudo de caso incluem (i) uma abordagem sistemática para identificação, agrupamento e classificação de dependências lógicas que pode ser reutilizada para pesquisas futuras, (ii) uma classificação das origens de dependências lógicas de um sistema real, (iii) a identificação de oportunidades de pesquisa baseadas em tal classificação e (iv) a implementação de uma versão modificada do algoritmo de janela móvel de tempo (sliding time window) na XFlow.

\footnotetext{
${ }^{10}$ Todas as publicações relativas ao GW podem ser encontradas em http://www.groupwareworkbench.org.br/publicacoes
} 
O restante deste capítulo está organizado como segue. Na Seção 5.1, descreveremos o método de pesquisa empregado, assim como seu planejamento. Na Seção 5.2, apresentaremos os resultados do estudo, incluindo a classificação das origens das dependências lógicas. Na Seção 5.3, discutiremos as ameaças à validade desse estudo. Na Seção 5.4, apresentaremos os trabalhos relacionados. Na Seção 5.5, colocaremos nossas conclusões e ideias de trabalhos futuros.

\subsection{Método de Pesquisa}

Estudo de caso é um método de pesquisa voltado à investigação de fenômenos contemporâneos em seus contextos naturais [Rob02]. O estudo de caso reportado a seguir reflete nosso objetivo de identificar e categorizar as origens das dependências lógicas no projeto GW por meio da mineração de seu repositório de código (SVN). Nossa motivação deriva, primariamente, de estudos prévios que estressaram a relação entre dependências lógicas e qualidade de software (Seção $2.2)$.

Nós conduzimos um estudo de caso explanatório. Nesse tipo de estudo de caso, o pesquisador procura por uma explicação adequada para uma determinada situação ou problema [Yin03]. Em contrate com estudos de caso embutidos, nos quais múltiplas unidades de análise são estudadas dentro de um mesmo caso, o nosso estudo de caso é essencialmente holístico, isto é, ele é estudado "como um todo". De acordo com Seaman [Sea99], uma combinação de dados quantitativos e qualitativos (também conhecido como "métodos mistos de pesquisa") frequentemente proporciona um entendimento mais rico do fenômeno de interesse. Nosso estudo de caso se baseia tanto em dados quantitativos (tipo de arquivos, tamanho das revisões, nível de contribuição dos desenvolvedores e métricas para dependências lógicas) quanto em dados qualitativos (comentários de revisões, diffs de código e entrevistas informais com desenvolvedores). Em particular, os dados quantitativos foram primariamente empregados para filtrar os dados qualitativos a serem analisados subsequentemente.

\subsubsection{A Escolha do Caso}

Para o estudo de caso, nós precisamos de um projeto de software que satisfizesse os seguintes requisitos: (i) software livre hospedado em um repositório SVN com acesso anônimo para leitura, já que nossa ferramenta para mineração dá suporte apenas a esse repositório (Capítulo 7); (ii) disponibilidade dos desenvolvedores do software para colher informações sobre o projeto durante o processo de classificação de dependências lógicas; (iii) histórico de versão pequeno (500 a 1000 revisões), já que este estudo assume uma classificação manual das dependências lógicas; e (iv) código escrito em uma linguagem orientada a objetos (tais como $\mathrm{C}++, \mathrm{C} \#$ ou Java), de modo que possamos investigar se dependências lógicas são formadas por conta do uso das técnicas de reflexão de código e injeção de dependências.

Nós selecionamos o software Groupware Workbench (GW), que é um projeto FLOSS desenvolvido em parceria entre universidades brasileiras: USP, UFES e PUC-Rio. O GW satisfaz todos os requisitos previamente especificados, já que (i) ele está hospedado no Google Code e armazenado em um repositório SVN; (ii) ele está altamente ativo e a maior parte dos desenvolvedores permanecem na universidade trabalhando no projeto e (iv) ele é inteiramente escrito em Java. Com relação ao item (iii), nós decidimos analisar somente a pasta trunk do projeto 
no SVN, já que 727 revisões (47\% do total) envolveram arquivos de tal pasta. Esse montante de revisões engloba um período de desenvolvimento de dois anos e três meses.

O projeto GW é apoiado pelo Centro de Competência em Software Livre (CCSL) do IMEUSP e o gerente do projeto é o orientador deste trabalho. $\mathrm{O}$ GW é escrito em Java (aproximadamente 40 mil linhas de código) e ele tem por objetivo oferecer um toolkit para desenvolvimento de sistemas colaborativos para Web 2.0. O GW consiste de duas partes: o núcleo (kernel) e os kits de componentes. O núcleo dá suporte para a instalação, atualização, agrupamento, personalização (customization), reúso e gerenciamento do ciclo de vida dos componentes. Os kits de componentes, por sua vez, dão suporte para o desenvolvimento de ferramentas colaborativas. Os componentes são manipulados por operações do sistema de arquivos e personalizados por arquivos descritores. Uma versão móvel do GW está sendo desenvolvido para dispositivos com sistema operacional Android. Atualmente, o GW está sendo utilizado no desenvolvimento de três projetos de software: uma rede social focada no compartilhamento de imagens de arquitetura brasileira, uma plataforma colaborativa para publicação de notícias e um $F A Q$ online sobre software livre.

\subsubsection{Instrumentos e Métodos para Coleta de Dados}

Estudos empíricos que mineram repositórios de software usualmente requerem pesado apoio de ferramentas por conta da abundante quantidade de dados que precisam ser coletados, processados e analisados [DLL09]. Neste estudo, nós empregamos a XFlow, uma ferramenta extensível e interativa que provê mecanismos para realização de análises abrangente da evolução de projetos de software por meio de mineração de repositórios. Conforme ilustrado na Figura 15, a XFlow coleta e analisa sintaticamente os logs das mensagens das revisões de sistemas de controle de versão (fase de coleta de dados), identifica dependências a partir dos dados extraídos (fase de processamento), calcula métrica sobre os dados coletados (fase de métricas) e, finalmente, apresenta visualizações interativas que apoiam na compreensão da evolução do projeto de software (fase de visualização). Atualmente, a ferramenta dá suporte apenas para repositórios SVN.

Neste estudo, nós inicialmente utilizamos a XFlow para obter informações básicas sobre o GW, tais como o tamanho das revisões, nível de contribuição dos desenvolvedores e a distribuição dos tipos de arquivos do projeto. Após isso, nós utilizamos a ferramenta para identificar dependências lógicas a partir de código-fonte no repositório SVN.

Baseado em entrevistas iniciais com desenvolvedores do GW, nós identificamos a necessidade de implementar uma versão modificada do algoritmo de janela móvel de tempo (Seção 3.3), já que alguns desenvolvedores relataram terem feito commits de artefatos relativos a uma mesma tarefa em diferentes (embora próximos) instantes de tempo. A janela móvel de tempo é uma técnica proposta por Zimmerman et al. [ZW04] para reconstrução de transações de mudança em sistemas de controle de versão que não davam suporte a commits atômicos (mais notavelmente, CVS). Esse algoritmo, que é uma melhoria sobre o algoritmo de janela de tempo fixa (fixed time window), restringe o hiato máximo entre dois commits subsequentes, de modo que a janela de tempo estabelecida é sempre deslocada para o próximo commit (desde que do mesmo autor e com mesmo comentário). Nós adaptamos o algoritmo de janela móvel de tempo para agrupar revisões do SVN e o implementamos na XFlow. Esse procedimento refinou o processo de identificação de dependências lógicas, de modo que novas dependências entre arquivos foram capturadas. Segundo 
nossas pesquisas, essa foi a primeira vez que o algoritmo foi adaptado e aplicado para um sistema de controle de versão com suporte a commits atômicos, como o SVN.

Em entrevistas com os desenvolvedores do GW, eles recomendaram uma janela de tempo de 2 a 3 minutos. Valores oriundos da literatura [ZWDZ05], [DLL09] convergem para uma janela de 200 segundos. Portanto, baseados tanto na informação provida pelos desenvolvedores do GW quanto em trabalhos prévios da literatura, nós decidimos aplicar uma janela de tempo de 200 segundos.

A fim de lidar com possíveis instabilidades do repositório SVN remoto, nós construímos um espelho (mirror) local de tal repositório. Depois de concluirmos o espelhamento, executamos as fases de coleta e processamento da XFlow (Figura 15), que resultou na identificação das dependências lógicas. Por fim, utilizamos a ferramenta novamente para aplicar o algoritmo de janela móvel e assim obter o novo conjunto de dependências lógicas derivado das revisões agrupadas. Os resultados da coleta de dados são dados na Seção 5.2.1.

\subsubsection{Filtragem de Dados}

Limiares de suporte e confiança são comumente usados para filtrar dependências lógicas e, seus respectivos valores, são determinados de acordo com as características do projeto de software em questão [ZW04, ZWDZ05]. Nesse trabalho, aplicamos uma simples análise estatística para escolher valores apropriados. Primeiramente, analisamos a medida de confiança, que revela a "força" das regras de associação (dependências lógicas). O objetivo foi excluir dependências cujo valor de confiança era muito baixo em um grafo de linha cumulativo. Subsequentemente, analisamos a medida de suporte para as dependências lógicas restantes.

Dado que o objetivo era realizar uma análise manual das dependências, nós limitamos o número dessas dependências com base em suas relevâncias. Em particular, realizamos uma análise de quartis da distribuição do número de dependências por valor de suporte e selecionamos apenas dependências cujo valor de suporte era alto (outliers). Os resultados da filtragem de dados, assim como os limiares escolhidos, serão mostrados na Seção 5.2.2.

\subsubsection{Instrumentos e Métodos para Análise de Dados}

Nós criamos uma planilha contendo os arquivos antecedente (LHS) e consequente (RHS) de todas as dependências lógicas. Depois disso, para cada dependência, nós identificamos todas as revisões associadas, bem como os respectivos comentários dessas revisões. Todas essas informações foram obtidas por meio de consultas à base de dados do projeto que foi gerada pela XFlow.

Triangulação de dados, que envolve tomar diferentes ângulos de observação em direção ao objeto de estudo, é uma importante técnica utilizada para aumentar a precisão da pesquisa empírica [RH09]. As conclusões relativas às origens das dependências lógicas foram alcançadas com base em tal técnica, já que nós contamos com (i) comentários das revisões, (ii) os sete anos de experiência em desenvolvimento de software do autor desta dissertação e (iii) os comentários dos desenvolvedores ativos do GW. Em particular, para cada classificação não-trivial, nós envolvemos os desenvolvedores do GW e solicitamos ajuda deles. Os resultados da análise de dados são dados na Seção 5.2.3. 


\subsection{Resultados}

Nas próximas subseções, nós apresentamos os resultados da coleta de dados, da filtragem desses dados e da classificação das origens das dependências lógicas.

\subsubsection{Resultados da Coleta de Dados}

Nas próximas subseções, nós apresentamos informações relativas ao tamanho das revisões, níveis de contribuição de desenvolvedores e a distribuição dos tipos de arquivos no GW.

\subsubsection{Tamanho das Revisões}

O tamanho das revisões proveem indícios sobre hábitos de commit no projeto. Nós analisamos o tamanho das revisões do projeto por meio do cálculo de estatísticas descritivas básicas para a variável "número de arquivos por revisão" (veja Tabela 6 e Tabela 7). Um sumário gráfico ilustrando a distribuição da variável (A) e o boxplot associado (B) pode ser visto na Figura 24.

\begin{tabular}{cccccc}
\hline $\mathbf{N}$ & Soma & Média & Desvio Padrão & Assimetria & Curtose \\
\hline 692,0 & $9.536,0$ & 13,78 & 43,16 & 8,16 & 83,75 \\
\hline
\end{tabular}

Tabela 6: Número de Arquivos por Revisão no Projeto $G W-$ Estatísticas descritivas

\begin{tabular}{ccccccc}
\hline Min & Q1 & Mediana & Q3 & Max & IQR & Whisker Superior \\
\hline 1,0 & 1,0 & 3,0 & 10,0 & 612,0 & 9,0 & 23,0 \\
\hline
\end{tabular}

Tabela 7: Número de Arquivos por Revisão no Projeto $G W-$ Análise de Quartis

Número de revisões e número de arquivos. Executar a primeira fase da análise de dados resultou em 692 revisões agrupadas (a partir das 727 revisões iniciais). A soma do número de arquivos por revisão foi de 9.536 arquivos.

Média e desvio padrão. A Tabela 6 indica que revisões contêm aproximadamente 14 arquivos em média. O valor do desvio padrão mostra que a dispersão dos dados é alta, isto é, há revisões que envolveram poucos arquivos e há também revisões que envolveram um número razoavelmente grande de arquivos. As próximas medidas de estatísticas descritivas foram empregadas para auxiliar numa melhor compreensão dessa dispersão.

Assimetria (Obliquidade) e Curtose. O valor positivo de assimetria $(8,16)$ indica que o conjunto de dados é assimétrico-positivo, isto é, a distribuição tem uma cauda direita. O alto valor de curtose $(83,75)$ indica que o conjunto de dados tem um pico perto da média, declina razoavelmente rápido e possui caudas "pesadas".

Teste para normalidade. Análise de assimetria, curtose e do histograma de frequência mostrou que os dados não seguem uma distribuição normal. De fato, nós conduzimos o teste de normalidade Kolmogorov-Smirnov e obtivemos um p-value $<0,010$.

Análise de quartis. O boxplot provê outra vista sobre a distribuição do conjunto de dados, mostrando sua forma, tendência central e variabilidade. Uma vez que o valor interquartil é 9 , os whiskers inferior e superior revelam que as revisões usualmente englobam de 1 a 23 arquivos. A 
maior revisão do GW incluiu 612 arquivos, que corresponde a uma movimentação da versão 0.1 do GW dentro do SVN (de uma branch para a pasta trunk).

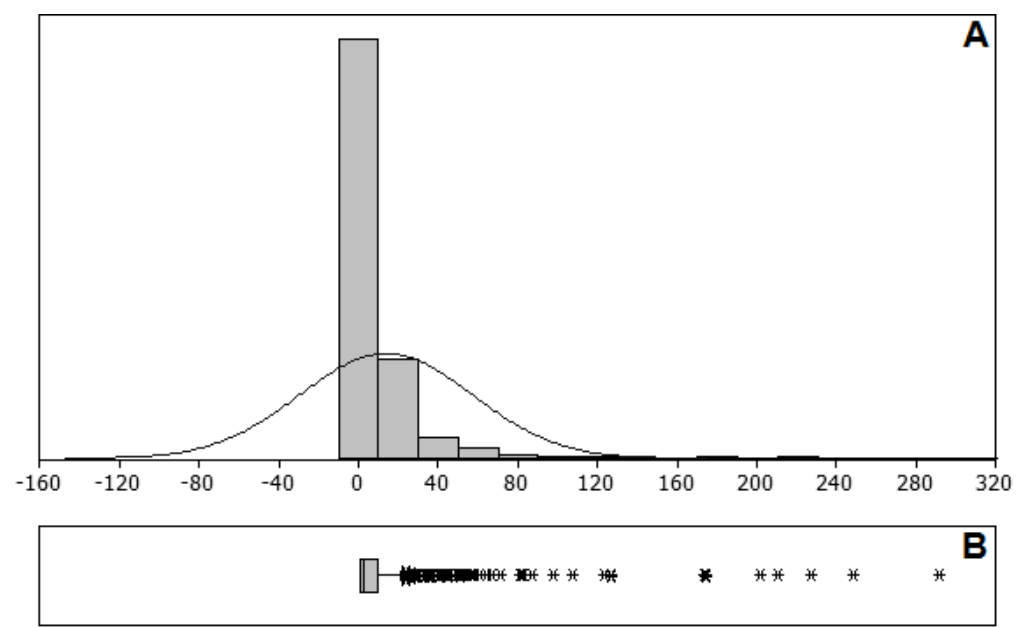

Figura 24: Resumo gráfico da distribuição da variável "número de arquivos por revisão"

\subsubsection{Contribuição dos Desenvolvedores}

Nós computamos o número de arquivos trabalhados por desenvolvedor (Figura 25) e o número de commits por desenvolvedor (Figura 26) a fim de identificar desenvolvedores principais a quem iríamos entrevistar durante o estudo.

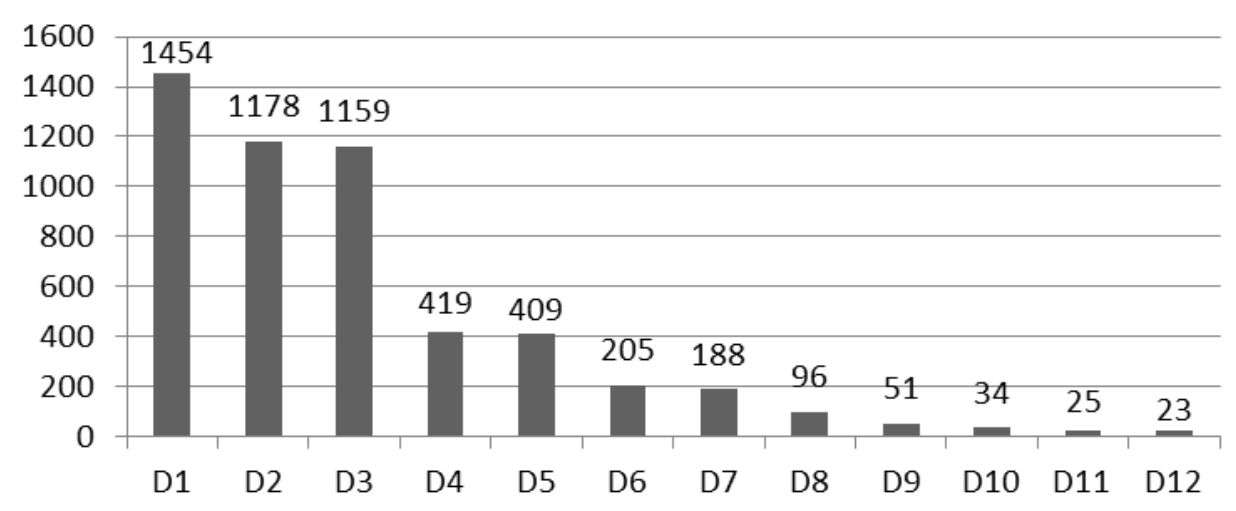

Figura 25: Número de arquivos modificados por desenvolvedor

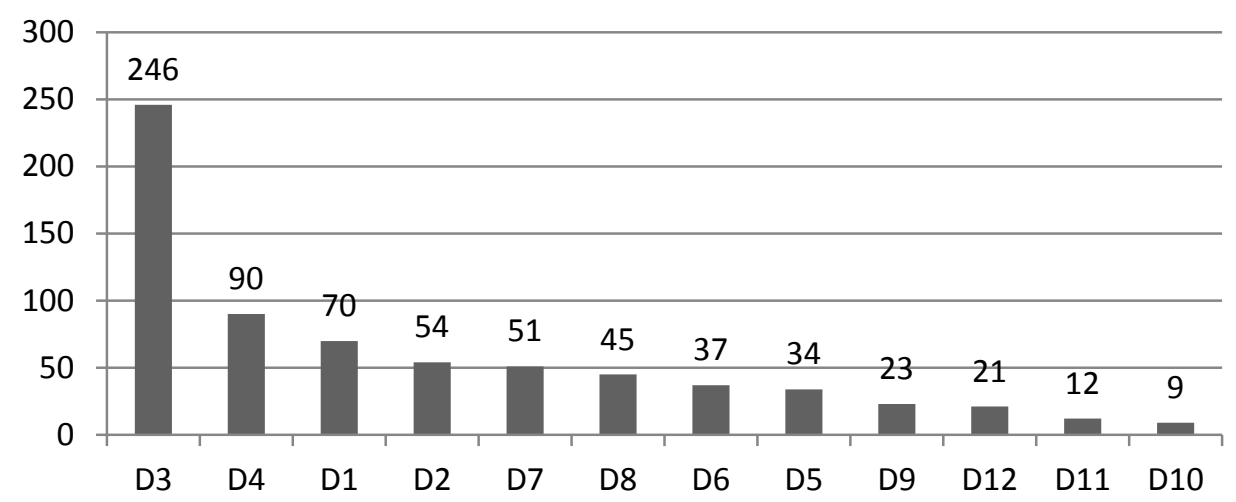

Figura 26: Número de commits (agrupados) por desenvolvedor 
Os desenvolvedores D1 e D2 já deixaram o projeto e não estavam mais disponíveis, assim, eles foram excluídos de nossa análise. Desenvolvedores D3 e D4 foram nossos principais contatos, já que eles trabalharam em um grande número de arquivos (1159 e 419, respectivamente) e realizaram o maior número de commits (246 e 90, respectivamente) ao longo do desenvolvimento do GW. Em particular, D3 é responsável por aproximadamente um terço do total do número de commits.

\subsubsection{Tipos de Arquivos}

A fim de reconhecer os artefatos que compuseram o GW ao longo de seu desenvolvimento, nós computamos a distribuição de tipos de arquivos (número de arquivos com uma particular extensão) com o auxílio da XFlow (Figura 27).

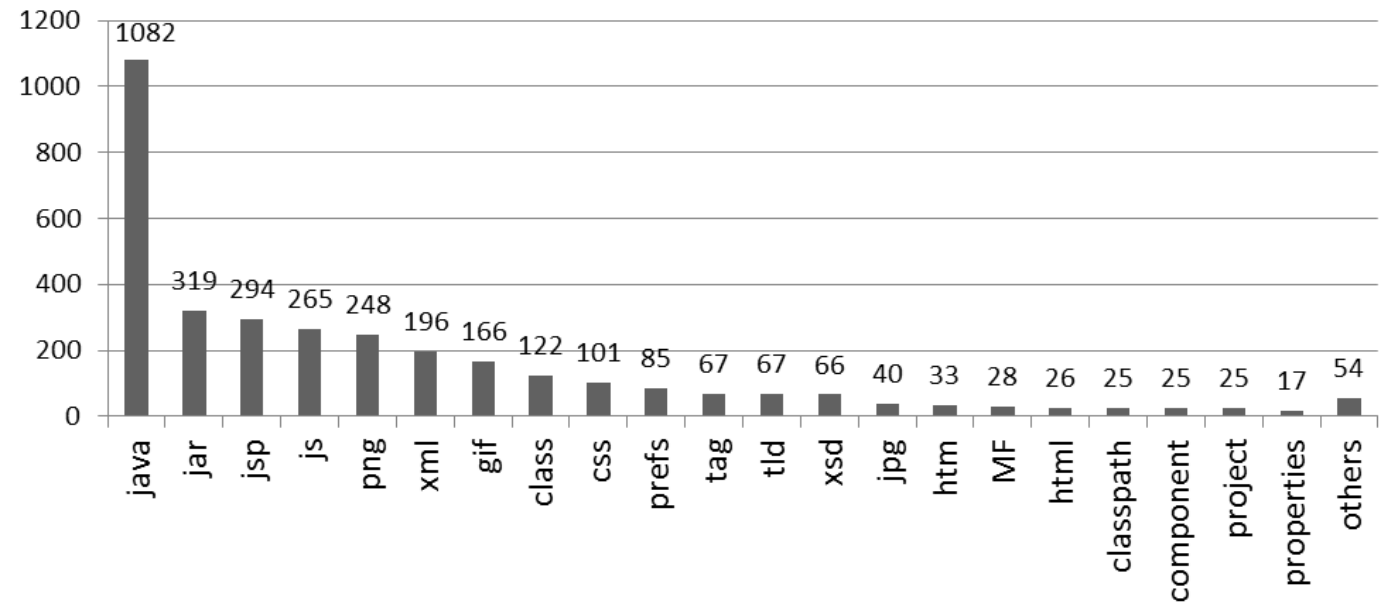

Figura 27: Distribuição dos tipos de arquivo no $G W$

Aproximadamente um terço de todos os arquivos são classes Java. Outros tipos de arquivos relevantes incluem jar, jsp, js, png, xml, class, css, prefs, tag, tld e xsd.

\subsubsection{Resultados da Filtragem de Dados}

Nós utilizamos a ferramenta XFlow e ela identificou 1.237.128 dependências lógicas (com base nas revisões agrupadas) no GW. Conforme especificado na Seção 5.1.1, nós analisamos somente a pasta trunk do projeto, que sozinha foi responsável 727 revisões. Nesta seção, nós reportamos os resultados da aplicação das técnicas de filtragem de dados descritas na Seção 5.1.3.

Estabelecendo um limiar para a medida de confiança. Nós configuramos o limiar para a medida de confiança por meio da avaliação do grafo de linha cumulativo apresentado na Figura 28. O eixo horizontal denota os valores de confiança, enquanto o eixo vertical denota a porcentagem cumulativa de dependências lógicas cobertas. Concluímos que os valores de confiança maiores ou iguais a 50\% cobriram aproximadamente $78 \%$ das dependências. Portanto, nós selecionamos dependências lógicas cujo valor de confiança era de pelo menos $50 \%$. 


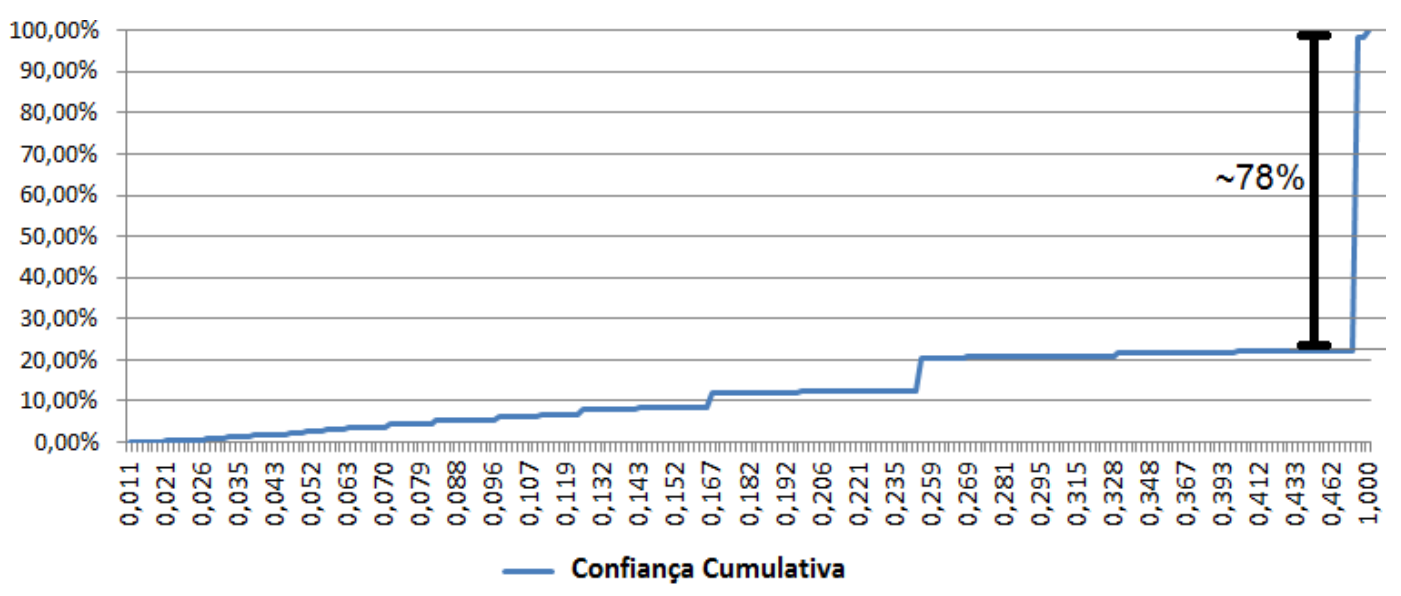

Figura 28: Confiança cumulativa

Estabelecendo um limiar para a medida de suporte. Depois de aplicar o filtro de confiança, nós analisamos o conjunto restante de dependências para definir o limiar de suporte. Prontamente, excluímos dependências lógicas com valor de suporte igual a 1, já que elas claramente são irrelevantes. Nós então calculamos o número de dependências lógicas por valor de suporte (Tabela 8)

\begin{tabular}{cc}
\hline Suporte & Número de Dependências Lógicas \\
\hline 22 & 1 \\
16 & 2 \\
15 & 1 \\
14 & 3 \\
11 & 3 \\
9 & 17 \\
8 & 35 \\
7 & 82 \\
6 & 42 \\
5 & 100 \\
4 & 778 \\
3 & 2801 \\
2 & 9778 \\
\hline
\end{tabular}

Tabela 8: Número de dependências lógicas por valor de suporte

Logo em seguida, nós realizamos uma análise de quartis (Tabela 9 e Figura 29) a fim de selecionarmos apenas valores outliers. Isso garantiu que a inspeção manual subsequente fosse focada apenas em dependências lógicas relevantes. Portanto, depois de conduzir tal análise, nós selecionamos apenas dependências cujo valor de suporte foi maior que 4.

\begin{tabular}{ccccccc}
\hline Min & Q1 & Mediana & Q3 & Max & IQR & Whisker Superior \\
\hline 1,0 & 2,0 & 2,0 & 3,0 & 22,0 & 1,0 & 4,0 \\
\hline \multicolumn{7}{c}{ Tabela 9: } \\
Suporte das dependências lógicas - Análise de Quartis
\end{tabular}




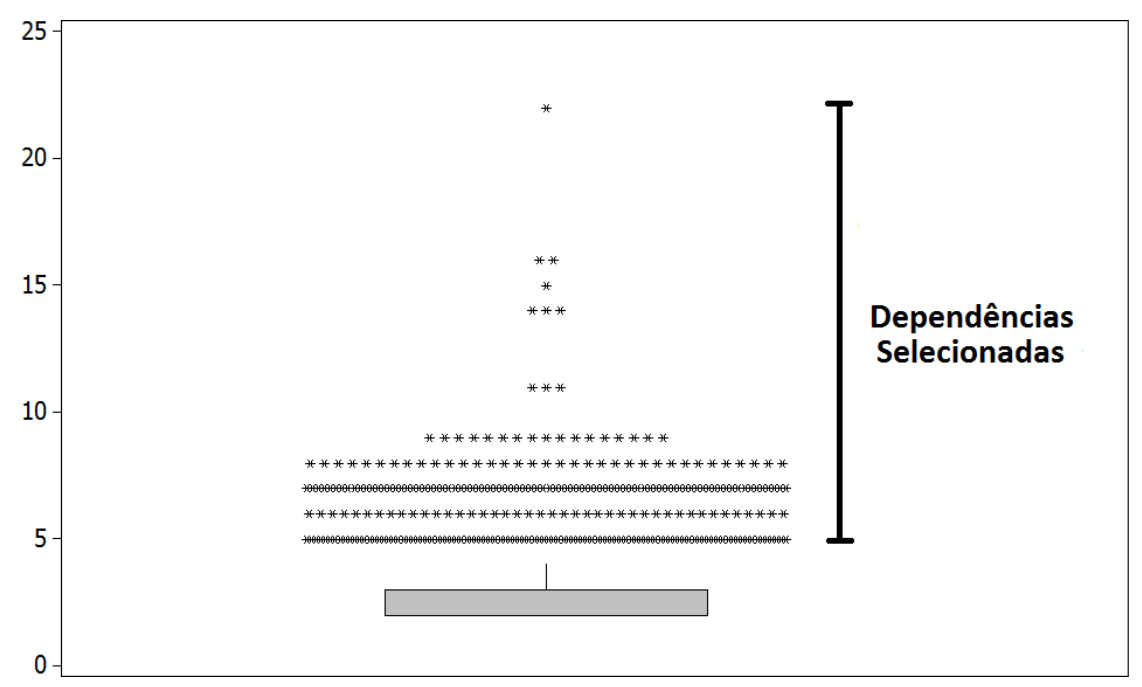

Figura 29: Boxplot para valores de suporte

Como resultado final, nós obtivemos um conjunto de 286 dependências lógicas relevantes.

\subsubsection{Origens das Dependências Lógicas}

Nós iniciamos nossa análise investigando a distribuição de dependências lógicas de acordo com os tipos de arquivo de LHS e RHS (Tabela 10). Valores em parênteses na última coluna se referem a um valor normalizado de total baseado na distribuição dos tipos de arquivos (Figura 27).

\begin{tabular}{|c|c|c|c|c|c|c|c|c|c|c|c|c|c|c|}
\hline \#Linha & LHS & RHS & Sup.22 & Sup.16 & Sup.15 & Sup.14 & Sup.11 & Sup.9 & Sup.8 & Sup.7 & Sup.6 & Sup.5 & Total & Total $\%$ \\
\hline 1 & Java & Java & 0 & 1 & 0 & 1 & 1 & 10 & 7 & 72 & 33 & 89 & 214 & $74,8 \%(1.83)$ \\
\hline 2 & Java & JSP & 0 & 0 & 0 & 0 & 0 & 0 & 0 & 0 & 0 & 1 & 1 & $0,3 \%(0.03)$ \\
\hline 3 & XML & XML & 0 & 0 & 0 & 0 & 2 & 6 & 3 & 0 & 0 & 2 & 13 & $4,5 \%(3.40)$ \\
\hline 4 & XSD & XSD & 0 & 0 & 0 & 0 & 0 & 0 & 6 & 3 & 0 & 0 & 9 & $3,1 \%(2.10)$ \\
\hline 5 & XSD & XML & 0 & 0 & 0 & 0 & 0 & 0 & 9 & 5 & 0 & 0 & 14 & $4,9 \%(10.82)$ \\
\hline 6 & XML & XSD & 0 & 0 & 0 & 0 & 0 & 0 & 0 & 1 & 0 & 0 & 1 & $0,3 \%(0.77)$ \\
\hline 7 & XML & Props & 0 & 0 & 1 & 0 & 0 & 0 & 0 & 0 & 0 & 1 & 2 & $0,7 \%(6.00)$ \\
\hline 8 & JSP & JSP & 0 & 1 & 0 & 2 & 0 & 0 & 2 & 0 & 2 & 3 & 10 & $3,5 \%(0.12)$ \\
\hline 9 & JS & Java & 0 & 0 & 0 & 0 & 0 & 0 & 0 & 0 & 1 & 0 & 1 & $0,3 \%(0.03)$ \\
\hline 10 & JS & JSP & 0 & 0 & 0 & 0 & 0 & 0 & 0 & 0 & 2 & 0 & 2 & $0,7 \%(0.26)$ \\
\hline 11 & Tag & Tag & 0 & 0 & 0 & 0 & 0 & 0 & 0 & 1 & 1 & 4 & 6 & $2,1 \%(1.36)$ \\
\hline 12 & Prefs & Prefs & 0 & 0 & 0 & 0 & 0 & 1 & 8 & 0 & 0 & 0 & 9 & $3,1 \%(1.26)$ \\
\hline 13 & Props & Props & 1 & 0 & 0 & 0 & 0 & 0 & 0 & 0 & 3 & 0 & 4 & $1.4 \%(14.71)$ \\
\hline \multicolumn{3}{|c|}{ Total } & 1 & 2 & 1 & 3 & 3 & 17 & 35 & 82 & 42 & 100 & 286 & \\
\hline \multicolumn{3}{|c|}{ Total (\%) } & $0,3 \%$ & $0,7 \%$ & $0,3 \%$ & $1,0 \%$ & $1,0 \%$ & $5,9 \%$ & $12,2 \%$ & $28,7 \%$ & $14,7 \%$ & $35,0 \%$ & & $100 \%$ \\
\hline
\end{tabular}

Tabela 10: Dependências lógicas por tipo de arquivo

As linhas horizontais da tabela apresentam o total de dependências lógicas de acordo com os tipos de arquivos de LHS e RHS. Nós notamos que aproximadamente três quartos das dependências lógicas foram estabelecidos entre arquivos Java (linha 1). Contudo, em termos de totais normalizados, dependências lógicas envolvendo arquivos de propriedades (linha 13) foram as mais frequentes. Também, dependências lógicas cujos LHS e RHS são dos tipos XSD e XML respectivamente (linha 5), também apresentaram um alto total normalizado. Esta última situação 
parece plausível, já que arquivos XSD expressam um conjunto de regras que documentos XML devem atender, isto é, arquivos XML dependem de arquivos XSD. Além disso, notamos que as dependências lógicas estabelecidas envolveram apenas um pequeno subconjunto de todos os tipos de arquivos presentes no GW.

As colunas da Tabela 10 apresentam o número de dependências lógicas por valor de suporte. Os cinco maiores valores de suporte possuem um número similares de dependências lógicas associadas. Em particular, o intervalo formado por esses cinco valores de suporte compreende apenas $3,3 \%$ do total de dependências. Portanto, concluímos que há um pequeno número de arquivos altamente logicamente acoplados no sistema. Os outros valores de suporte possuem um número muito maior de dependências. Em especial, o menor valor de suporte engloba aproximadamente um terço do número de dependências.

Na próxima subseção, discutimos os resultados preliminares da inspeção manual das origens das dependências lógicas.

\subsubsection{Inspeção Manual}

Nós manualmente investigamos as origens de 75 dependências lógicas, o que corresponde a aproximadamente um quarto do total de dependências lógicas relevantes (Seção 5.2.2). Estas dependências lógicas englobam todas as classes Java do GW oriundas dos pacotes de reflexão (.../commonswidgets/reflection), upload (.../communic/upload) e de banco de dados (.../bd/jpa/entities). Dependências entre algumas classes de teste Java também fizeram parte do conjunto de dependências analisado. A investigação manual incluiu avaliar code diffs e comentários de revisões, bem como realizar entrevistas informais com desenvolvedores.

A partir dos resultados de nossa inspeção, nós concluímos que as dependências lógicas estabelecidas envolveram arquivos que mudaram juntos por diferentes razões. Um exemplo real envolvendo uma dependência lógica com valor de suporte igual a 9 é mostrado na Tabela 11.

\begin{tabular}{ccc}
\hline \multicolumn{2}{c}{ LHS } & \multicolumn{2}{c}{ RHS } \\
\hline ... UploadMgrInstance.java & . . CommentMgrInstance.java \\
\hline \#Mudança conjunta & Revisão & Origem da mudança conjunta \\
\hline 1 & 1172 & Pacotes Java renomeados \\
2 & 1186 & Aplicação de licença em arquivos Java \\
3 & 1203 & Dependência estrutural para um terceiro elemento \\
4 & 1220 & Refatorando elementos que pertencem à mesma classe semântica \\
5 & 1224 & Refatorando elementos que pertencem à mesma classe semântica \\
6 & 1245 & Refatorando elementos que pertencem à mesma classe semântica \\
7 & 1307 & Criação do pacote "annotations" \\
8 & 1507 & Mudanças no cabeçalho de arquivos Java \\
9 & 1508 & Mudanças no cabeçalho de arquivos Java \\
\hline
\end{tabular}

Tabela 11: Exemplo real de dependência lógica no GW retratando diferentes razões para mudanças conjuntas

As 75 dependências lógicas envolveram 408 mudanças conjuntas de pares de artefatos. Com base em uma análise individual dessas mudanças conjuntas, nós concebemos a categorização listada na Tabela 12.

Categoria

Mudanças Conjuntas $\quad$ Total $\%$




\begin{tabular}{ccc}
\hline $\begin{array}{c}\text { Refatorar elementos que pertencem a uma } \\
\text { mesma classe semântica }\end{array}$ & 80 & $19.6 \%$ \\
$\begin{array}{c}\text { Dependências estruturais que incorrem } \\
\text { sobre uma classe semântica }\end{array}$ & 9 & $2.2 \%$ \\
Interesses transversais & 165 & $40.4 \%$ \\
Revisão sobrecarregada & 60 & $14.7 \%$ \\
Operação de repositório & 21 & $5.1 \%$ \\
Dependências estruturais que incorrem & 66 & $16.2 \%$ \\
sobre elementos específicos & 7 & $1.7 \%$ \\
Outras razões & $\mathbf{4 0 8}$ & $\mathbf{1 0 0 \%}$ \\
\hline Total &
\end{tabular}

Tabela 12: Origens das mudanças conjuntas

A seguir, nós descrevemos cada categoria, fornecendo exemplos ilustrativos e apontando oportunidades de pesquisa.

Refatorar elementos que pertencem a uma mesma classe semântica. Notamos que artefatos mudaram juntos por conta de ações de refatoração feitas sobre uma classe semântica. Denotamos por classe semântica o grupo de artefatos de software que intrinsecamente compartilha uma mesma funcionalidade básica ou papel arquitetural (por exemplo, entidades, controladores, classes de teste e elementos da camada de persistência). No GW, algumas ações que resultaram nesse tipo de mudança conjunta foram, por exemplo, mudar o runner padrão de classes Java de testes e incluir um método específico em todos os elementos controladores. Portanto, acreditamos que projetar arquiteturas de software nas quais classes semânticas são facilmente identificáveis deve aprimorar a "evolucionabilidade" do sistema. Além disso, identificar tais classes semânticas incentiva e dá suporte para a manutenção planejada, já que o conjunto de artefatos naturalmente impactados por uma mudança seria conhecido antes da aplicação efetiva de tal mudança.

Dependências estruturais que incorrem sobre uma classe semântica. Esta categoria é um caso especial da anterior. Nesse caso, relações lógicas são caracterizadas como um efeito-colateral de ações de refatoração realizadas sobre uma classe semântica. Um exemplo ilustrativo é dado na Figura 30, que retrata quatro classes que mudaram juntas em uma revisão específica.

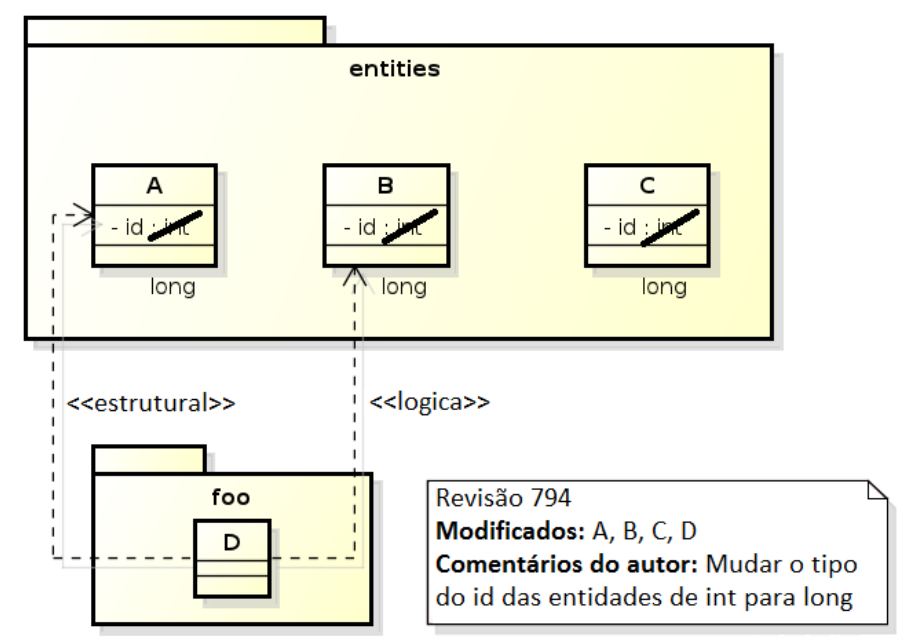

Figura 30: Exemplo de dependência estrutural cujo fornecedor pertence a uma classe semântica (entidade) que sofreu alteração (mudança do tipo de um atributo)

Classes A, B e C pertencem a uma mesma classe semântica (entidade) que passou por uma mudança (mudar o atributo o tipo do atributo id de int para long). Embora a classe D estruturalmente dependa somente da classe A, a dependência lógica envolvendo os arquivos D e B 
(ou D e C) ganha mais uma mudança conjunta, já que esses dois arquivos também mudaram juntos. Assim, dependências estruturais que incorrem sobre um elemento que pertence a uma determinada classe semântica potencialmente originam diferentes dependências lógicas.

Interesses transversais. Interesses transversais (cross-cutting concerns) se referem a interesses periféricos (por exemplo, logging, gerência de transações, controle de concorrência) que estão espalhados entre uma quantidade significativa de módulos de um sistema de software (Figura $31)$.

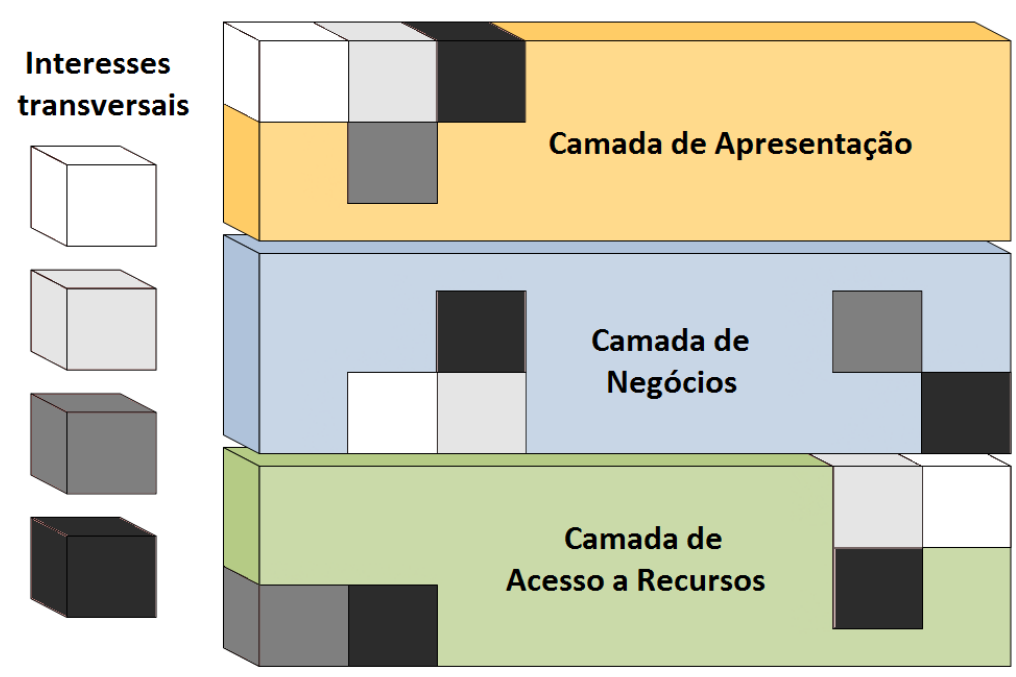

Figura 31: Interesses transversais em um sistema de software

Exemplos encontrados no GW incluem aplicar uma licença de software em todos os arquivos Java, mudar o cabeçalho de arquivos Java e implementar a interface Java Serializable (para salvar/restaurar o estado corrente de um objeto para/de um stream). Isso provê alguma evidência de que interesses transversais tendem a formar dependências lógicas entre um alto número de elementos que se apoiam em tal interesse. Assim, acreditamos que examinar dependências lógicas pode ser uma maneira efetiva de identificar interesses transversais que podem ser posteriormente encapsulados em aspectos [KH01], a fim de melhorar a modularidade do sistema [Par72]. De fato, essa categoria corrobora os resultados encontrados em [BZL06], [AJH10].

Revisões sobrecarregadas. Surpreendentemente, notamos que pares de arquivos mudaram juntos simplesmente por acaso ou por conveniência. Nós identificamos as seguintes particulares situações:

(i) Revisões multi-ação. Isso ocorre quando um autor modifica diferentes arquivos por diferentes razões e realiza um único commit englobando todos os arquivos, conforme ilustrado na Figura 32. Ocasionalmente, um autor também realiza ações que não estão explicitamente documentadas nos comentários Portanto, durante nossa análise, comentários de revisões serviram somente como diretrizes gerais para a identificação das razões das mudanças conjuntas.

Esse tipo de revisão leva ao estabelecimento de dependências lógicas inesperadas entre arquivos. Um exemplo real é dado pela revisão 1276, a qual incorporou seis ações completamente diferentes: aprimorar três classes Java não relacionadas, consertar um bug, excluir uma página jsp, implementar suporte à transações, criar uma classe de teste e alterar a ordem de tarefas em scripts ant. 


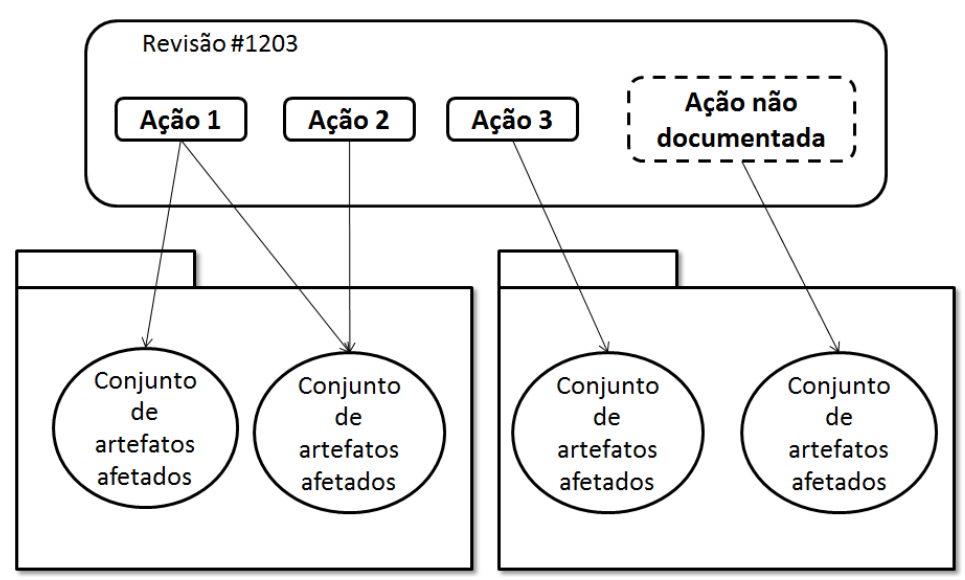

Figura 32: Revisão multi-ação

(ii) Conveniência. Em algumas circunstâncias, uma classe Java mudou simplesmente por questões de conveniência. Por exemplo, enquanto um desenvolvedor estava procurando por classes de entidade para mudar o tipo do atributo id de int para long, ele se deparou com uma classe cujo código estava mal formatado (leiaute ruim). Portanto, ele decidiu consertar a formatação de tal classe. Outro exemplo incluiu um desenvolvedor consertando a codificação do texto (text encoding) e, ao mesmo tempo, implementando a interface Serializable em todas as classes apropriadas.

Assim, mudanças conjuntas que resultaram de revisões sobrecarregadas (incluindo aquelas com ações não documentadas) levaram ao estabelecimento de dependências lógicas "falsas" entre os arquivos. Estas dependências falsas prejudicam a efetividade de técnicas de manutenção e evolução de software baseadas nesse tipo de dependência, tais como predição de mudanças [ZWDZ05] e definição de requisitos de coordenação entre desenvolvedores [CWHC06].

Por meio da inspeção de dependências lógicas, nós concluímos que o alto número médio de arquivos por revisão $(13,78)$ deriva parcialmente dessas revisões sobrecarregadas. Mecanismos poderiam ser desenvolvidos para medir o grau de sobrecarga de revisões. Uma abordagem ingênua poderia consistir em contar o número de pontos finais ('.') em comentários a fim de descobrir o número de ações diferentes tomadas pelo autor.

Operações de repositório. Operações de repositório usualmente envolvem mover um alto número de arquivos na hierarquia de diretórios. Na revisão 722, 327 arquivos foram movidos de uma branch para a pasta trunk do projeto no SVN. Embora somente uma operação de repositório tenha sido identificada no GW, ela gerou um alto número de mudanças conjuntas e contribui para o estabelecimento de dependências lógicas (já que muitos pares de arquivos acabaram mudando juntos pelo menos uma vez).

Dependências estruturais que incorrem sobre elementos específicos. Artefatos de software mudaram juntos por conta de dependências estruturais de clientes para fornecedores específicos. Embora esse fenômeno fosse de alguma forma esperado, subclasses irmãs e não estruturalmente relacionadas mudaram também mudaram juntas devido a uma substituição da superclasse correspondente. Mudanças arquiteturais, como reorganizar classes em novos pacotes e renomear pacotes existentes, também contribuíram para o estabelecimento de dependências lógicas entre os elementos afetados.

A literatura clássica de Engenharia de Software há tempos declara que acoplamento estrutural deve ser minimizado, porque toda vez que uma classe fornecedora muda, seus clientes se tornam propensos a mudar também [Par72], [BME+07], [Lar04]. Interessantemente, apenas uma 
pequena quantidade de mudanças conjuntas (16,2\%) estava diretamente associada com dependências estruturais. Isso corrobora os resultados encontrados no capítulo anterior desta dissertação.

Outras razões. Notamos que classes mudaram juntas por conta de implementações de funcionalidades internas. Vale ressaltar que essa categoria é diferente da categoria "revisões sobrecarregadas", em que arquivos mudaram juntos por propósitos distintos e que não estão ligados a implementação de uma funcionalidade específica bem definida. Também notamos que algumas classes mudaram juntas porque ambas passaram por formatação de código.

\subsection{Ameaças à validade}

Há alguns fatores podem ter influenciado a validade deste estudo. A seguir, discutimos cada um desses fatores.

Validade interna. O subconjunto de dependências lógicas analisadas envolveu arquivos que mudaram juntos por várias razões. Em particular, esse subconjunto englobou dependências lógicas cujo valor de suporte era de no máximo 9. É possível então que dependências lógicas com valores mais altos de suporte (isto é, 22, 16, 15, 14 e 11) possuam uma única origem bem definida.

Nós contatamos e entrevistamos o desenvolvedor D3 a fim de obter suas impressões sobre os dados da Tabela 10. O desenvolvedor D3 afirmou que esperava uma quantidade maior de dependências lógicas envolvendo arquivos Java e JSP. Nós tentamos identificar essas dependências por meio de mineração do repositório da XFlow com diferentes limiares de suporte e confiança, porém não obtivemos sucesso. Nós planejamos entrevistas outros desenvolvedores para colher suas impressões sobre esse mesmo fenômeno (já que o desenvolvedor D3 pode simplesmente estar errado). Caso o problema seja confirmado, nós vamos investigar técnicas alternativas para agrupar commits, tais como aquelas avaliadas por Pirklbauer [Pir10].

Validade externa. Hábitos de commit dos desenvolvedores do GW pode ter influenciado a generalização dos resultados deste estudo. A fim de termos um baseline para compararmos resultados, nós comparamos os valores das estatísticas descritivas mostradas na Seção 4.1 com os valores do repositório da ASF reportados na Seção 4.2.1. No repositório da ASF, o número de médio de arquivos por revisão é de 6,21 (contra 13,78 do GW) e revisões "comuns" englobam de 1 a 8 arquivos (contra 1 a 23 do GW). Assim, na média, desenvolvedores do GW realizam commits com muito mais arquivos por revisão do que desenvolvedores de um projeto aleatório da ASF. Conforme observado na Seção 5, esse fenômeno pode ser parcialmente explicado por conta de revisões sobrecarregadas. Embora nós tenhamos cuidadosamente analisado esse tipo de revisão, acreditamos que outros projetos de software com revisões mais focadas podem eventualmente dar origem a uma quantidade menor de dependências lógicas. Além disso, a relação lógica intrínseca entre os arquivos LHS e RHS se tornaria mais em tais projetos.

Ameaças à generalização deste estudo são dadas por conta da precisa natureza do método de pesquisa empregado. McGrath afirma que métodos de pesquisa podem ser avaliados segundo três dimensões (generalização, realismo e precisão) e ele argumenta que nenhum método é capaz de satisfazer todas as três dimensões ao mesmo tempo. Em particular, estudos de caso naturalmente maximizam o realismo, mas raramente satisfazem completamente o aspecto de generalização (já que envolvem um número pequeno de situações não aleatoriamente selecionadas) ou precisão (já que há baixo nível de controle sobre os fatores de influência). Portanto, nós enaltecemos o realismo 
de nossos resultados e conclusões. Contudo, dadas as atuais pesquisas em mineração de repositórios de software [BZL06], [AJH10], [VR10], acreditamos que ao menos algumas das categorias listadas na Tabela 12 (como "interesses transversais", "refatorar elementos que pertencem a uma mesma classe semântica" e "operações de repositório") devem ocorrer em outros projetos de software com características similares. Portanto, também consideramos que nossa taxonomia possa ser utilizada como base para uma classificação mais abrangente e detalhada das origens de dependências lógicas que ocorrem em outros projetos de software.

\subsection{Trabalhos Relacionados}

A seguir, discutimos os trabalhos relacionados que abordam a questão das origens das dependências lógicas.

Cataldo et al. [CMRH09] conjecturaram que as origens das dependências lógicas poderiam estar relacionadas a chamadas de função em cascata, dependências semânticas e evolução de plataforma. Embora o significado de "dependências semânticas" não esteja claramente dado pelos autores, nós acreditamos que ele possa estar associado com as categorias "refatorar elementos que pertencem a uma mesma classe semântica" e "dependências estruturais que incorrem sobre uma classe semântica" que foram concebidas durante a análise das origens das dependências lógicas.

Conforme discutido na Seção 4.5, Hanakawa estudou a relação entre os conjuntos de elementos altamente acoplados estruturalmente (M) e de elementos altamente acoplados logicamente (L) [Han07]. A hipótese colocada pela autora é de que a média da interseção entre M e L tende a diminuir ao longo do tempo. Isso ocorreria por conta de (i) um acréscimo de ações de "copiar e colar" código (resultando em acoplamento lógico apenas) e (ii) desenvolvedores esquecendo-se de fazer o commit de classes estruturalmente relacionadas de uma vez só (resultando em apenas acoplamento estrutural apenas).

Costa et al. [dRCFdS08] desenvolveram uma ferramenta chamada RaisAware, que tem por objetivo dar suporte a relação entre a arquitetura do software e a coordenação de atividades de atividades de desenvolvimento de software. Ao definir o conceito de dependências lógicas (cochanges), os autores afirmam que o uso das técnicas de reflexão e injeção de dependências pode ser detectado por meio de análise das dependências lógicas. No GW, embora tenhamos examinado o pacote reflection, nós não identificamos qualquer mudança conjunta que tivesse sido causada por mecanismos de reflexão.

Durante nossa análise, nós notamos que o estabelecimento de algumas dependências lógicas estava relacionado à existência de interesses transversais no sistema. De fato, Breu et al. [BZL06] desenvolveram uma técnica de mineração que se apoia em análise formal de conceitos (teoria algébrica) e uma noção mais específica de dependências lógicas para identificar a introdução de interesses transversais. Adams et al. [AJH10] desenvolveram uma técnica de mineração de interesses transversais chamada COMMIT que trata três problemas comuns encontrados em trabalhos relacionados: a inabilidade de juntar seeds com variações, a tendência de ignorar importantes facetas de interesses e a falta de informação sobre a relação entre seeds. 


\subsection{Conclusão e Trabalhos Futuros}

Cataldo et al. sugerem que uma melhor compreensão da natureza das dependências lógicas possui implicações em diversas áreas, tais como qualidade de software e aperfeiçoamento de ferramentas de desenvolvimento [CMRH09]. Neste trabalho, nós investigamos as origens de dependências lógicas por meio de um estudo de caso envolvendo um projeto livre escrito em Java. Nós conduzimos uma inspeção manual das origens das dependências por meio da leitura de comentários de revisões, observação de diffs de código e realização de reuniões informais com desenvolvedores do projeto. Resultados preliminares mostraram que não havia uma razão distinta por detrás do estabelecimento das dependências lógicas analisadas, já que elas envolveram pares de arquivos que mudaram juntos por razões diversas. Nós então concebemos uma categorização das mudanças conjuntas envolvidas na formação de tais dependências. Acreditamos que nossa abordagem para identificação, agrupamento e classificação de dependências lógicas possa ser também reutilizada e adaptada para pesquisas futuras no mesmo domínio.

Como trabalho futuro, planejamos inspecionar um conjunto maior de dependências do GW, de modo que nós possamos ampliar nossos resultados e conclusão. Planejamos, também, executar o módulo de detecção de "copia e cola" do $\mathrm{PMD}^{11}$ no GW e então verificar se as classes detectadas originaram dependências lógicas. Ainda, acreditamos que a taxonomia proposta poderia ser validada em outros projetos de software por meio da elaboração e desenvolvimento de mecanismos automatizados para verificar as mudanças conjuntas contra cada uma das categorias listadas na Tabela 12. Investigar as origens das dependências lógicas de outros projetos de software também levaria a um aprimoramento e extensão de nossa taxonomia.

Adicionalmente, visionamos experimentos quantitativos de larga-escala para auxílio na descoberta das origens de dependências lógicas. Por exemplo, investigar a relação entre dependências lógicas e certos tipos de arquivos por meio da análise de uma vasta quantidade de projetos de software livre parece promissor. Finalmente, conforme já mencionado no capítulo anterior, investigar a interação entre os diferentes tipos de dependência deve constituir um tópico fértil de pesquisa com fortes implicações nas áreas de manutenção e evolução de software.

\footnotetext{
${ }^{11}$ http://pmd.sourceforge.net/cpd.html
} 


\section{Capítulo 6}

\section{Visualização de Dependências}

A área de "Visualização de Software" estuda a representação visual estática ou animada da informação sobre um sistema de software baseado em sua estrutura, comportamento ou evolução [Die10]. Esta representação pode ser em 2-D ou 3-D [MFM03], [WL07]. O objetivo central da visualização de software é apoiar a compreensão e análise de sistemas e algoritmos. No contexto deste trabalho, a visualização de software se enquadra como uma das atividades essenciais do ciclo de gerência de dependências (Figura 33).

Ao longo dos anos, foram concebidos diversos modelos e formas de visualização de dependências. Essa pluralidade de opções possibilita que as dependências sejam analisadas segundo diferentes níveis de abstração e perspectivas. Em sua essência, as visualizações consistem em uma representação visual do grafo de dependências obtido ao fim da atividade de identificação de dependências. Nesse capítulo, fazemos um levantamento das principais técnicas de visualização de dependências (Figura 34).

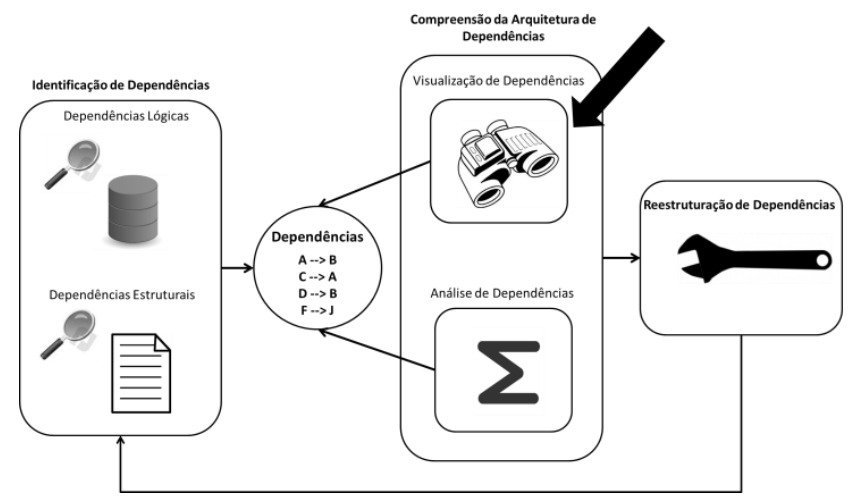

Figura 33: Ênfase na atividade "Visualizar dependências" do ciclo de gerência de dependências

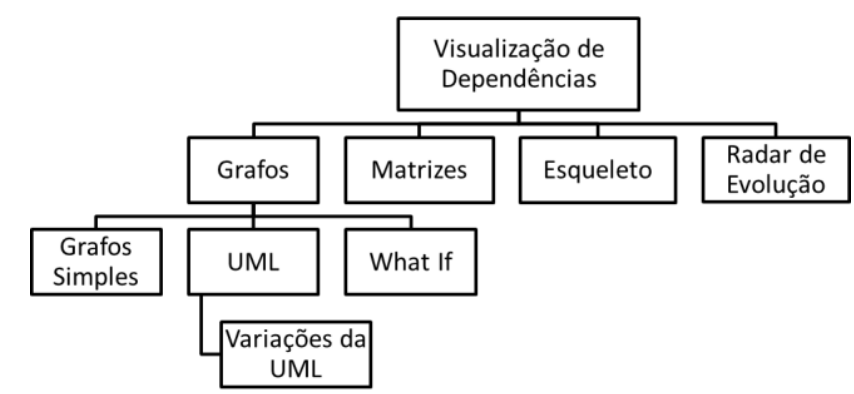

Figura 34: Taxonomia para visualização de dependências

\subsection{Trabalhos Relacionados}

Há muitos trabalhos na literatura envolvendo a visualização de software. Um bom resumo é o trabalho de Diehl, que apresenta conceitos básicos e diversas técnicas de visualização de software [Die10]. Sensalire et al. descrevem lições aprendidas na comparação de ferramentas de visualização [SOT09]. Padda et al. discutem o suporte à compreensão de ferramentas de visualização [PSM09]. D'Ambros et al. propõem ferramentas de visualização para evolução de software, das quais 
destacamos o Evolution Radar, capaz de representar dependências lógicas entre artefatos [DGLP08].

Há muitos trabalhos a respeito de visualização de software na forma de grafos. Destacamos o levantamento (survey) realizado por Herman et al. [HMM00], que apresenta os principais problemas da área e as técnicas de leiaute e navegação existentes. Aracic e Mezini propõem um conjunto de estratégias de abstração flexíveis (heurísticas) para tratar problemas de leiaute dos nós e arestas em grafos de dependências e as implementam em uma ferramenta chamada ISPACE ${ }^{12}$.

Browning revisa e aponta novas direções na aplicação de DSMs para decomposição de sistemas e problemas de integração [Bro01]. Sangal et al. apresentam uma abordagem para gerência de dependências apoiada pelo uso de DSMs [SJSJ05]. O portal DSM Web ${ }^{13}$ é uma excelente contribuição da Universidade Técnica de Munique (Alemanha) e da comunidade de DSM. O portal reúne conceitos básicos, publicações e ferramentas sobre DSMs.

\subsection{Grafos}

A representação na forma de grafos é simples: classes e módulos compõem o conjunto de nós e dependências compõem o conjunto de arestas. Presumidamente fácil de ser entendida, essa visualização é implementada pela maior parte das ferramentas analisadas (Apêndice C). Contudo, esse tipo de representação depende de algoritmos sofisticados e heurísticas de leiaute para que possa escalar, já que grafos com muitos elementos comprometem a compreensão devido à sobreposição de nós e arestas [HMM00].

Um grande esforço tem sido investido na minimização do cruzamento de arestas [TGDB98], [ES90], já que tal cruzamento tem sido reconhecido como um grande obstáculo para a legibilidade de grafos. Isso é usualmente feito através da minimização do número de cruzamentos entre arestas entre duas camadas consecutivas. Esse passo de minimização é o núcleo da complexidade de todo o algoritmo. Esta estratégia, contudo, não trata o problema de minimização do número de cruzamentos no grafo como um todo: mesmo com a restrição de se observar apenas camadas consecutivas, a minimização de cruzamentos é difícil e complexa. De fato, Garey e Johnson provaram que o problema é NP-difícil [GJ83] e Eades e Whitesides provaram que o problema de decisão correspondente é NP-completo [EW94].

Nas subseções seguintes, apresentamos técnicas de visualização de dependências na forma de grafos, cada qual explorando um leiaute específico.

\subsubsection{Grafos Simples}

A ferramenta ByeCycle (seção C.9 do Apêndice C) é um plugin para a plataforma Eclipse que auxilia na detecção de dependências cíclicas. A ferramenta conta com um algoritmo de leiaute automático não determinístico que fica movendo os elementos do grafo de maneira a minimizar o número de interseç̧ões de arestas.

\footnotetext{
12 http://atlanmod.emn.fr/www/papers/eTX2006/

${ }^{13}$ http://www.dsmweb.org/
} 


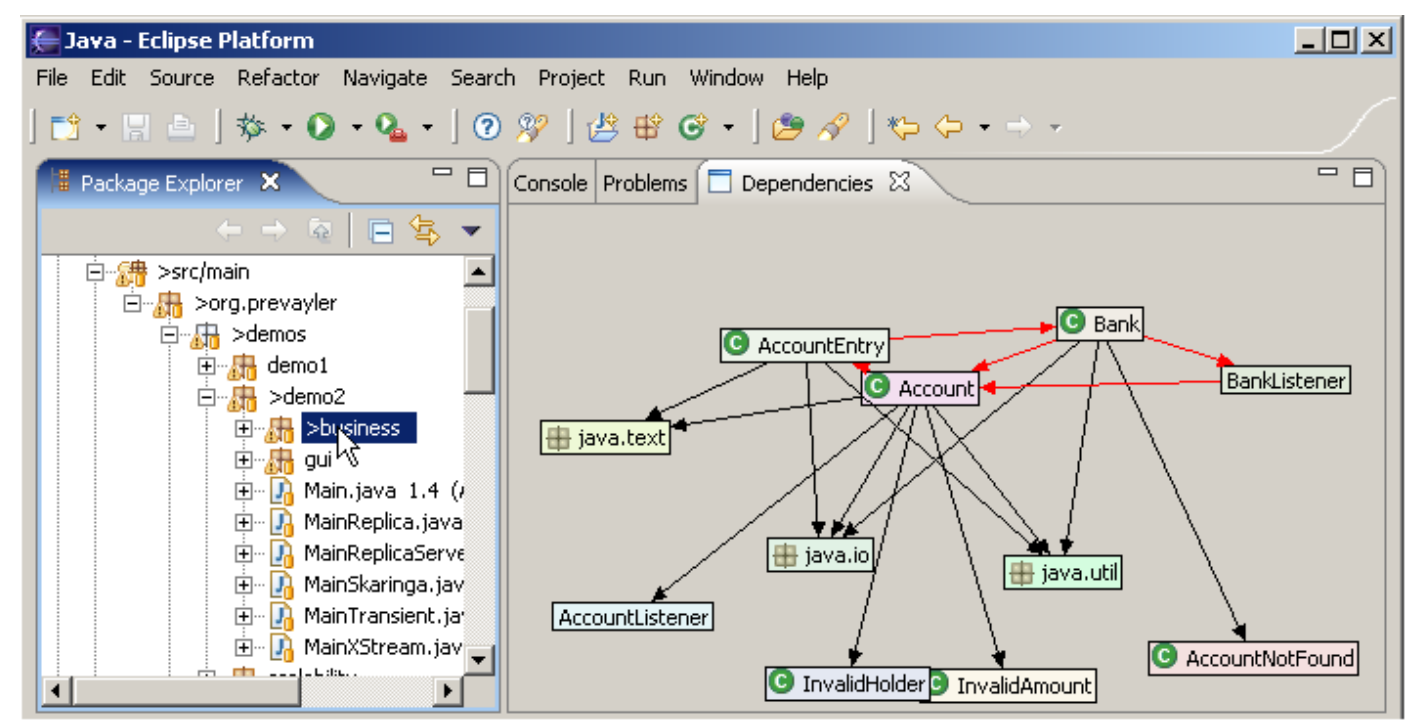

Figura 35: Visualização na forma de grafos através da ferramenta ByeCycle

A ferramenta Metrics (seção C.7 do Apêndice C) oferece um grafo interativo das dependências entre pacotes (Figura 36). O grafo destaca as componentes fortemente conexas do grafo, mostrando o número de pacotes envolvidos e o tamanho do caminho mais longo (longest walk). É possível ainda saber quais classes participam de um determinado ciclo. Esta implementação de visualização atribui significados específicos para as cores das arestas e dos vértices do grafo, assim como para o comprimento das arestas.

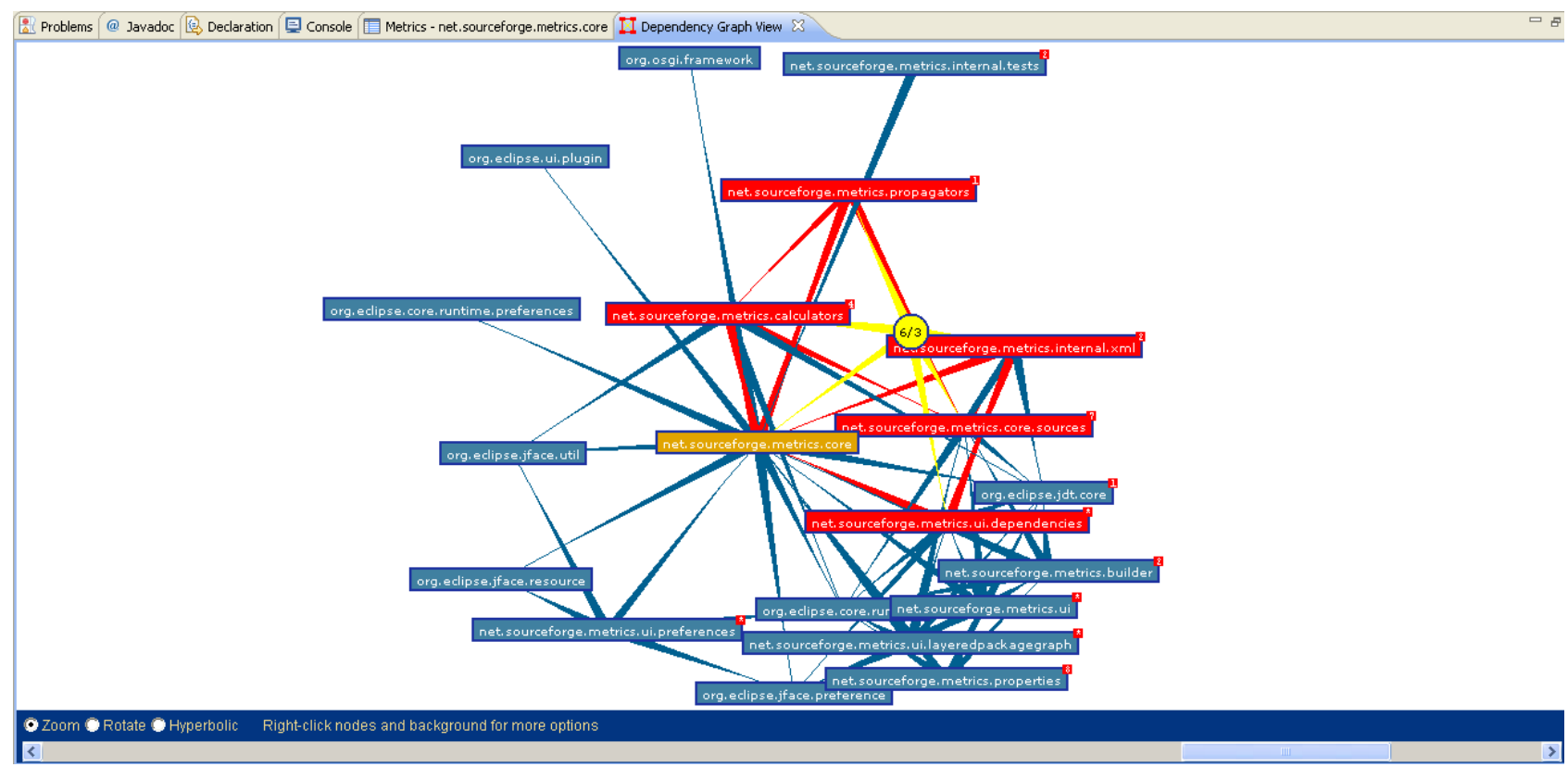

Figura 36: Visualização na forma de grafos através da ferramenta Metrics

\subsubsection{Unified Modeling Language (UML)}

A Unified Modeling Language é uma linguagem de modelagem gráfica que estende o modelo de visualização baseado em caixas e linhas. A UML é destinada à visualização, especificação, construção e documentação dos artefatos de um sistema de software complexo [BRJ05]. A UML é um padrão controlado pelo OMG (Object Management Group), um consórcio de empresas formado 
para estabelecer e aprovar padrões abertos para aplicações orientadas a objetos. Tal linguagem se tornou não somente a notação gráfica dominante para o paradigma de orientação a objetos, como também uma técnica popular para outros paradigmas [Fow03].

Na UML 2.x, uma dependência é ilustrada com uma linha tracejada com seta partindo do cliente para o fornecedor (Figura 37). A linha pode ser rotulada com um estereótipo e um nome.

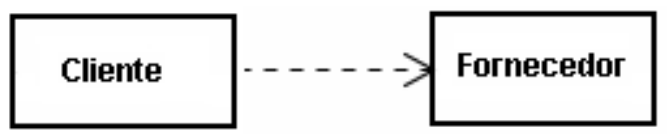

Figura 37: Notação UML para Dependência

Um estereótipo é uma extensão do vocabulário da UML, possibilitando que sejam criados novos tipos de blocos de construção similares aos já existentes, porém específicos para o problema em questão. Graficamente, um estereótipo é ilustrado como um nome cercado por guillemets (aspas francesas, ou seja, $<<$ e >>), colocado acima do nome de outro elemento. Opcionalmente, o elemento estereotipado pode ser ilustrado através de um ícone associado com o estereótipo [BRJ05]. Estereótipos comuns para o relacionamento de dependência incluem: call, derive, instantiate, refine e use.

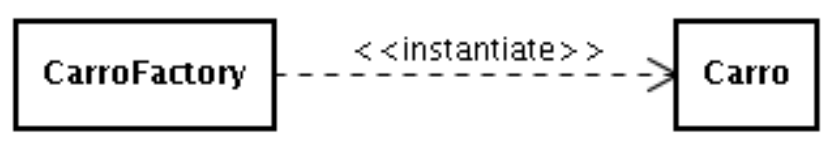

Figura 38: Exemplo de dependência com estereótipo

Todos os relacionamentos da UML, incluindo generalização, associação e realização são conceitualmente tipos de dependências. Contudo, generalização, associação e realização têm semânticas suficientemente importantes para que sejam tratados formalmente como tipos distintos na especificação (meta-modelo) da UML (Figura 39).

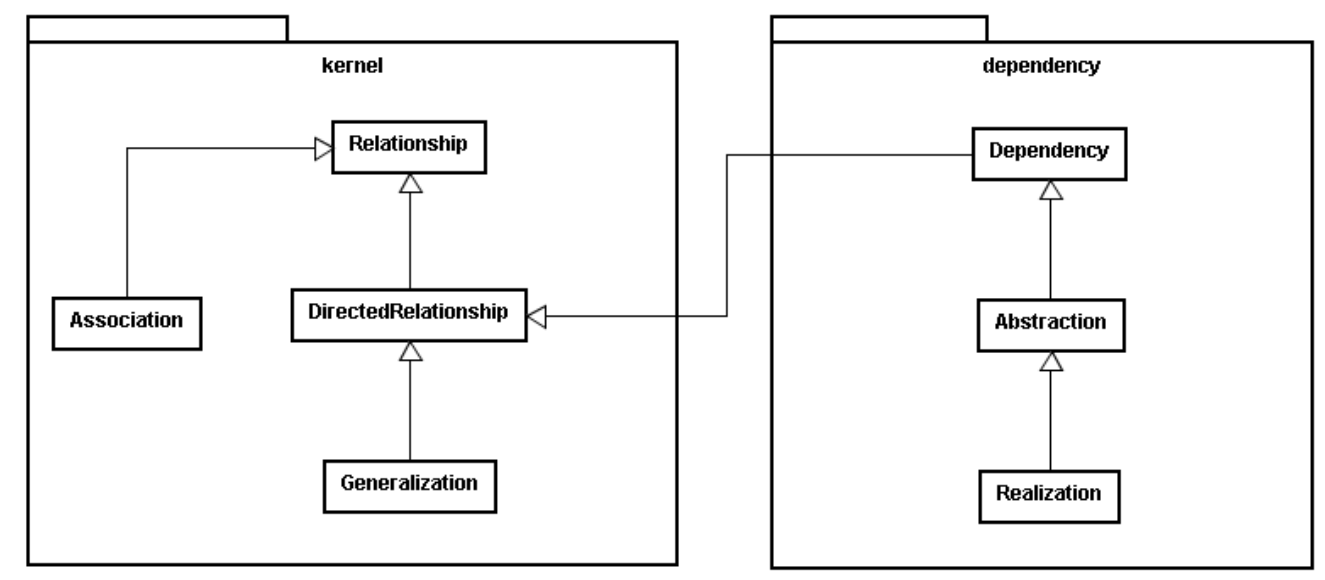

Figura 39: Meta-modelo UML destacando semântica do termo "dependência" segundo especificação formal

Dado o código-fonte (ou compilado) de um programa, há muitas ferramentas que geram o diagrama de classes UML correspondente, como por exemplo: Borland Together, Rational Rose, ESS-Model, BlueJ e Fujaba. Eichelberger compilou uma lista de 15 critérios de estética para serem usados para o leiaute de diagramas de classe UML [Eic03]. Ele também avaliou o leiaute 
automático de 42 ferramentas $\mathrm{CASE}^{14}$. Ele concluiu que "as ferramentas frequentemente produzem resultados horríveis transformando o leiaute e implicitamente e acidentalmente mudando as semânticas de todo o diagrama". Enquanto ferramentas como as citadas anteriormente utilizam algoritmos baseados no leiaute hierárquico, recentemente dois algoritmos de leiaute ortogonal foram desenvolvidos utilizando a abordagem forma-métrica (shape-metrics approach) [EGK+04]. Esses algoritmos proporcionam melhores resultados para diagramas de classe UML que possuem um número pequeno de arestas de herança e um grande número de associações [HMM00]. A Figura 40 mostra um mesmo diagrama de classes UML, ora gerado por uma ferramenta CASE da indústria e ora gerado pela ferramenta GoVisual (que implementa a abordagem forma-métrica).
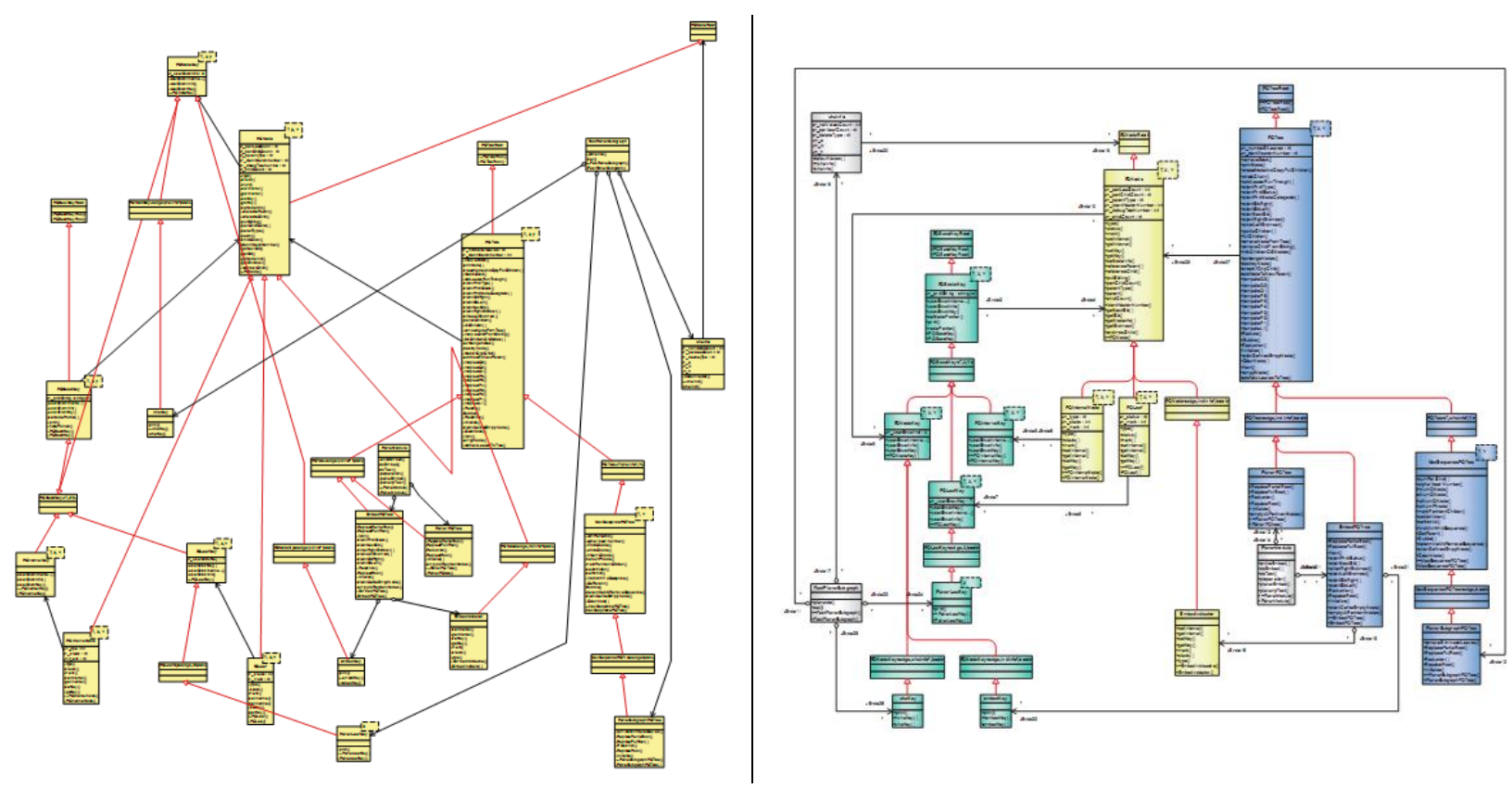

Figura 40: Um mesmo diagrama de classes gerado por ferramenta CASE da indústria (esquerda) e ferramenta GoVisual (direita) [Die10]

\subsubsection{Variações da UML}

A ferramenta SA4J possibilita visualizar as dependências entre pacotes, classes e interfaces utilizando leiaute radial e uma notação inspirada na UML (Figura 41). Os elementos que aparecem ao redor do item analisado dependem do filtro selecionado na aba Explorer. Por padrão, são exibidas as dependências e os dependentes do elemento em questão. Mais informações a respeito dessa ferramenta estão disponíveis na seção C.1 do Apêndice C.

\footnotetext{
14 Trata-se de um relatório disponível em:

http://wwwi2.informatik.uni-wuerzburg.de/mitarbeiter/eichelberger/reports/evalReport2002.pdf
} 


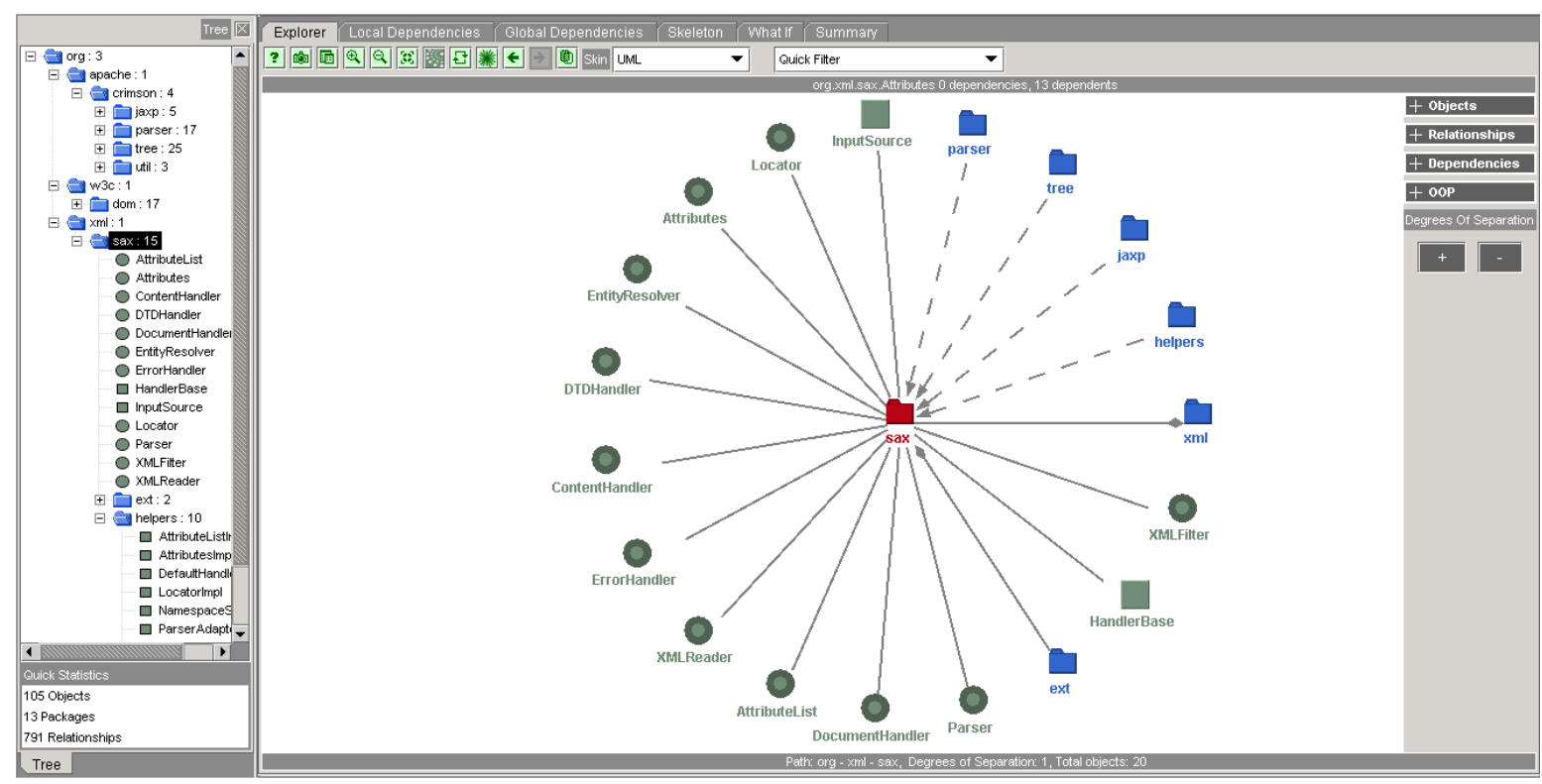

Figura 41: Visualização na forma de grafos através da ferramenta SA4J

A ferramenta S101 também implementa a visualização de dependências na forma de um grafo inspirado na UML (Figura 42). As classes são representadas como nós e cada relacionamento carrega o peso da dependência. Ao selecionar a aresta, a ferramenta exibe mais detalhes sobre a dependência. A ferramenta apoia ainda a visualização de dependências entre outros elementos, como arquivos JAR, pacotes e membros internos de classe (campos, métodos e outros). Mais detalhes sobre a ferramenta estão disponíveis na seção C.2 do Apêndice C.

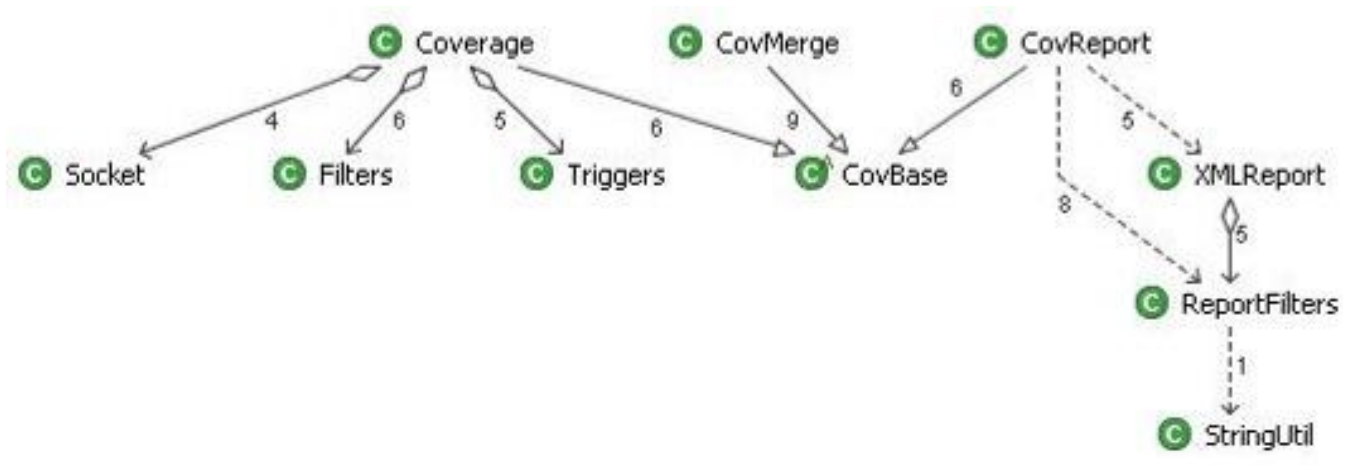

Figura 42: Visualização na forma de grafos através da ferramenta $S 101$

\subsubsection{What If}

A técnica de visualização chamada de what if foi concebida para a ferramenta IBM SA4J com o intuito de determinar o máximo impacto de mudança em uma determinada classe ou interface do projeto analisado (Figura 43). Dessa maneira, visualizam-se os efeitos de uma mudança sem ter que realizá-la propriamente. 


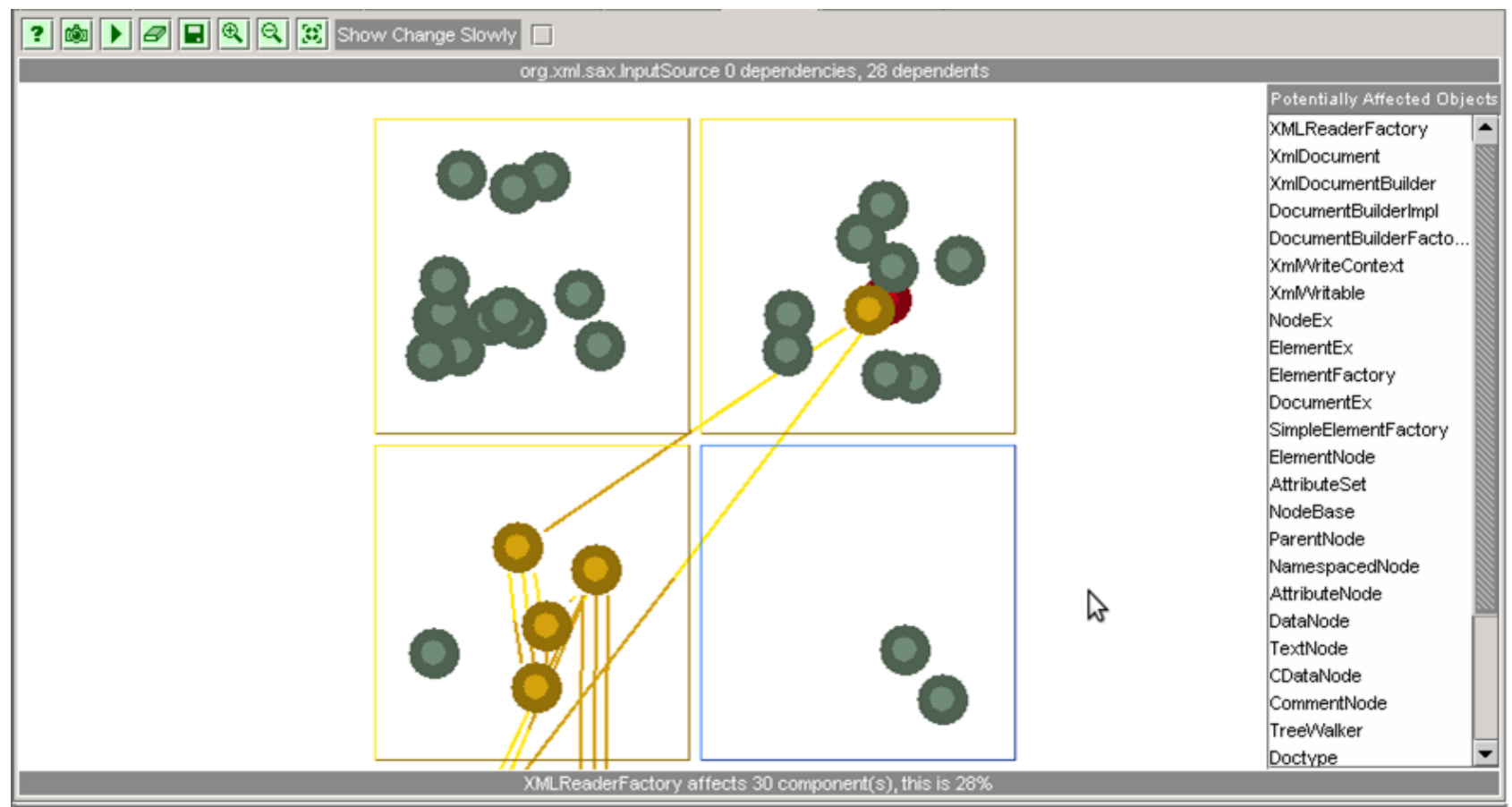

Figura 43: Visualização de dependências na forma What If na ferramenta $S A 4 J$

As classes e interfaces (nós) são representadas por círculos e os pacotes são representados por quadrados (agrupadores de nós). Quando um determinado círculo é selecionado, a ferramenta percorre em profundidade o grafo de dependências e destaca todos os círculos que dependem (inclusive transitivamente) do círculo selecionado, inserindo arestas e colorindo-os com outra cor. Trata-se, portanto, de uma análise de pior caso. Na coluna da direita são listados os nomes de todos os itens que foram pintados e no rodapé são informados o número e o percentual de itens afetados.

\subsection{Matrizes}

A matriz de estrutura de dependências (dependency structure matrix), também conhecida como matriz de estrutura de design (design structure matrix), foi inventada há mais de 30 anos para otimização de processos de desenvolvimento de produtos industriais [SJSJ05].

O termo "matriz de estrutura de dependências" (DSM) refere-se tanto a uma particular representação de tais dependências como a algoritmos para reorganizar as dependências através de reordenação e agrupamento de tarefas. Trata-se de uma simples matriz de adjacências com os módulos rotulando os eixos horizontal e vertical, e uma marca na i-ésima coluna e na j-ésima linha quando o i-ésimo módulo depende do j-ésimo. Autodependências não são consideradas, portanto nunca existem marcas ao longo da diagonal. Alternativamente, pode-se exibir o peso da dependência em vez da marca.

Algoritmos têm sido desenvolvidos para otimizar a ordenação e agregação de módulos (ou quaisquer outros elementos) em grupos de modo que a matriz se torne triangular inferior, isto é, sem entradas acima da diagonal. Tais algoritmos são conhecidos como algoritmos de particionamento. Enunciamos um importante corolário: 
(i) As linhas (módulos) da matriz podem ser permutadas de modo que ela se torne triangular inferior $\Leftrightarrow$ o sistema não possui módulos mutuamente dependentes (dependências cíclicas) [SJSJ05].

A Figura 44 mostra uma DSM simples. Como os módulos A e C são mutuamente dependentes, as linhas não podem ser reordenadas de modo que a matriz se torne triangularinferior. Contudo, se A e C forem tratados como um único módulo composto, o ciclo pode ser eliminado. A Figura 45 ilustra essa estratégia, com um sombreamento indicando o módulo composto. Tal DSM, que foi reorganizada para que todas as dependências caiam abaixo da diagonal ou em grupos, é dita estar na forma bloco-triangular.

\begin{tabular}{|l|l|l|l|l|l|}
\hline \multicolumn{2}{|l|}{} & 1 & 2 & 3 & 4 \\
\hline Módulo A & 1 &. & & X & X \\
\hline Módulo B & 2 & &. & X & \\
\hline Módulo C & 3 & $X$ & &. & X \\
\hline Módulo D & 4 & & & & . \\
\hline
\end{tabular}

Figura 44: Uma DSM simples (traduzida de [SJSJ05])

\begin{tabular}{|l|l|l|l|l|l|}
\hline \multicolumn{2}{|l|}{} & 1 & 2 & 3 & 4 \\
\hline Módulo D & 1 & $\cdot$ & & & \\
\hline Módulo A & 2 & $\mathrm{X}$ & $\cdot$ & $\mathrm{X}$ & \\
\hline Módulo C & 3 & $\mathrm{X}$ & $\mathrm{X}$ & $\cdot$ & \\
\hline Módulo B & 4 & & & $\mathrm{X}$ & $\cdot$ \\
\hline
\end{tabular}

Figura 45: DSM bloco-triangular após particionamento (traduzida de [SJSJ05])

O agrupamento de módulos pode ser mostrado de maneiras diferentes. Um método consiste na criação de módulos compostos, resultando em uma matriz triangular-inferior (Figura 46). Alternativamente, as identificações dos módulos podem ser preservadas através da inclusão de uma estrutura hierárquica, como na Figura 47, na qual o agrupamento de A e C é mostrado através de endentação.

Uma classe diferente de algoritmos, conhecidos como algoritmos de clusterização, otimizam a ordenação e agregação de elementos (linhas) para reduzir o número de dependências fora da diagonal. O propósito não é meramente eliminar os ciclos, mas reduzir a incidência de quaisquer dependências entre grupos de elementos.

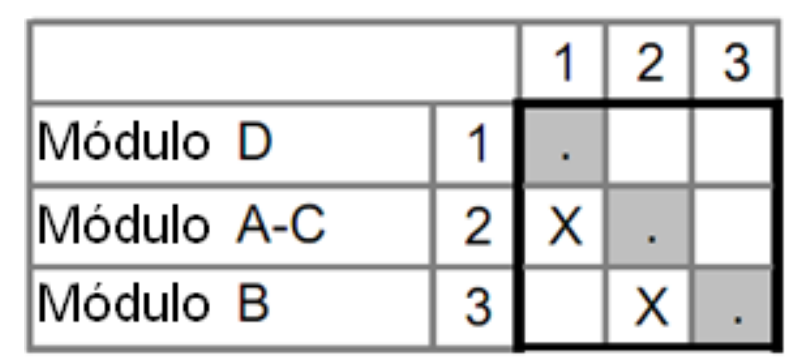

Figura 46: DSM triangular-inferior (traduzida de [SJSJ05])

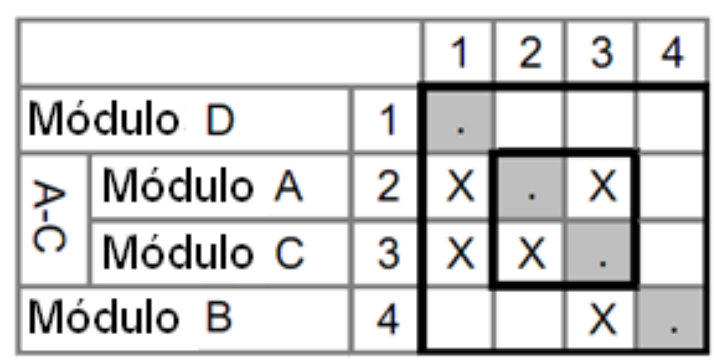

Figura 47: DSM hierárquica (traduzida de [SJSJ05])

A matriz auxilia na identificação de camadas arquiteturais. Em uma arquitetura em camadas, a camada mais alta é composta por módulos com fornecedores, mas sem clientes. Esses módulos são aqueles cuja linha não apresenta quaisquer marcas. Analogamente, a camada mais baixa é formada por módulos "responsáveis", que possuem clientes, mas nenhum fornecedor. Tais 
módulos são aqueles cuja coluna não apresenta quaisquer marca. A matriz também auxilia na identificação de sistemas com arquitetura em camadas (Figura 48 ).

\begin{tabular}{|c|c|c|c|c|c|c|c|}
\hline \multicolumn{3}{|c|}{ \$root } & \multirow{2}{*}{$\frac{\rightarrow}{.}$} & \multirow[t]{2}{*}{ N } & \multirow[t]{2}{*}{$\omega$} & \multirow[t]{2}{*}{$\rightarrow$} & \multirow[t]{2}{*}{ on } \\
\hline \multirow{5}{*}{ 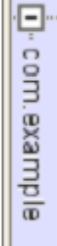 } & +- application & 1 & & & & & \\
\hline & + model & 2 & 37 & . & & & \\
\hline & + domain & 3 & 17 & 29 & & & \\
\hline & + framework & 4 & 75 & 53 & 42 & . & \\
\hline & +- util & 5 & 10 & 13 & 16 & 13 & . \\
\hline
\end{tabular}

\begin{tabular}{|c|c|c|c|c|c|c|c|}
\hline \multicolumn{3}{|c|}{ \$root } & \multirow[t]{2}{*}{$\rightarrow$} & \multirow[t]{2}{*}{ N } & \multirow[t]{2}{*}{$\omega$} & \multirow[t]{2}{*}{-} & \multirow[t]{2}{*}{ v } \\
\hline$\underset{7}{-1}$ & +- application & 1 & & & & & \\
\hline \multirow{4}{*}{ 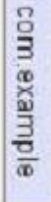 } & \$- model & 2 & 37 & - & & & \\
\hline & + domain & 3 & & 29 & . & & \\
\hline & +-framewark & 4 & & & 42 & . & \\
\hline & + util & 5 & & & & 13 & \\
\hline
\end{tabular}

Figura 48: Sistema com arquitetura em camadas (esquerda) e sistema com arquitetura em camadas estritas (direita) [SJSJ05]

A aplicação da DSM para software possui uma série de vantagens em relação a outros tipos de representação [SJSJ05]. A representação na forma de matrizes escala melhor do que diagramas com caixas e linhas (como na UML), sendo que a inclusão de hierarquia é particularmente útil. Também, algoritmos de particionamento encontram camadas e destacam ciclos, além de proverem um mecanismo automático para revelação de padrões e estilos arquiteturais em bases de código grandes. Por outro lado, a leitura de uma DSM não é tão imediata e simples quanto a de um grafo, especialmente no caso de dependências transitivas. Isto sugere que esse tipo de visualização seja mais efetivo para a análise de propriedades arquiteturais do sistema, sob uma perspectiva de alta granularidade.

A ferramenta Lattix (Seção C.5 do Apêndice C) implementa esse modelo de visualização de dependências. A Figura 49 mostra uma DSM para o aplicativo Ant v.1.4.1, onde as camadas são identificadas por conta da natureza bloco-triangular da matriz. Nota-se também a grande quantidade de dependentes e dependências do módulo 5 (classes na raiz do pacote ant.taskdefs). Em particular, esse tipo de módulo é conhecido como propagador de mudanças e é discutido em detalhes na Seção 5.4.4.

\begin{tabular}{|c|c|c|c|c|c|c|c|c|c|c|c|c|c|c|c|}
\hline \multicolumn{4}{|c|}{$\$ r o o t$} & \multirow{2}{*}{$\vec{b}$} & \multirow{2}{*}{ N } & \multirow[t]{2}{*}{ u } & \multirow[t]{2}{*}{$\rightarrow$} & \multirow{2}{*}{ or } & \multirow{2}{*}{ の } & \multirow{2}{*}{$\checkmark$} & \multirow{2}{*}{$\infty$} & \multirow[t]{2}{*}{$\omega$} & \multirow{2}{*}{$\overrightarrow{0}$} & \multirow{2}{*}{$\vec{\forall}$} & \multirow{2}{*}{$\vec{N}$} \\
\hline \multirow{12}{*}{ 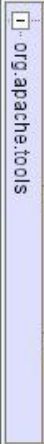 } & $\square$ & + optional & 1 & & & & & & & & & & & & \\
\hline & \multirow{4}{*}{ 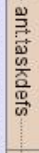 } & † compilers & 2 & & . & & & 2 & & & & & & & \\
\hline & & + condition & 3 & & & . & & 2 & & & & & & & \\
\hline & & + rmic & 4 & & & & . & 2 & & & & & & & \\
\hline & & $+*$ & 5 & 1 & 5 & 2 & 2 & . & & & & & & & \\
\hline & \multirow{4}{*}{$\begin{array}{l}\square \\
\stackrel{7}{2}\end{array}$} & †- listener & 6 & & & & & & . & & & & & & \\
\hline & & $+t^{*}$ & 7 & & 5 & 4 & 5 & 17 & 5 & . & 8 & 3 & & & \\
\hline & & + types & 8 & & 4 & & 4 & 19 & & 6 & . & 1 & & & \\
\hline & & † util & 9 & & & & 1 & 7 & & 2 & 1 & & & & \\
\hline & \multirow{3}{*}{$\begin{array}{l}\text { 豆 } \\
\text { 들 }\end{array}$} & + zip & 10 & & & & & 2 & & & & & . & & \\
\hline & & + tar & 11 & & & & & 3 & & & & & & . & \\
\hline & & + mail & 12 & & & & & 1 & & & & & & & . \\
\hline
\end{tabular}

Figura 49: DSM para Ant v1.4.1 com o auxílio da ferramenta Lattix [SJSJ05]

O uso de DSMs tem avançado por meio de trabalhos no MIT, Harvard, Universidade de Illinois e outros lugares onde a técnica é aplicada para a análise de sistemas complexos ${ }^{15}$.

\footnotetext{
${ }^{15}$ http://www.lattix.com/technology
} 


\subsection{Esqueleto}

A forma de visualização em esqueleto (skeleton view) foi concebida pela ferramenta SA4J. Nesse modelo, as classes sem dependência são colocadas na base (primeiro nível) e em seguida as classes que dependem diretamente delas são colocadas no segundo nível e assim por diante (Figura 50). Segundo o documento de guia do usuário do SA4J, sistemas com estabilidade geral alta possuem esqueletos que se parecem com pirâmides, isto é, remontam a estruturas fisicamente estáveis.

Os quadrados representam classes (inclusive inner classes), interfaces e pacotes do sistema analisado. Os quadros com um ' $\mathrm{T}$ ' representam componentes fortemente conexas. Esses componentes são mapeados para apenas um quadrado, já que todos os elementos que o compõem mudam juntos.

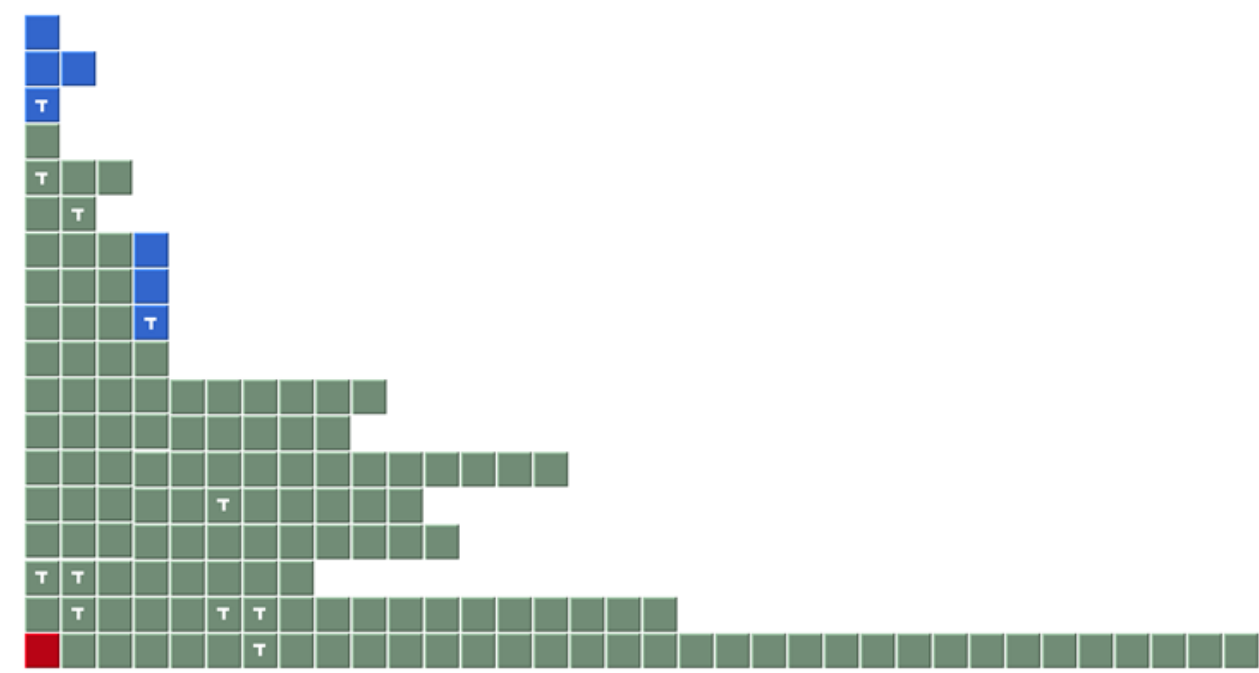

Figura 50: Visualização de dependências na forma de esqueleto na ferramenta SA4J

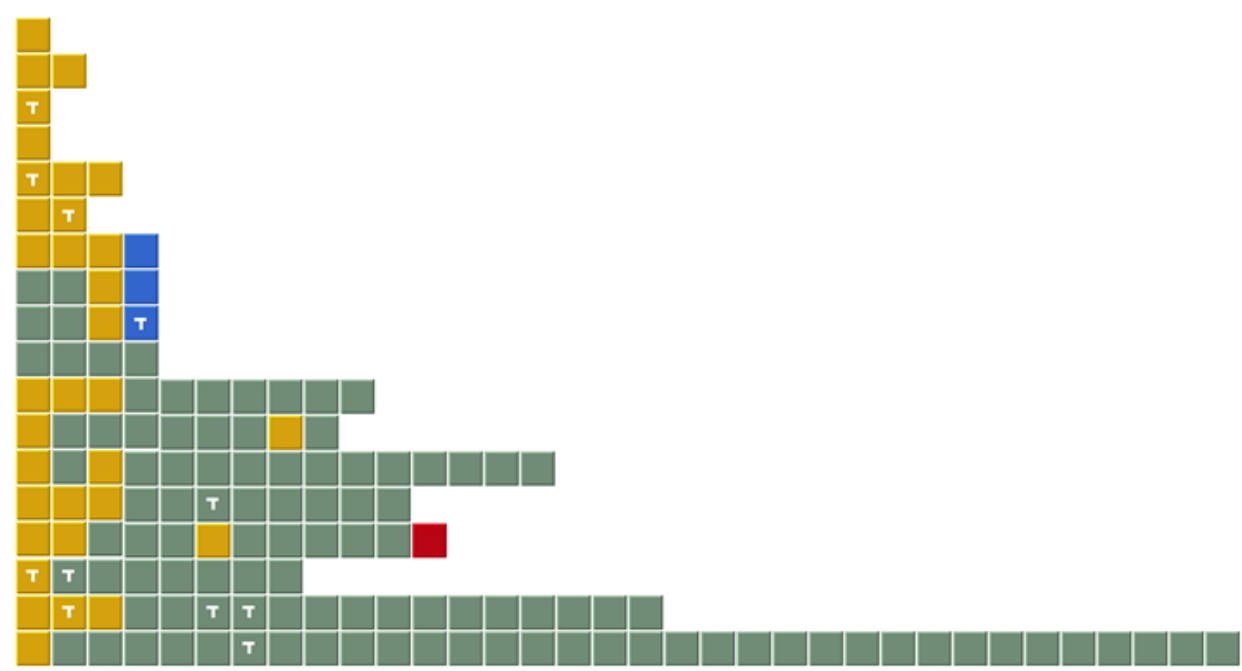

Figura 51: Visualização do impacto de mudanças através de um esqueleto na ferramenta SA4J

Quando um quadrado é selecionado, o aplicativo destaca com todos os outros quadrados que dependem transitivamente dele (Figura 51). Isto possibilita visualizar de forma rápida e imediata o impacto de uma mudança em um determinado elemento no pior caso. 


\section{Capítulo 7}

\section{XFlow - Uma Ferramenta para Visualização de Dependências}

Diversos trabalhos constataram a decadência da qualidade de um sistema de software ao longo do tempo [LPR+97], ressaltando a importância e os desafios envolvidos na manutenção e evolução de software. Em particular, o processo evolutivo ao qual sistemas de software são submetidos [BR00] tornou-se tópico de grande interesse tanto para a indústria quanto para a comunidade acadêmica. Esse interesse motivou a construção de diversas ferramentas para apoiar avaliações analíticas e empíricas a respeito da evolução de sistemas de software.

As ferramentas até então propostas fazem intensivo uso de técnicas de visualização de informação [Die10]. No entanto, muitas dessas ferramentas apresentam visões de sistemas exclusivamente sob o foco de aspectos técnicos [ZWDZ05], [WL07], [DL10] ou sociais [dSQTR07], [GK07]. Embora existam raras exceções de ferramentas que tratem ambos os aspectos [dSFD05], [SMWH09], elas oferecem apoio limitado para análises cruzadas, uma vez que não foram projetadas para esse fim. Além disso, tais ferramentas também desconsideram fatores importantes do desenvolvimento de software, como por exemplo, a arquitetura e seus efeitos sobre os desenvolvedores [CSDS09]. Essa limitação representa um grande viés para a extração de informações a partir da visualização dos sistemas, uma vez que estudos anteriores mostram uma grande relação entre os aspectos técnicos e sociais [Con68], tornando imprescindível a visualização desse relacionamento para de fato compreender sistemas de software.

Visando superar as deficiências das soluções disponíveis, desenvolvemos a ferramenta XFlow, que dá suporte à análise da evolução de sistemas de software por meio da visualização integrada de aspectos técnicos e sociais. De fato, o maior diferencial da ferramenta em relação às demais é a pluralidade de técnicas de processamento, métricas e, sobretudo, de tipos de visualização distintos oferecidos. Esse conjunto de recursos dá origem a uma gama de perspectivas de análise que possibilitam retratar o software de modo mais adequado e viabilizam uma compreensão mais profunda a respeito do processo evolutivo. A ferramenta XFlow foi construída por Francisco Werther Santana (UFPA), sob orientação do professor Dr. Cleidson R. B. de Souza (IBM Research). Minhas contribuições para a ferramenta são aquelas descritas nos capítulos referentes aos estudos empíricos.

Neste capítulo, descrevemos a ferramenta XFlow e mostramos seu potencial, servindo assim como uma aplicação do estudo de visualização de dependências feito no capítulo anterior. Em particular, nas próximas subseções, apresentaremos os principais recursos da ferramenta, bem como dois exemplos de uso, em que investigamos os efeitos da arquitetura sobre desenvolvedores e o papel de desenvolvedores em um projeto respectivamente. 


\subsection{A Ferramenta}

A XFlow é uma ferramenta livre ${ }^{16}$ desenvolvida em Java, com arquitetura extensível, e que tem por objetivo dar suporte à compreensão de sistemas de software por meio da visualização de sua evolução ao longo do tempo, considerando aspectos técnicos e sociais [SOdSG11]. Ao exibir esses diferentes aspectos, a ferramenta apoia estudos que exijam uma compreensão mais profunda a respeito de aspectos específicos da evolução do software, tais como: a relação entre dependências estruturais e lógicas (Capítulo 4), degradação arquitetural, efeitos exercidos por decisões arquiteturais sobre o projeto de software, grau de contribuição de desenvolvedores e troca de papéis entre desenvolvedores.

\subsubsection{Princípios de funcionamento}

A XFlow minera sistemas de controle de versão para coletar dados a respeito da evolução do software. Posteriormente, a ferramenta processa tais dados para identificação de dependências entre artefatos, requisitos de coordenação entre desenvolvedores [CWHC06] e outras características do sistema.

Uma vez coletadas e processadas as informações do projeto, a XFlow oferece cinco visualizações distintas para observação do projeto, bem como um conjunto de mecanismos para interação com as mesmas. Essa pluralidade de opções possibilita que o software seja visualizado segundo diferentes perspectivas e níveis de abstração, proporcionando uma compreensão mais abrangente do sistema. Em particular, inspirados pelo "mantra" de visualização proposto por Shneiderman "visão geral inicial, zoom e filtragem, e detalhes sob demanda" [SP06], projetamos a XFlow para tratar complexidade e superar alguns dos obstáculos que dificultam estudos empíricos em evolução de software.

\subsubsection{Mecanismos de Interação}

Dado que pesquisadores podem ser facilmente ofuscados pela grande quantidade de dados referentes à evolução de um sistema de software [BWKG05], é fundamental que as ferramentas ofereçam ao usuário mecanismos para interagir com as visualizações e exibir apenas valores interessantes para a análise sendo conduzida. Nesse sentido, a XFlow oferece dois tipos de mecanismos de interação, diferenciados em controles e filtros, de modo que o usuário se concentre em detalhes específicos do projeto durante sua visualização, exibindo apenas um subconjunto específico dos dados.

Controles são elementos que afetam mais de uma das visualizações do projeto, e tem como objetivo garantir as mesmas condições de análise ao alternar entre tais visualizações. A XFlow conta atualmente com dois controles: o slider e o painel de desenvolvedores. A interação com o slider oferece ao usuário a possibilidade de limitar o escopo de uma análise, ampliando ou reduzindo o período de dados históricos exibidos dinamicamente conforme o desejo do usuário, e

\footnotetext{
${ }^{16}$ A ferramenta XFlow está registrada sob licença GPL.
} 
afeta todas as visualizações. O painel de desenvolvedores identifica todos os atores que submeteram suas contribuições ao sistema de controle de versão do projeto e atribui uma cor diferente para cada um deles. Esse recurso proporciona ao usuário a possibilidade de tornar visível ou esconder as contribuições de um determinado desenvolvedor, de modo que o usuário possa acompanhar as contribuições de um único desenvolvedor ou de um determinado grupo para o projeto. O painel de desenvolvedores é atualmente aplicável para as visualizações de dispersão, treemap e atividade.

Filtros, por sua vez, são mecanismos que atuam apenas dentro de uma determinada visualização, oferecendo ao usuário ainda mais recursos para facilitar a análise. Dessa forma, filtros possibilitam extrair ainda mais informações úteis de uma visualização específica, disponibilizando, por exemplo, filtragens de dados mais específicas, exibição valores de referência ou diferentes layouts de apresentação dos dados para a escolha do usuário.

\subsubsection{Leque de visualizações}

Há cinco visualizações atualmente implementadas no XFlow. A visualização em linha (i) apresenta um gráfico que favorece a comparação entre duas variáveis ao longo de um plano cartesiano 2D (Figura 52). Essa visualização possibilita que pesquisadores identifiquem tendências e façam previsões.

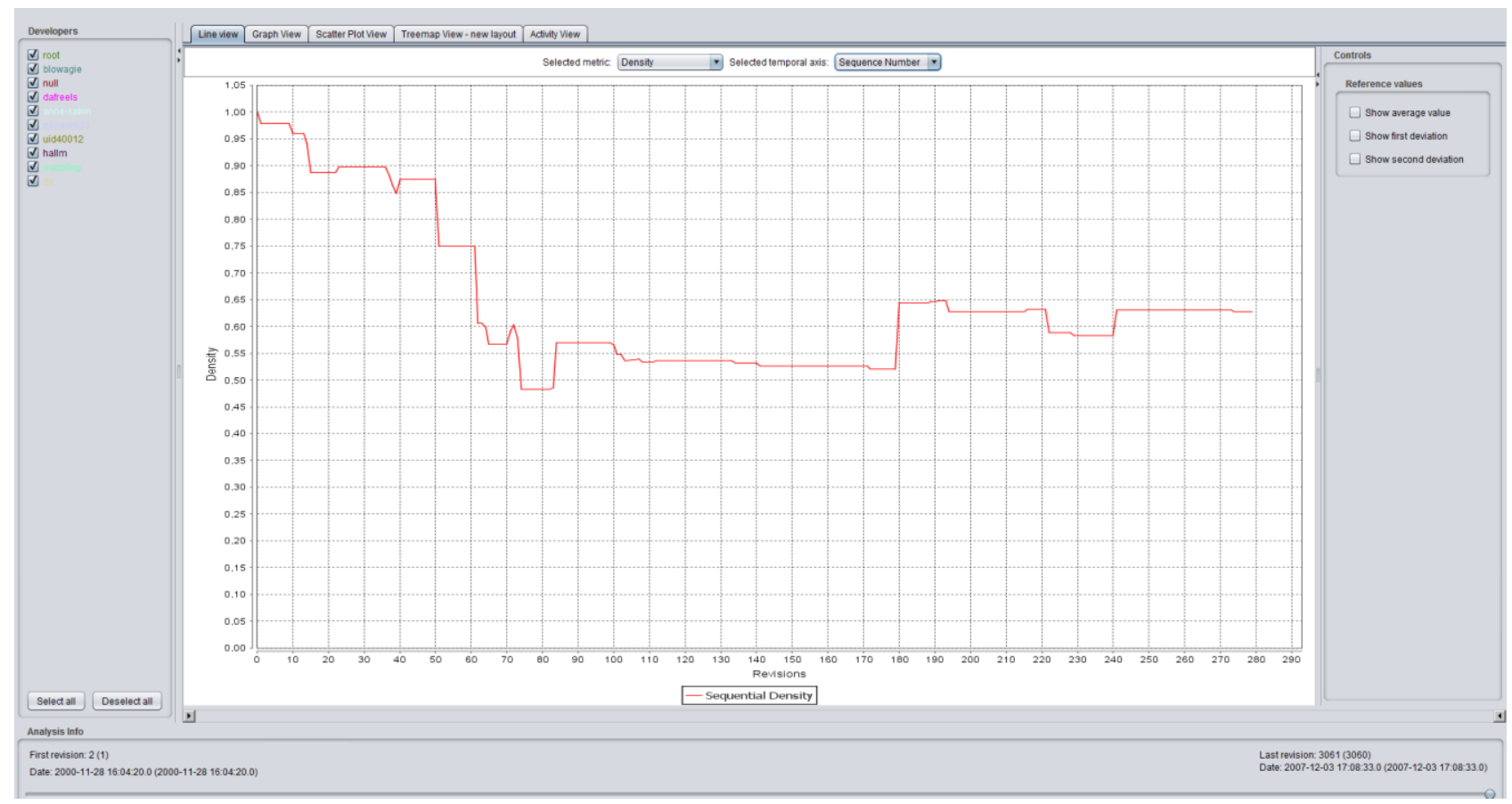

Figura 52: Visualização de linha na XFlow

A visualização de grafo (ii) mostra dependências entre quaisquer combinações de entidades (desenvolvedores e artefatos) em uma estrutura de grafo, sendo que cada entidade é representada como um vértice e as dependências entre tais entidades como arestas (a espessura indica o grau da dependência). Essa visualização é particularmente útil para a visualização das redes sociotécnicas de um projeto (Figura 53). 


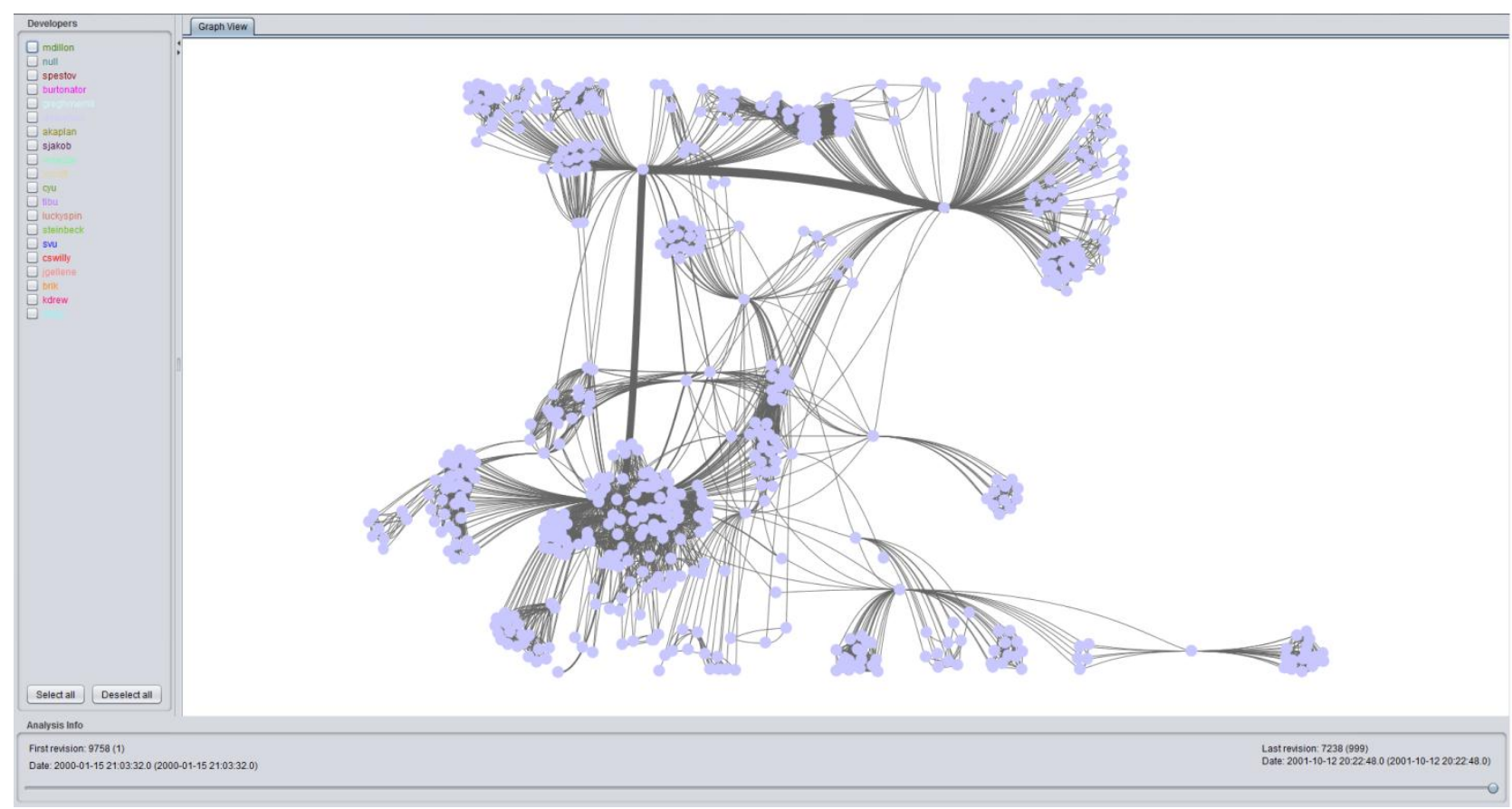

Figura 53: Visualização de grafo na XFlow

A visualização de dispersão (iii) mostra correlação entre variáveis plotando uma coleção de pontos (Figura 54). Cada ponto representa um commit e recebe uma cor específica que está atrelada a um desenvolvedor. Essa visualização viabiliza a investigação das contribuições feitas por um único desenvolvedor (v.g., se ele alcançou os arquivos do núcleo do sistema analisado).

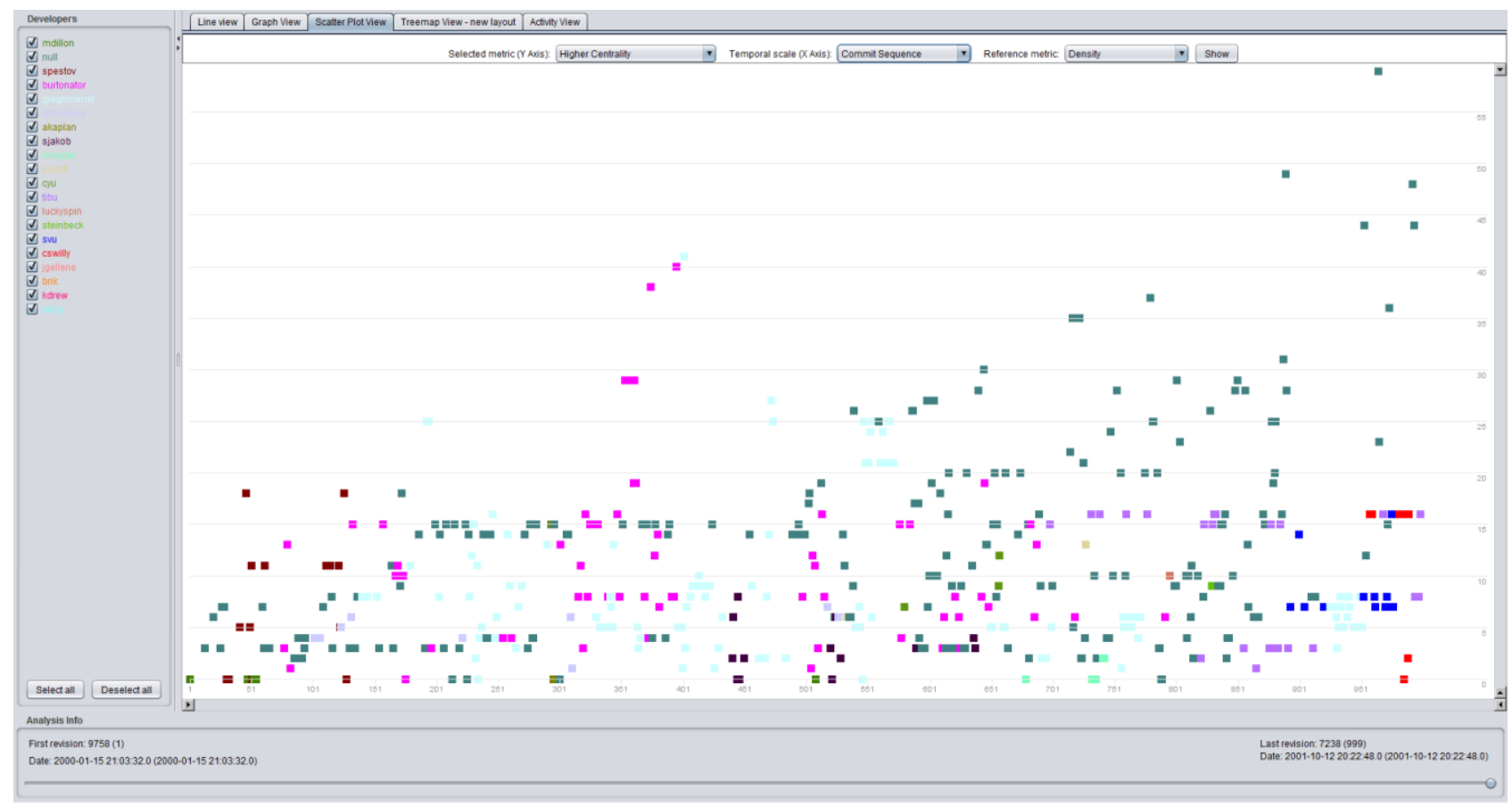

Figura 54: Visualizaçao de dispersão na XFlow

A visualização treemap (iv) utiliza retângulos aninhados para exibir informações com características hierárquicas (Figura 55). A ferramenta emprega treemaps para representar pacotes e arquivos de modo escalável, i.e. a ferramenta é capaz de retratar de forma precisa a estrutura completa do sistema em um determinado momento e para desenvolvedores específicos. 


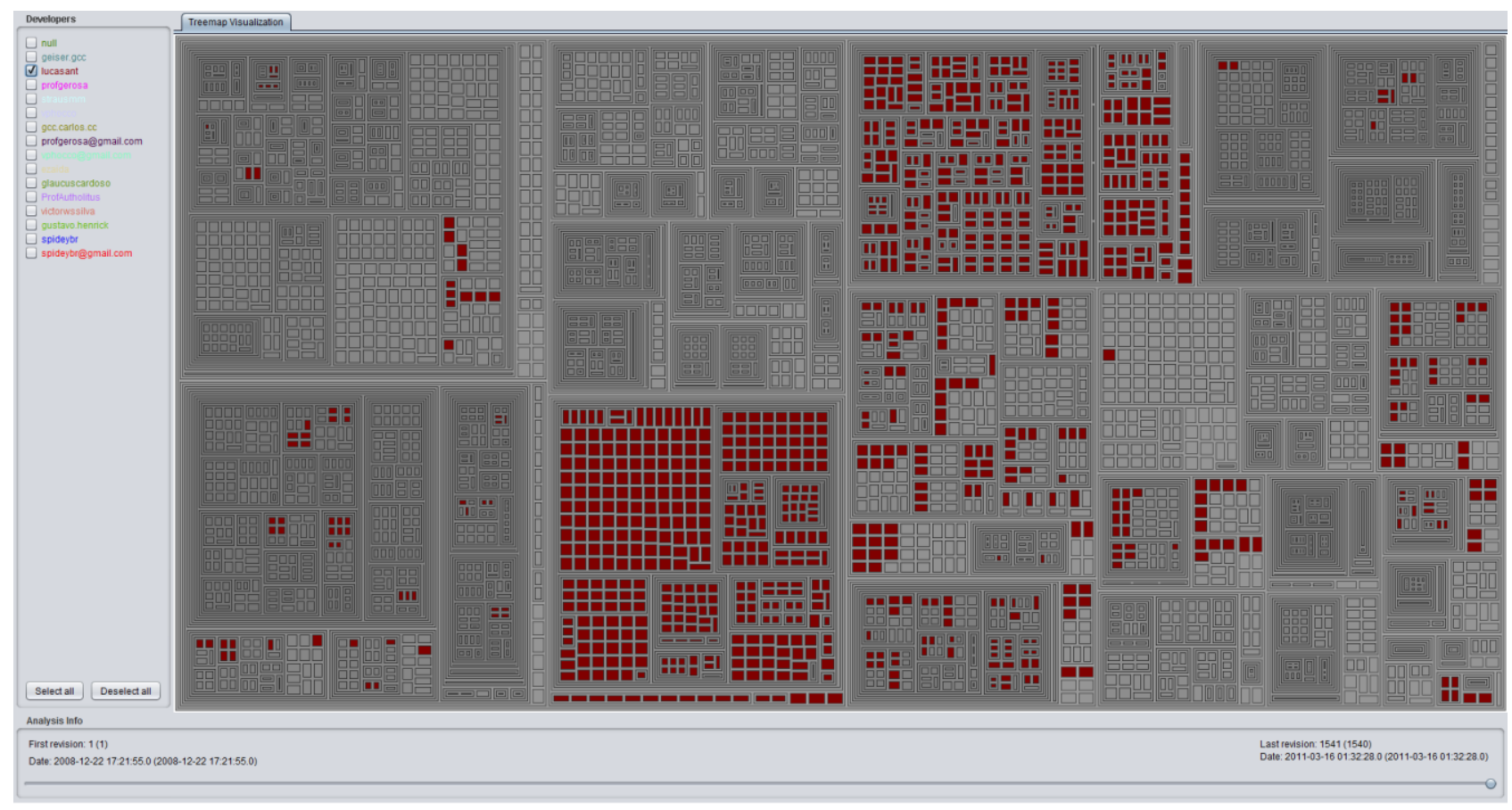

Figura 55: Visualização treemap na XFlow

Por fim, a visualização de atividade (v) é composta por um gráfico de barras e um gráfico de área empilhada, sendo que ambos fazem uso de cores para distinguir desenvolvedores (Figura 56). O gráfico de barras representa o período de contribuição dos desenvolvedores, enquanto que o outro gráfico apresenta o grau de contribuição dos desenvolvedores na forma de uma métrica (v.g. número de commits por mês ou número de artefatos modificados por semana), sendo o respectivo valor indicado pela área no gráfico.

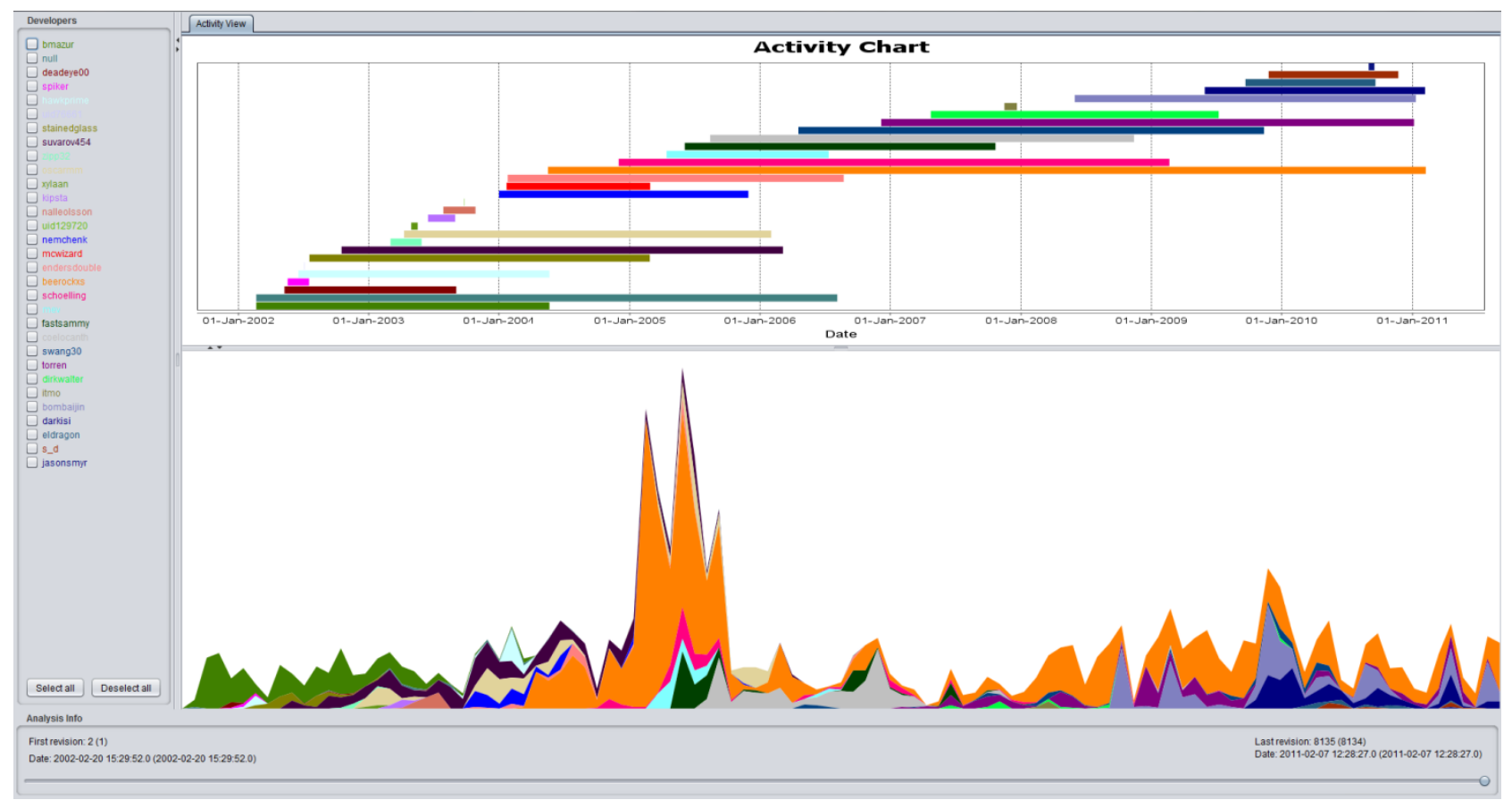

Figura 56: Visualização de atividade na XFlow 


\subsubsection{Caracterização}

Kagdi et al. [KCM07] elaboraram uma taxonomia de quatro camadas para caracterizar abordagens de MSR no contexto de Evolução de Software (Figura 57). Ainda, os autores defendem que tal taxonomia é suficientemente expressiva e efetiva. A primeira camada (evolução de software) diz respeito aos objetos de estudo típicos em investigações MSR: características das mudanças de propriedades de alto nível de um sistema de software, mudanças detalhadas nos próprios artefatos ou ambos. A segunda camada (propósito) envolve o tipo das questões respondidas por tais estudos. Tais questões podem ser do tipo (i) questões cesto-de-compra (por exemplo, se A ocorre, então o que mais ocorre regularmente?) e (ii) questões de prevalência (por exemplo, quantas vezes A foi modificado ao longo dos últimos 2 anos de desenvolvimento?). A camada 3 (representação) se refere ao tipo (por exemplo, físico) e granularidade (por exemplo, sistema, módulos, classes) dos objetos de estudo. A última camada retrata as fontes de informação (artefatos, diferenças entre artefatos, meta-dados) que estão prontamente disponíveis nos repositórios, assim como aquelas que precisam tornar-se disponíveis para dar suporte ao estudo de MSR.

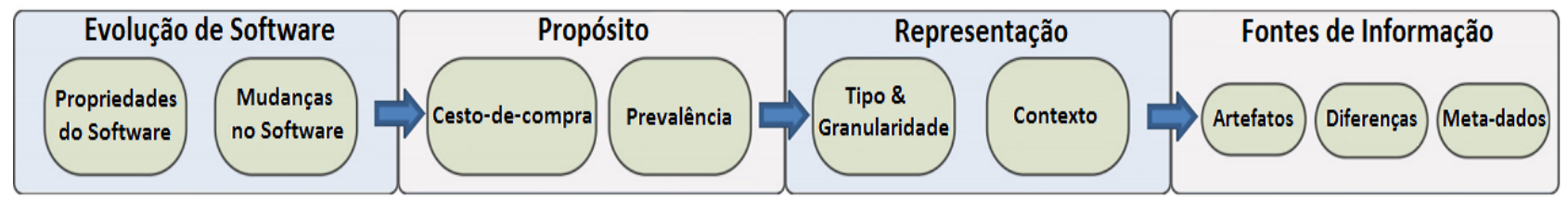

Figura 57: Taxonomia para abordagens de MSR (adaptada de [KCM07])

Com relação à primeira camada, a XFlow dá suporte a análises de propriedades de alto nível e também de mudanças detalhadas em artefatos. De modo similar, os propósitos da XFlow englobam ambas as questões de cesta-de-mercado (detecção e visualização de dependências lógicas) e de prevalência (por exemplo, número de máximo de linhas de código adicionadas em um arquivo dentre todos os arquivos de todos os commits). Embora a XFlow minere o SVN, o qual é limitado a uma representação de nível físico do código fonte (como arquivo e número de linhas), ela representa as informações em termos de arquivos e desenvolvedores. Finalmente, a XFlow opera diretamente sobre código e também sobre meta-dados obtidos a partir de logs de commits.

\subsection{Exemplos de Uso}

Nas subseções seguintes, descrevemos dois exemplos de uso da XFlow. No primeiro, avaliamos os efeitos da arquitetura sobre desenvolvedores e, no segundo, investigamos os papéis de desenvolvedores ao longo de um projeto. Ambas as análises são fundamentadas nas dependências lógicas existentes entre os artefatos de código.

\subsubsection{Efeitos da Arquitetura sobre Desenvolvedores}

A ferramenta XFlow prove diferentes maneiras de investigar a correlação entre a arquitetura do software e seus efeitos sobre desenvolvedores. Por meio da visualização de grafo da XFlow, nós tratamos a seguinte questão: como um sistema de software cresce para acomodar novos recursos? 
A Figura 58 ilustra o grafo de dependências lógicas dos artefatos do Apache Lucene (A), bem como os requisitos de coordenação entre desenvolvedores (B). É notório que ambos os grafos são bastante densos, o que indica não só uma arquitetura altamente acoplada, como também uma grande necessidade de coordenação entre os desenvolvedores do projeto. A Figura 59 ilustra, por sua vez, o grafo de dependência dos artefatos do jEdit (A), bem como os requisitos de coordenação entre desenvolvedores (B). Nesse caso, o grafo de dependências é também denso (embora um pouco menos do que aquele do Lucene). Porém, curiosamente, os requisitos de coordenação são mostrados como um grafo desconectado, o que sugere que os desenvolvedores do jEdit são especialistas em módulos específicos ou pequeno conjunto de artefatos.
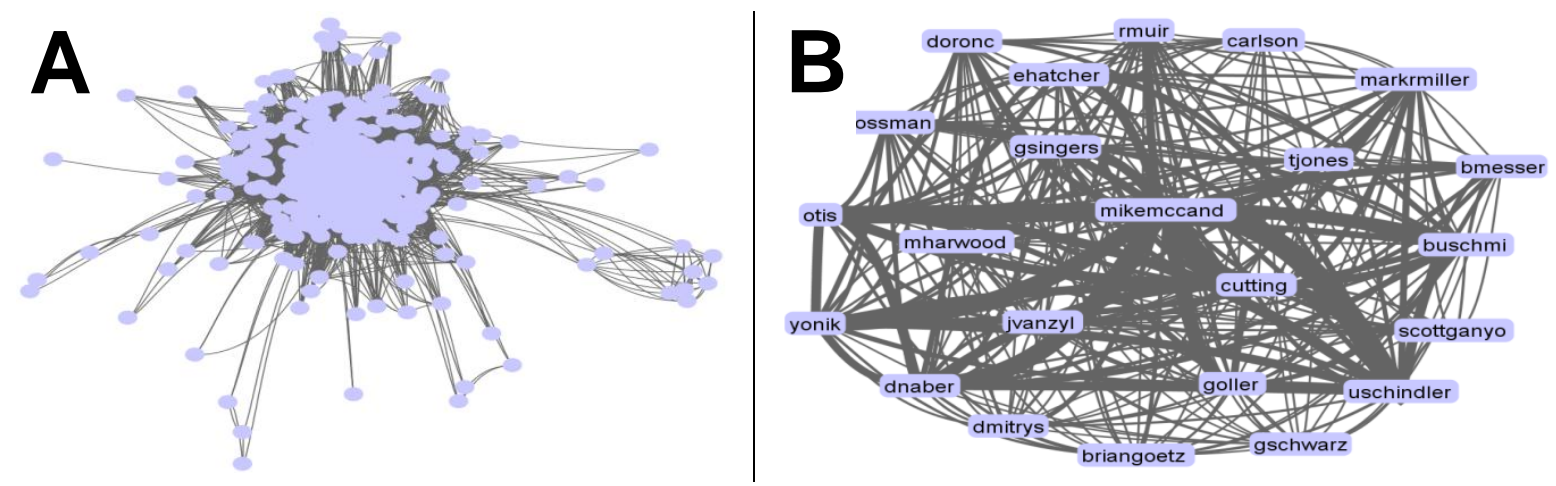

Figura 58: Grafo de dependências (A) e requisitos de coordenação (B) do Apache Lucene
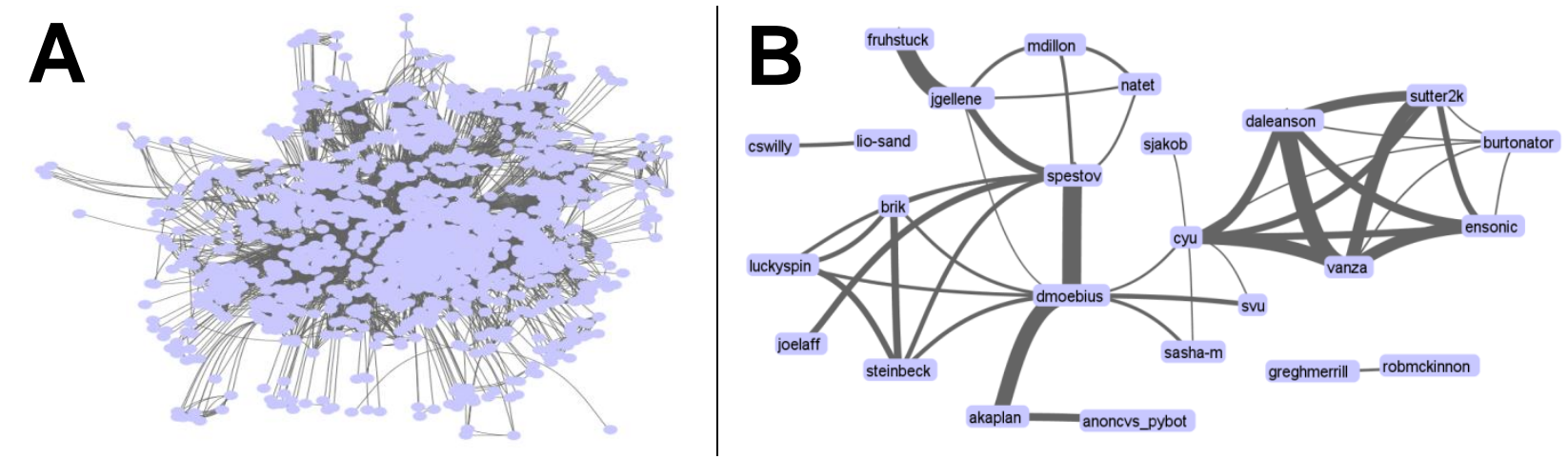

Figura 59: Grafo de dependências (A) e requisitos de coordenação (B) do jEdit

Nós acreditamos que uma investigação mais profunda acerca das diferenças entre o Lucene e o jEdit possa ajudar pesquisadores em Engenharia de Software a compreenderem melhor o design de sistemas modulares e seus requisitos de coordenação associados.

\subsubsection{Compreendendo o Papel de Desenvolvedores}

Escolhemos o projeto de software livre jEdit para a demonstração das perspectivas de análise oferecidas pela XFlow. O jEdit é um editor de textos multiplataforma destinado a programadores e disponível sob licença GPL. O software é escrito em Java e tem como diferencial sua arquitetura baseada em plugins, existindo dezenas deles para várias áreas de atuação. Mais informações estão disponíveis no sítio http://www.jedit.org.

$\mathrm{Na}$ fase de coleta, recuperamos 10895 commits do projeto jEdit, o que compreende um período de aproximadamente 6 anos e meio de desenvolvimento (Janeiro de 2000 até Julho 2007) e envolve 88 desenvolvedores. Na fase de processamento, consideramos apenas arquivos com extensão Java e excluímos commits com mais de 35 arquivos (commits outliers segundo análise de quartis). 
Finalmente, esses dados foram processados para que fossem identificadas dependências lógicas entre esses arquivos. De posse dessas informações, analisamos a contribuição de três desenvolvedores $k_{\_}$satoda, jgellene e orutherfurd ao longo do projeto.

Tradicionalmente, as ferramentas para estudo de evolução de software implementam a visualização de grafos. A Figura 60 e a Figura 61 exibem o grafo de requisitos de coordenação entre os desenvolvedores [CWHC06]. O núcleo da rede destacado na Figura 60 se refere aos desenvolvedores que possuem maiores requisitos de coordenação (estão ligados com mais desenvolvedores). Uma análise visual baseada tão somente nesses grafos pode induzir o pesquisador a concluir que os três desenvolvedores em destaque na Figura 61 são centrais para o projeto, uma vez que eles ocupam posições no núcleo da rede de coordenação representada.

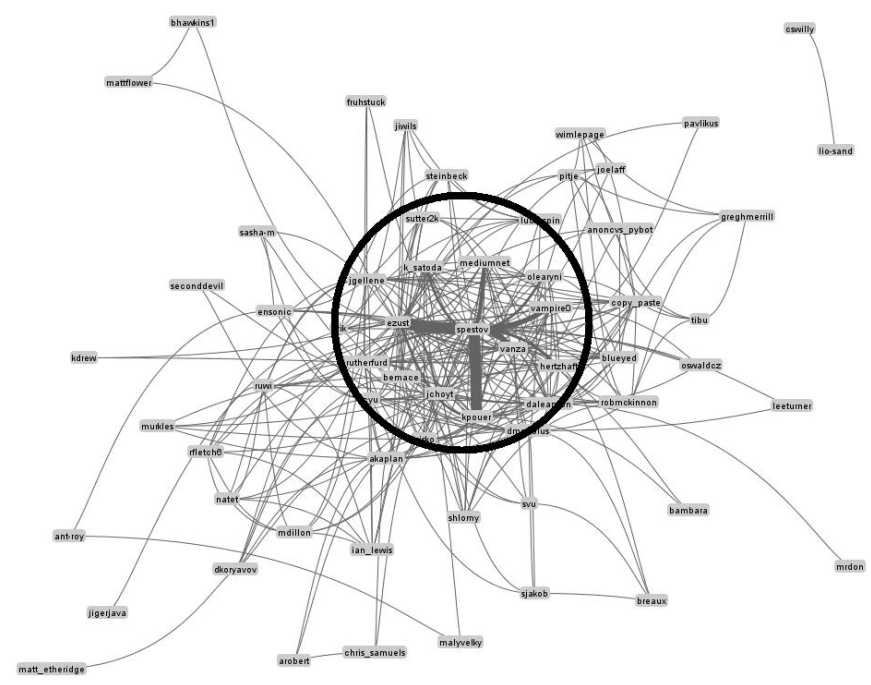

Figura 60: Requisitos de coordenação entre desenvolvedores (destaque no núcleo da rede)

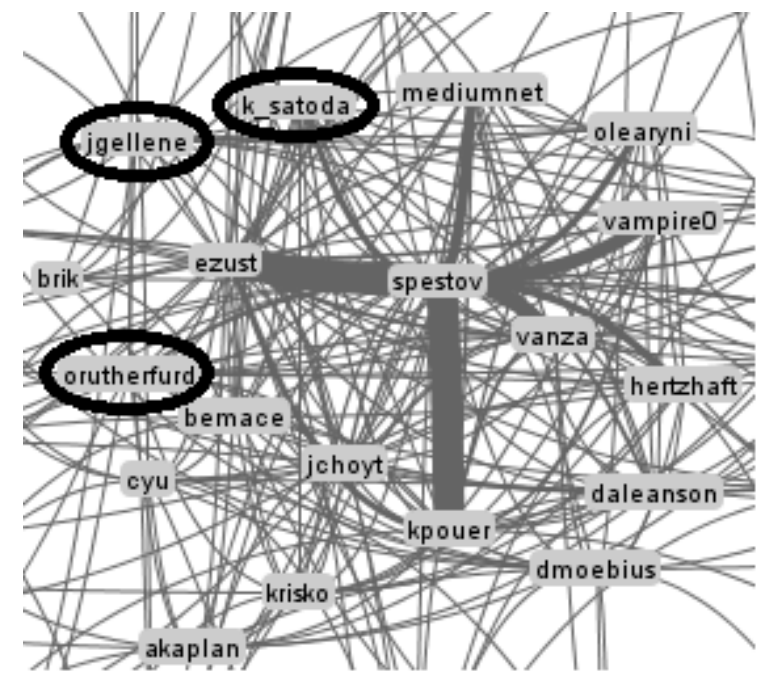

Figura 61: Foco nos desenvolvedores analisados

A fim de melhor investigar esse fenômeno, utilizamos a visualização de dispersão. A visualização de dispersão se apoia na métrica de centralidade de grau (degree centrality) de arquivos, sendo que o valor do grau é dado em termos das dependências lógicas entre tais arquivos. A Figura 62 exibe a centralidade máxima atingida por cada desenvolvedor em cada commit, enquanto a Figura 63 exibe o valor máximo de centralidade atingido por cada desenvolvedor dentre todas as suas contribuições ao longo do tempo.

A curva traçada não representa um desenvolvedor em particular, mas sim valores de referência da métrica observada, isto é, os valores máximos da centralidade dentre as contribuições de todos os desenvolvedores. Com base nessas duas últimas imagens, verificamos que o desenvolvedor jgellene lida apenas com arquivos periféricos. O desenvolvedor oruthefurd, por sua vez, faz apenas um commit que envolve arquivos do núcleo do projeto. No restante do tempo, ele também lida apenas com arquivos periféricos. Por fim, notamos que apenas o desenvolvedor k_satoda lida com alguma frequência com arquivos centrais. Em particular, dentre todos os desenvolvedores observados, ele é o único a atingir arquivos com centralidade máxima em algumas de suas contribuições (Figura 63). 


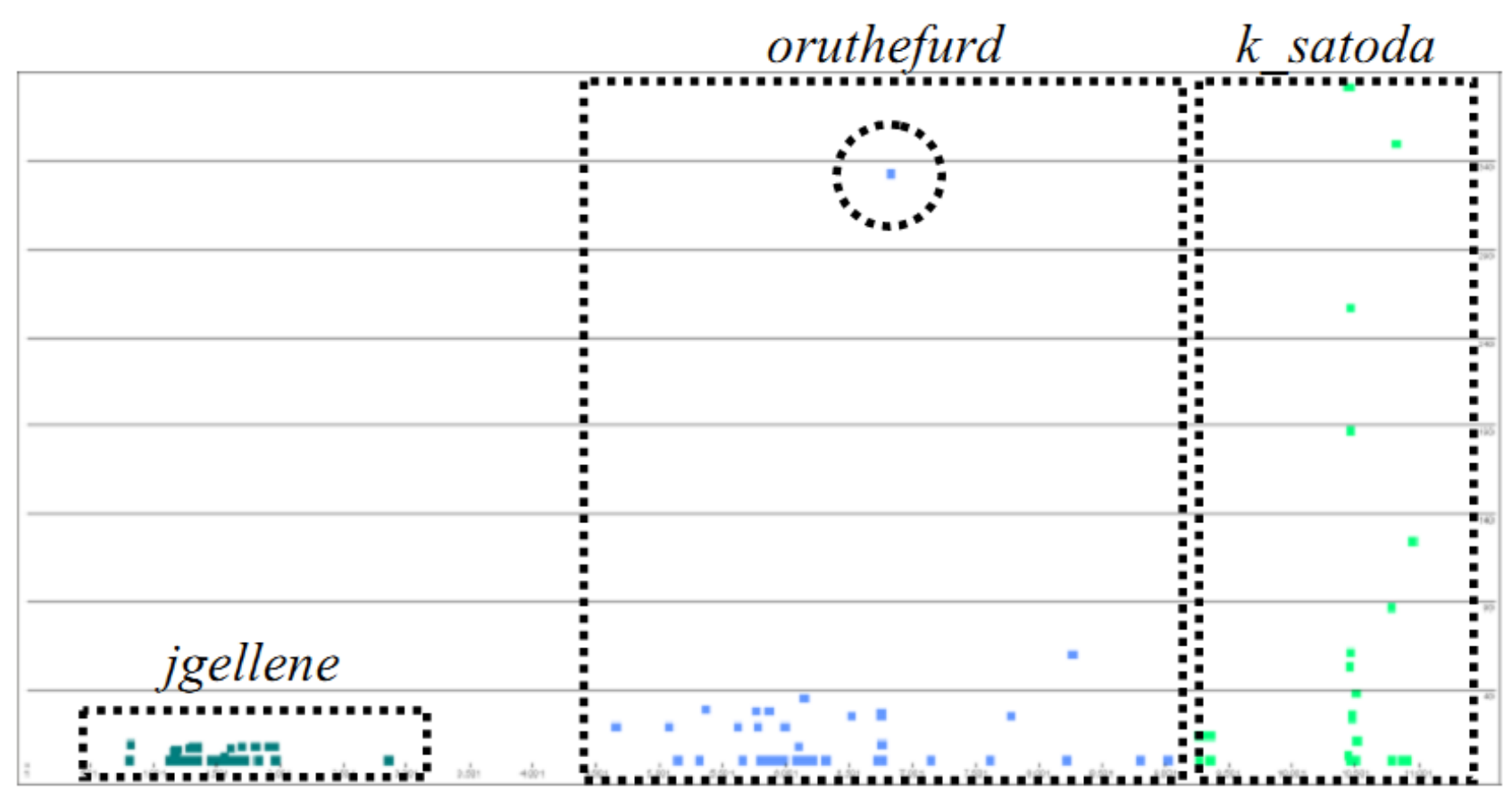

Figura 62: Visualização de dispersão (máxima centralidade na revisão)

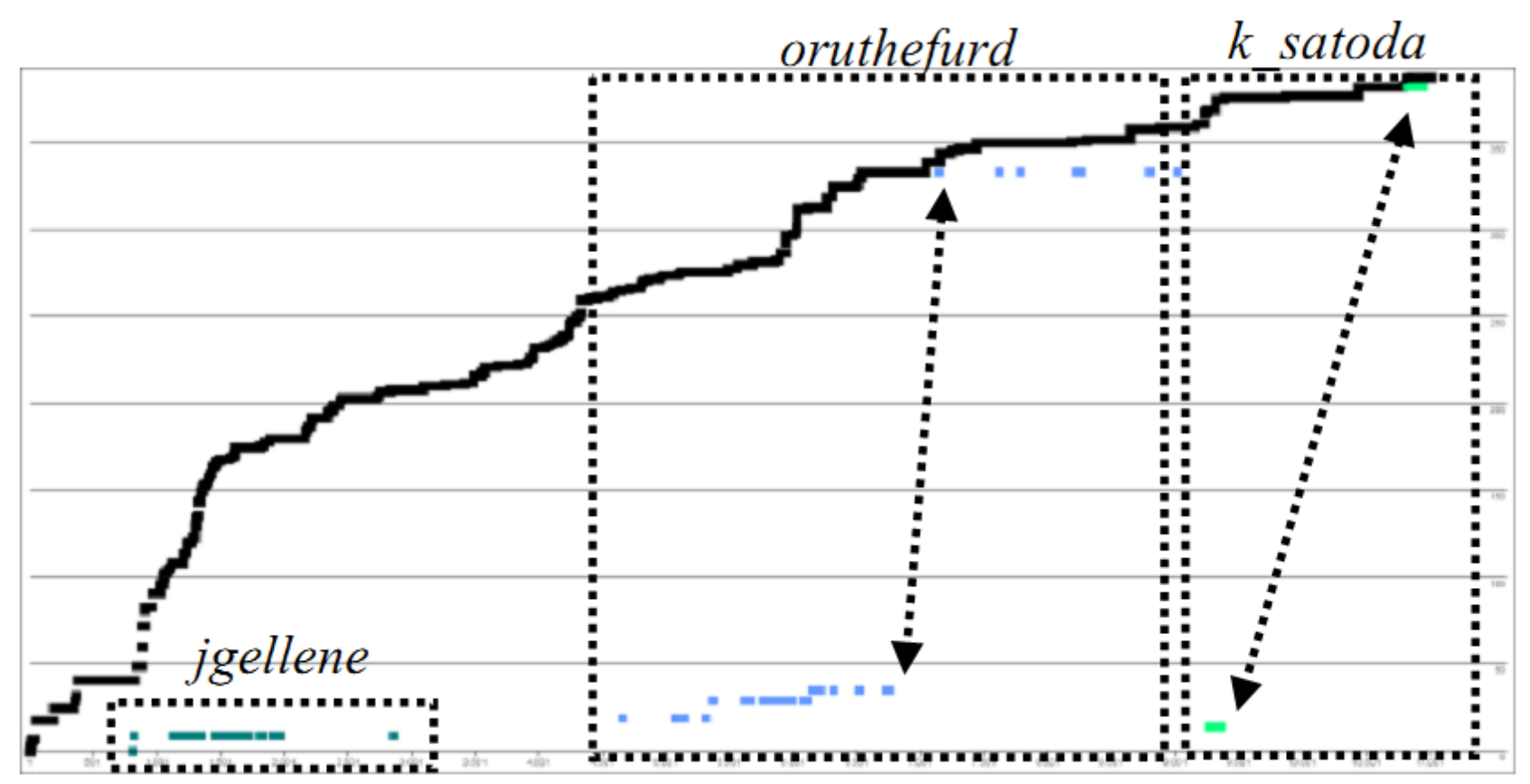

Figura 63: Visualização de dispersão (máxima centralidade "até então")

Embora o diagrama de dispersão seja esclarecedor, ele não fornece informações temporais acerca da participação dos desenvolvedores no projeto. Para esse fim, utilizamos a visualização de atividade (Figura 64). Por meio dessa visualização, verificamos que oruthefurd permaneceu por

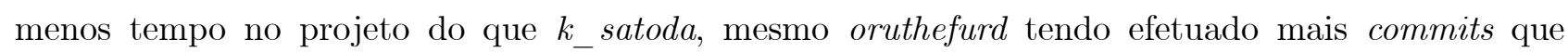
$k_{\text {_satoda. }}$ 


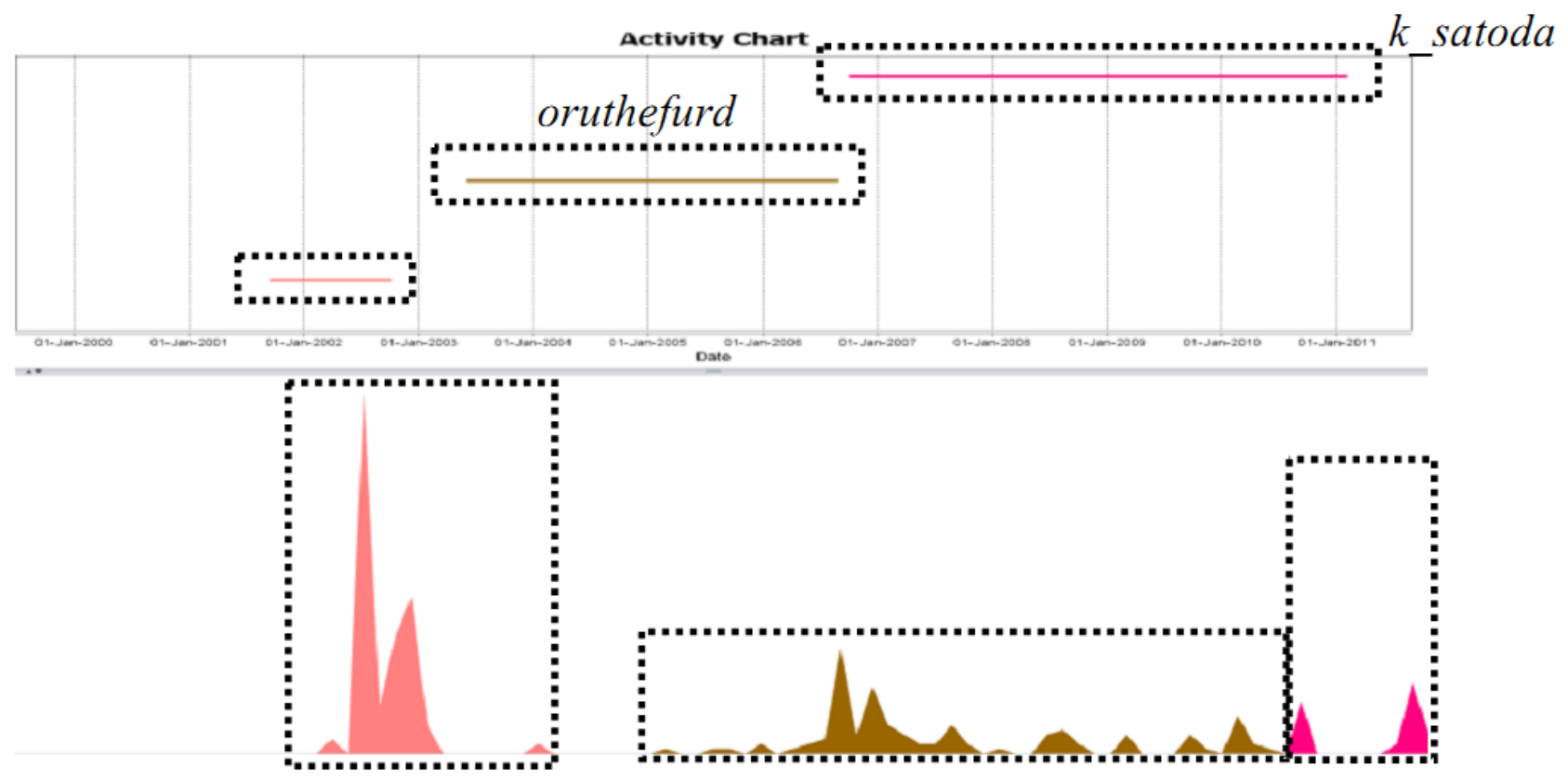

Figura 64: Visualização de atividade

Portanto, utilizando mecanismos de visualização de dependências e outros recursos oferecidos pela XFlow, pudemos melhor compreender o papel de três desenvolvedores específicos ao longo de todo o projeto. 


\section{Capítulo 8 Conclusão}

A gerência de dependências entre classes e módulos em sistemas orientados a objetos envolve conhecimento de diversas áreas da Engenharia de Software, tais como: Evolução de Software, Visualização de Software, Métricas de Software, Engenharia Reversa e Reengenharia. Desse modo, elaborar uma abordagem eficaz para a gerência de dependências requer uma base conceitual complexa e ampla. Neste trabalho, investigamos as técnicas de identificação de dependências estruturais e lógicas. Em particular, por meio de um estudo de larga-escala, comparamos os conjuntos de dependências estruturais e lógicas. Em seguida, conduzimos um estudo de caso a fim de descobrir algumas das origens reais por detrás da formação de dependências lógicas. Após isso, investigamos as técnicas de visualização de dependências por meio de um levantamento das abordagens existentes na área. Por fim, com o apoio de uma ferramenta de visualização de dependências que desenvolvemos (XFlow), nós estudamos e discutimos alguns fenômenos sociotécnicos.

A seguir, apresentamos a lista de publicações resultante dos estudos conduzidos e as oportunidades de pesquisa que surgiram ao longo desta dissertação.

\subsection{Lista de Publicações}

- Oliva, G. A. ; GerosA, M. A. . On the Interplay between Structural and Logical Dependencies in Open-Source Software. In: II Congresso Brasileiro de Software - XXV Simpósio Brasileiro de Engenharia de Software (CBSoft 2011 - SBES), 2011, São Paulo. Proceedings of CBSoft 2011, 2011.

- Oliva, G. A. ; SAntAnA, F. W. ; GerosA, M. A. ; DE SOUZA, C. R. B. . Towards a Classification of Logical Dependencies Origins: A Case Study. In: 12th International Workshop on Principles on Software Evolution and 7th ERCIM Workshop on Software Evolution (IWPSE-EVOL 2011), 2011, Szeged, Hungary. Proceedings of IWPSE-EVOL 2011, 2011.

- SAntanA, F. W. ; Oliva, G. A. ; DE SOUZA, C. R. B. ; GEROSA, M. A. . Visualização da evolução de software com XFlow: Integrando aspectos técnicos e sociais em múltiplas visualizações. In: I Workshop Brasileiro de Visualização de Software (WBVS 2011), 2011, São Paulo - SP. 
- SAntanA, F. W. ; Oliva, G. A. ; DE SOUZA, C. R. B. ; GEROSA, M. A. . XFlow: An Extensible Tool for Empirical Analysis of Software Systems Evolution. In: VIII Experimental Software Engineering Latin American Workshop (ESELAW 2011), 2011, Rio de Janeiro - RJ. Proceedings ESELAW 2011, 2011.

- Oliva, G. A. ; GEROSA, M. A. . Gerência de Dependências entre Módulos em Sistemas de Software Orientados a Objeto. In: Workshop de teses e dissertações em Engenharia de Software (CBSOFT-SBES2010-WTES2010), 2010, Bahia. Proceedings of CBSoft 2010, 2010 .

\subsection{Oportunidades de Pesquisa}

Ao longo da produção dessa dissertação, identificamos uma série de oportunidades de pesquisa relativas à gerência de dependências. Dados os limites práticos de escopo e tempo, não pudemos explorá-las em profundidade. Listamos, a seguir, aquelas que julgamos mais relevantes:

- Outras formas de dependências

Ao longo do levantamento bibliográfico, encontramos outros tipos de dependência, a saber: dependências ocultas (hidden/data-flow dependencies) [VR10] e dependências conceituais (conceptual dependencies) [PM06], [GSW05], [GDK+07]. Investigar a relação destas dependências com as já estudadas deve dar origem a métodos e ferramentas mais eficazes para a gerência de dependências.

- "Maus cheiros" de design propostos por Robert Martin

Deteç̧ão algorítmica dos "maus cheiros" de design propostos por Robert Martin. Prova da hipótese de que "maus cheiros" de código derivam de "maus cheiros" de design;

- Um método para gerência de dependências

Elaboração de um método para gerência de dependências que possa ser incorporado como uma atividade no Processo Unificado (Larman, 2004). 


\section{Apêndice A}

\section{Design, Arquitetura e Implementação}

\section{A.1 Etimologia do Termo Design}

Design é um processo técnico e criativo relacionado à configuração, concepção, elaboração e especificação de um artefato. Tal processo normalmente é orientado por uma intenção ou objetivo, ou para a solução de um problema.

A origem imediata da palavra está na língua inglesa, na qual o substantivo design se refere tanto à ideia de plano, desígnio, intenção, quanto à de configuração, arranjo, estrutura. A origem mais remota da palavra está no latim designare, verbo que abrange os sentidos de designar e desenhar [Car08]. O termo em inglês é bastante abrangente, mas quando os profissionais o absorveram para o português, queriam designar somente a prática profissional do design. Era preciso, então, diferenciar design de drawing (ou seja, o projeto diferente do desenho), enfatizando que a profissão envolvia mais do que a mera representação dos elementos projetados. Na língua espanhola também há essa distinção: existem as palavras diseño (que se refere ao design) e dibujo (que se refere ao desenho).

Estudos etimológicos de Luiz Vidal Negreiros Gomes indicam que também na língua portuguesa existiam essas nuances de significado com as palavras "debuxo", "esboço" e outras denotando o mesmo que dibujo, e "desenho" comportando toda a riqueza de significados do diseño [Gom96], [GS97]. O arquiteto brasileiro João Batista Vilanova Artigas tentou resolver a questão propondo a palavra "desígnio" como sendo a tradução correta de design, pois dessa forma, apresentaria diferenças do simples desenho. Apesar de ser desenho, o design possuiria algo mais: uma intenção (ou desígnio) [Art04]. Entretanto, apesar das pesquisas realizadas pelo arquiteto, sua proposta não foi adotada. O filólogo Antônio Houaiss tentou solucionar o impasse propondo o neologismo "projética", mas também não obteve êxito [Str10].

Dado esse problema etimológico e o risco de mal-entendimento, decidimos não traduzir o termo "design" ao longo deste trabalho. Vamos nos valer da semântica que o termo em inglês oferece.

\section{A.2 Distinção entre Arquitetura, Design e Implementação}

A falta de uma clara distinção entre os termos "arquitetura" (design estratégico), "design" (design tático) e "implementação" é causa de muitos pensamentos confusos, comunicação imprecisa e esforços sobrepostos e desperdiçados. O uso inconsistente e informal desses termos sugere que qualquer distinção, se existir, é meramente uma questão de escala. Assim, os termos acabam por 
descrever um continuum de afirmações a respeito de design de software que se estendem de descrições que não proveem informação sobre o programa (a mais "abstrata") até o próprio programa em si (o código-fonte). A Figura 65 ilustra essa intuição.

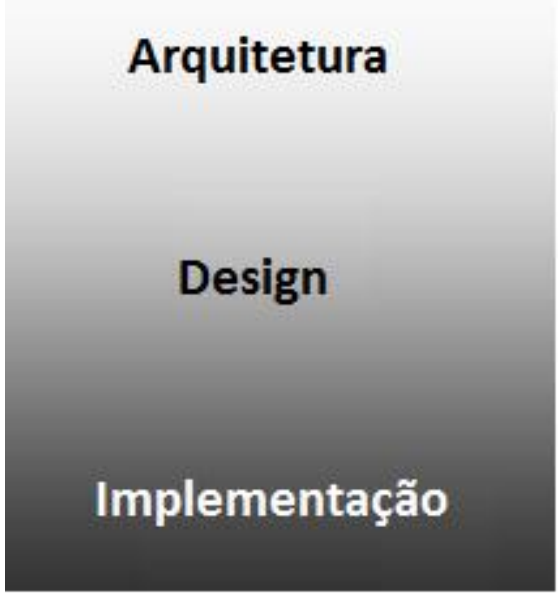

Figura 65: Noção informal dos termos 'arquitetura', 'design' e 'implementação' [EHK06]

De modo a elucidar a relação entre especificações de arquitetura, design e implementação, estudos conduzidos no SEI deram origem à Hipótese da Intenção/Localidade [EHK06], sumarizada na Tabela 13. A hipótese é baseada em duas interpretações para o conceito de abstração:

- Intencional (vs. extensional): especificações são "abstratas" no sentido de que podem ser formalmente caracterizadas pelo uso de variáveis lógicas que variam ao longo de um domínio ilimitado.

- Não-local (vs. local): especificações são "abstratas" no sentido de que se aplicam a todas as partes do sistema.

\begin{tabular}{ccc}
\hline Arquitetura & Intencional & Não-local \\
Design & Intencional & Local \\
Implementação & Extensional & Local \\
\hline
\end{tabular}

Tabela 13: Hipótese da Intenção/Localidade ${ }^{17}$

Considere, por exemplo, o estilo "arquitetura em camadas" descrito por Garlan e Shaw: "Um sistema em camadas é organizado hierarquicamente, de modo que cada camada provê serviço para a camada superior e se apresenta como cliente para a camada inferior" [GS92]. A definição pode ser formalizada por meio do cálculo de predicados de primeira ordem como:

(i) $\quad \forall e \exists ! k \in\{\mathbb{N}\} \bullet$ Layer $(e)=k$

(isto é, cada elemento é definido em exatamente uma camada) e

(ii) $\quad \forall x, y \bullet \operatorname{Depends}(x, y) \Rightarrow$ Layer $(x) \geq \operatorname{Layer}(y)$

(isto é, a definição de cada elemento pode depender somente de definições na mesma camada ou em camadas inferiores).

\footnotetext{
${ }^{17}$ Tabela extraída de http://www.sei.cmu.edu/library/abstracts/news-at-sei/architect1q03.cfm
} 
É evidente que um número ilimitado de programas podem satisfazer (i) e (ii) simultaneamente, portanto a especificação é intencional. Para provar que a especificação é nãolocal, considere uma violação do estilo, em que a definição de um elemento depende da definição de outro elemento situado em uma camada superior. Uma vez que isso seria uma violação independentemente de onde ocorresse, então a especificação é não-local.

A Figura 66 ilustra as implicações da Hipótese da Intenção/Localidade observadas pelos autores e a Tabela 14 sumariza as evidências que corroboram a hipótese. As provas referentes às evidências estão disponíveis em [EHK06].

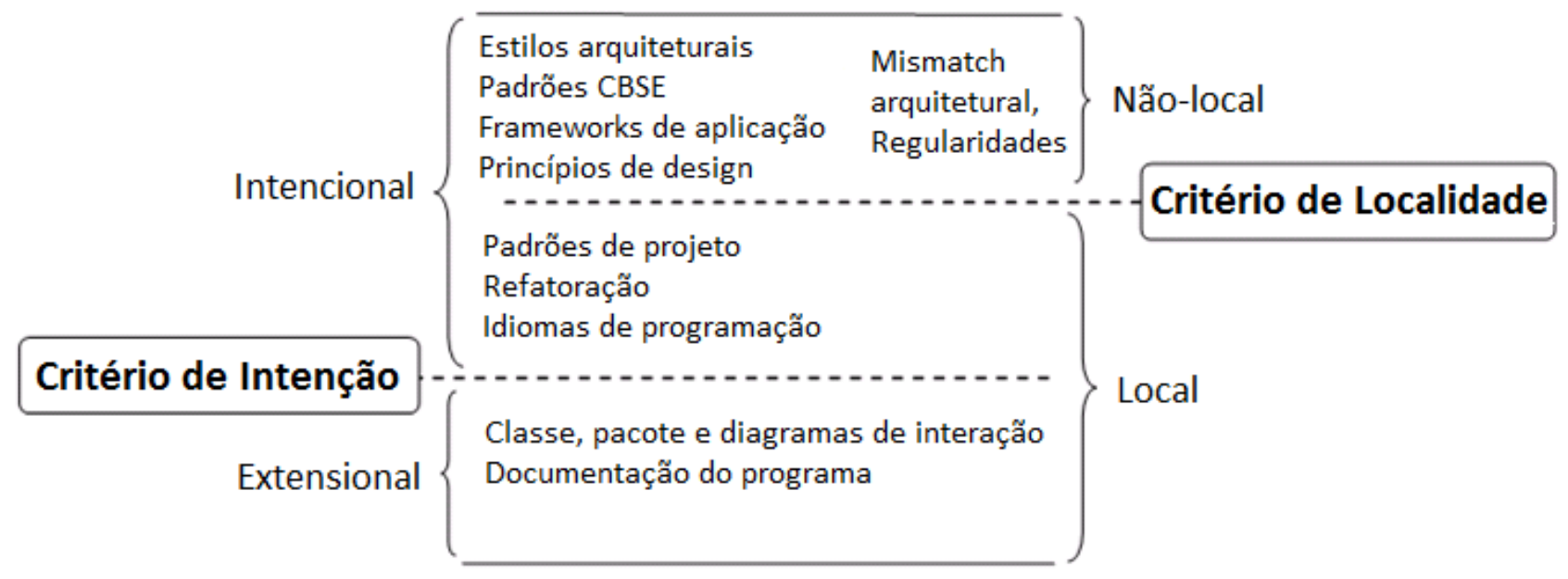

Figura 66: Implicações da Hipótese da Intenção/Localidade [EHK06] 


\begin{tabular}{|c|c|}
\hline \multicolumn{2}{|c|}{ Declarações não-locais (NL) } \\
\hline Paradigmas de programação & Ocultamento de informações (Information Hiding) \\
Axiomas de design orientado a objetos
\end{tabular}

Tabela 14: Evidências corroborando a Hipótese da Intenção/Localidade [EHK06]

Portanto, enquanto a arquitetura é um design estratégico, em que há preocupação com aspectos globais do sistema e paradigmas, o design é tático, detalhista e pontual. Segundo Booch, a arquitetura envolve um conjunto de decisões substanciais de projeto que dão forma ao sistema, restringindo seu design e sua construção, sendo que "substancial" é uma medida do custo da mudança ${ }^{18}$. A relação entre arquitetura e design é também verificada na definição simplista e pragmática dada por Eoin Woods ${ }^{19}$ : "arquitetura de software é o conjunto de decisões de design que, se feitas incorretamente, podem levar o projeto a ser cancelado".

\footnotetext{
${ }^{18}$ Extraído de http://www.handbookofsoftwarearchitecture.com/index.jsp?page=Blog\&part=2006

${ }^{19}$ Definição extraída de http://www.sei.cmu.edu/architecture/start/community.cfm
} 


\section{Apêndice B}

\section{Identificação de Dependências Estruturais em Código Java Compilado}

\section{B.1 Arquivos Java Class}

Para evitar ambiguidades e risco de mal entendimento, definimos um vocabulário específico para identificação de dependências em código Java. Utilizamos classe para designar tanto uma classe quanto uma interface Java, e método para referenciar tanto um método quanto um construtor Java. Dependências na forma de herança e implementação de interface são juntas referenciadas como dependências arquiteturais e todos os outros tipos de dependências são tratados como referências.

Arquivos class contêm estruturas que descrevem a classe, bem como bytecode de máquina virtual para os métodos da classe (Listagem 2). Esses arquivos foram concebidos para serem portáveis, de modo que podem ser movidos de um projeto para outro sem recompilação. Logo, arquivos class necessariamente armazenam toda a informação sobre dependências, pois compiladores Java não podem remover quaisquer dependências através de processos de otimização ${ }^{20}$.

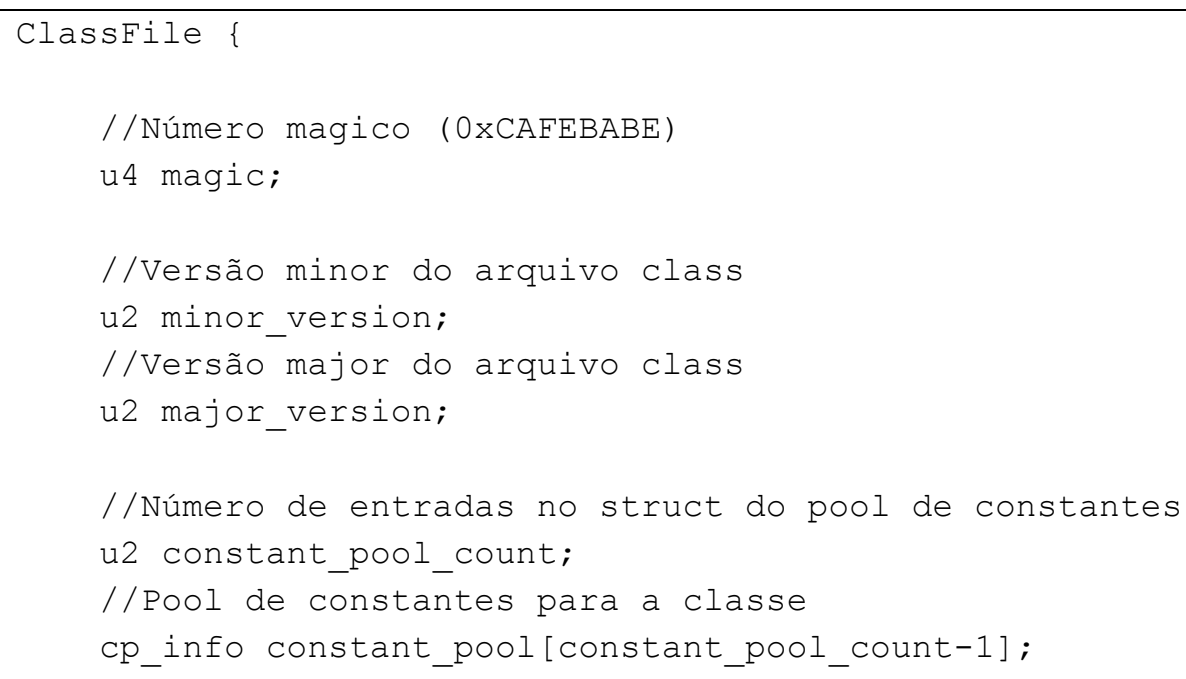

${ }^{20}$ Em Java, os processos de otimização ocorrem em tempo de execução. 


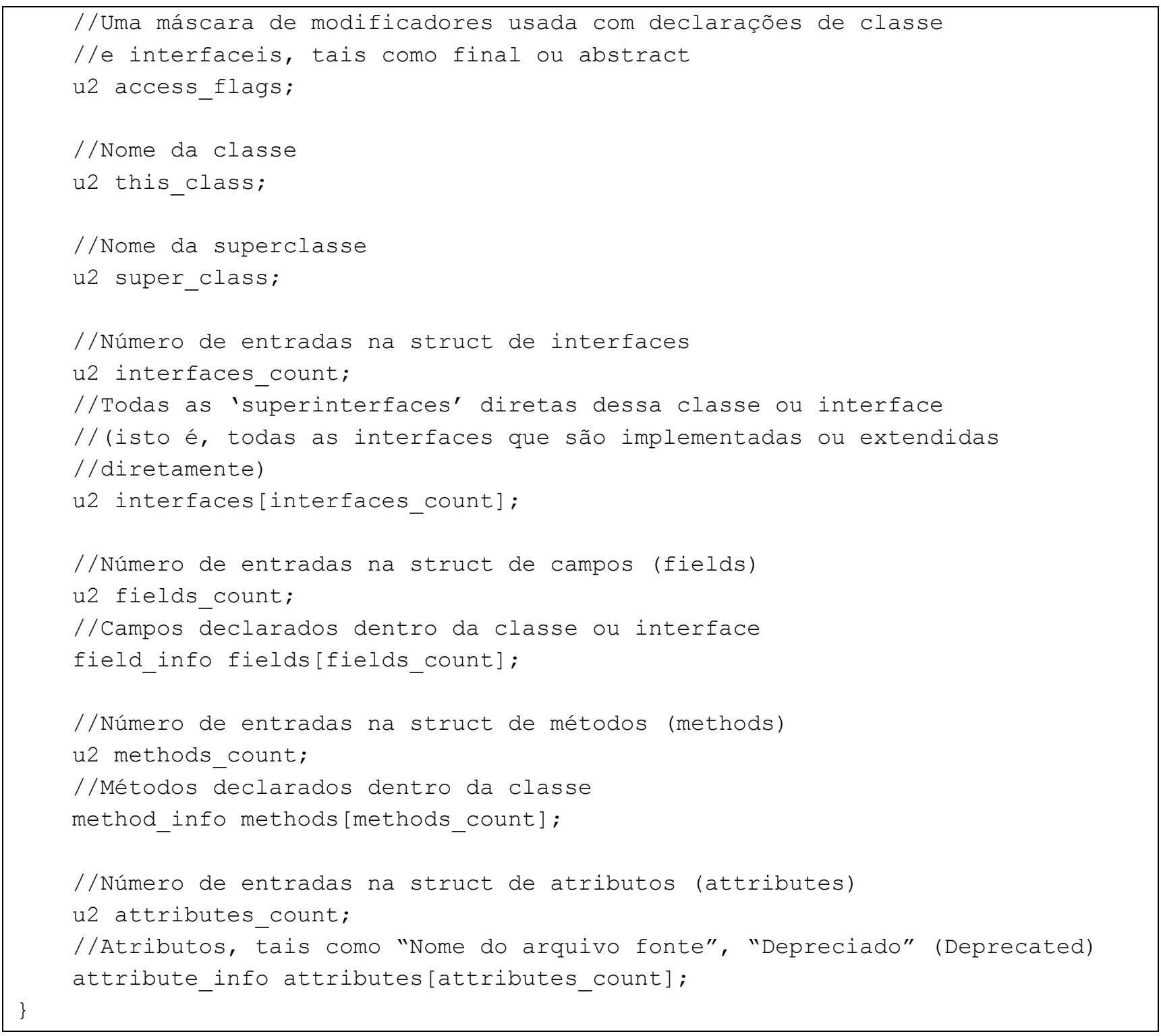

Listagem 2: Formato do arquivo class descrito por meio de pseudoestruturas $C$

O formato do bytecode Java está especificado em detalhes no livro Java Virtual Machine Specification $^{21}$. Ainda, a própria linguagem fornece classes convenientes para leitura do código objeto.

\section{B.2 Identificando Dados Brutos sobre Dependências}

Cada arquivo class contém uma referência para a superclasse (u2 super_class) ${ }^{22}$, assim como uma lista das interfaces implementadas (u2 interfaces []). Isso abrange a identificação de todas as dependências arquiteturais. As referências são encontradas no pool de constantes (cp_info constant_pool[]). Esta estrutura contém representações de, entre outras coisas, classes, métodos e campos externos que podem ser usados pela classe. De maneira prática, pode-se assumir que qualquer classe, método ou campo no pool de constantes é utilizado pela classe e representa uma

${ }^{21}$ Disponível online em http://java.sun.com/docs/books/jvms/

${ }^{22} \mathrm{O}$ valor de super_class nunca é zero, exceto para a classe object 
dependência. A tabela de campos (field_info fields[]) pode ser utilizada para distinguir associações de outras referências. A tabela de métodos (method_info methods[]) contém uma representação de cada método, incluindo o seu respectivo bytecode. A localização de uma dependência no código-fonte (número da linha) ocorre através da análise sintática do bytecode.

\section{B.3 Implementação com Dependency Finder}

Dependency Finder é uma ferramenta capaz de identificar dependências a partir de bytecode. Arquivos JAR, arquivos ZIP ou arquivos class servem como entrada. A ferramenta varre os arquivos das classes e coleta as dependências montando um grafo de dependências (Figura 67). Esse grafo revela uma abordagem menos abstrata que o usual, pois considera dependências entre features de classes. O termo feature é usado para designar atributos, construtores e métodos da classe, sendo que a ferramenta não faz distinção entre eles.

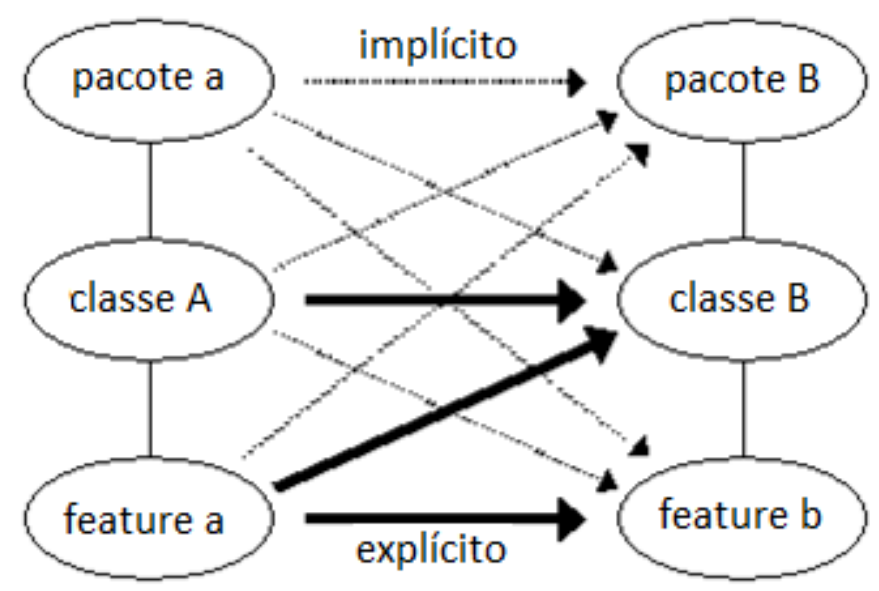

Figura 67: Grafo de dependências do Dependency Finder

A ferramenta começa com um nó por pacote Java. Em seguida é adicionado um nó por classe Java (incluindo inner classes) e depois um nó para cada feature de cada classe. São definidos dois tipos de arestas para esse grafo: composição e dependência. Composição ocorre entre o pacote e suas respectivas classes e entre classes e suas features. O segundo tipo de aresta ocorre em três situações: dependência de classe para classe (por exemplo, quando uma classe A herda de outra classe B), dependência de feature para classe (por exemplo, quando uma classe A tem um atributo cujo tipo é outra classe) e dependência de feature para feature (por exemplo, quando um método de uma classe A invoca um método de uma classe B).

A partir da detecção dessas dependências, a aplicação infere dependências implícitas entre os nós dos grafos. Por exemplo, uma dependência entre classes de diferentes pacotes implica em uma dependência implícita entre os seus respectivos pacotes. A ferramenta não captura informações sobre o tipo de dependência e nem sobre os pesos das dependências. 


\section{Apêndice C}

\section{Ferramentas para Dependências Estruturais}

\section{C.1 Structural Analysis for Java (SA4J)}

Structural Analysis for Java é resultado de um projeto de pesquisa da IBM sobre análise de dependências estruturais em aplicativos Java (Figura 68). A ferramenta é autônoma (standalone) e de código fechado, porém é gratuita e roda em diversas versões dos sistemas operacionais Microsoft Windows, Linux e Solaris.

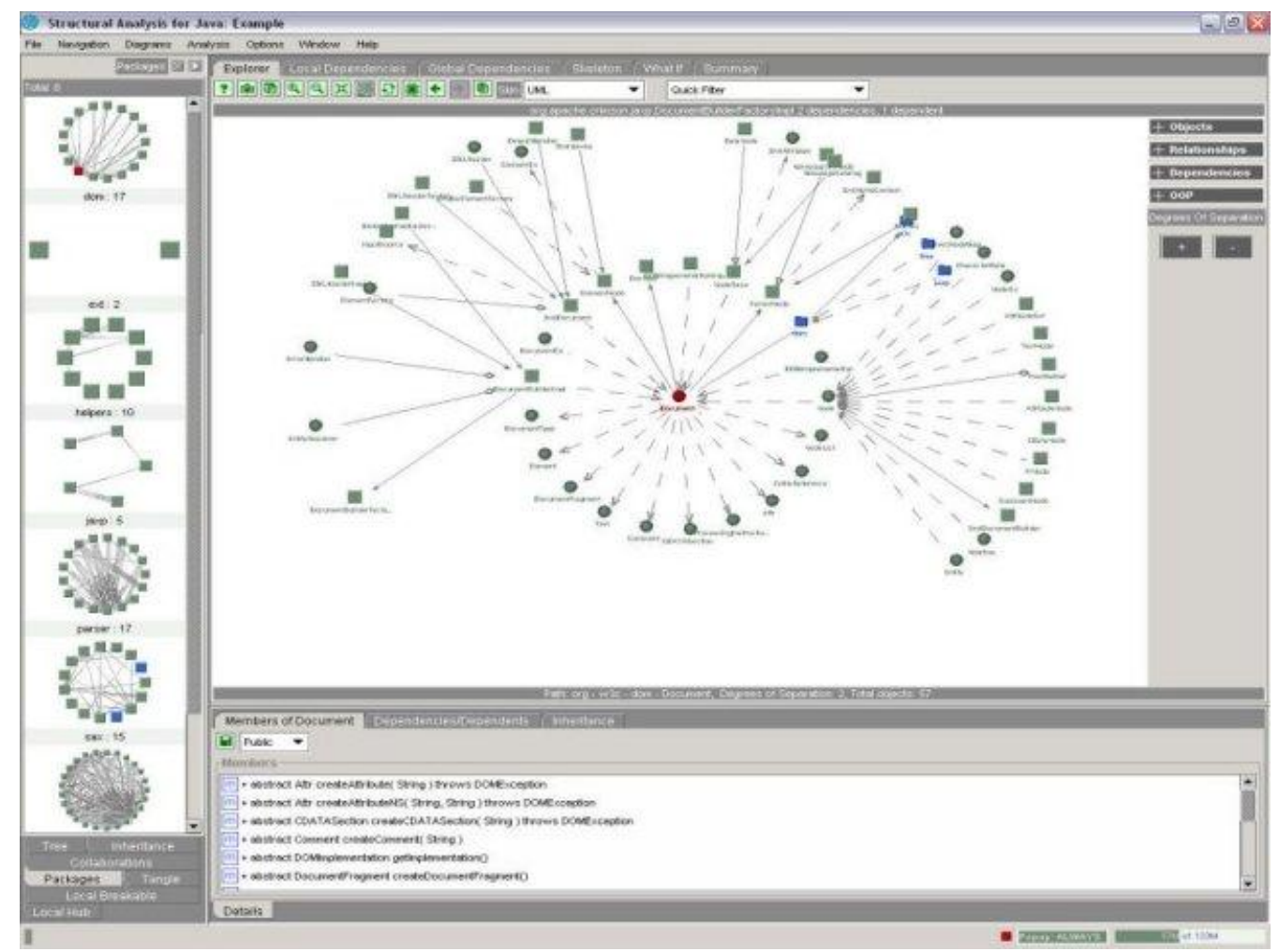

Figura 68: Structural Analysis for Java (SA4J)

A ferramenta analisa as dependências estruturais de aplicativos Java com o objetivo de medir a estabilidade deles, detecta antipadrões e provê navegação no grafo de dependências para exploração detalhada desses antipadrões e oferece dois mecanismos alternativos de análise visual chamados skeleton view e what if analysis (detalhados no Capítulo 6), que têm por objetivo avaliar o impacto de mudanças na estrutura da aplicação. SA4J também calcula a métrica de estabilidade de pacotes definida por Robert Martin [MM06]. Por fim, a ferramenta gera um relatório sumarizado em que são informadas a estabilidade arquitetural, as classes envolvidas em antipadrões 
estruturais e algumas estatísticas, como o número médio de classes afetadas pela modificação em uma classe qualquer.

O desenvolvimento do SA4J foi descontinuado por falta de orçamento e algumas de suas funcionalidades foram migradas para os ambientes de desenvolvimento integrados IBM Rational Application Developer (IBM RAD) e IBM Rational Software Architect (IBM RSA), ambos baseados na plataforma Eclipse.

\section{C.2 Structure 101 (S101)}

Structure 101 é uma ferramenta comercial de código fechado da empresa Headway que extrai informações de projetos Java, .NET e C/C ++ a partir da investigação do código compilado, possibilitando que a arquitetura do software e a complexidade estrutural sejam controladas (Figura 69). A empresa conta com um conjunto grande de clientes de renome, como IBM, Cisco, GE e Nasa. No sítio oficial, há uma afirmação de Kent Beck dizendo que utiliza a ferramenta quando ele quer entender a estrutura global de um sistema e avaliar potenciais mudanças.

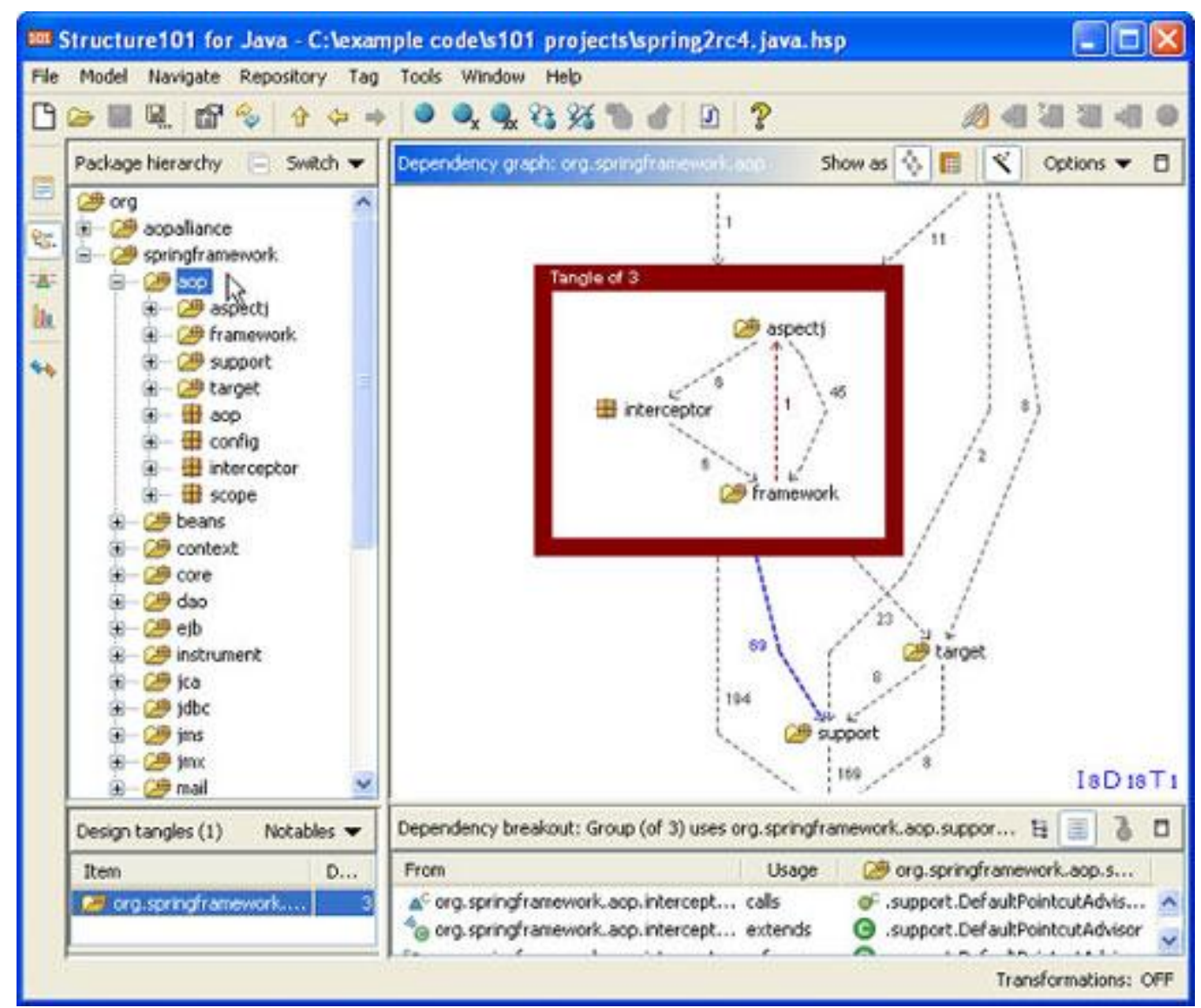

Figura 69: Structure101 for Java (S101)

O aplicativo é dividido em três componentes. O primeiro é um aplicativo baseado na plataforma Eclipse que possibilita principalmente visualizar a estrutura de um aplicativo alvo através de diagramas e relatórios. Esse aplicativo inclui ainda um arcabouço chamado de $X S$ (derivado do inglês excess) para medir complexidade estrutural excessiva O segundo é um plugin para os ambientes de desenvolvimento integrado Eclipse (Java), IntelliJ (Java) e Visual Studio (.NET) que provê alertas sobre quaisquer violações arquiteturais realizadas enquanto o código é 
escrito e manipulado. Por fim, o terceiro componente é uma aplicação web que provê um gerador de relatórios (com suporte $R S S$ ) e que possibilita acesso remoto ao repositório via HTTP.

\section{C.3 SonarJ}

SonarJ é uma ferramenta comercial de gerência de arquitetura para aplicativos Java construída pela empresa Hello2Morrow e que roda em sistemas operacionais Microsoft Windows, MacOS X e Linux (Figura 70). Em 2007, a ferramenta recebeu o prêmio de segundo lugar no JAX Innovation Award e foi indicada para a premiação da ICT (Information and Communication Technologies) européia ${ }^{23}$. O SonarJ é disponibilizado gratuitamente para análise de aplicativos Java com até 50.000 instruções de bytecode (aproximadamente 20.000 linhas de código).

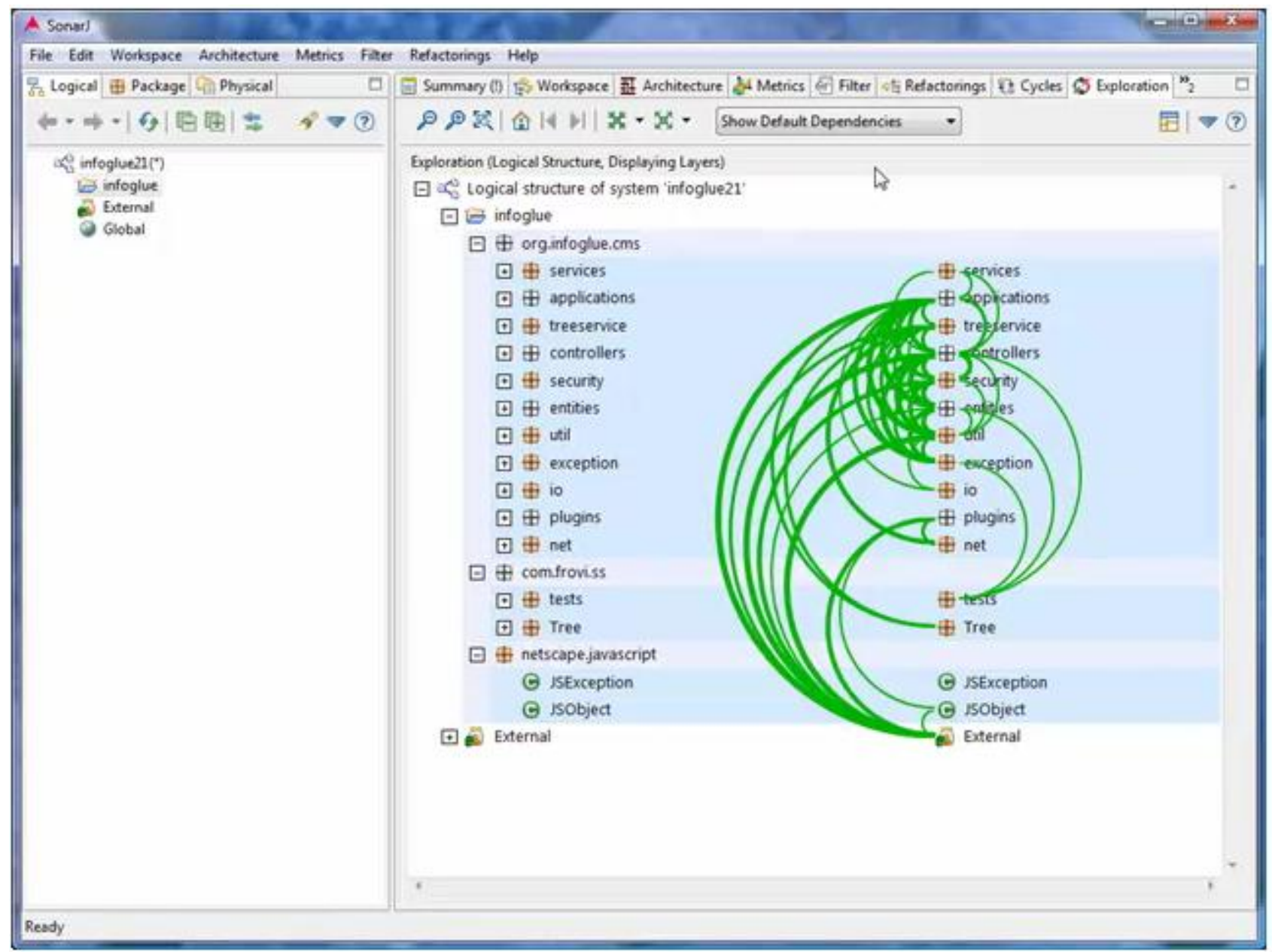

Figura 70: SonarJ

A ferramenta é autônoma, recebe como entrada código Java compilado e tem por objetivo principal detectar violações de restrições arquiteturais e dependências cíclicas. SonarJ conta ainda com um grande conjunto de métricas (acoplamento, coesão, estabilidade, complexidade ciclomática e outras) e possibilita que limiares sejam estabelecidos para todas elas Destaca-se o suporte da ferramenta para geração de relatórios com métricas e estatísticas do projeto através de uma tarefa

${ }^{23}$ http://www.hello2morrow.com/company/awards 
para a ferramenta $\mathrm{Ant}^{24}$ ou de um plugin para o Maven ${ }^{25}$. Dessa maneira, uma build do sistema pode ser invalidada caso limiares de uma determinada métrica não sejam satisfeitos. Juntamente com o SonarJ, é disponibilizada uma outra ferramenta chamada qatracker que extrai dados desses relatórios para criar gráficos com o histórico dos valores. A empresa disponibiliza ainda um plugin chamado Sonarclipse para o ambiente Eclipse a fim de verificar em tempo real se violações arquiteturais estão ocorrendo ou se o limiar de alguma métrica está sendo extrapolado.

\section{C.4 JDepend}

JDepend é uma ferramenta de código aberto com licença BSD (Berkeley Software Distribution) disponível para sistemas Microsoft Windows e Unix (bash) que percorre os diretórios do código-fonte da aplicação Java fornecida como entrada e gera métricas de qualidade de design para cada pacote em termos de extensibilidade, reusabilidade e gerenciabilidade (Figura 71).

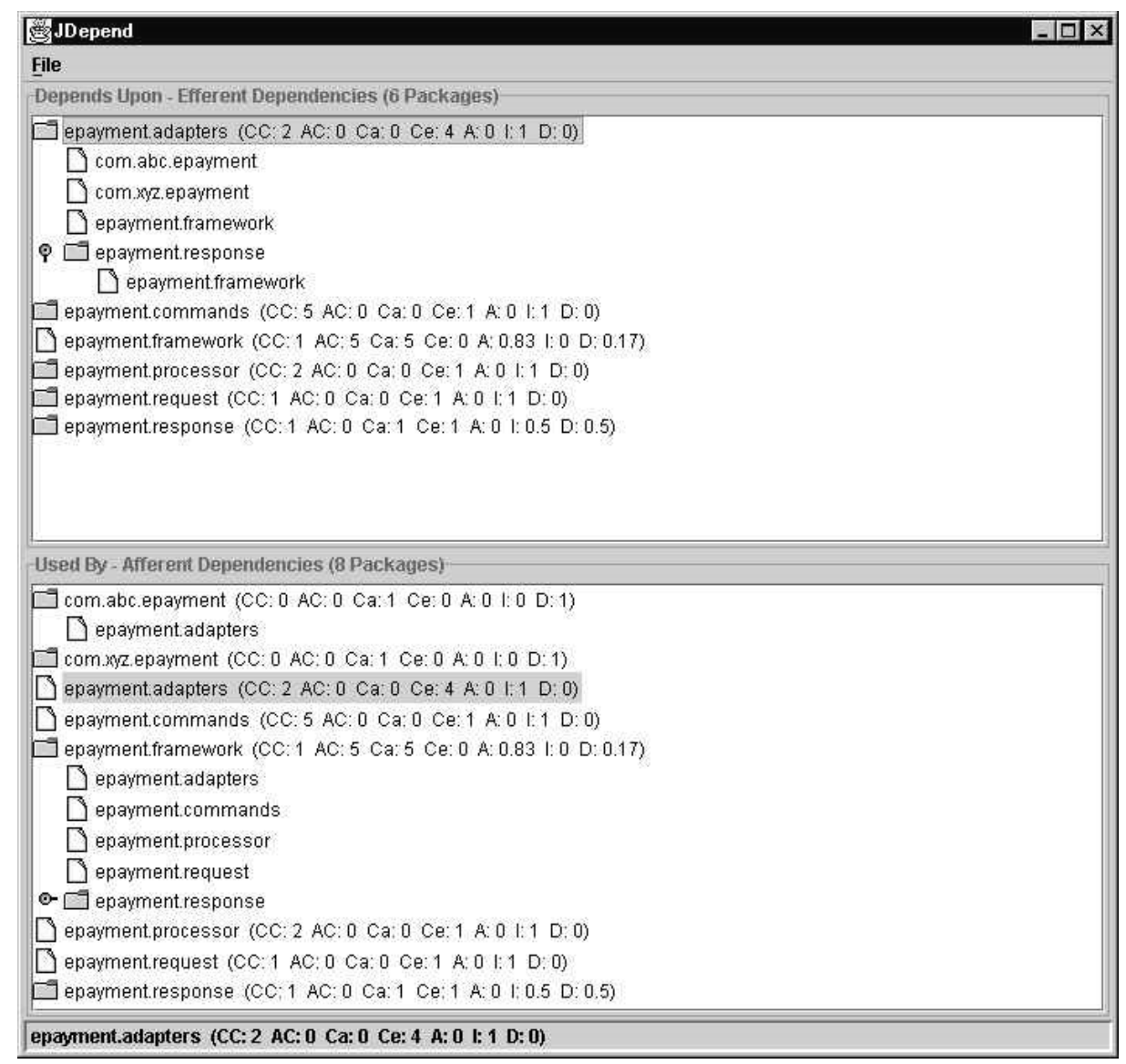

Figura 71: Interface gráfica da ferramenta JDepend

A ferramenta é autônoma e possui uma interface gráfica, uma interface textual e uma interface XML. A interface textual mostra métricas detalhadas separadas por vírgula, dependências e ciclos para cada pacote Java em um formato texto. A interface XML pode ser utilizada para

\footnotetext{
${ }^{24}$ http://ant.apache.org/

${ }^{25}$ http://maven.apache.org/
} 
integração com outras ferramentas - integração com a ferramenta de código aberto Graphviz ${ }^{26}$ é nativa.

Segundo o sítio da ferramenta, os seus principais objetivos são: medir a qualidade do design, inverter dependências, encorajar desenvolvimento paralelo e Extreme Programming [BA04], isolar dependências para pacotes de terceiros, empacotar módulos para release e identificar dependência cíclica entre pacotes. Mais precisamente, as métricas calculadas pela ferramenta são aquelas propostas por Robert Martin e discutidas em detalhe no Capítulo 5. Além disso, a ferramenta ainda possui um mecanismo de detecção de dependências cíclicas entre pacotes. O aplicativo está também disponível na forma de um plugin para a plataforma Eclipse chamado JDepend4Eclipse ${ }^{27}$.

O JDepend também oferece uma biblioteca jar para escrita de testes unitários com JUnit ${ }^{28} \mathrm{e}$ um fixture chamado Module Dependencies FitNesse Fixture para ser utilizado com o FitNesse ${ }^{29}$ uma ferramenta para desenvolvimento colaborativo de testes de aceitação escrita pelos renomados Micah Martin, Justin Martin, Robert C. Martin e Michael Feathers.

\section{C.5 Lattix}

Lattix é uma ferramenta comercial de código fechado da empresa Lattix Software para gerência de arquitetura de software (Figura 72). Os objetivos principais são descobrir, analisar, definir e controlar a arquitetura.

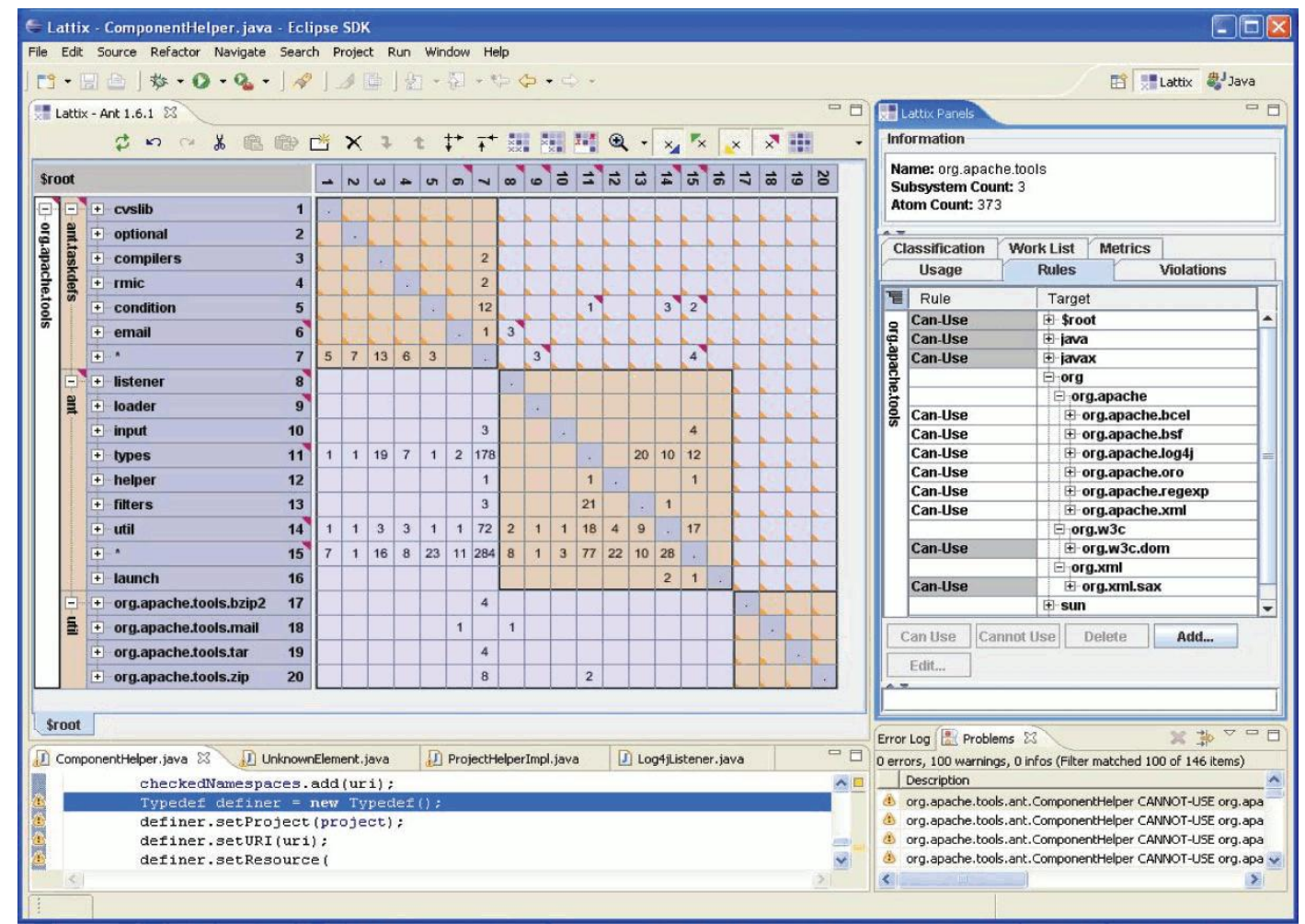

Figura 72: Lattix

\footnotetext{
${ }^{26}$ http://www.graphviz.org/

${ }^{27}$ http://andrei.gmxhome.de/jdepend4eclipse/index.html

${ }^{28}$ http://www.junit.org/

${ }^{29}$ http://fitnesse.org/
} 
A ferramenta possibilita analisar a arquitetura em detalhes, editar a estrutura para criar arquiteturas desejadas e então criar regras de design para formalizar e comunicar tal arquitetura para toda a equipe de desenvolvimento. O diferencial da ferramenta está em representar as dependências do aplicativo analisado na forma de uma matriz. Esse modelo compacto e escalável foi concebido há mais de 30 anos e tem suas origens na otimização de processos de desenvolvimento de produtos [SJSJ05]. Tal modelo é conhecido na literatura como matriz de estrutura de dependências, matriz de estrutura de design ou simplesmente DSM. A empresa Lattix Software alega ser a primeira a aplicar esse modelo para arquitetura de software. Esse modelo de representação é tratado com mais detalhes no Capítulo 6 .

O Lattix conta com módulos para um conjunto grande de linguagens de programação, como $\mathrm{C} / \mathrm{C}++$, Delphi Pascal, Java (plugins para Eclipse e Netbeans) e .NET (integração com Visual Studio). Há ainda outros módulos específicos para análise da arquitetura de banco de dados, incluindo Oracle, SQLServer e Sybase.

\section{C.6 Dependency Finder}

Dependency Finder é uma suíte de ferramentas de código aberto com licença BSD que analisa código compilado de aplicações Java e gera o grafo de dependências correspondente (Figura $73)$.

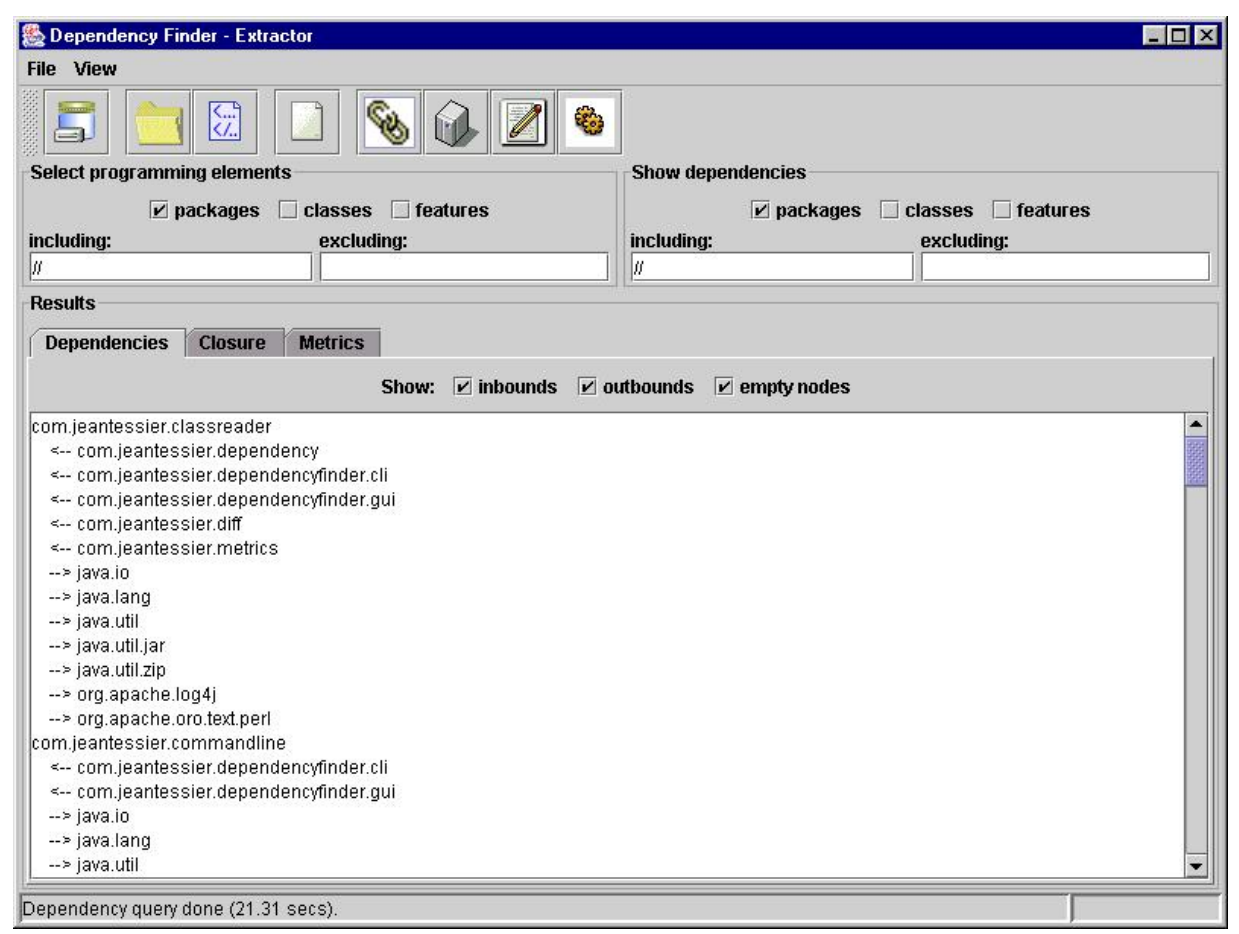

Figura 73: Dependency Finder

No núcleo do Dependency Finder está um aplicativo de análise de dependências que gera um grafo de dependências e o explora para obter informações úteis. Esse aplicativo está disponível em quatro formas: ferramentas de linha de comando, um aplicativo baseado em Java Swing, um aplicativo web pronto para ser implantado em um servidor de aplicações e um conjunto de tarefas para a ferramenta Ant. 
Duas ferramentas destacam-se dentro da suíte. A primeira chama-se JarJarDiff e compara duas versões distintas de uma mesma base de código. Ela gera um relatório personalizável com as diferenças na API, incluindo elementos novos, modificados ou removidos, tais como pacotes, classes, métodos e outros. A outra é uma ferramenta chamada OO Metrics que computa uma vasta quantidade de métricas para sistemas orientados a objetos, sendo parte delas exclusivas para análise de dependências.

\section{C.7 Metrics}

Metrics é um software gratuito de código aberto, possui licença CPL 1.0 (Common Public License 1.0) e provê cálculo de métricas e análise visual de dependências de código Java para a plataforma Eclipse (Figura 74).

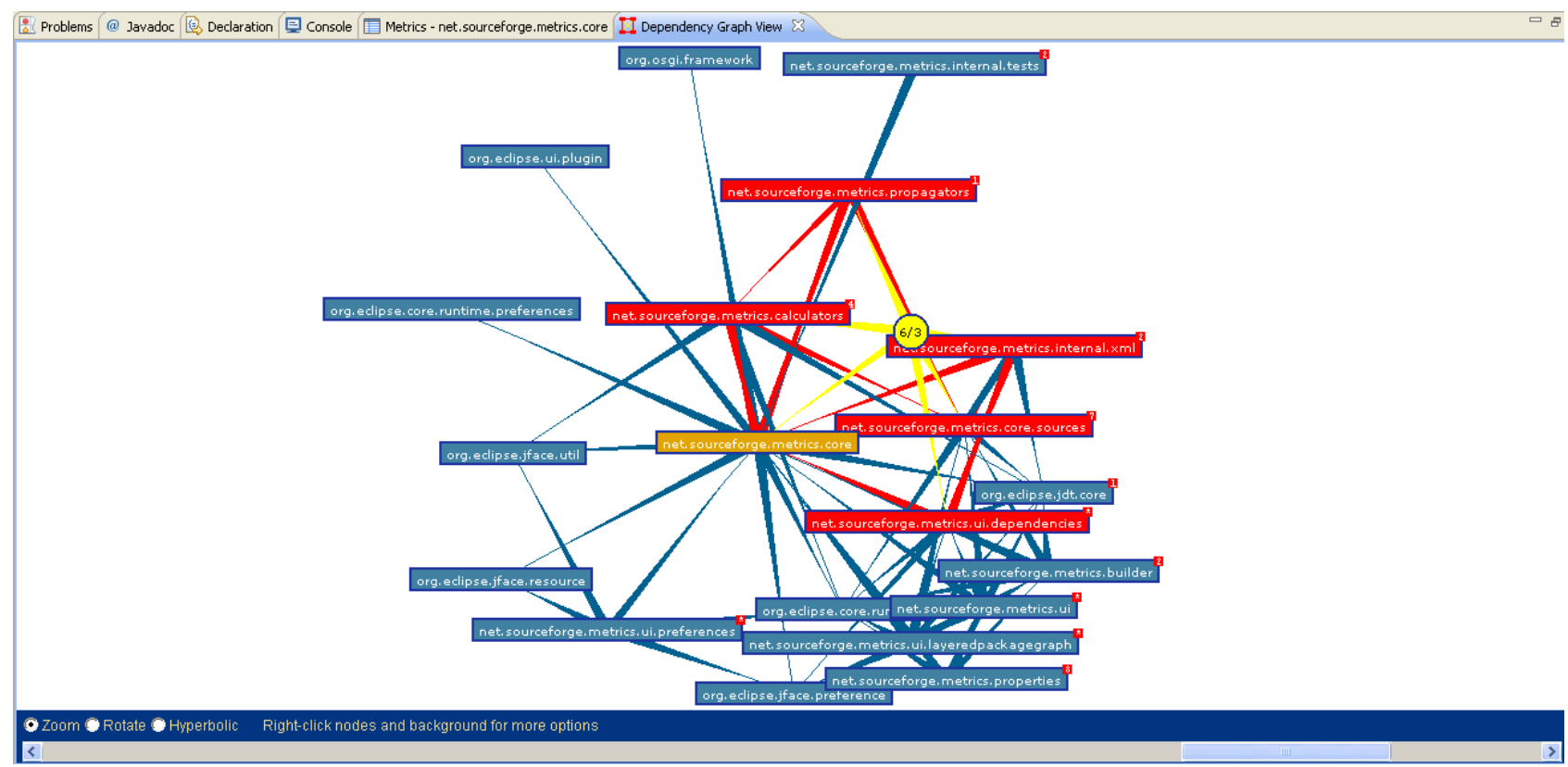

Figura 74: Grafo gerado pela ferramenta Metrics

A ferramenta disponibiliza um vasto conjunto de métricas, sendo a maior parte delas extraídas do trabalho de Brian Henderson-Sellers em [HS95]. As métricas podem ser exportadas para XML e são exibidas de forma tabular, sendo que para cada métrica são informadas a média, o desvio padrão e o valor máximo. Além disso, o Metrics possui tarefas para a ferramenta Ant para que o XML com as métricas possa ser gerado juntamente com o build do sistema analisado.

A análise visual se dá através de um grafo interativo das dependências entre pacotes. O grafo destaca as dependências cíclicas, mostrando o número de pacotes envolvidos e o tamanho do caminho mais longo (longest walk). É possível ainda saber quais classes participam de um determinado ciclo. Esta implementação de visualização atribui significados para as cores das arestas e dos vértices do grafo e também para o comprimento das arestas. 


\section{C.8 Classycle}

Classycle é uma ferramenta de código aberto com licença BSD que tem por objetivo principal detectar dependências cíclicas entre classes e pacotes em aplicativos Java. A ferramenta é dividida em dois componentes: um analisador e um verificador de dependências.

O primeiro componente analisa o bytecode e gera um relatório em XML que contém o grafo direcionado de dependências e os componentes fortes com mais de um vértice, isto é, os ciclos de dependências. Também, é fornecida uma transformação XSL para renderizar o relatório XML em uma página $\mathrm{HTML}^{30}$.

O outro componente possibilita procurar por dependências não desejadas entre dois conjuntos de classes. Uma dependência não desejada entre o conjunto inicial e o conjunto final pode ser tanto direta (uma classe do conjunto inicial usa uma classe do conjunto final ) ou indireta (existe um caminho através de classes intermediárias). Estas restrições são definidas através de um arquivo texto com sintaxe específica chamado de dependency definition file. Esse componente também verifica a existência de ciclos grandes.

A ferramenta pode ser executada apenas através da linha de comando ou por meio de uma tarefa Ant. Ainda, ela conta com um plugin chamado ClassyclePlugin ${ }^{31}$ (Figura 75) para o ambiente de desenvolvimento integrado Eclipse.

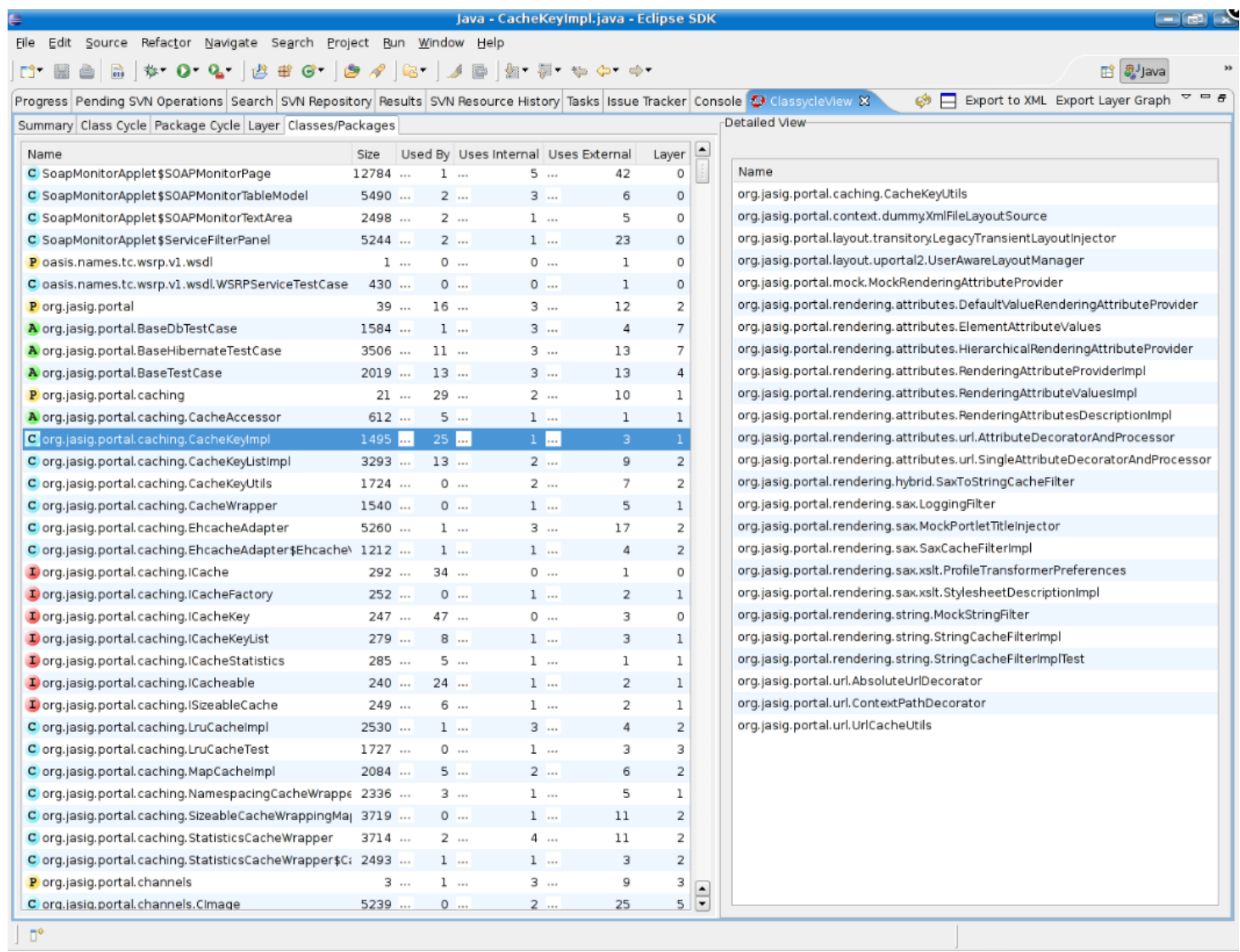

Figura 75: Classycle Plugin

\footnotetext{
${ }^{30}$ Exemplos de relatórios gerados pelo Classycle estão disponíveis em http://classycle.sourceforge.net/examples.html

${ }^{31}$ http://classycle.sourceforge.net/index.html
} 


\section{C.9 ByeCycle}

ByeCycle é um plugin de código aberto para a plataforma Eclipse disponibilizado sob a licença GPL (General Public License) e construído por um time de renomados profissionais, como Klaus Wuestefeld e Kent Beck (Figura 76).

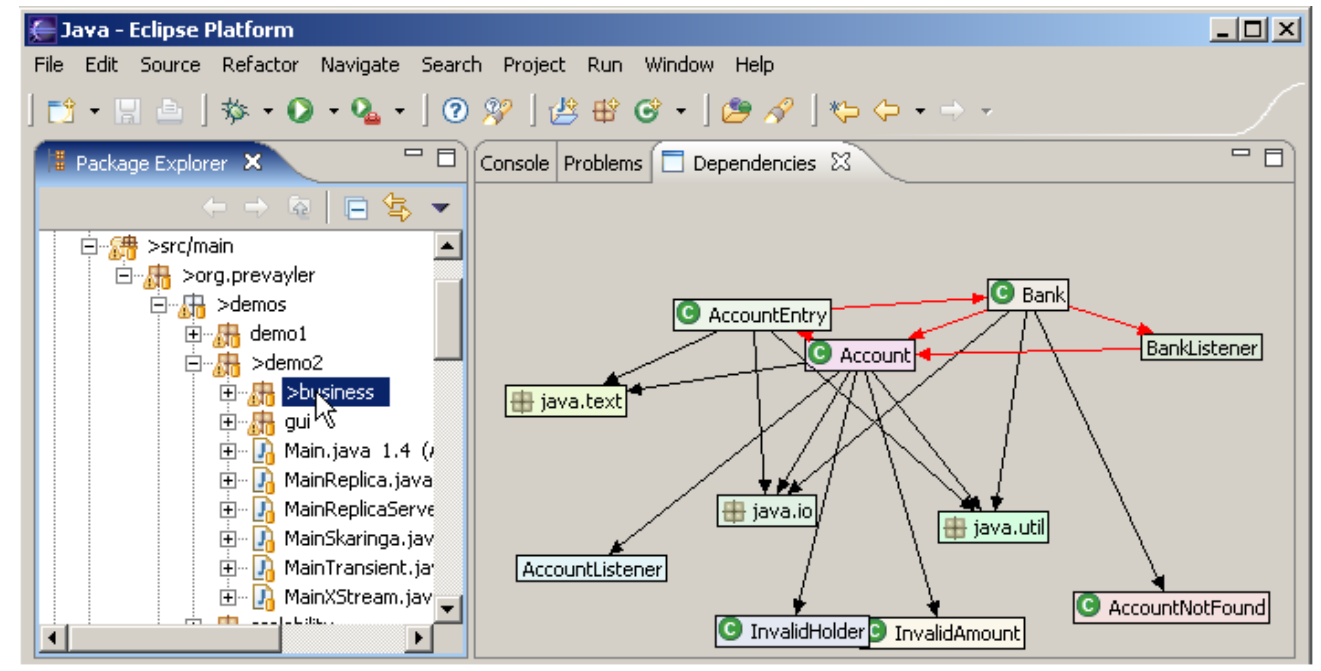

Figura 76: ByeCycle

A ferramenta tem por objetivo detectar dependências cíclicas entre classes e pacotes. Ao selecionar um pacote no Package Explorer do Eclipse, o plugin mostra um grafo com as dependências entre os elementos. Os elementos são dispostos de maneira que as dependências apontam sempre para baixo, para que as camadas do design fiquem evidenciadas. As arestas destacadas representam ciclos entre elementos.

Uma funcionalidade de destaque é o algoritmo de leiaute automático (auto-layout algorithm), que fica movendo os elementos do grafo de maneira a minimizar o número de interseç̧ões de arestas. Esse algoritmo consome no máximo $20 \%$ da CPU e quanto mais outras tarefas precisarem do processador, menos o ByeCycle o utilizará.

\section{C.10 DependencyViewer}

O DependencyViewer é uma ferramenta gratuita, porém de código fechado, que computa as métricas de qualidade de design sugeridas por Robert Martin [MM06]. A Figura 77 mostra a ferramenta em ação. 


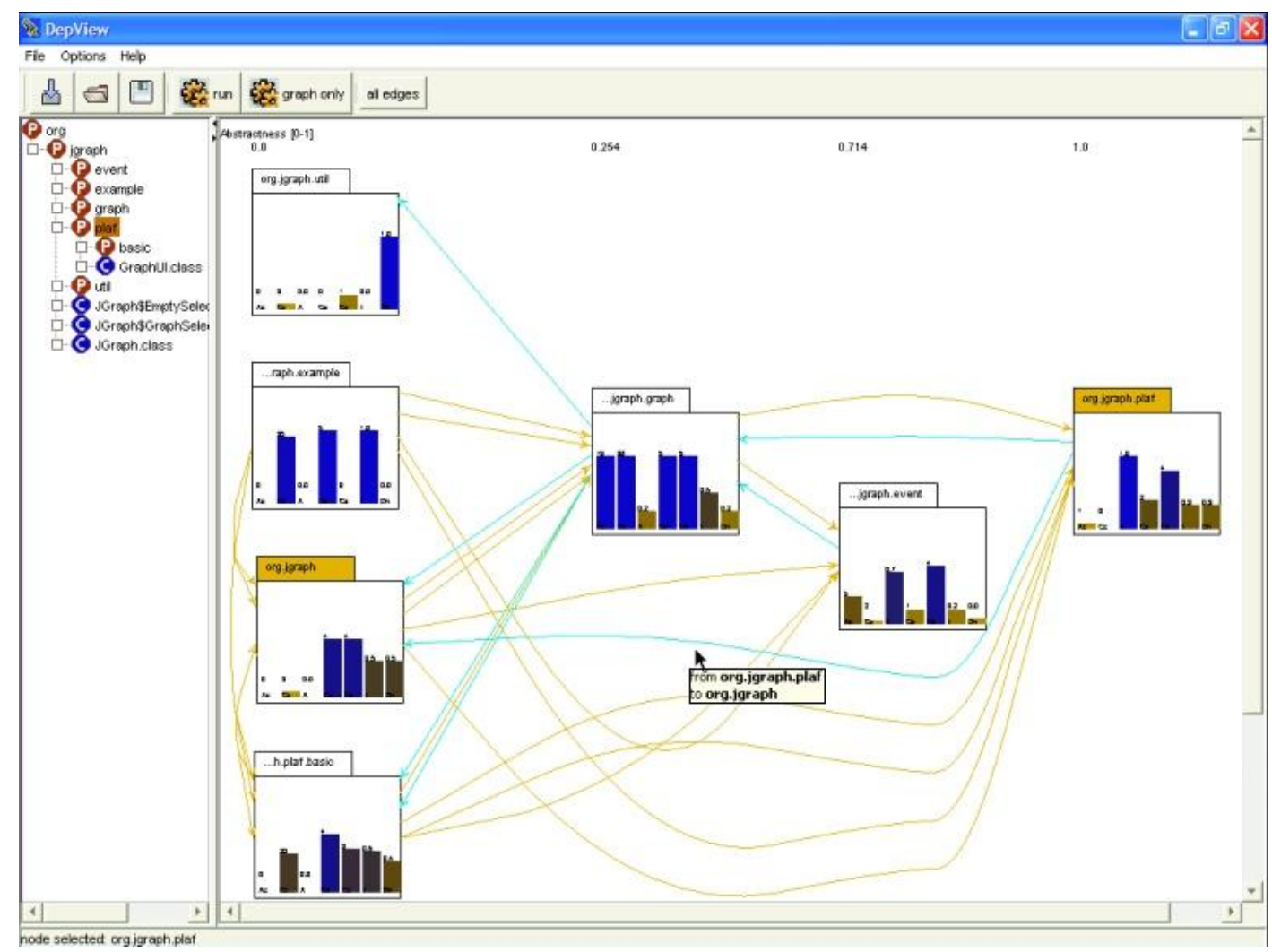

Figura 77: Dependency Viewer

A ferramenta está integrada com JDepend e Dependency Finder por meio de classes wrappers e pode salvar as métricas calculadas em um arquivo XML. O DependencyViewer conta ainda com uma visualização das dependências entre os pacotes na forma um grafo, sendo que os pacotes são distribuídos no espaço por camadas conforme o valor das métricas de abstração e estabilidade. As arestas que violam princípios de design de pacotes são destacadas. 


\section{Referências Bibliográficas}

[AJH10] Bram Adams, Zhen Ming Jiang e Ahmed E. Hassan. Identifying crosscutting concerns using historical code changes. Em Proceedings of the 32nd ACM/IEEE International Conference on Software Engineering - Volume 1, ICSE '10, páginas 305-314, New York, NY, USA, 2010. ACM.

[Art04] João Batista Vilanova Artigas. Caminhos da Arquitetura. Cosac \& Naify, fourth edição, 2004.

[BA04] Kent Beck e Cynthia Andres. Extreme Programming Explained: Embrace Change. AddisonWesley Professional, second edição, 2004.

[BAHS97] Thomas Ball, Jung-Min Kim Adam, A. Porter Harvey e P. Siy. If your version control system could talk... Em ICSE Workshop on Process Modeling and Empirical Studies of Software Engineering, Março 1997.

[BCK03] Len Bass, Paul Clements e Rick Kazman. Software Architecture in Practice. Addison-Wesley Professional, second edição, 2003.

[BDW99] Lionel C. Briand, John W. Daly e Jrgen K. Wst. Ä unified framework for coupling measurement in object-oriented systems. IEEE Transactions on Software Engineering, 25(1):91121, Janeiro 1999.

[BDW05] Michael Burch, Stephan Diehl e Peter Wei. Visual data mining in software archives. Em Proceedings of the 2005 ACM symposium on Software visualization, SoftVis '05, páginas 3746, New York, NY, USA, 2005. ACM.

[BI02] Larry A. Barowski e James H. Cross II. Extraction and use of class dependency information for java. Em Arie van Deursen e Elizabeth Burd, editors, WCRE, página 309. IEEE Computer Society, 2002.

[Bin07] David Binkley. Source code analysis: A road map. Em 2007 Future of Software Engineering, FOSE '07, páginas 104-119, Washington, DC, USA, 2007. IEEE Computer Society.

[BLL09] Henrike Barkmann, Rudiger Lincke e Welf Lowe. Quantitative evaluation of software quality metrics in open-source projects. Em Proceedings of the 2009 International Conference on Advanced Information Networking and Applications Workshops, WAINA '09, páginas 1067-1072, Washington, DC, USA, 2009. IEEE Computer Society.

[BME $\left.{ }^{+} 07\right] \quad$ Grady Booch, Robert A. Maksimchuk, Michael W. Engel, Bobbi J. Young, Jim Conallen e Kelli A. Houston. Object-Oriented Analysis and Design with Applications. AddisonWesley Professional, third edição, 2007.

[BN05] Dirk Beyer e Andreas Noack. Clustering software artifacts based on frequent common changes. Em Proceedings of the 13th International Workshop on Program Comprehension, páginas 259-268, Washington, DC, USA, 2005. IEEE Computer Society.

[BR00] Keith H. Bennett e Václav Rajlich. Software maintenance and evolution: a roadmap. Em ICSE - Future of SE Track, páginas 73-87, 2000.

[BRJ05] Grady Booch, James Rumbaugh e Ivar Jacobson. The Unified Modeling Language User Guide. Addison-Wesley Professional, second edição, 2005.

[Bro95]Frederick P. Brooks. The Mythical Man-Month: Essays on Software Engineering. AddisonWesley Professional, second edição, 1995.

[Bro01] Tyson R. Browning. Applying the design structure matrix to system decomposition and integration problems: a review and new directions. IEEE Transactions on Engineering Management, 48(3):292-306, aug 2001. 
[BWKG05] Jennifer Bevan, E. James Whitehead, Jr., Sunghun Kim e Michael Godfrey. Facilitating software evolution research with kenyon. SIGSOFT Softw. Eng. Notes, 30:177-186, September 2005.

[BZL06] Silvia Breu, Thomas Zimmermann e Christian Lindig. Mining eclipse for crosscutting concerns. Em Proceedings of the 2006 international workshop on Mining software repositories, MSR '06, páginas 94-97, New York, NY, USA, 2006. ACM.

[Car08]Rafael Cardoso. Uma Introdução à História do Design. Edgard Blucher, third edição, 2008.

[CASA11] Trosky B. Callo Arias, Pieter Spek e Paris Avgeriou. A practice-driven systematic review of dependency analysis solutions. Empirical Softw. Engg., 16:544-586, October 2011.

[Cha03] Alexander Chatzigeorgiou. Mathematical assessment of object-oriented design quality. IEEE Trans. Softw. Eng., 29:1050-1053, November 2003.

$\left[\mathrm{CHK}^{+} 01\right] \quad$ Ned Chapin, Joanne E. Hale, Khaled Md. Kham, Juan F. Ramil e Wui-Gee Tan. Types of software evolution and software maintenance. Journal of Software Maintenance, 13:3-30, January 2001.

[CK94] Shyam R. Chidamber e Chris F. Kemerer. A metrics suite for object oriented design. IEEE Transactions on Software Engineering, 20(6):476-493, 1994.

[CMRH09] Marcelo Cataldo, Audris Mockus, Jeffrey A. Roberts e James D. Herbsleb. Software dependencies, work dependencies, and their impact on failures. IEEE Trans. Softw. Eng., 35:864878, November 2009.

[CN10] Marcelo Cataldo e Sangeeth Nambiar. The impact of geographic distribution and the nature of technical coupling on the quality of global software development projects. Journal of Software Maintenance and Evolution: Research and Practice, 2010.

[Coc02] Alistair Cockburn. Agile software development. Addison-Wesley Longman Publishing Co., Inc., Boston, MA, USA, 2002.

[Coh09] Mike Cohn. Succeeding with Agile: Software Development Using Scrum. AddisonWesley Professional, 2009.

[Con68] M.E. Conway. How do committees invent. Datamation, 14(4):28-31, 1968.

[CSDS09] Jean M. R. Costa, Francisco W. Santana e Cleidson R. B. De Souza. Understanding open source developers' evolution using transflow. Em Proceedings of the 15th international conference on Groupware: design, implementation, and use, CRIWG'09, páginas 65-78, Berlin, Heidelberg, 2009. Springer-Verlag.

[CWHC06] Marcelo Cataldo, Patrick Wagstrom, James D. Herbsleb e Kathleen M. Carley. Identification of coordination requirements: implications for the design of collaboration and awareness tools. Em Pamela J. Hinds e David Martin, editors, CSCW, páginas 353-362. ACM, 2006.

[DDM10] Torgeir Dingsyr, Tore Dyb e Nils Brede Moe. Agile Software Development: Current Research and Future Directions. Springer Publishing Company, Incorporated, 1st edição, 2010.

[DDN09] Serge Demeyer, Stéphane Ducasse e Oscar Nierstrasz. Object-Oriented Reenginering Patterns. Square Bracket Associates, first edição, 2009.

[DGLP08] Marco D'Ambros, Harald Gall, Michele Lanza e Martin Pinzger. Analysing software repositories to understand software evolution. Em Tom Mens e Serge Demeyer, editors, Software Evolution, páginas 37-67. Springer, 2008.

[dHF10] Aurélio Buarque de Holanda Ferreira. Mini Aurélio: Dicionário da Lingua Portuguesa. Positivo Livros, tenth edição, 2010.

[Die10] Stephan Diehl. Software Visualization: Visualizing the Structure, Behaviour, and Evolution of Software. Springer, first edição, 2010. 
[DL10] Marco DAmbros e Michele Lanza. Distributed and collaborative software evolution analysis with churrasco. Sci. Comput. Program., 75:276-287, April 2010.

[DLL09] Marco D'Ambros, Michele Lanza e Mircea Lungu. Visualizing co-change information with the evolution radar. IEEE Trans. Software Eng, 35(5):720-735, 2009.

[dRCFdS08] Jean Marcel dos Reis Costa, Rafael Martins Feitosa e Cleidson Ronald Botelho de Souza. Raisaware: Uma ferramenta de auxilio A engenharia de software colaborativa baseada em analises de dependencias. Em Jacques Wainer e Mariano Gomes Pimentel, editors, SBSC, páginas 254-264. IEEE Computer Society, 2008.

[dSFD05] Cleidson de Souza, Jon Froehlich e Paul Dourish. Seeking the source: software source code as a social and technical artifact. Em Proceedings of the 2005 international ACM SIGGROUP conference on Supporting group work, GROUP '05, páginas 197-206, New York, NY, USA, 2005. ACM.

[dSQTR07] Cleidson R. de Souza, Stephen Quirk, Erik Trainer e David F. Redmiles. Supporting collaborative software development through the visualization of socio-technical dependencies. Em Proceedings of the 2007 international ACM conference on Supporting group work, GROUP '07, páginas 147-156, New York, NY, USA, 2007. ACM.

$\left[\mathrm{EGK}^{+} 02\right] \quad$ S. G. Eick, T. L. Graves, A. F. Karr, A. Mockus e P. Schuster. Visualizing software changes. IEEE Trans. Softw. Eng., 28:396-412, April 2002.

[EGK $\left.{ }^{+} 04\right]$ Markus Eiglsperger, Carsten Gutwenger, Michael Kaufmann, Joachim Kupke, Michael Jünger, Sebastian Leipert, Karsten Klein, Petra Mutzel e Martin Siebenhaller. Automatic layout of UML class diagrams in orthogonal style. Information Visualization, 3(3):189-208, 2004.

[EHK06] A.H. Eden, Y. Hirshfeld e R. Kazman. Abstraction classes in software design. IEE Proceedings Software, 153(4):163 -182, august 2006.

[Eic03] Holger Eichelberger. Nice class diagrams admit good design? Em Stephan Diehl, John T. Stasko e Stephen N. Spencer, editors, SOFTVIS, páginas 159-167. ACM, 2003.

[ES90] P. Eades e K. Sugiyama. How to draw a directed graph. Journal of Information Processing, 13(4):424-437, 1990.

[Eva03] Eric Evans. Domain-Driven Design: Tackling Complexity in the Heart of Software. Addison-Wesley Professional, first edição, 2003.

[EW94] Peter Eades e Sue Whitesides. Drawing graphs in two layers. Theoretical Computer Science, 131(2):361-374, 1994.

[Fow03] Martin Fowler. UML Distilled: A Brief Guide to the Standard Object Modeling Language. Addison-Wesley Professional, third edição, 2003.

[FY99] Brian Foote e Joseph W. Yoder. Pattern Languages of Program Design, volume 4. AddisonWesley Professional, 1999.

[GDK $\left.{ }^{+} 07\right]$ Tudor Gîrba, Stéphane Ducasse, Adrian Kuhn, Radu Marinescu e Daniel Ratiu. Using concept analysis to detect co-change patterns. Em Massimiliano Di Penta e Michele Lanza, editors, IWPSE, páginas 83-89. ACM, 2007.

[GHJ98] Harald Gall, Karin Hajek e Mehdi Jazayeri. Detection of logical coupling based on product release history. Em Proceedings of the International Conference on Software Maintenance, ICSM '98, páginas 190-, Washington, DC, USA, 1998. IEEE Computer Society.

[GJ83] M.R. Garey e D.S. Johnson. Crossing number is NP-complete. SIJADM: SIAM Journal on Algebraic and Discrete Methods, 4:312-316, 1983.

[GK07]Eric Gilbert e Karrie Karahalios. Codesaw: a social visualization of distributed software development. Em Proceedings of the 11th IFIP TC 13 international conference on Humancomputer interaction - Volume Part II, INTERACT'07, páginas 303-316, Berlin, Heidelberg, 2007. Springer-Verlag. 
[GKMS00] Todd L. Graves, Alan F. Karr, J. S. Marron e Harvey Siy. Predicting fault incidence using software change history. IEEE Trans. Softw. Eng., 26:653-661, July 2000.

[Gom96] Luiz Vidal Negreiros Gomes. Desenhismo. UFSM - Universidade Federal de Santa Maria, first edição, 1996.

[GS92] D. Garlan e M. Shaw. An introduction to software architecture. Em V. Ambriola e G. Tortora, editors, Advances in Software Engineering and Knowledge Engineering, páginas 1-40. World Scientific Publishing Co., 1992.

[GS97] Luiz Vidal Negreiros Gomes e Ana Amélia Steiner. Debuxo. UFSM - Universidade Federal de Santa Maria, first edição, 1997.

[GSW05] Bernhard Ganter, Gerd Stumme e Rudolf Wille. Formal Concept Analysis: Foundations and Applications. Springer, first edição, 2005.

[Han07] Noriko Hanakawa. Visualization for software evolution based on logical coupling and module coupling. Em Proceedings of the 14th Asia-Pacific Software Engineering Conference, APSEC '07, páginas 214-221, Washington, DC, USA, 2007. IEEE Computer Society.

[HMM00] Herman, G. Melançon e M. S. Marshall. Graph visualization and navigation in information visualization: A survey. Em Hans Hagen, editor, IEEE Transactions on Visualization and Computer Graphics, volume 6 (1), páginas 24-43. IEEE Computer Society, 2000.

[HS95] Brian Henderson-Sellers. Object-Oriented Metrics: Measures of Complexity. Prentice Hall, first edição, 1995.

[Jac92] Ivar Jacobson. Object-Oriented Software Engineering: A Use Case Driven Approach. Addison-Wesley Professional, first edição, 1992.

[KCM07] Huzefa Kagdi, Michael L. Collard e Jonathan I. Maletic. A survey and taxonomy of approaches for mining software repositories in the context of software evolution. J. Softw. Maint. Evol., 19:77-131, March 2007.

[Ker04]Joshua Kerievsky. Refactoring to Patterns. Addison-Wesley Professional, 2004.

[KG02] Ralf Kollmann e Martin Gogolla. Metric-based selective representation of uml diagrams. Em Proceedings of the 6th European Conference on Software Maintenance and Reengineering, CSMR '02, páginas 89-98, Washington, DC, USA, 2002. IEEE Computer Society.

[KH01] Gregor Kiczales e Erik Hilsdale. Aspect-oriented programming. Em Proceedings of the 8th European software engineering conference held jointly with 9th ACM SIGSOFT international symposium on Foundations of software engineering, ESEC/FSE-9, páginas 313-, New York, NY, USA, 2001. ACM.

[Koc07] Stefan Koch. Software evolution in open source projectsa large-scale investigation. $J$. Softw. Maint. Evol., 19:361-382, November 2007.

[Lak96]John Lakos. Large-Scale $C++$ Software Design. Addison-Wesley Professional, first edição, 1996.

[Lar04] Craig Larman. Applying UML and Patterns: An Introduction to Object-Oriented Analysis and Design and Iterative Development. Prentice Hall, third edição, 2004.

[LH93] Wei Li e Sallie Henry. Maintenance metrics for the object-oriented paradigm. Em Proc. IEEE Symp. Software Metrics, páginas 52-60, Maio 1993.

[LLL08] Rüdiger Lincke, Jonas Lundberg e Welf Löwe. Comparing software metrics tools. Em Proceedings of the 2008 international symposium on Software testing and analysis, ISSTA '08, páginas 131-142, New York, NY, USA, 2008. ACM.

[LM06] Michele Lanza e Radu Marinescu. Object-oriented Metrics in Practice: Using Software Metrics to Characterize, Evaluate, and Improve the Design of Object-Oriented Systems. Springer, first edição, 2006. 
[LPR ${ }^{+}$97] Manny Lehman, Dewayne Perry, Juan Ramil, Wladyslaw Turski e Paul Wernick. Metrics and laws of software evolution-the nineties view. Em Proceedings IEEE International Software Metrics Symposium (METRICS'97), páginas 20-32, Los Alamitos CA, 1997. IEEE Computer Society Press.

[MD08a] Tom Mens e Serge Demeyer, editors. Software Evolution, páginas IX-XII. Springer, 2008.

[MD08b] Tom Mens e Serge Demeyer, editors. Software Evolution, páginas 1-11. Springer, 2008.

[MFM03] Andrian Marcus, Louis Feng e Jonathan I. Maletic. 3D representations for software visualization. Em Proceedings of the ACM Symposium on Software Visualization, páginas 27-36. IEEE, 2003.

[MK07] K. Mustafa e R. A. Khan. Software Testing: Concepts and Practices. Alpha Science International, first edição, 2007.

[MM06] Robert C. Martin e Micah Martin. Agile Principles, Patterns, and Practices in C\#. Prentice Hall, first edição, 2006.

[MT06]Hayden Melton e Ewan D. Tempero. Identifying refactoring opportunities by identifying dependency cycles. Em Vladimir Estivill-Castro e Gillian Dobbie, editors, Computer Science 2006, Twenty-Nineth Australasian Computer Science Conference (ACSC2006), Hobart, Tasmania, Australia, January 16-19 2006, volume 48 of CRPIT, páginas 35-41. Australian Computer Society, 2006.

[MW00] Audris Mockus e David Weiss. Predicting risk of software changes. Bell Labs Technical Journal, 5(2), Abril 2000.

[OG11] Gustavo Ansaldi Oliva e Marco Aurelio Gerosa. On the interplay between structural and logical dependencies in open-source software. Em Proceedings of the 2011 25th Brazilian Symposium on Software Engineering, SBES '11, páginas 144-153, Washington, DC, USA, 2011. IEEE Computer Society.

[OIAGAG05] Sunday O. Olatunji, Syed U. Idrees, Yasser S. Al-Ghamdi e Jarallah Saleh Ali AlGhamdi. Mining software repositories - a comparative analysis. International Journal of Computer Science and Network Security, 10:161-174, 2005.

[OSGdS11] Gustavo Ansaldi Oliva, Francisco W.S. Santana, Marco A. Gerosa e Cleidson R.B. de Souza. Towards a classification of logical dependencies origins: a case study. Em Proceedings of the 12th International Workshop on Principles of Software Evolution and the 7th annual ERCIM Workshop on Software Evolution, IWPSE-EVOL '11, páginas 31-40, New York, NY, USA, 2011. ACM.

[Par72]D. L. Parnas. On the criteria to be used in decomposing systems into modules. Commun. ACM, 15:1053-1058, December 1972.

[PFK10] Guenter Pirklbauer, Christian Fasching e Werner Kurschl. Improving change impact analysis with a tight integrated process and tool. Em Proceedings of the 2010 Seventh International Conference on Information Technology: New Generations, ITNG '10, páginas 956-961, Washington, DC, USA, 2010. IEEE Computer Society.

[Pir10] Guenter Pirklbauer. Empirical evaluation of strategies to detect logical change dependencies. Em Proceedings of the 36th Conference on Current Trends in Theory and Practice of Computer Science, SOFSEM '10, páginas 651-662, Berlin, Heidelberg, 2010. Springer-Verlag.

[PM06]Denys Poshyvanyk e Andrian Marcus. The conceptual coupling metrics for object-oriented systems. Em ICSM, páginas 469-478. IEEE Computer Society, 2006.

[Pre09] Roger Pressman. Software Engineering: A practitioner's approach. McGraw-Hill, seventh edição, 2009. 
[PSM09] Harkirat Padda, Ahmed Seffah e Sudhir Mudur. Investigating the comprehension support for effective visualization tools - a case study. Em Proceedings of the 2009 Second International Conferences on Advances in Computer-Human Interactions, ACHI '09, páginas 283288, Washington, DC, USA, 2009. IEEE Computer Society.

[Raj97]Václav Rajlich. A model for change propagation based on graph rewriting. Em Proceedings: 1997 International Conference on Software Maintenance (ICSM 1997), páginas 84-91. IEEE Computer Society Press, 1997.

[Raj00]Václav Rajlich. Modeling software evolution by evolving interoperation graphs. Ann. Softw. Eng., 9:235-248, January 2000.

[RH09] Per Runeson e Martin Höst. Guidelines for conducting and reporting case study research in software engineering. Empirical Softw. Engg., 14:131-164, April 2009.

[Rob02] Colin Robson. Real World Research. John Wiley \& Sons, second edição, 2002.

[SB91] Richard W. Selby e Victor R. Basili. Analyzing error-prone system structure. IEEE Trans. Softw. Eng., 17:141-152, February 1991.

[Sea99] Carolyn B. Seaman. Qualitative methods in empirical studies of software engineering. IEEE Trans. Softw. Eng., 25:557-572, July 1999.

[SJSJ05] Neeraj Sangal, Ev Jordan, Vineet Sinha e Daniel Jackson. Using dependency models to manage complex software architecture. Em Proceedings of OOPSLA '05, páginas 167-176, 2005.

[SM07] Andrew Sutton e Jonathan I. Maletic. Recovering UML class models from $\mathrm{C}++$ : A detailed explanation. Information \& Software Technology, 49(3):212-229, 2007.

[SMWH09] Anita Sarma, Larry Maccherone, Patrick Wagstrom e James Herbsleb. Tesseract: Interactive visual exploration of socio-technical relationships in software development. Em Proceedings of the 31st International Conference on Software Engineering, ICSE '09, páginas 2333, Washington, DC, USA, 2009. IEEE Computer Society.

[SOdSG11] Francisco Santana, Gustavo Oliva, Cleidson R. B. de Souza e Marco Aurélio Gerosa. Xflow: An extensible tool for empirical analysis of software systems evolution. Em Proceedings of the VIII Experimental Software Engineering Latin American Workshop, ESELAW '11, 2011.

[SOT09] M. Sensalire, P. Ogao e A. Telea. Evaluation of software visualization tools: Lessons learned. Em Visualizing Software for Understanding and Analysis, 2009. VISSOFT 2009. 5th IEEE International Workshop on, páginas 19 -26. IEEE Computer Society, sept. 2009.

[SP06] Ben Shneiderman e Catherine Plaisant. Strategies for evaluating information visualization tools: multi-dimensional in-depth long-term case studies. Em Enrico Bertini, Catherine Plaisant e Giuseppe Santucci, editors, BELIV, páginas 1-7. ACM Press, 2006.

[Str10] Gilberto Strunck. Viver de Design. 2AB Editora, sixth edição, 2010.

[TCM $\left.{ }^{+} 10\right]$ Antonio Terceiro, Joenio Costa, João Miranda, Paulo Meirelles, Luiz Romário Rios, Lucianna Almeida, Christina Chavez e Fabio Kon. Analizo: an extensible multi-language source code analysis and visualization toolkit. Tools Section of the 1st Brazilian Conference on Software (CBSoft 2010), Setembro 2010.

[TGDB98] Ioannis G. Tollis e Roberto Tamassia Giuseppe Di Battista, Peter Eades. Graph Drawing: Algorithms for the Visualization of Graphs. Prentice Hall, first edição, 1998.

[TRDL07] M. Torchiano, F. Ricca e A. De Lucia. Empirical studies in software maintenance and evolution. Em Software Maintenance, 2007. ICSM 2007. IEEE International Conference on, páginas $491-494$, oct. 2007.

[VR10] Radu Vanciu e Vaclav Rajlich. Hidden dependencies in software systems. Em Proceedings of the 2010 IEEE International Conference on Software Maintenance, ICSM '10, páginas 1-10, Washington, DC, USA, 2010. IEEE Computer Society. 
[WJRR08] Lee White, Khaled Jaber, Brian Robinson e Václav Rajlich. Extended firewall for regression testing: an experience report. J. Softw. Maint. Evol., 20:419-433, November 2008.

[WL07]Richard Wettel e Michele Lanza. Visualizing software systems as cities. Em Proceedings of VISSOFT 2007 (4th IEEE International Workshop on Visualizing Software For Understanding and Analysis), páginas 92-99, 2007.

[YCM78] Stephen S. Yau, J. S. Collofello e T. MacGregor. Ripple effect analysis of software maintenance. Em The IEEE Computer Society's Second International Computer Software and Applications Conference, páginas 60-65. IEEE Press, Novembro 1978.

[Yin03]Robert K. Yin. Case study research: Design and methods. Sage Publications, third edição, 2003.

[ZW04]Thomas Zimmermann e Peter Weißgerber. Preprocessing CVS data for fine-grained analysis. Em Proceedings 1st International Workshop on Mining Software Repositories (MSR 2004), páginas 2-6, Los Alamitos CA, 2004. IEEE Computer Society Press.

[ZWDZ05] Thomas Zimmermann, Peter Weissgerber, Stephan Diehl e Andreas Zeller. Mining version histories to guide software changes. IEEE Trans. Softw. Eng., 31:429-445, June 2005. 